\title{
LA MORTALIDAD
}

EN LA ARGENTINA

ENTRE 1869 Y 1960

JORGE L. SOMOZA

CENTRO DE INVESTIGACIONES SOCIALES INSTITUTO TORCUATO DI TELLA

CENTRO LATINOAMERICANO DE DEMOGRAFIA 
La mortalidad en la Argentina entre 1869 y 1960

IOAR $\frac{0013010}{20 / 8166}$ AnCHIVO de DOCUMENTCS

Publicacioon del Programa Población y Sociedad Serie Naranja: Sociología 
(C) Derechos reservados por Editorial del Instituto, Florida 936, Buenos Aires, Argentina.

Queda hecho el depósito que previene la ley 11.723.

Este libro se terminó de imprimir el 20 de abril de 1971

en los Talleres Gráficos Julio M. Alvarez, Venezuela 841, Buenos Aires, Argentina. 
E1 Programa Población y Sociedad comprende un conjunto de investigaciones que lleva a cabo el Centro de Investigaciones Sociales del Instituto Torcuato Di Tella. Dirigido por los profesores Gino Germani y Jorge L. Somoza, su realización cuenta con el auspicio y apoyo económico del Population Council, el Centro Latinoamericano de Demografía y el Instituto Torcuato Di Tella. La presente publicación es parte de este programa. 


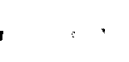


INDICE

Parte Primera: Introducción y conclusiones

Capîtulo I: Introducción, 1

Capitulo II: Conclusiones, 3

Primera sección: la evolución de la mortalidad en el tiempo, 3

(A) E1 descenso de la tasa bruta anual de mortalidad entre 1914 y 1965,3

(B) La reducción de la incidencia de las muertes causadas por enfermedades infecciosas y parasitarias en el total de defunciones como indicio del descenso de la mortalidad en el tiempo, 7

(C) Indicios indirectos del descenso de la mortalidad en el tiempo aportados por información censal, 14

(D) La reducción de la mortalidad en el tiempo que resulta de la comparación de tablas de vida de diferentes épocas, 18

Resumen, 21

Segunda sección: diferencias de mortalidad entre sectores de la poblaciôn, 23

(A) La variación de la mortalidad según el sexo, 23

(B) La variación del nivel de la mortalidad según regiones, 26

(C) La variación del nivel de la mortalidad según el origen de la población, 30

Parte Segunda

Capítulo III: Los dos procedimientos utilizados en la elaboración de tablas de vida, 39

Epocas anteriores a 1914, 40

Epocas: 1914 y posteriores, 43

Capítulo IV: Estimación del nivel de 1a mortalidad por sexo, en los periodos 1869-1895 y 1895-1914, 47

Asignación de edad a las relaciones de supervivencia por cinco años, 48

Elaboración de tablas de vida por sexo para el período 1869-1895 de la población nacida en la Argentina, 50

Mortalidad masculina 1869-1895. Población nacida en 1a Argentina, 52

Mortalidad femenina 1869-1895. Población nacida en la Argentina, 54

Cálculo de las funciones de las tablas de vida por sexo, 1869-1895, población nacida en la Argentina, 55 
Elaboración de tablas de vida por sexo para el período 1895-1914 de la población nacida en la Argentina, 56

Mortalidad masculina 1895-1914. Población nacida en la Argentina, 58

Mortalidad femenina 1895-1914. Población nacida en la Argentina, 59

Resumen, 59

Tablas de vida de la poblacióntotal, nacida en la Argentina o en el exterior, por sexo y para ambos sexos. Períodos intercensales 1869-1895 y 1895-1914, 60

Capítulo V: Las tablas de mortalidad de 1913-1915, 1946-1948 y 1959-1961, 71 Fuentes de datos y ajustes del material básico, 71

El tramo inicial de las tablas de vida, 72

E1 tramo intermedio de las tablas de vida, 76

El tramo final de las tablas de vida, 79

Elaboración de las tablas abreviadas de mortalidad en función de los datos elaborados para los diferentes tramos de vida, 82

Comparación de las tablas de mortalidad elaboradas con otras ya existentes, 84

Capítulo VI: Las tablas abreviadas de mortalidad elaboradas en este trabajo, 101

Parte Tercera

Capítulo VII: Análisis de los resultados, 145

La variación del nivel de la mortalidad en el tiempo, 146

Comparación con otros países, 149

La variación del nivel de la mortalidad según el sexo, 153

Diferencia de mortalidad por sexo en la población total (nacida en la Argen tina $y$ en el exterior), 153

Diferencia de mortalidad por sexo en la población nacida en el país, 156

La variación del nivel de la mortalidad según regiones, 160

La variación del nivel de la mortalidad según el origen de la población. Pe ríodo 1913-1915, 164

Anexos

Anexo I (al capítulo II): Corrección del subregistro de muertes en 1914 , 1947 y 1960,169

Anexo II (al capítulo II): Agrupamiento de las muertes clasificadas según causa a fin de obtener un conjunto representativo de las originadas en enfermedades infecciosas y parasitarias, 173 
Anexo III (al capítulo III): Selección de provincias con registros de muertes razonablemente completos, 177

Anexo IV (al capítulo V): Fuentes de datos y ajuste del material básico, 185 1. Tablas de mortalidad 1913-1915, 185

2. Tablas de mortalidad 1946-1948, 186

3. Tablas de mortalidad 1959-1961, 188

Referencias, 191 

INDICE DE CUADROS

Cuadro II-1. República Argentina: Tasas brutas anuales de mortalidad observadas y corregidas por omisión de los registros. Período 1914-1965 (por mil), 5

Cuadro II-2. Cálculo del porcentaje del total de defunciones atribuidas a en fermedades infecciosas y parasitarias en diferentes conjuntos de jurisdicció nes argentinas $y$ en diversos períodos, 9

Cuadro II-3. (A) Porcentaje de viudos por sexo y grupos de edades según los censos de 1869,1895 y 1960; (B) Porcentaje de viudos por sexo en la población mayor de 14 o 15 años según los cinco censos nacionales, 17

Cuadro II-4. República Argentina: Esperanza de vida al nacer para ambos sexos en diferentes períodos, aumento de ese índice en cada período y en promedio por año, 19

Cuadro II-5. Indicadores derivados de los censos de 1869, 1895 y 1960 que muestran que la mortalidad masculina superaba a la femenina, 24

Cuadro II-6. Argentina: Esperanza de vida al nacer por sexo, en diferentes épocas, 26

Cuadro II-7. Distribución porcentual de la población en cuatro regiones según los censos de 1914,1947 y 1960,28

Cuadro II-8. Esperanza de vida al nacer para ambos sexos por regiones. Perío dos 1913-1915, 1946-1948 y 1959-1961, 28

Cuadro II-9. Porcentaje de viudos según sexo, grupos de edades seleccionados $\mathrm{y}$ origen en los censos de 1869 y 1895,31

Cuadro II-10. Esperanza de vida a la edad de 5 años, segün sexo y origen de la población. Período 1913-1915, 32

Cuadro III-1. Importancia de la población de 10 provincias en el total del país a través de los censos de 1914, 1947 y 1960, 45

Cuadro IV-1. Edades (y) estimadas y ajustadas a las que corresponde 1a función $5^{\mathrm{P}}(\mathrm{y})$, calculada a partir de ${ }_{\mathrm{n}} \mathrm{P}(\mathrm{x})$ mediante la extracción de la raíz de orden $\mathbf{n} / 5$, conforme con seis tablas de mortalidad argentina y dos valores de $\mathrm{n}(20$ y 25$), 62$

Cuadro IV-2. Población nacida en 1a Argentina. Câlculo de relaciones de supervivencia por cinco años según sexo y grupos quinquenales de edad para el período 1869-1895 a partir de la población censada en 1869 y 1895, 63 
Cuadro IV-3. Relaciones de supervivencia por cinco años según sexo y grupos quinquenales de edad: (A) ajustadas de la población nacida en la Argentina para el período 1869-1895, sexo masculino, (B) de la tabla de vida de Kern, sexo masculino, de la Ciudad de Buenos Aires, 1887, (C) de dos tablas mode1o de las Naciones Unidas, sexo masculino, con esperanza de vida al nacer, para ambos sexos, equivalente a 30.0 y 32.5 años, (D) ajustadas de 1a pobla ción nacida en la Argentina para el período 1869-1895, sexo femenino, 64

Cuadro IV-4. Población nacida en la Argentina. Cálculo de relaciones de supervivencia por cinco años según sexo y grupos quinquenales de edad para el período 1895-1914, a partir de la población censada en 1895 y 1914, 65

Cuadro IV-5. Relaciones de supervivencia por cinco años ${ }_{5} \mathrm{P}(\mathrm{x})$ ajustadas de la población nacida en la Argentina, por sexo y grupos quinquenales de edad, de tres épocas: 1869-1895, 1895-1914 y 1913-1915, 66

Cuadro V-1. Datos básicos y muertes anuales estimadas por generación utiliza dos en la construcción del tramo inicial de la tabla de vida de la región BUENOS AIRES, varones, período 1913-1915, 86

Cuadro V-2. Cálculo de las probabilidades de supervivencia y muerte de las edades 0 y 1. Región BUENOS AIRES, varones, 1913-1915, 87

Cuadro V-3. Tasas anuales de mortalidad observadas y ajustadas por grupos quinquenales de edad según sexo, origen y región. Epoca: 1913-1915, 88

Cuadro V-4. Tasas anuales de mortalidad observadas y ajustadas por grupos quinquenales de edad según sexo y región. Epoca: 1946-1948, 90

Cuadro V-5. Tasas anuales de mortalidad observadas y ajustadas por grupos quinquenales de edad según sexo y región. Epoca: 1959-1961, 91

Cuadro V-6. Número de muertes de más de 90 años de edad observado y ajustado en las clases de población estudiadas en 1913-1915 y 1946-1948, 92

Cuadro V-7. Factores de separación de las muertes de menores de un año por sexo y regiones para las diferentes épocas censales, 93

Cuadro V-8. Comparación entre índices seleccionados de tablas de mortalidad existentes para 1a Argentina y los correspondientes a las que se elaboran en este trabajo, 94

Cuadro VI-1. Funciones de las tablas abreviadas de mortalidad que se tabulan. Notación convencional y la adoptada en este trabajo en la presentación de las tablas, 101

Cuadro VI-2. Indice de las tablas abreviadas de mortalidad elaboradas en es te trabajo, 102 
Cuadro VII-1. Indices seleccionados de las tablas de vida ordenados de modo de facilitar la comparación del nivel de la mortalidad en el tiempo, según región y sexo, 147

Cuadro VII-2. Indices por épocas, regiones y sexos, calculados con las probabilidades de muerte, de tramos seleccionados de edades, utilizando como base los valores del período 1913-1915, 148

Cuadro VII-3. Esperanza de vida al nacer, por sexo, a través del tiempo en Italia y Suecia, 152

Cuadro VII-4. Indices seleccionados de las tablas de vida ordenados de modo de facilitar la comparación del nivel de la mortalidad por sexo, según región y época, 154

Cuadro VII-5. Indices seleccionados de las tablas de vida ordenados de modo de facilitar la comparación del nivel de la mortalidad de la población naci da en el país por sexo, según época, 155

Cuadro VII-6. Número de casos en que la mortalidad de un sexo excede a la del otro resultantes de la comparación de 6 indices de mortalidad por edades de 15 pares de tablas de vida, de 1913-1915, 1946-1948 y 1959-1961, 155

Cuadro VII-7. Indice por edad de mortalidad masculina en relación con la de ambos sexos para tres conjuntos de valores: promedios de tablas de vida de diversos paises y tablas de vida de la población nacida en la Argentina, $1913-1915,158$

Cuadro VII-8. Indices seleccionados de las tablas de vida ordenados de modo de facilitar la comparación del nivel de la mortalidad por región, según sexo y época, 161

Cuadro VII-9. Indices por regiones y êpocas, de ambos sexos, calculados con las probabilidades de muerte de tramos seleccionados de edades, utilizando como base los valores de la ARGENTINA, 163

Cuadro VII-10. Indices seleccionados de las tablas de vida ordenados de modo de facilitar la comparación del nivel de la mortalidad por origen, según región y sexo. Período 1913-1915, 166

\section{Tablas Anexos}

Tabla I-1. Determinación de factores de corrección de las muertes registradas a fin de obtener las muertes ocurridas. Años 1914, 1947 y 1960, 171

Tabla II-1. Definición del grupo de "enfermedades infecciosas y parasitarias" según períodos y fuentes de la información, 175 
Tabla III-1. República Argentina 1914 - Indicadores: (A) presumiblemente asociados con la omisión en los registros de muertes y (B) socioculturales inversamente asociados con el desarrollo, 181

Tabla III-2. República Argentina 1947 - Indicadores: (A) presumiblemente asociados con la omisión en los registros de muertes y (B) socioculturales inversamente asociados con el desarrollo, 182

Tabla III-3. República Argentina 1960 - Indicadores: (A) presumiblemente asociados con la omisión en los registros de muertes y (B) socioculturales inversamente asociados con el desarrollo, 183 
INDICE DE GRAFICOS

Gráfico II-1. República Argentina: Tasas brutas anuales de mortalidad obser vadas y corregidas por omisión de los registros. Período 1914-1965, 6

Gráfico II-2. República Argentina: Porcentajes del total de defunciones atri buidas a enfermedades infecciosas y parasitarias en diferentes conjuntos de jurisdicciones $\mathrm{y}$ en diversos períodos, 12

Gráfico II-3. República Argentina: Tasas de mortalidad general y tasas de mortalidad de enfermedades infecciosas y parasitarias. Período 1914-1960, 15

Grâfico II-4. República Argentina: Probabilidades quinquenales de muerte a edades seleccionadas para ambos sexos y cinco períodos, 22

Gráfico II-5. Ubicación geogräfica de las cuatro regiones estudiadas, 27

Gráfico II-6. Esperanza de vida al nacer (ambos sexos) según regiones y épocas, 29

Gráfico IV-1. Relaciones de supervivencia quinquenales, sexo masculino, $1869-1895,67$

Gráfico IV-2. Relaciones de supervivencia quinquenales, población nacida en e1 pais, 1869-1895, 68

Gráfico IV-3. Relaciones de supervivencia quinquenales, sexo masculino, población nacida en el país, 1895-1914, 69

Gráfico IV-4. Relaciones de supervivencia quinquenales, sexo femenino, pobla ción nacida en el país, 1895-1914, 70

Gráfico V-1. Diagrama de Lexis con información de la región BUENOS AIRES, vạ rones, período 1911-1915, 95

Gráfico V-2. Región BUENOS AIRES. Tasas anuales de mortalidad -observadas y ajustadas- por grupos quinquenales de edad según sexo y origen, 1913-1915, 96

Gráfico V-3. Región CENTRO-LITORAL. Tasas anuales de mortalidad -observadas y ajustadas- por grupos quinquenales de edad según sexo y origen, 1913-1915, 97

Gráfico V-4. Región CUYO. Tasas anuales de mortalidad - observadas y ajustä das- por grupos quinquenales de edad según sexo y origen, 1913-1915, 98 
Gráfico V-5. Región NOROESTE. Tasas anuales de mortalidad -observadas y ajus tadas- por grupos quinquenales de edad según sexo y origen, 1913-1915, 99

Grâfico VII-1. Esperanza de vida al nacer, población masculina a través del tiempo en la Argentina, Italia y Suecia, 150

Gráfico VII-2. Esperanza de vida al nacer, población femenina a través del t:iempo en la Argentina, Italia y Suecia, 151

Gráfico VII-3. Indice por edad de mortalidad masculina en relación con las de ambos sexos para tres conjuntos de valores: promedios de tablas de vida de diversos países y tablas de vida de la población nacida en la Argentina, $1913-1915,159$ 
PARTE PRIMERA

INTRODUCCION Y CONCLUSIONES 

Capítulo I

INTRODUCCION

1. El propósito principal de esta monografía es estimar cuál fue el nivel de la mortalidad en la Argentina en épocas que cubren el período 1869-1960 limitado por dos censos nacionales de población: el primero y el último.

Es importante en esta Introducción dejar establecido claramente qué contie ne el estudio, lo que significa también, claro está, dejar dicho lo que no contiene. La denominación genérica la mortalidad en la Argentina entre 1869 y 1960 puede sugerir muchas ideas, en relación con una investigación de mortalidad, que el estudio no cubre. A fin de evitar esas posibles expectativas, que resultarían después frustadas, digamos pues muy nrecisamen te cuál es su contenido.

2. Estimar el nivel de la mortalidad significa para nosotros elaborar una tabla de vida. Eso es fundamentalmente lo que hemos hecho para el país en conjunto en las épocas remotas, 1869-1895 y 1895-1914 y para una parte subs tancial de su población en las épocas en torno a las fechas de los censos nacionales levantados en 1914, 1947 y 1960. En la medida de lo posible, es to es, en que los datos lo han permitido, hemos elaborado tablas de mortal $\underline{\underline{i}}$ dad por sexo según el origen de la población (nacida en la Argentina o en el exterior) y según regiones dentro del país (definimos cuatro según se ve rá oportunamente).

3. Sólo ocasionalmente se ha utilizado información sobre muertes registradas relativa a años alejados de los censales (para elaborar una serie anual de tasas crudas de mortalidad) o emprendido el estudio de la mortalidad por causas (a fin de elaborar un Indice que mide la incidencia de la mortalidad originada por causas infecciosas y parasitarias sobre el total). Tampoco hemos explotado la posibilidad de elaborar tablas de vida por provincias o ciudades a partir de resultados provenientes de registros y censos locales.

4. Pese a lo limitado del objetivo, pensamos que los resultados alcanzados justifican esta publicación, pues vienen a. llenar un vacío importante en el conocimiento de la mortalidad de la población del país. Las tablas de vida aquí presentadas resultarán seguramente de utilidad para la realización de otros estudios demográficos de interés.

5. Parece oportuno explicar por qué se elaboran tablas de mortalidad en tor no a las épocas censales de 1914,1947 y 1960 cuando es sabido que para esos años ya existen tablas construidas por diversos autores. La razón es que es te estudio requiere comparabilidad de los resultados en el tiempo y sobre to do (y esto no 10 permiten las tablas existentes) comparabilidad entre regiones del país. Con el propósito de obtener resultados comparables se trabaja en las tres épocas con un número limitado de provincias seleccionadas (que 
se supone disponen de información sobre muertes registradas de razonable cabalidad) y se emplean, en la construcción de las tablas para las épocas mencionadas, procedimientos uniformes.

6. Esta monografía es parte integrante del programa "Población y Sociedad" que desarrolla el Centro de Investigaciones Sociales (CIS) del Instituto Torcuato Di Tella. Se ha realizado dentro del acuerdo de coopera ción entre ese organismo y el Centro Latinoamericano de Demografía (CELADE) de las Naciones Unidas. Debe considerarse como sólo un paso en el estudio de la mortalidad del país que deberá continuar con otras investí gaciones, algunas de las cuales ya están en pleno desarrollo. La monografía se ha dividido en tres partes formadas por siete capítulos. Contiene además cuatro anexos.

7. La parte primera está integrada por dos capítulos. Esta Introducción constituye e1 I. E1 capítulo II adelanta, en forma resumida, las conclusiones del trabajo y aporta varios índices que prueban claramente el descenso operado en la mortalidad de la población a lo largo del período estudiado.

8. La parte segunda está integrada por cuatro capítulos y se ocupa de la construcción de las tablas de vida. El capítulo III explica brevemente los dos procedimientos utilizados en la elaboración de las tablas según. se trate de las correspondientes a los primeros períodos intercensales 0 de las más recientes. Estos procedimientos son descritos en detalle en los dos capítulos siguientes: el IV se ocupa de la forma en que se elaboraron las tablas intercensales a partir de información censal; el $\mathrm{V}$ del método seguido para construir las tablas a partir de 1914. En el capítu1o VI se presentan los resultados: un conjunto de 75 tablas de vida.

9. La tercera y última parte consta de un solo capítulo, el VII. Se ana lizan en él los resultados obtenidos en la parte segunda. Indices derivā dos de las tablas permiten conocer la variación del nivel de la mortalidad en el tiempo, entre sexos en diferentes regiones dentro del país, o según lugar de origen de la población.

10. En la realización de esta monografía colaboraron María Mulller de Centro de Investigaciones Sociales del Instituto Torcuato Di Tella (CIS) y Julio Ortúzar del Centro Latinoamericano de Demografía (CELADE), que tuvo a su cargo la elaboración de información por medio de un computador. 
Capítulo II

CONCLUSIONES

1. En este capítulo se resumen las conclusiones más destacadas del trabajo que a fin de facilitar la exposición conviene considerar en dos secciones: la primera, que trata de aquellas relacionadas con la evolución de la morta lidad en el tiempo y la segunda, de conclusiones referentes a diferencias en la mortalidad entre sectores de la población, considerada en un momento dado.

2. En la primera sección, cuando se trata de probar que la mortalidad ha variado en el tiempo, se recurre a cuatro juegos de indicadores: (a) la ta sa bruta anual de mortalidad, (b) la proporción en el total de defunciones de las muertes causadas por enfermedades infecciosas y parasitarias, (c) indicios derivados de información de los censos (porcentajes de viudos y huérfanos) y (d) tablas de vida para períodos intercensales o épocas en tor no a las fechas de los censos.

3. A fin de estudiar, en la segunda sección, diferencias de mortalidad entre sectores, se clasifica a la población por (a) sexo, (b) regiones y (c) origen y se procura medir cómo se diferencia la mortalidad en las categorías resultantes.

Primera sección: 1a evolución de 1a mortalidad en el tiempo

(A) E1 descenso de la tasa bruta anual de mortalidad entre 1914 y 1965

4. En los puntos que se siguen se examina la tasa bruta anual de mortalidad. Este Indice se define como el cociente entre el número anual de muertes y el número medio de habitantes de una población. Se la expresa generalmente por mil individuos.

5. Esa tasa de mortalidad, como todas las tasas denominadas brutas, tiene el defecto de no tomar en cuenta la estructura de la población; en particu lar, su composición por edades. Esto es una seria limitación pues es bien sabido que la mortalidad está estrechamente asociada con la edad. La tasa bruta de mortalidad depende, por lo tanto, tanto del nivel de la mortalidad como de la estructura por edades de la población.

6. La ventaja de este índice sobre otros radica en que su cálculo requiere un mínimo de información: basta disponer del número anual de muertes y de una estimación del número total de habitantes de la población. Por esta ra zón es ampliamente utilizado. Ese también es el motivo por el cual lo pre- 
sentamos aquí: si se desea estudiar la evolución anual de la mortalidad en el país, a lo largo del período 1914-1965, no se dispone de otra información que del total de defunciones y estimaciones anuales de población.

7. Antes de pasar a examinar los niveles que muestra en el tiempo la tasa bruta de mortalidad del país ajustada por omisión de los registros (ver Anexo I) es oportuno mencionar que la población de la Argentina ha experi mentado, a travês del período 1914-1965, con ligeras desviaciones, un sos tenido proceso de envejecimiento: 1a proporción de niños disminuye con e $\overline{1}$ tiempo en tanto que la de personas de edad avanzada - con más alta mortali dad- aumenta.

8. En vista de 10 anterior podría concluirse que si el nivel de mortalidad del país se hubiera mantenido uniforme en el tiempo, la tasa bruta de mortalidad hubiera aumentado por efecto del proceso de envejecimiento. Si no lo ha hecho, como se verá, es porque la baja de mortalidad ha tenido una incidencia mayor en la tasa bruta que la influencia del envejecimiento.

9. Teniendo presente la observación anterior examinemos ahora los datos que muestran el Cuadro II-1 y el Gráfico II-1. Surge clara la tendencia general: la tasa bruta de mortalidad ha descendido en forma persistente, aunque con altibajos desde los primeros años considerados hasta alrededor de 1956, pese a que la población ha envejecido durante ese período. E1 va lor máximo lo alcanzó en 1918-1919, época de una epidemia de gripe. A par tir de entonces los valores -exceptuado el año 1957, afectado otra vez por una epidemia de gripe- oscilan entre 8.1 y 8.6 en torno a un promedio de 8.5 por mil. Puede anticiparse, sin mucho riesgo de errar, que en los próximos años esta estabilidad continuará como resultado de factores que actúan con sentido opuesto en el valor de la tasa bruta: el descenso de la mortalidad por edades, que tiende a hacerla bajar; el envejecimiento de 1a población, que opera en sentido contrario. E1 efecto de ambos fac tores ha sido aproximadamente el mismo en años recientes y lo será posiblemente en el futuro inmediato.

10. A más largo plazo -y suponiendo que no se altere la fecundidad de la población- puede preverse que necesariamente el ritmo de descenso de 1a mor talidad por edades deberá aminorarse -en alguna medida ya lo ha hecho según indicios que surgen del análisis de la mortalidad dentro del periodo 19471960 (véase Refexencias, 1)*y, consecuentemente, el envejecimiento de la población que probablemente continuará, hará que la tasa bruta aumente levemente. Tal es la tendencia que anticipan las proyecciones de población elaboradas más recientemente (véase Referencias, 2). Según ellas la tasa bruta oscilará por encima de 9 por mil, aunque sin alcanzar el valor de 10, hacia fines de siglo.

* Referencias bibliográficas numeradas inclüdas al final de la publicación. 
Cuadro II-1

República Argentina: Tasas brutas anuales de mortalidad observadas y corregidas por omisión de los registros. Período 1914-1965

(Por $\mathrm{mil}$ )

\begin{tabular}{|c|c|c|c|c|c|}
\hline \multirow{2}{*}{ Año } & \multicolumn{2}{|c|}{ Tasas anuales } & \multirow{2}{*}{ Año } & \multicolumn{2}{|c|}{ Tasas anuales } \\
\hline & Observadas & $\overline{\text { Corregidas }}$ & & Observadas & Corregidas \\
\hline 1914 & 15.2 & 16.8 & 1940 & 10.7 & 11.7 \\
\hline 1915 & 15.5 & 17.1 & 1941 & 10.4 & 11.4 \\
\hline 1916 & 16.8 & 18.5 & 1942 & 10.3 & 11.3 \\
\hline 1917 & 15.5 & 17.1 & 1943 & 10.1 & 11.1 \\
\hline 1918 & 17.4 & 19.2 & 1944 & 10.2 & 11.2 \\
\hline 1919 & 17.4 & 19.2 & 1945 & 10.3 & 11.3 \\
\hline 1920 & 14.7 & 16.2 & 1946 & 9.6 & 10.5 \\
\hline 1921 & 15.0 & 16.5 & 1947 & 9.9 & 10.8 \\
\hline 1922 & 13.3 & 14.6 & 1948 & 9.4 & 10.2 \\
\hline 1923 & 13.8 & 15.2 & 1949 & 9.0 & 9.8 \\
\hline 1924 & 13.6 & 15.0 & 1950 & 9.0 & 9.7 \\
\hline 1925 & 13.3 & 14.6 & 1951 & 8.9 & 9.6 \\
\hline 1926 & 12.8 & 14.1 & 1952 & 8.5 & 9.1 \\
\hline 1927 & 13.4 & 14.7 & 1953 & 8.7 & 9.3 \\
\hline 1928 & 12.6 & 13.8 & 1954 & 8.4 & 8.9 \\
\hline 1929 & 13.1 & 14.4 & 1955 & 8.9 & 9.4 \\
\hline 1930 & 12,2 & 13.4 & 1956 & 8.4 & 8.8 \\
\hline 1931 & 11.9 & 13.1 & 1957 & 9.1 & 9.5 \\
\hline 1932 & 11.4 & 12.5 & 1958 & 8.3 & 8.7 \\
\hline 1833 & 11.3 & 12.4 & 1959 & 8.5 & 8.8 \\
\hline 1934 & 11.1 & 12.2 & 1960 & 8.6 & 8.9 \\
\hline 1935 & 12.5 & 13.7 & 1961 & 8.3 & 8.6 \\
\hline 1936 & 11.3 & 12.4 & 1962 & 8.6 & 8.9 \\
\hline 1937 & 11.5 & 12.6 & 1963 & 8.5 & 8.8 \\
\hline 1938 & 11.8 & 12.9 & 1964 & 8.3 & 8.6 \\
\hline 1939 & 10.7 & 11.7 & 1965 & 8.1 & 8.4 \\
\hline
\end{tabular}

Fuentes:

- Dirección Nacional de Estadística y Censos, Informe demográfico de la República Argentina, 1944-1954, Guillermo Kraft Ltda., Buenos Aires, 1956.

- Instituto Nacional de Estadística y Censos, Proyección quinquenal de la población 1965-2000. Buenos Aires, 1968.

- United, Nations, Demographic Yearbook 1966, Nueva York, 1966.

Nota: en el Anexo I se explica el procedimiento utilizado para elaborar las tasas anuales corregidas. 

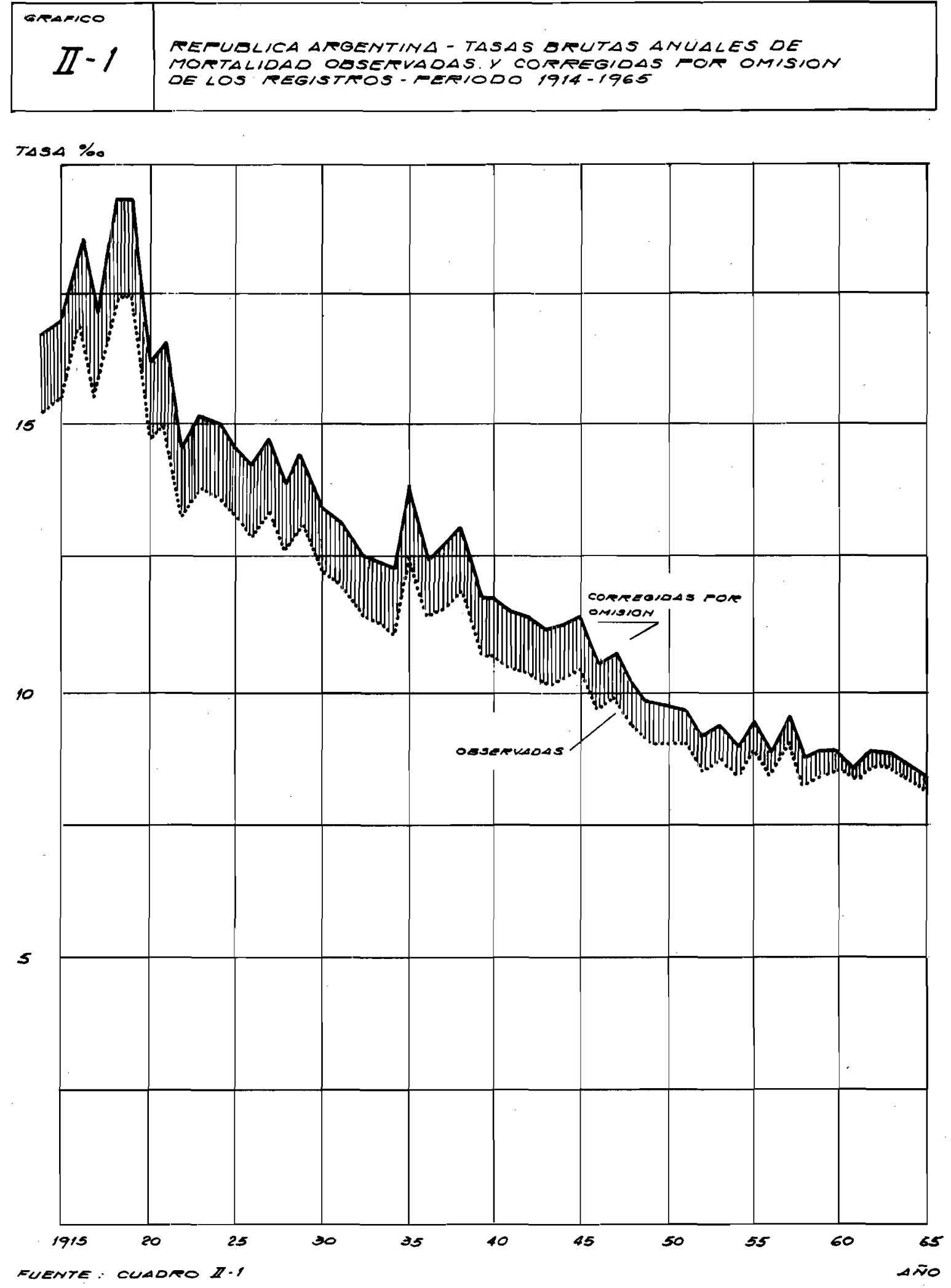
(B) La reducción de la incidencia de las muertes causadas por enfermedades infecciosas y parasitarias en el total de defunciones como indicio del des censo de la mortalidad en el tiempo

11. Nuestro objetivo en esta parte es buscar un indicador, derivado de la estructura de las muertes por causas, que sea sensible a la variación de la mortalidad; obtener así otro indicio, concurrente con lo mostrado por la ta sa bruta de mortalidad analizada anteriormente y con lo que señalan otros que se analizarán después, que ponga de manifiesto que la mortalidad ha venido descendiendo. No pretendemos abordar con amplitud, ni mucho menos, el análisis de la mortalidad según causas.

12. Ese estudio, el de la mortalidad por causas, ofrece en general serias dificultades, que se acrecientan aun más cuando la investigación se hace a través del tiempo, esto es, comparando información relativa a distintos mo mentos.

13. Se comprende fácilmente la razón de los problemas que deben eñfrentarse en tal estudio.

(a) es difícil establecer en los casos de muchas muertes cuál es la enferme dad que la provoca. Puede variar la asignación de la causa según el criterio del médico que interviene. Además cuando son varias las enfermedades que actuando concurrentemente praducen la muerte, se agrega la dificultad de tener que optar por una de èllas, y aunque existen normas para establecer la causa directa, no es fácil aplicarlas con uniformidad.

(b) es frecuente que la certificación de la muerte, y por ende la determinación de la causa, no sea hecha por un médico. Las estadísticas, por lo tanto, estân sujetas por esta razôn, a serias deficiencias que alteran el peso relativo de las causas. A título de ejemplo: en 1960 en la Argentina las muertes asignadas al rubro "senilidad y causas mal definidas y descono cidas" (designado B-45 en la clasificación internacional abreviada de enfêr medades, traumatismos y causas de defunción de 1955) representaba un 27.3 por ciento del total (véase Referencias, 3). Para formarse una idea de 10 exagerado de ese valor baste mencionar que en países con estadísticas de ca lidad satisfactoria, como por ejemplo Inglaterra y Gales (con una estructura por edades mucho más envejecida que 1a Argentina, lo que haría esperar $\underline{u}$ na incidencia por senilidad mayor allí que aquí) el rubro comentado tiene $\underline{u}$ na importancia relativa del orden de 12 por ciento (véase Referencias, 4). Un peso elevado del rubro $B-45$ se ha tomado a veces como indicación de mala calidad de las estadísticas de muertes por causas (véase Referencias, 4). La conclusión es que en la Argentina, aun en épocas recientes, las estadísticas en esta materia son deficientes.

(c) a través del tiempo se han modificado los criterios de clasificación de las causas de defunción. Los datos que se analizan más adelante resultan de aplicar cinco criterios diferentes que varían según el tiempo y las provincias, ya que en un mismo año la clasificación de las causas de muertes se ha hecho, frecuentemente, con criterios diferentes según las provincias. 
(d) los cambios en los criterios de clasificación reflejan, por otra parte, un hecho evidente: el progreso de la ciencia médica ha hecho posible que los diagnósticos de las causas de muerte se establezcan ahora con mayor precisión que en el pasado. Si bien esto es ventajoso cuandó se analizan datos de épocas recientes, conspira contra la comparabilidad de los datos en el tiempo.

14. Información sobre muertes clasificadas por causa puede encontrarse para algunas ciudades o provincias argentinas para años anteriores a 1911. Cabe hacer notar, sin embargo, que a nivel del país, es sólo a partir de ese año que los esfuerzos del Departamento Nacional de Higiene produjeron los primeros resultados aceptables. Los datos que se analizan a continuación cubren el período que va desde 1911 a 1960, con dos interrupciones, como se verá oportunamente.

15. E1 propósito mencionado en el primer punto, buscar un indicador asociado con el nivel de la mortalidad, parece alcanzable por dos caminos: ya sea defi niendo un indice que refleje $1 \mathrm{a}$ incidencia relativa creciente de ciertas enfer medades con el descenso de la mortalidad, ya utilizando un indicador que mida el peso decreciente de otras causas de muerte, asociado también a esa baja. Un indicador del primer tipo sería, por ejemplo, el porcentaje de muertes causadas por enfermedades cardiovasculares; un índice de la segunda clase: el por centaje de defunciones derivadas de enfermedades infecciosas.

16. Por razones prácticas se eligió el segundo tipo de indicador: el porcenta je de las muertes totales provenientes de enfermedades infecciosas y parasitarias. En efecto, tales enfermedades han sido generalmente agrupadas con crite rio bastante uniforme a través del tiempo y su diagnóstico ha estado menos influenciado por los cambios tecnológicos mencjonados antes. Puede también pensarse que el diagnóstico en muchas enfermedades de este tipo, aunque hecho por un lego, resulte más acertado que si se trata de enfermedades de otra naturale za.

17. En e1 Anexo II se considera el agrupamiento de las muertes según causa que se utilizó a fin de obtener un conjunto representativo de las originadas en enfermedades infecciosas y parasitarias. Se mencionan allí los problemas que debieron enfrentarse, los que generalmente no pudieron ser resueltos. Como por ejemplo, la carencia de información para ciertos años o para ciertas provincias. En la Tabla II-1, del anexo aludido, se indica la definición del grupo "enferme dades infecciosas y parasitarias" según los períodos estudiados indicándose 1a fuente de la que se extrajo la información.

18. En el Cuadro II-2 se presenta el cálculo del porcentaje del total de defun ciones atribuidas a enfermedades infecciosas y parasitarias en diferentes conjuntos de jurisdicciones y en diversos períodos. Los valores allí obtenidos aparecen representados en el Gráfico II-2. 
Cuadro II-2

Cálculo del porcentaje del total de defunciones atribuidas a enfermedades infecciosas y parasitarias en diferentes conjuntos de jurisdicciones argen tinas $y$ en diversos períodos

Período: $1911-1930$

Cobertura geográfica: Capital Federal y las 14 provincias

\begin{tabular}{|c|c|c|c|}
\hline Año & $\begin{array}{l}\text { Muertes } \\
\text { totales }\end{array}$ & $\begin{array}{c}\text { Muertes asignadas a } \\
\text { causas infecciosas } \\
\text { o parasitarias al }\end{array}$ & $\begin{array}{l}\text { Porcentaje del } \\
\text { total que } \\
\text { representan }\end{array}$ \\
\hline 1911 & 120681 & 21877 & 18.13 \\
\hline 1912 & $116 \quad 631$ & 18601 & 15.95 \\
\hline 1913 & 117370 & $20 \quad 281$ & 17.28 \\
\hline 1914 & 115796 & 19824 & 17,12 \\
\hline 1915 & 118876 & 19387 & 16.31 \\
\hline 1916 & 130683 & 21767 & 16.66 \\
\hline 1917 & 124878 & 22073 & 17.68 \\
\hline 1918 & 141539 & $28 \quad 135$ & 19.88 \\
\hline 1919 & 145720 & 23485 & 16.12 \\
\hline 1920 & 124345 & 21719 & 17.47 \\
\hline 1921 & 128938 & 21243 & 16.48 \\
\hline 1922 & 117818 & 20682 & 17.55 \\
\hline 1923 & 128050 & 20511 & 16.02 \\
\hline 1924 & 128383 & $20 \quad 264$ & 15.78 \\
\hline 1925 & 129279 & 21437 & 16.58 \\
\hline 1926 & 128875 & 21631 & 16.78 \\
\hline 1927 & $136 \quad 113$ & 22059 & 16.21 \\
\hline 1928 & 132111 & 21515 & 16.29 \\
\hline 1929 & 141880 & $22 \quad 852$ & 16.11 \\
\hline 1930 & 132275 & 21563 & 16.30 \\
\hline
\end{tabular}


Cuadro II-2 (continuación)

Período: 193.4-1936

Cobertura geográfica: todo el país

\begin{tabular}{llcc}
\hline Año & $\begin{array}{c}\text { Muertes } \\
\text { totales }\end{array}$ & $\begin{array}{c}\text { Muertes provenientes } \\
\text { del grupo "enfermeda } \\
\text { des infecciosas y } \\
\text { parasitarias" a/ }\end{array}$ & $\begin{array}{c}\text { Porcentaje de1 } \\
\text { total que } \\
\text { representan }\end{array}$ \\
\hline 1934 & 142157 & 22791 & 16.03 \\
1935 & 162683 & 25548 & 15.70 \\
1936 & 150149 & 22735 & 15.14 \\
\hline
\end{tabular}

Período: 1945-1953

\begin{tabular}{|c|c|c|c|c|}
\hline Año & $\begin{array}{l}\text { Cobertura geográfica } \\
\text { (número de jurisdic- } \\
\text { ciones sobre } 24 \text { ) }\end{array}$ & $\begin{array}{l}\text { Muertes } \\
\text { totales }\end{array}$ & $\begin{array}{l}\text { Muertes del grupo } \\
\text { de "enfermedades } \\
\text { infecciosas y pa- } \\
\text { rasitarias" a/ }\end{array}$ & $\begin{array}{l}\text { Porcentaje } \\
\text { que repre- } \\
\text { sentan del } \\
\text { total }\end{array}$ \\
\hline 1945 & 19 & 115969 & 13632 & 11.75 \\
\hline 1946 & 24 & $144 \quad 441$ & 18033 & 12.48 \\
\hline 1947 & 24 & 157051 & 18455 & 11.75 \\
\hline 1948 & 24 & 151615 & 15100 & 9.96 \\
\hline 1949 & 24 & 149546 & 13090 & 8.75 \\
\hline 1950 & 24 & 153457 & 12204 & 7.95 \\
\hline 1951 & 24 & 155266 & 11390 & 7.34 \\
\hline 1952 & 23 & 145865 & 9369 & 6.42 \\
\hline 1953 & 19 & 102092 & 5550 & 5.44 \\
\hline
\end{tabular}


Cuadro II-2 (conclusión)

Período: 1954-1960

Cobertura geogräfica: todo el país

\begin{tabular}{lccc}
\hline Mño & \multicolumn{1}{c}{$\begin{array}{c}\text { Muertes del grupo } \\
\text { de "enfermedades } \\
\text { infecciosas y pa- } \\
\text { rasitarias" }\end{array}$} & $\begin{array}{c}\text { Porcentaje } \\
\text { que representan } \\
\text { de1 total }\end{array}$ \\
\hline 1954 & 156347 & 7599 & 4.86 \\
1955 & 167357 & 7403 & 4.42 \\
1956 & 161319 & 7203 & 4.47 \\
1957 & 179579 & 7423 & 3.86 \\
1958 & 166235 & 6409 & 3.75 \\
1959 & 173397 & 6502 & 3.67 \\
1960 & 179266 & 6576 & \\
\hline
\end{tabular}

a/ En la tabla II-1 del Anexo II se indica la fuente en la que se especifica el significado de "enfermedades infecciosas y parasitarias" en cada caso:

19. Se ha creído de interés, a costa de extender el contenido del Cuadro II-2, presentar los números absolutos de muertes anuales totales y las causadas por en fermedades infecciosas y parasitarias porque esa información no surge directamente de las fuentes sino que resulta de una elaboración tanto en el período 19111930, como en los dos más recientes, 1945-1953 y 1954-1960.

20. En el primer caso porque, como se indica en el Anexo II, el grupo de causas infecciosas y parasitarias es elaborado por nosotros por suma de muertes provenientes de 34 enfermedades. En los dos últimos períodos, porque la Dirección Nacional de Estadística y Censos publica los datos sólo a nivel provincial ante la imposibilidad de obtener cifras comparables. Puede ser de interés copiar la nota que acompaña a una de las publicaciones de la que se extrajeron los datos porque queda en evidencia el problema de la calidad del material básico. Dice textualmente: "En esta publicación no se presentan cifras totales para el país, de las defunciones según su causa. Este hecho obedece a que las provincias no utilizaron una codificación uniforme para clasificar las defunciones, según la causa que las provoca. En efecto, algunas emplearon la Codificación Internacio nal de 1938, o de 1948 y otras, en cambio, utilizaron la de 1955. La Dirección Naciona1 de Estadística, recibe de los Registros Civiles de cada provincia los datos ya agrupados según la codificación empleada y en razón de la divergencia que ellas presentan entre sí noha resultado posible convertir las cifras a una 
GMAmOO

77 - $P$ ATPIDUIOAS $\triangle$ ENFENMEOADES INFECCIOSAS Y PANASITANIAS

EN DIFENENTES COMJUNTOS DE JUAISDICCIONES Y EN DIVERSOS PERIODOS.

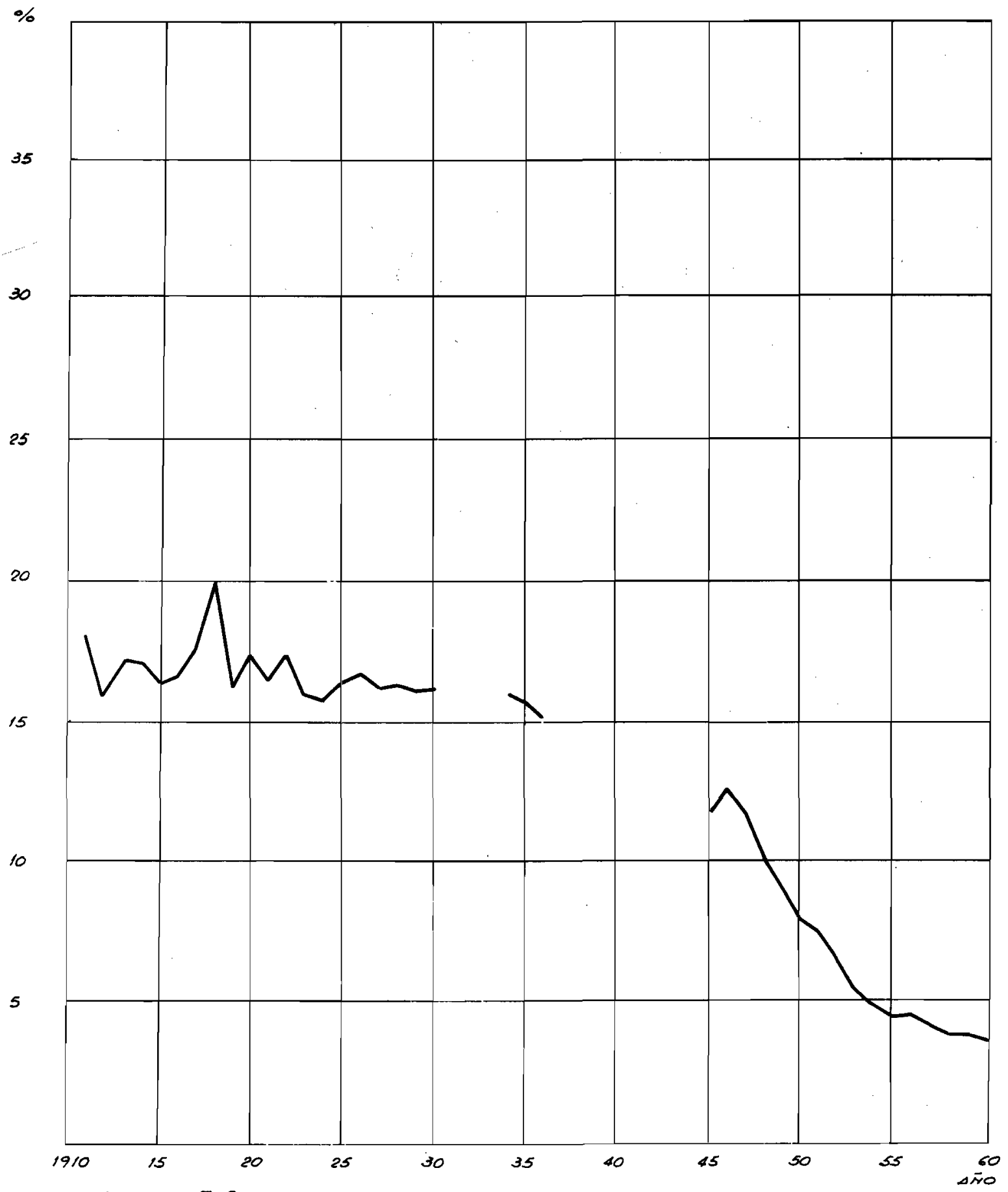

FuENTE: CUADTO II-2 
de las tres codificaciones citadas. Por lo tanto, sólo se consignan totales por provincia expresados en la codificación adoptada en cada caso, y según los años [ (pág.177) (véase Referencias, 5)].

21. Las limitaciones de los indices obtenidos derivadas de las dificultades señaladas anteriormente no impiden su utilización para el propósito de este trabajo. Ellos muestran una variación con el tiempo que consideramos signi ficativa y que concuerda con 10 que hubiéramos esperado, es decir, que con el descenso de la mortalidad general la incidencia de las enfermedades infec ciosas y parasitarias perdiera importancia.

22. Tal tendencia, sin embargo, no surge de lo que los índices muestran durante los primeros años del período analizado. En efecto, de la observación cuidadosa de los valores presentados en el Cuadro II-2 y el Gráfico II-2 se desprende 1a conclusión de que la incidencia de las enfermedades infecciosas y parasitarias en el total se mantuvo más o menos estacionaria hasta 1930. Debemos recordar, según se ha visto en el Gráfico II-1, que durante esos años la mortalidad descendió. Consecuentemente, puede deducirse que la estabilidad mencionada significa que entre 1911 y 1930 la mortalidad por enfermedades infecciosas y parasitarias debió haber bajado con una intensidad similar a la de la mortalidad general, La variación del índice considerado, en sí misma, no refleja ningún cambio en la mortalidad.

23. A partir de los datos de 1934 , y mucho más claramente de los que corresponden al período que se inicia en 1945, la situación es muy diferente a la descrita en el punto anterior: el índice, que mide la importancia de las enfermedades infecciosas y parasitarias, baja sostenidamente, principalmente en tre 1946 y 1955, poniendo en evidencia, seguramente, la eficiencia de las medidas sanitarias adoptadas y el avance de la medicina curativa durante esos años cuyo efecto principal debió ser el control de enfermedades de ese tipo. Debe señalarse también que el nivel inicial del índice en torno al año 1945 es claramente inferior al que tenía en 1930, y aun en 1934-1936. En otras pa labras, durante los años 1937-1944 la variación del índice -si se conocieraseguramente marcaría también una tendencia decreciente.

24. Podría atribuirse la baja comentada en el punto anterior al hecho de que la población argentina, durante los años analizados, ha cambiado su estructura por edades, pasando de una composición muy joven más expuesta a enfermedades infecciosas y parasitarias que de otra naturaleza, a una más envejecida, en la que prevalecen otro tipo de causas de muerte. Ese argumento, sin embargo, no sería suficiente para explicar una baja del índice de la importan cia de la que los datos muestran (baja de un 16 a 4 por ciento en cifras aproximadas a lo largo del período estudiado).

25. Resumiendo las conclusiones de los puntos anteriores puede decirse: pe se a las limitaciones que tiene el índice estudiado, porcentaje de las muér tes totales causadas por enfermedades infecciosas y parasitarias, surge clara la tendencia con que evolucionó en el tiempo: durante los primeros veinte años estudiados, 1911-1930, permaneció prácticamente invariable, sin reflejar 
la baja en la mortalidad que sabemos, por otros indices, se estaba produciendo; en los años posteriores y hasta 1960, el índice muestra una decidida tendencia a decrecer, que acompaña el descenso continuado de la mortalidad general.

26. Uniendo ahora los resultados de esta sección con los de la anterior, que trata, como se recordará, de la tasa bruta de mortalidad, puede elabo rarse el Gráfico II-3 que muestra, en escala logarítmica -para facilitar la representación y llamar la atención sobre el valor relativo de los cam bios producidos- cómo variaron en el tiempo dos series de tasas: (a) 1a bruta de mortalidad y (b) la tasa de mortalidad por enfermedades infeccio sas y parasitarias, definida como el cociente entre el número anual de muertes causadas por esas enfermedades y la población estimada en cada año.

27. El examen del gráfico mencionado permite comprobar lo dicho anterior mente: durante los primeros años, 1914-1930, ambas series descienden siguiendo un ritmo parecido, lo que se refleja en el gráfico en el paralelismo que se advierte en la variación de las dos series de tasas. A par tir de 1945, cuando la segunda serie se reinicia -a un nivel muy inferior a1 que tenía en 1930- la baja de las tasas brutas de mortalidad general siguen una tendencia de descenso muy moderado en comparación con la serie de tasas de mortalidad por enfermedades infecciosas y parasitarias, que decrecen decididamente. Una conclusión que puede sacarse de esto último es que una menor incidencia de muertes por causas infecciosas y parasitarias en el total de defunciones, por ser ya de una importancia relativa muy pequeña, tiene un efecto de muy poca importancia en la tasa de morta lidad general.

(C) Indicios indirectos del descenso de 1a mortalidad en e1 tiempo aportados por información censal

28. En las secciones anteriores se han analizado dos índices, 1a tasa bruta de mortalidad entre 1914 y 1965 y el porcentaje de muertes totales originadas en enfermedades infecciosas y parasitarias en períodos compren didos entre 1911 y 1960 , que mostraron, de un modo directo el primero, en forma indirecta el segundo, que la mortalidad ha descendido en la Argenti na durante los períodos señalados. En esta sección, previa al estudio de índices más refinados que toman en cuenta la edad y e1 sexo de la población presentamos otros indicios, elaborados a partir de datos censales, que también confirman la tendencia descendente de la mortalidad. Se trata del porcentaje de viudos y de la proporción de huérfanos. Tienen la venta $j a$, sobre los indices utilizados anteriormente, de que permiten extender $e \bar{l}$ análisis hasta la época del primer censo nacional de población, esto es, hasta 1869 .

29. La proporción de viudos a una edad dada depende de varios factores, algunos de los cuales son fáciles de enunciar: 1a nupcialidad de la pobla ción -que puede variar según la edad, la época, el origen de la población, 


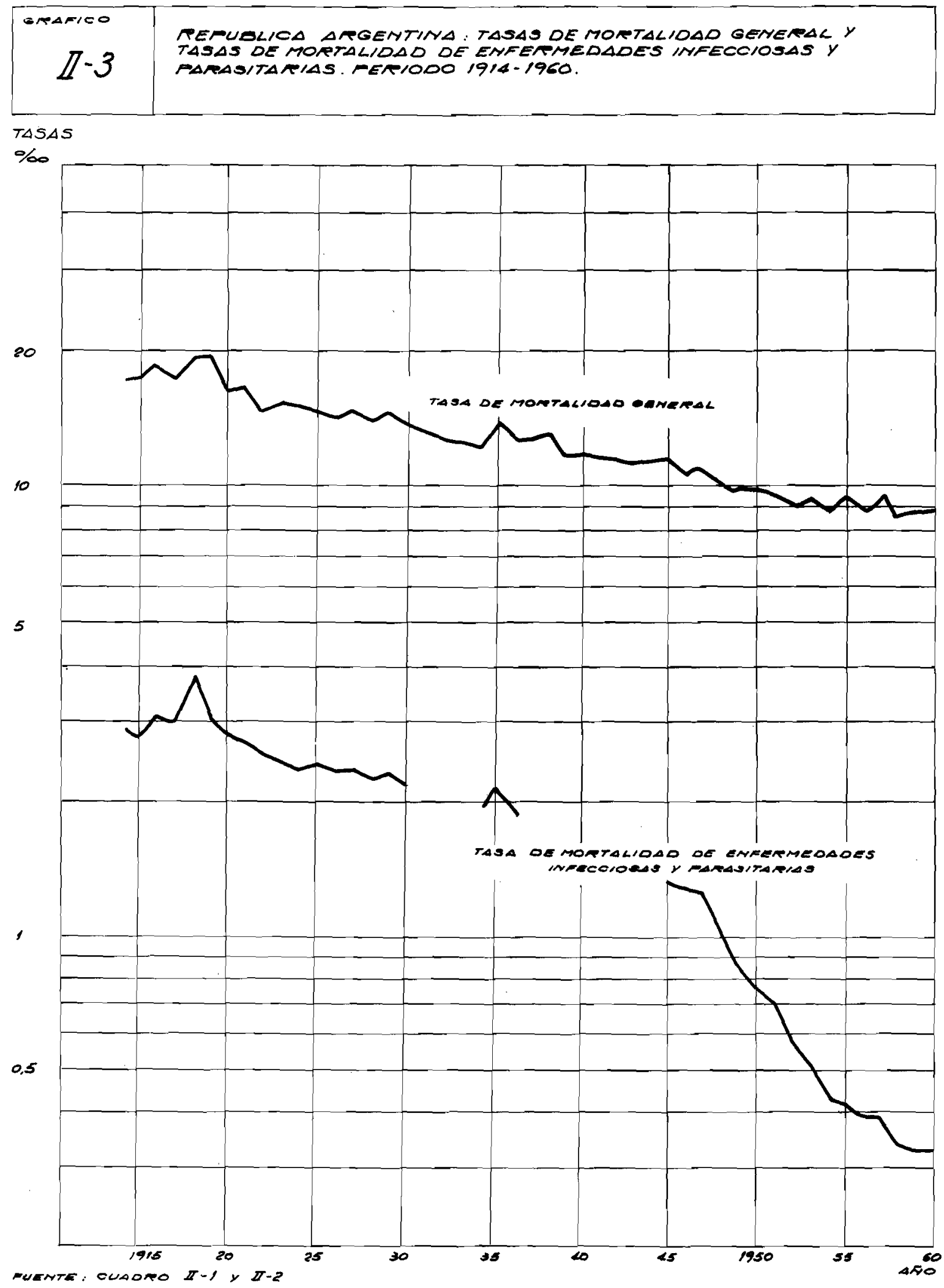


etc.,- la frecuencia con que los viudos vuelven a contraer matrimonio y la mortalidad. Idealmente sería interesante aislar los efectos de cada uno de estos factores. Podría entonces conocerse el peso aislado de cada uno de ellos, en particular el de la mortalidad, en los cambios que muestran las proporciones de viudos con el tiempo,

30. Parece casi innecesario decir que tal análisis no puede realizarse porque no se cuenta con la información adecuada. Puede hacerse, sin embar go, un análisis burdo consistente en analizar la proporción de viudos, según el sexo -ya que como se verá la incidencia de la viudez es muy diferen te en la población masculina y en la femenina- en diferentes épocas: si tó dos los demás factores permanecieran inalterados y la mortalidad descendiẹ ra, esa proporción debería también descender como consecuencia de esa baja. Sería imprudente concluir, si tal tendencia se manifestara, que con ese aná lisis quedaría probado el descenso de la mortalidad. Pero, cuando sucede que a través de tres censos, en todos los grupos de edades que se consideran y en la población de ambos sexos, esa tendencia se manifiesta, el cúmu lo de indicios es tal que parece aceptable concluir que es muy posible que la baja en las proporciones de viudos, afectadas por una variedad de facto res, estên también reflejando un descenso en el nivel de 1a mortalidad.

31. En el Cuadro II-3, en su parte (A), se presentan los porcentajes de viudos clasificados por sexo y edad, en grupos quinquenales entre los $30 \mathrm{y}$ 65 años, segûn los censos de 1869, 1895 y 1960。 Las tabulaciones censales necesarias para el cálculo de estas proporciones, están disponibles solamen te para los censos de 1895 y 1960. Las de 1869 se elaboraron en base a $1 \bar{a}$ muestra de este Censo preparada en el Centro de Investigaciones Sociales de1 Instituto Torcuato Di Te1la.

32. Los porcentajes muestran una tendencia clara: descienden sistemáticamente, sin ninguna excepción entre 1869 y 1895 , y también entre 1895 y 1960. Esto es cierto tanto para los varones como para las mujeres y para cada uno de los grupos de edades estudiados. Es, a nuestro juicio, un indicio elocuente de que la mortalidad descendía a lo largo de los períodos intercensales.

33. En la parte (B) del mismo Cuadro II-3 se presenta un Índice más burdo que el anterior: la proporción de viudos, por sexo, en la población de más de 14 o de más de 15 años. E1 objeto de este cuadro es ampliar la informa ción dada en la parte (A) utilizando resultados provenientes de los censos de 1914 y 1947. Se hace necesario elaborar dos series de datos ya que la información de cada uno de estos dos censos utiliza un límite de edad dife rente en el estudio del estado civil de la población. Los valores, que descienden con el tiempo, confirman las tendencias mostradas por los indices comentados anteriormente. No se presenta ninguna desviación, a pesar de que la composición por edades de la población, que puede influir en la proporción de viudos, varía con el tiempo. 
Cuadro II-3

(A) Porcentaje de viudos por sexo y grupos de edades según los censos de 1869,1895 y 1960

\begin{tabular}{|c|c|c|c|c|c|c|}
\hline \multirow{2}{*}{$\begin{array}{l}\text { Grupos de } \\
\text { edades }\end{array}$} & \multicolumn{3}{|c|}{ Varones } & \multicolumn{3}{|c|}{ Mujeres } \\
\hline & 1869 & 1895 & 1960 & 1869 & 1895 & 1960 \\
\hline $30-34$ & 3.26 & 2.06 & 0,36 & 9.48 & 5.93 & 1.00 \\
\hline $35-39$ & 5.02 & 3.38 & 0.58 & 13,90 & 9.51 & 2.00 \\
\hline $40-44$ & 7.16 & 5.01 & 1.00 & 20,59 & 15.37 & 4.00 \\
\hline $45-49$ & 9.40 & 7.12 & 1.64 & 25.07 & 20.70 & 7.21 \\
\hline $50-54$ & 12.22 & 10,53 & 2.76 & 35,25 & 30.14 & 12.45 \\
\hline $55-59$ & 15.24 & 13.63 & 4.47 & 41,38 & 36.90 & 19.51 \\
\hline $60-64$ & 21.73 & 18.53 & 7.50 & 51.68 & 47.18 & 28.18 \\
\hline
\end{tabular}

(B) Porcentaje de viudos por sexo en la población mayor de 14 o 15 años según los cinco censos nacionales

\begin{tabular}{|c|c|c|c|c|}
\hline \multirow{2}{*}{$\begin{array}{c}\text { Año del } \\
\text { censo }\end{array}$} & \multicolumn{2}{|c|}{ Varones } & \multicolumn{2}{|c|}{ Mujeres } \\
\hline & Más de 14 & Mâs de 15 & Más de 14 & Más de 15 \\
\hline 1869 & 4.85 & 5.04 & 12.49 & 13.01 \\
\hline 1895 & 3.87 & 4.01 & 10.00 & 10.41 \\
\hline 1914 & $\ldots$ & 3.72 & $\ldots$ & 10.06 \\
\hline 1947 & 3.21 & ... & 8.85 & ... \\
\hline 1960 & 2.54 & 2.61 & 8.53 & 8.75 \\
\hline
\end{tabular}

Fuentes:

-Censo de 1869: Somoza, Jorge L, y Lattes, Alfredo E,, Muestras de los dos primeros censos nacionales de población, 1869 y 1895 . Centro de Investiga ciones Sociales, Documento Trabajo $N^{\circ} 46$, Buenos Aires, 1967.

-Publicaciones oficiales de los censos de 1895, 1914, 1947 y 1960. 
34. Digamos, por ûltimo, que otro indicio burdo del descenso de la mortalidad, esta vez a lo largo de1 primer período intercensal, 1869-1895, la da la reducción de un censo a otro de la proporción de húerfanos absolutos, esto es huérfanos de padre y madre. E1 censo de 1869 arrojó una proporción de 17 huérfanos menores de 14 años por mill, conforme con los resultados iné ditos de la muestra elaborada por el Centro de Investigaciones Sociales, en tanto que en el censo de 1895 , la proporción fue de 8 por mil.

35. Aunque aisladamente ninguno de los indicios anteriores podría tomarse como prueba del descenso de la mortalidad, el conjunto de ellos, todos cohe rentes con esa tendencia, es para nosotros casi una prueba de que el nivel de la mortalidad descendió. No debe asignarse a los indices otro valor que el de señalar esa tendencia; no sirven para cuantificar la importancia del cambio en el nivel de la mortalidad. Para ello es forzoso recurrir a instru mentos estadísticos más refinados, que toman en cuenta la composición por edades y sexo de la población, es decir, las tablas de mortalidad. Es 1o que nos aprestamos a hacer en los puntos que siguen.

(D) La reducciôn de la mortalidad en el tiempo que resulta de la comparación de tablas de vida de diferentes épocas.

36. Como se adelantó en el Capítulo I, en este trabajo se elaboran tablas de vida para diferentes períodos. Las primeras cubren los intervalos inter censales que separan los tres primeros censos, es decir, unas reflejan la mortalidad del período 1869-1895 y otras la que corresponde a la época 18951914. A partir de 1914, las tablas de vida se elaboran con información proveniente de los registros de muertes y en torno a los años censales. Se tie nen así para 1913-1915, 1946-1948 y 1959-1961. En la Parte Segunda de la mo nografía se describen los pasos seguidos en la elaboración de las tablas de vida; allí también se presentan los valores resultantes, Es el propósito de esta parte adelantar algunos índices derivados de las tablas construidas que muestran cómo varió el nivel de la mortalidad con el tiempo durante las épocas estudiadas. Una ampliación de este estudio se hace en el capítulo VII.

37. E1 Cuadro II-4 presenta el valor de la esperanza de vida al nacer, para ambos sexos, segûn tablas de cada período estudiado. La esperanza de vida al nacer, o vida media, representa el promedio de años que viviría cada componente de una generación de recién nacidos que estuviera durante su vida ex puesta al nivel de mortalidad representado por una tabla de vida, si los años que vive el conjunto de componentes de la generación fuera dividido uniformemente entre todos ellos.

38. En el Cuadro II-4 se indica el período que cubre cada tabla estudiada, el año central de cada período y el intervalo, medido en años enteros, que me dia entre esos momentos centrales, La información demográfica comprende el valor estimado de la esperanza de vida al nacer en la tabla de vida correspon diente a cada período, el aumento de ese indice, entre los momentos centrales de cada dos períodos contiguos y, finalmente, el aumento promedio anual. 
Cuadro II-4

República Argentina: Esperanza de vida al nacer para ambos sexos en difé rentes períodos, aumento de ese índice en cada período y en promedio por año

\begin{tabular}{|c|c|c|c|c|c|}
\hline \multirow[t]{2}{*}{$\begin{array}{l}\text { Epoca de la } \\
\text { tabla de vida }\end{array}$} & \multirow[t]{2}{*}{$\begin{array}{l}\text { Año central } \\
\text { del período }\end{array}$} & \multirow[t]{2}{*}{$\begin{array}{l}\text { Esperanza } \\
\text { de vida } \\
\text { al nacer }\end{array}$} & \multirow{2}{*}{$\begin{array}{c}\text { Amplitud } \\
\text { del } \\
\text { período } \\
\text { (en años) }\end{array}$} & \multicolumn{2}{|c|}{$\begin{array}{l}\text { Aumento de la } \\
\text { esperanza de } \\
\text { vida al nacer }\end{array}$} \\
\hline & & & & $\begin{array}{c}\text { Por } \\
\text { período }\end{array}$ & $\begin{array}{l}\text { Por } \\
\text { año }\end{array}$ \\
\hline $\begin{array}{l}1869-1895 \\
1895-1914 \\
1913-1915 \\
1946-1948 \\
1959-1961\end{array}$ & $\begin{array}{l}1883 \\
1905 \\
1914 \\
1947 \\
1960\end{array}$ & $\begin{array}{l}32.86 \\
40.04 \\
48.50 \\
61.08 \\
66.37\end{array}$ & $\begin{array}{r}22 \\
9 \\
33 \\
13\end{array}$ & $\begin{array}{r}7.18 \\
8.46 \\
12.58 \\
5.29\end{array}$ & $\begin{array}{l}0.33 \\
0.94 \\
0.38 \\
0.41\end{array}$ \\
\hline
\end{tabular}

39. Aunque puede considerarse, con razón, que es burdo asignar el nivel de la mortalidad dado por la tabla al año central de un período intercensal ex tenso, como sucede en los dos primeros casos que se refieren a los intervalos intercensales 1869-1895 y 1895-1914, puede defenderse el procedimiento empleado por ser el más objetivo y porque además los valores numéricos hallados que miden la variación anual de la vida media, no son tomados como expresiones exactas sino meramente como indicadores de la tendencia general.

40. Hechas esas advertencias cabe ahora examinar los resultados que muestra el Cuadro II-4. Se ve en él que la esperanza de vida al nacer aumentó de un nivel estimado de 32.86 años para el período 1869-1895, que se atribuye al año centra1, 1883, a un valor de 66.37 años en 1959-1961, período centrado en 1960. Un aumento que significa una duplicación, a lo largo de un período estimado en 77 años.

41. La variación del Indice, según 10 muestra el mismo cuadro, no fue pareja en los diferentes períodos. Se destaca netamente la baja de la mortalidad producida entre el período intercensal 1895-1914, con un año central en 1905, y el intervalo 1913-1915, en torno a 1914. Durante ese tiempo, estimado apro ximadamente en 9 años, el aumento promedio anual de la esperanza de vida al nacer fue del orden de 0.94 año por año. Resulta muy superior a los incremen tos medios anuales del período anterior y también de los dos siguientes. Estos últimos se caracterizan por mostrar aumentos uniformes de la vida media en torno a 0.40 año por año. 
42. Podría ponerse en duda el valor de las cifras anuales promedias, en cuyo cálculo intervienen los años centrales de los dos primeros períodos intercensales, por ser éstos muy extensos, El año central, al cual se re fiere la estimación de la mortalidad, puede no corresponder al momento del período en el que se dio ese nivel. En particular, cabría preguntarse en qué medida la estimación mencionada en el punto anterior, según la cual la esperanza de vida al nacer aumentó a un promedio cercano a un año por año, puede estar dependiendo de la elección del año central como representativo del período. A fin de dar una idea del efecto que hubiera tenido en los resultados la elección de otro año y no el central, como re presentativo de la mortalidad del período intercensal, se han hecho los cálculos adoptando, arbitrariamente, el año 1902 en lugar de 1905 . Con es te supuesto, claro está, se aumenta la importancia del descenso de la mor talidad del primer período y se disminuye la del segundo. Los promedios anuales de aumento de la vida media pasan a ser 0.38 y 0.70 en lugar de los presentados en el cuadro, esto es, 0.33 y 0.94 para el primero y segun do período, respectivamente. Se ve que, aunque como era de esperar el promedio anual de aumento en la esperanza de vida al nacer correspondiente a los primeros años del siglo disminuye de 0.94 a 0.70 , la importancia de 1 descenso de la mortalidad sigue siendo muy superior a la de cualquier otra época, y es este un hecho que merece ser destacado.

43. En efecto, si se aceptara la aceleración de la baja de la mortalidad a comienzos del siglo, habría que asociarla con el desarrollo general que se operó en el país en las últimas décadas del siglo XIX y las primeras del $\mathrm{XX}$ antes que con una acción sanitaria particularmente eficiente, si es que se supone que tales acciones producen efectos principalmente en la lucha contra enfermedades infecciosas y parasitarias. Según se ha visto al consi derarse la incidencia de estas enfermedades, no fue el descenso de las tasas de mortalidad causadas por ellas -entre 1911 y 1930-particularmente 1lamativo; tuvo aproximadamente la misma intensidad que la baja de la morta lidad general, Si se aceptara que esa tendencia, observada a partir de $19 \overline{1} 1$, fuera también válida en la década anterior, habría que concluir que no fue el control de enfermedades infecciosas lo que determinó la aceleración del descenso de la mortalidad en la época considerada, y por lo tanto habría que atribuirlo al progreso del país, que se refleja en elocuentes indicadores eco nómicos y sociales.

44. En el descenso de la mortalidad en la Argentina, a partir de 1869, podrían distinguirse claramente $-y$ la división es forzada por la limitación de 1a información- tres etapas: una inicial que se extendería desde un momento no precisado hasta comienzos del siglo XX, con un ritmo de baja del nivel de la mortalidad significativo pero moderado; una segunda etapa, que las cifras permiten ubicar entre la primera y segunda década de1 siglo XX, durante la cual se habría acelerado el proceso de reducción alcanzando un ritmo excepcio nalmente rápido para la época y, finalmente, el período último; desde 1914 al momento actual, a lo largo del cual el descenso de la mortalidad habría conti nuado a un ritmo uniforme, equivalente a un aumento de la vida media del orden de 0.40 año por año. 
45. De ser verdadera la tendencia descrita en el punto anterior -y nosotros creemos que lo es, pese a las limitaciones señaladas de los datos que se ana lizan- la Argentina presentaría una evolución en el nivel de la mortalidad en el tiempo muy diferente a la experiencia de la mayoría de los países lati noamericanos. En éstos ha sido característico un nivel de mortalidad muy elevado en los años iniciales del siglo, muy superior al de la Argentina de esa época; poca variación en el tiempo hasta la década iniciada en 1940 y un descenso posterior muy pronunciado, que se ha asociado generalmente con la puesta en marcha de eficientes campañas sanitarias (caso típico la lucha con tra el paludismo).

46. La esperanza de vida al nacer es un índice sintético que oculta las diferencias muy marcadas que tiene la intensidad de la mortalidad según la edad. Para mostrar los cambios en el tiempo de la mortalidad según la edad es apropiado utilizar probabilidades de muerte por edades calculadas para diferentes épocas. Es esto lo que se hace en el Gráfico II-4 en el que se han representado en escala logarítmica las probabilidades de morir por plazos quinquenales para edades que van desde 0 hasta 70 años. Esto es, 1a probabilidad de morir antes de alcanzar la edad $x+5$, que tiene una persona en el momento en que cum ple la edad $x$, la que, con la notación actuarial usual, se escribe ${ }_{5} x^{*}$ La información fue extraída directamente de las tablas de vida pertinentes presentadas en el Capítulo VI o elaborada expresamente para este gráfico, con base a esas tablas (en el caso de ${ }_{5} q_{0}$ ).

47. E1 grâfico mencionado da una visión clara de la importancia relativa del descenso de la mortalidad según la edad a través de las épocas consideradas. La conclusión más obvia es que la mortalidad descendió principalmente en las edades jóvenes, tanto infantiles, como juveniles y adultas jóvenes, y menos en las avanzadas -progresivamente menos- con el aumento de la edad tal como se evidencia por la convergencia, en las últimas edades consideradas, de las probabilidades correspondientes a diversas épocas. Un análisis más detenido de este punto, considerando grupos de edades seleccionados, es realizado en el Capítulo VII.

Resumen

48. En los puntos anteriores de esta sección, dedicada a considerar la evolü ción de la mortalidad en el tiempo, ha quedado documentado que invariablemente diferentes indicadores señalan que el nivel de 1a mortalidad descendió en todos los períodos estudiados: 1o muestra la tasa bruta anual de mortalidad, conocida entre 1914 y 1960 -pese a que la tendencia general descendente mues tra frecuentes oscilaciones de año a año-, lo sugiere la variación de la incidencia de las muertes debidas a causas infecciosas y parasitarias en el to tal de defunciones, conocida con interrupciones en 1931-1933 y 1937-1944 entre 1911 y 1960, lo refleja, en forma burda, la reducción en las proporciones de viudos y huérfanós establecidas con datos censales y, finalmente, queda probado a la luz de los resultados proporcionados por un conjunto de tablas de vida. 
onstoo

II. 4

FEFUELICA ATREMTINA: PROEAEILIDADES OUIMQLENALES

DE MUEPTE $\triangle$ EOADES SELECCIOMAOAS PARA AMOOS SEXOS

Y CIMCO PERIODOS

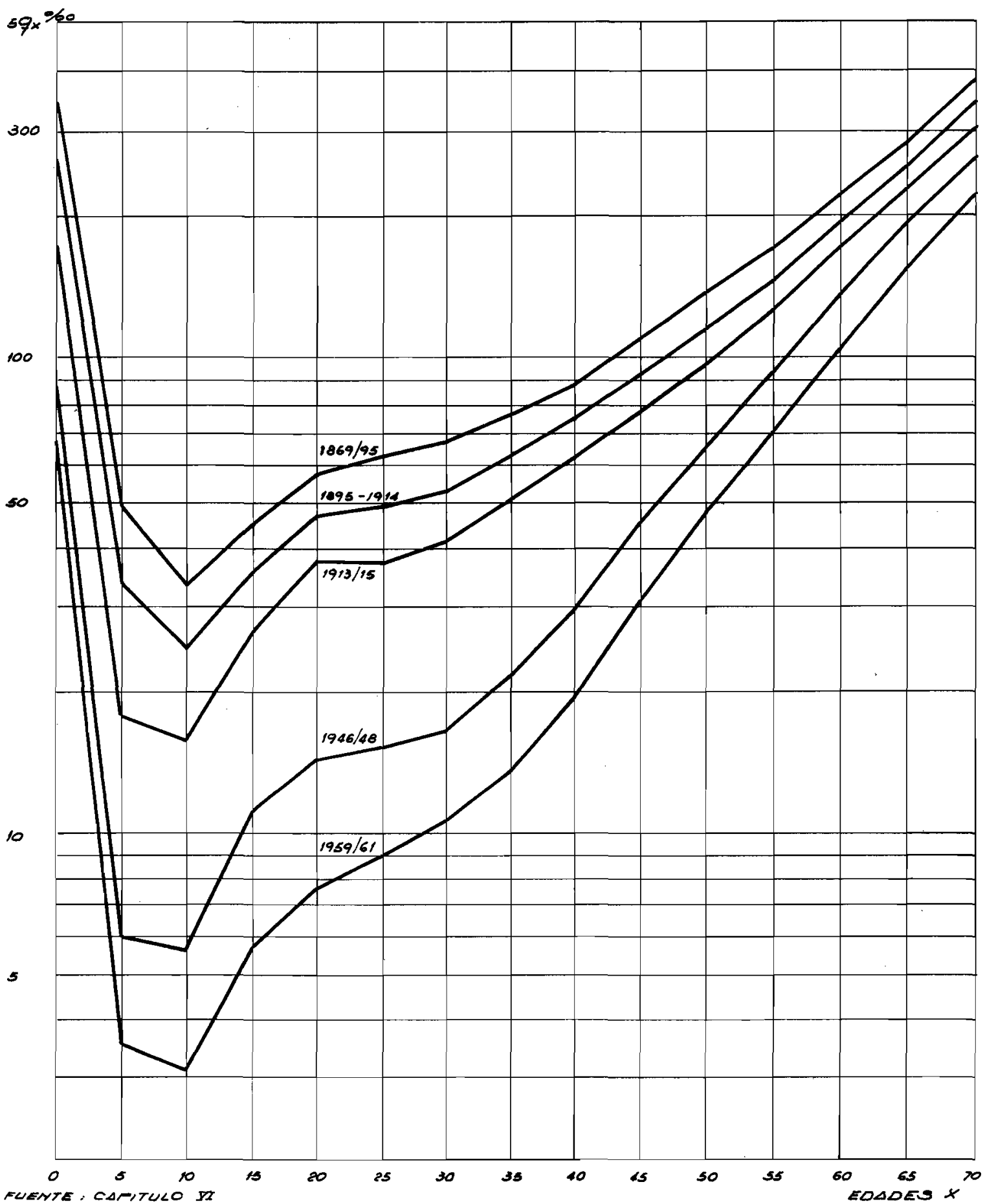


Segunda sección: diferencias de mortalidad entre sectores de la población

(A) La variación de la mortalidad según el sexo

49. Se presentan en esta sección, como en la anterior, tanto indicadores indirectos del sentido de la diferencia del nivel de la mortalidad entre va rones y mujeres, elaborados con datos censales, como índices derivados de tablas de vida por sexo, que permiten establecer y medir esa diferencia.

50. El Cuadro II-5 que consta de dos partes, presenta los primeros, es decir, indicadores derivados de los censos de 1869,1895 y 1960 que muestran que la mortalidad masculina superaba a la femenina. En la parte (A) de ese cuadro se presentan los porcentajes de huérfanos de padre o de madre según edad, elaborados con datos de la muestra del censo de 1869, en la (B) se da la proporción de viudos y de viudas, en cuatro grupos quinquenales de edad seleccionados, elaborada con información de los censos de 1869, 1895 y 1960.

51. E1 Índice de orfandad muestra que invariablemente, para cada edad considerada entre 0 y 13 , 1a proporción de huérfanos paternos supera a la de maternos, Tal tendencia surgiría también, aunque no hubiera diferencia de mortalidad por sexo, por el solo hecho de que la edad promedio de los padres es superior a la de las madres $y$, según se ha visto en los puntos anteriores de este capítulo, la mortalidad varía sensiblemente con la edad. Pero no es tanto la tendencia de las cifras comentadas lo que interesa destacar cuanto la importancia de la diferencia en los porcentajes. Tómese, por ejemplo, la edad de 11: años. E1 cuadro presenta un porcentaje, para esa edad de 9.31 de huérfanos de padre frente a 6.63 de húerfanos de madre. Las diferencias en las edades promedios entre padres y madres no son suficientes, suponiendo además igual nivel de mortalidad para ambos sexos, como para explicar una discrepancia tan amplia en las cifras comentadas. El ejemplo dado para la edad 11, por otra parte, es sólo ilustrativo de lo que se presenta a lo lar go de los 13 grupos de edades del cuadro y por ende del total, en el que sé computa el indice tomando en cuenta todos los niños menores de 14 años, sin distinguir la edad. Tenemos pues un indicio claro de que ya en 1869 la mor talidad masculina superaba a la femenina.

52. En la sección (B), como se indica en el Cuadro II-5, aparecen porcenta jes de viudos según el sexo, para sólo cuatro grupos de edades a fin de sim plificar el análisis. También en este caso, como en el anterior, las diferencias por sexo encontradas en los porcentajes pueden deberse a causas aje nas a la diferencia de mortalidad. Por ejemplo, si las mujeres se casan a edades más tempranas que los hombres, es natural que enviuden con mayor fre cuencia que éstos, aunque la mortalidad sea uniforme; si la frecuencia con que los viudos vuelven a casarse varía con el sexo, el porcentaje analizado estaría afectado por ese factor, independiente también de una posible diferen cia en la mortalidad. Al igual que con los indices de orfandad, no es tanto el sentido de las diferencias encontradas entre la proporción de viudos y de viudas 1o que debe interesarnos, ya que ella podría obedecer a diferentes causas, 
Cuadro II-5

Indicadores derivados de los censos de 1869,1895 y 1960 que muestran que la mortalidad masculina superaba a la femenina

(A) Porcentaje de huérfanos de padre o de madre según la edad. Censo de 1869

\begin{tabular}{rrc}
\hline Edad & $\begin{array}{c}\text { Huérfanos } \\
\text { de padre }\end{array}$ & $\begin{array}{c}\text { Huérfanos } \\
\text { de madre }\end{array}$ \\
\hline 0 & & 1.42 \\
1 & 2.61 & 2.01 \\
2 & 2.97 & 2.90 \\
3 & 3.99 & 3.81 \\
4 & 5.50 & 4.25 \\
5 & 6.05 & 4.15 \\
6 & 6.67 & 5.42 \\
7 & 7.64 & 6.27 \\
8 & 8.11 & 6.38 \\
9 & 9.10 & 6.57 \\
10 & 8.45 & 6.63 \\
11 & 9.31 & 7.68 \\
12 & 10.28 & 7.58 \\
13 & 9.01 & 4.65 \\
\hline
\end{tabular}

(B) Porcentaje de viudos por sexo en grupos de edades seleccionados según censos de 1869,1895 y 1960

\begin{tabular}{|c|c|c|c|c|c|c|}
\hline \multirow{2}{*}{$\begin{array}{c}\text { Grupos de } \\
\text { edades }\end{array}$} & \multicolumn{2}{|c|}{1869} & \multicolumn{2}{|c|}{1895} & \multicolumn{2}{|c|}{1960} \\
\hline & Viudos & Viudas & Viudos & Viudas & Viudos & Viudas \\
\hline $30-34$ & 3.3 & 9.5 & 2.1 & 5.9 & 0.4 & 1.0 \\
\hline $40-44$ & 7.2 & 20,6 & 5.0 & 15.4 & 1.0 & 4.0 \\
\hline $50-54$ & 12.2 & 35.2 & 10.5 & 30.1 & 2.8 & 12.4 \\
\hline $60-64$ & 21.7 & 51.7 & 18.5 & 47.2 & 7.5 & 28.2 \\
\hline
\end{tabular}

Fuentes:

(A) - Resultados inéditos de la muestra del censo de 1869, Centro de Investi gaciones Sociales del Instituto Torcuato Di Tella.

(B) - Somoza, Jorge L. y Lattes, Alfredo E., Muestras de los dos primeros censos nacionales de población, 1869 y 1895 , Centro de Investigaciones Sociales del Instituto Torcuato Di Tella, Documento de Trabajo $\mathrm{N}^{\circ} 46$, Buenos Aires, 1967.

- Publicaciones oficiales de 1 os censos de 1895 y 1960. 
cuanto la enorme diferencia de esos porcentajes que difícilmente podría dar se sin que prevalecieran niveles de mortalidad diferentes según los sexos, Puede verse, examinando los índices del cuadro comentado, que la proporción de viudas -que se toma, claro está, como indicador de la mortalidad masculi na- en los grupos de edades inferiores a los 55 años es aproximadamente, en 1869 y 1895, tres veces mayor que el valor correspontiente a los viudos -re presentativo de la mortalidad femenina-. Los datos de 1960 muestran diferencias relativas mucho mayores aún. Creemos, por lo tanto, que la importancia de la diferencia permite afirmar que los indicios son ciertos: la mortalidad femenina era inferior a la masculina ya en las épocas que prece dieron a los años de los censos primeros, 1869 y 1895 . Esa diferencia se ha acentuado con el tiempo como lo sugieren los índices de $1960 \mathrm{y}$ lo confir man valores derivados de tablas de vida, como se verá a continuación.

53. En este trabajo se elaboran, como se ha visto en la sección anterior, tablas de vida representativas del nivel de la mortalidad de cinco períodos: los dos primeros intercensales, 1869-1895 y 1895-1914, y los que se definen en torno a los años 1914, 1947 y 1960. Para estos últimos se cuenta con ta blas por sexo, obtenidas de la información básica, esto es, muertes anuales registradas y personas enumeradas en los censos. Para los dos primeros períodos, en cambio, las tablas se elaboran en base a relaciones de superviven cia que resultan de comparar informaciones de dos censos consecutivos. Tales relaciones constituyen el fundamento sobre el que se apoya la elaboración de las tablas de mortalidad masculina. No sucede 1o mismo en relación con las de población femenina porque, como se explica en el Capítulo IV, la infor mación censal no es adecuada en este caso, para el propósito de construir tablas de vida. Las que aparecen en este trabajo, como correspondientes a las mujeres, son el resultado de adoptar una diferencia de mortalidad por sexo, dentro de cada grupo de edad y según el nivel de la mortalidad, de modelos elaborados por las Naciones Unidas. Queda pues en evidencia que las diferencias de mortalidad por sexo, correspondientes a los períodos 1869-1895 y 1895-1914, no constituyen valores observados y, naturalmente, no tendría sig nificación analizarlas en este punto.

54. En el Cuadro II-6 se presentan 1os valores de 1a esperanza de vida al nacer por sexo, según las tablas de las diferentes épocas consideradas y se indica la diferencia entre la vida media de las mujeres y la de los varones. Puede advertirse que, a medida que la mortalidad desciende, la diferencia por sexo así calculada, aumenta. Vale algo más de 2 años en 1913-1915, 4,5 años en 1946-1948 y 1lega a cerca de 6 años en 1959-1961. En el cuadro comentado se han reproducido también los valores correspondientes a las tablas de 18691895 y 1895-1914, a pesar de que la diferencia por sexo de la vida media en estos casos no tiene significación según se ha explicado en el punto anterior, para comprobar que las diferencias supuestas para esas épocas siguen la tenden cia que señalan los valores observados en épocas posteriores.

55. En una sección del Capítulo VII se extiende el análisis de la diferencia del nivel de la mortalidad por sexo tomando en cuenta la edad y considerando, tanto la población total, independientemente de su lugar de nacimiento, como la población nacida en el país. Los datos que se utilizan en ese estudio re- 
sultan todos derivados de las tablas de mortalidad construidas en este tra bajo para êpocas posteriores a 1914.

Cuadro II-6

Argentina: Esperanza de vida al nacer por sexo, en diferentes épocas

\begin{tabular}{cccc}
\hline \multirow{2}{*}{ Epoca } & \multicolumn{3}{c}{ Esperanza de vida al nacer } \\
\cline { 2 - 4 } & Varones & Mujeres & Diferencia \\
& & & \\
\hline & 32.60 & 33.32 & 0.72 \\
$1869-1895$ & 39.48 & 40.67 & 1.19 \\
$1913-1915$ & 47.59 & 49.72 & 2.13 \\
$1946-1948$ & 59.09 & 63.59 & 4.50 \\
$1959-1961$ & 63.68 & 69.53 & 5.85 \\
\hline
\end{tabular}

(B) La variación del nivel de la mortalidad según regiones

56. Según se verá oportunamente en el Capítulo III, la investigación de 1a mortalidad a partir de 1914 debe limitarse a 10 jurisdicciones del país, ya que en el resto, aparentemente, los registros de las muertes están afectados por serias omisiones. Las 10 jurisdicciones, afortunadamente representan una parte substancial, alrededor de un 85 por ciento, de la población total. Ese conjunto fue subdividido en cuatro regiones, denominadas BUENOS AIRES, CENTRO LITORAL, CUYO y NOROESTE, según se explica en el citado capítulo. E1 peso relativo de cada una de esas regiones dentro del conjunto constituido por todas ellas, en los censos a partir de 1914, se da en el Cuadro II-7. En el Gráfico II-5 se indica en un mapa cómo está constituida cada región.

57. Nos ha parecido oportuno proporcionar la información del Cuadro II-7, así como también $1 a$ del Gráfico II-5, porque ella ayudará a interpretar las diferencias en el nivel general de la mortalidad que se registran entre regiones. El peso preponderante de BUENOS AIRES y CENTRO LITORAL, dentro del conjunto de las cuatro regiones, hace que los niveles de mortalidad estimados para es as regiones estén muy próximos al que se calcula para la unión de las cuatro. El Gráfico II-5 muestra apartada geográficamente a la región № ROESTE de las otras tres consideradas; puede esto explicar en parte la dispa ridad de su índice representativo del nivel general de la mortalidad alrededor de 1960. 

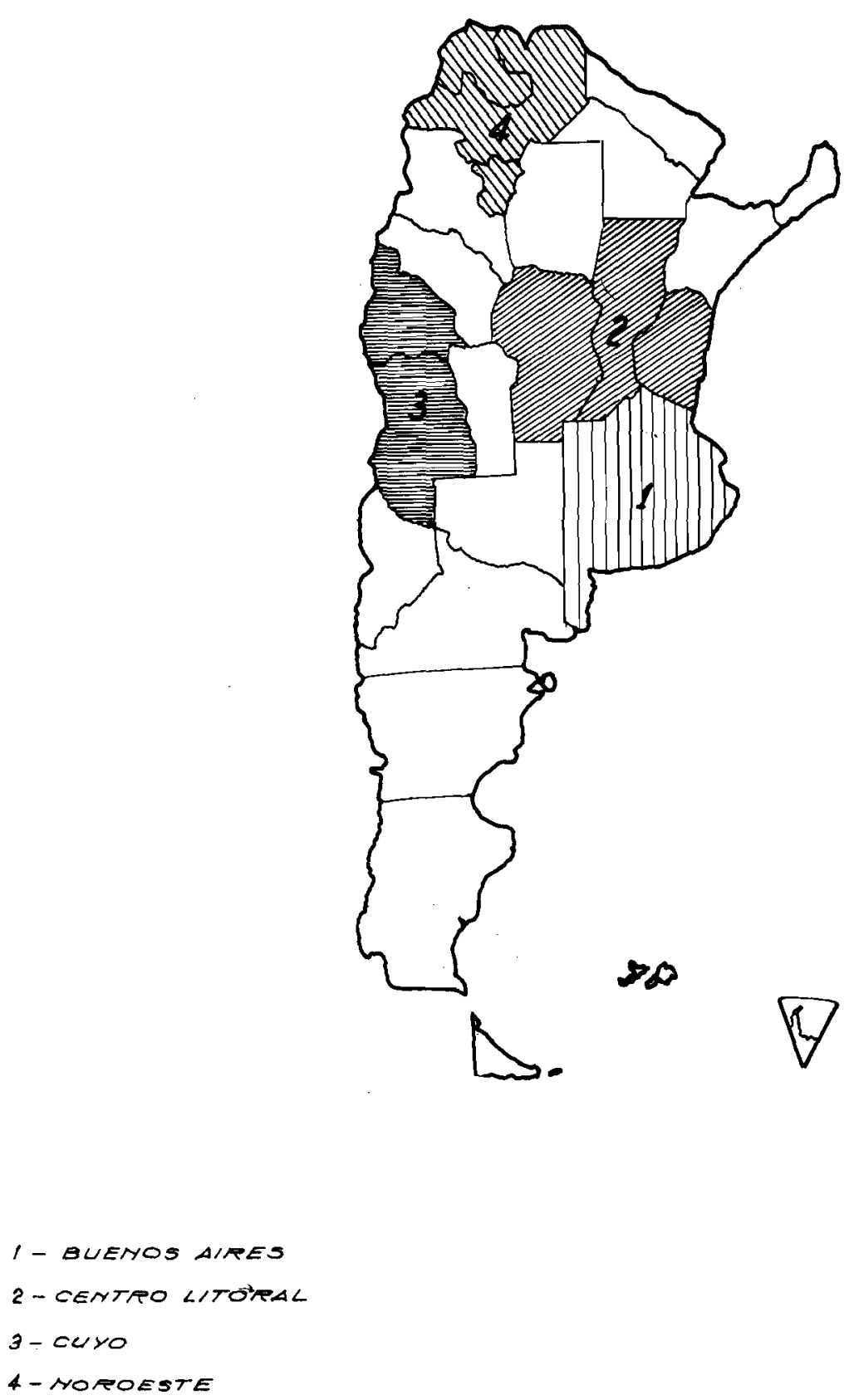
Cuadro II-7

Distribución porcentual de la población en cuatro regiones según los censos de 1914,1947 y 1960

\begin{tabular}{lrrr}
\hline \multicolumn{1}{c}{ Región } & 1914 & 1947 & 1960 \\
& & & \\
\hline & 54.8 & 55.2 & 58.0 \\
Buenos Aires & 31.0 & 30.3 & 26.5 \\
Centro Litoral & 5.9 & 6.5 & 7.0 \\
Cuyo & 8.3 & 8.0 & 8.5 \\
Noroes te & & & \\
\cline { 2 - 4 } Total cuatro regiones & 100.0 & 100.0 & 100.0 \\
\hline
\end{tabular}

58. Pueden hacerse comparaciones como las señaladas observando el Cuadro II-8 y e1 Gráfico II-6 que reproducen e1 valor de la vida media de las tablas de vida pertinentes. Se trata de las tablas de ambos sexos y de pobla ción de ambos orígenes (nacida en la Argentina y en el exterior).

Cuadro $I I-8$

Esperanza de vida al nacer para ambos sexos por regiones. Períodos 1913$1915,1946-1948$ y $1959-1961$

\begin{tabular}{lccc}
\hline \multirow{2}{*}{ Región } & \multicolumn{3}{c}{ Período } \\
\cline { 2 - 4 } & $1913-1915$ & $1946-1948$ & $1959-1961$ \\
\hline Buenos Aires & 51.37 & 63.77 & 68.15 \\
Centro Litoral & 48.75 & 61.42 & 66.81 \\
Cuyo & 41.45 & 57.95 & 64.82 \\
Noroeste & 37.94 & 51.08 & 57.66 \\
Argentina & 48.50 & 61.08 & 66.37 \\
\hline
\end{tabular}




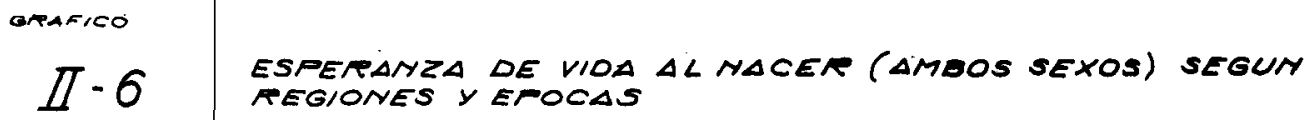

$1913-1915$

BUEMOS AIRES

CENTRO LITORAL

curo

MOTOESTE

$1946 \cdot 1948$

DUEMOS AIRES

CENTNO LITORAL

curo

MOROESTE

$1959-1961$

OUEMOS AITES

CEMTAO LITORAL

curo

MOTOESTE

RUEATE CUAOTO II-B

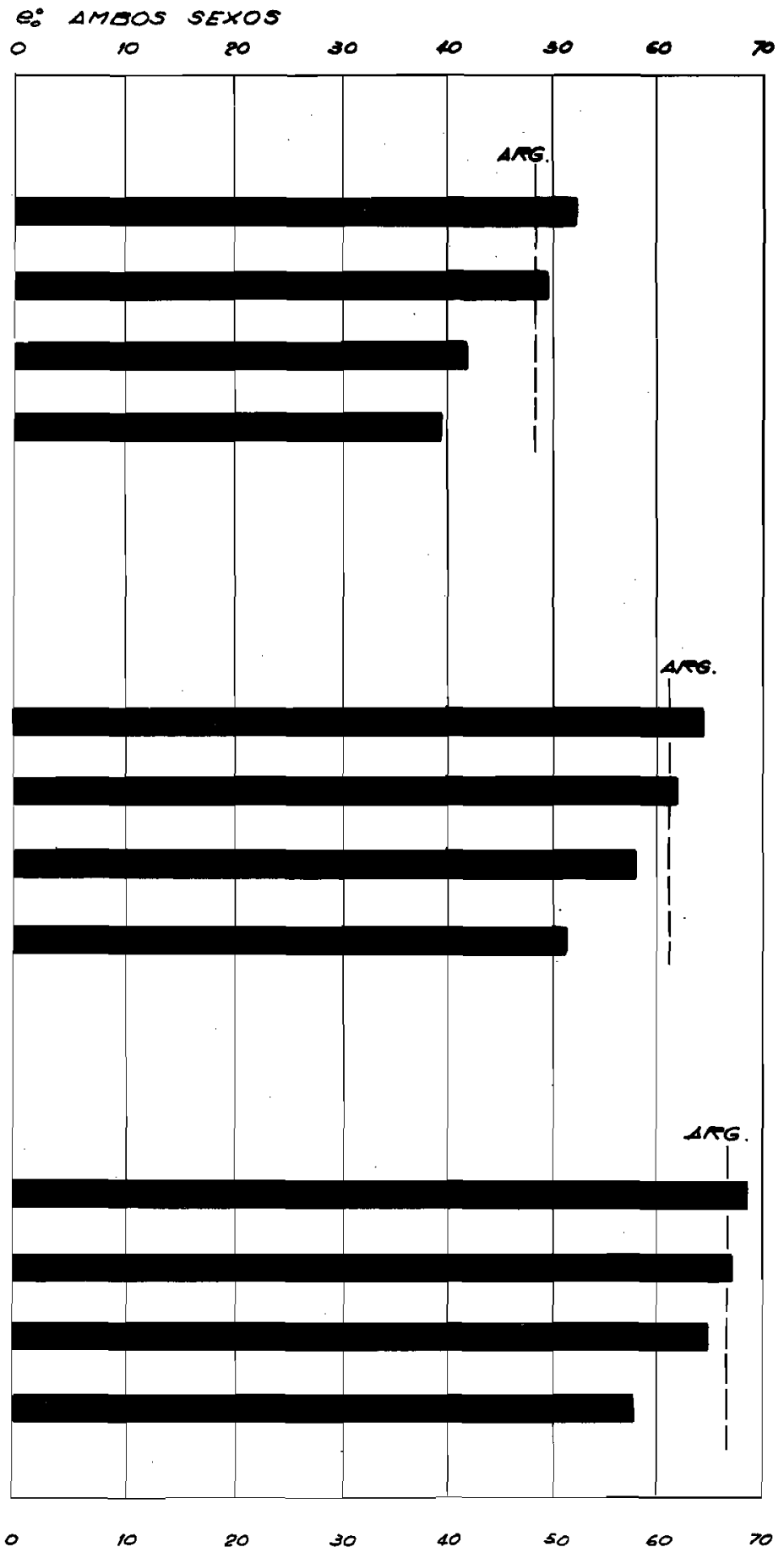


59. La representación gráfica pone de relieve algunos hechos interesantes: en la época 1913-1915 existía mayor variación que en años más recientes, en el nive1 de la mortalidad por regiones. BUENOS AIRES y CENTRO LITORAL mostraban niveles de vida media parecidos, aunque el de BUENOS AIRES es siempre superior, en tanto que CUYO y NOROESTE se aproximaban entre sí, con mor talidad claramente mayor. Con el correr de los años CUYO mejora su posición relativa acercándose más a las regiones con mortalidad menor y, consecuentemente, la región NOROESTE se alsla del resto. Esta evolución sucede sin perjuicio de producirse una baja general de la mortalidad que beneficia a las cuatro regiones; lo que no es parejo es el ritmo de evolución: es mayor en CUYO, menor en el NOROESTE. En esta última región la esperanza de vida en 1960 es todavía menor que la media estimada para el país en 1947.

60. Un análisis más detenido de la variación de la mortalidad por regiones, tomando en cuenta la edad, se efectúa en el Capítulo VII.

(C) La variación del nivel de la mortalidad según el origen de la población

61. En este punto y en los que siguen se analiza la diferencia de la morta lidad entre la población nacida en el país y la nacida en el exterior. Para esto debe recurrirse a indicadores indirectos salvo en el período 1913-1915 para el cual se cuenta simultáneamente con la población enumerada en el cen so de 1914 y con las muertes anuales registradas, clasificadas a la vez por sexo, edad y origen.

62. Los indicios sobre el nive1 de la mortalidad según origen, derivados de información censal, se refieren a los censos de 1869 y 1895 . Es, como cuando se analizó la variación de la mortalidad en el tiempo y la diferen cia de mortalidad por sexo, la proporción de viudos que se computan ahorā según sexo y origen en diferentes grupos de edad. Los resultados aparecen en el Cuadro II-9.

63. Es innecesario repetir aquí las limitaciones que el porcentaje de viudos según la edad tiene como indicador de la mortalidad. Fueron ya comenta das anteriormente, en especial en la sección donde se estudió la diferencia del nivel de la mortalidad según el sexo. A pesar de ellas creemos nosotros que es significativo encontrar en las cifras presentadas en el Cuadro II-9 que persistentemente, salvo una sola excepción (grupo de edades 40-44, sexo femenino, muestra del censo de 1869), los porcentajes de viudos son menores en "1a población nacida en el exterior que en la nativa. A veces los valores son muy próximos entre sí, lo que sucede por lo general en el grupo de edades más avanzadas que se considera; otras, particularmente entre los hombres y en edades jóvenes, las diferencias por origen son muy grandes, E1 primer indicio encontrado, por lo tanto, es que la mortalidad de la población naci $\mathrm{da}$ en el exterior, en el pasado, era inferior a la de la población nacida en el país, 
Cuadro II-9

Porcentaje de viudos según sexo, grupos de edades seleccionados y origen en los censos de 1869 y 1895

\begin{tabular}{|c|c|c|c|c|c|c|c|c|}
\hline \multirow{3}{*}{$\begin{array}{c}\text { Grupos } \\
\text { de } \\
\text { edades }\end{array}$} & \multicolumn{4}{|c|}{1869} & \multicolumn{4}{|c|}{1895} \\
\hline & \multicolumn{2}{|c|}{ Varones } & \multicolumn{2}{|c|}{ Mujeres } & \multicolumn{2}{|c|}{ Varones } & \multicolumn{2}{|c|}{ Mujeres } \\
\hline & Argen. & Exter. & Argen. & Exter. & Argen. & Exter. & Argen. & Exter. \\
\hline $30-34$ & 3.79 & 2.26 & 9.68 & 8.11 & 2.47 & 1.72 & 6.78 & 4.33 \\
\hline $40-44$ & 8.05 & 5.29 & 20.43 & 21.82 & 5.95 & 4.36 & 17.72 & 11.46 \\
\hline $50-54$ & 13,18 & 9.49 & 36.32 & 25.69 & 12.02 & 9.42 & 32.93 & 25.12 \\
\hline $60-64$ & 22.59 & 18.18 & 52.41 & 41.82 & 19.52 & 17.45 & 47.48 & 46.45 \\
\hline
\end{tabular}

Fuentes:

1869 - CIS, Documento de Trabajo $\mathrm{N}^{\circ} 46$.

1895 - Publicación oficial del censo.

64. Los resultados son concordantes con los ya conocidos para 1a población censada en la ciudad de Buenos Aires, en diferentes épocas, Aunque parciales, estos resultados tienen mucha significación, porque en la ciudad capital se concentró siempre una parte importante de la inmigración, especialmente la europea que constituỉa la gran mayoría de la población nacida en el exterior. Tablas de mortalidad de la ciudad de Buenos Aires para 1887 (véase Referencias, 6) y otras construidas para 1904 y 1908-1910 (véase Referencias, 7) muestran sistemáticamente una mortalidad inferior en la población inmigrante que en la nativa.

65. E1 estudio puede hacerse, sobre bases firmes, a nivel nacional, só lo para el período 1913-1915 según se dijo anteriormente, aunque cabe hacer la advertencia que se aceptan las cifras de muertes registradas, según origen, co mo si no estuvieran afectadas por error en la declaración del lugar de nacimiento, 10 que, desde luego, no puede saberse. En el Capítulo VII se hace un análisis de los resultados para este período. Baste sólo reproducir aquí el valor de la esperanza de vida a la edad de 5 años (ver Cuadro II-10) por sexo, que resulta para el país (agrupamiento de las cuatro regiones ya definidas) según el origen de la población. Tal como se explica en el Capítulo V, que trata sobre la construcción de las tablas de vida del período 1913-1915, la investigación de la mortalidad de la población nacida en el exterior se efectúa sólo a partir de esa edad en razón de que la población y muertes de niños menores de 5 años eran muy poco numerosas como para deducir de ellas las funciones de una tabla de vida. 
Cuadro II-10

Esperanza de vida a la edad de 5 años, según sexo y origen de la población. Período 1913-1915

\begin{tabular}{lrr}
\hline $\begin{array}{c}\text { Lugar de } \\
\text { nacimiento }\end{array}$ & Varones & Mujeres \\
\hline & & \\
Argentina & 49.47 & 51.38 \\
Exterior & 55.37 & 59.20 \\
Diferencia & 5.90 & 7.82 \\
\hline
\end{tabular}

66. Las cifras de1 Cuadro II-10 muestran una importante diferencia en e1 nivel de la mortalidad según el origen. La esperanza de vida, a la edad de 5 años, era casi 6 años superior, entre los varones nacidos en el exte rior que entre los nacidos en el país, En la población femenina la diferencia era aun mayor, próxima a los 8 años.

67. Cabe preguntar cuál era la situación en 1946-1948 y 1959-1961, los otros períodos para los cuales se extiende este trabajo. Desafortunada mente, no puede ni en uno, ni en el otro período, construirse tablas de vida por origen pues la información sobre defunciones no está clasifica da a la vez por edad y lugar de nacimiento.

68. Puede encararse un análisis indirecto. Los cálculos realizados por varias razones conducen a resultados sólo aproximados y consisten en computar el número de muertes en la población según origen y sexo aplicando a los datos censales de 1947 y 1960, que dan esa clasificación de las per sonas censadas, las tasas anuales obtenidas para el país, sin distinción de origen. Las muertes esperadas así obtenidas, esto es, el total de muer tes esperadas en la población nacida en el país y en el exterior, pueden compararse con las muertes totales según origen que dan los registros y de ducir de allí si el nivel medio de mortalidad aplicado conduce a valores superiores o inferiores de los registrados $y$, consecuentemente, si la mortalidad varía según el origen.

69. Surgen varios problemas en esta elaboración:

a) la población a la que se aplican las tasas, resultantes del censo, está afectada por errores de omisión censal y se tienen indicios (véase Referen cias, 2) de que esa omisión, en 1960, fue selectiva por origen -fueron omí tidos en la enumeración más extranjeros que argentinos en términos relativos-. Las omisiones censales tienden a subestimar el número de muertes es peradas ; 
(b) las tasas de mortalidad que se aplican, según se ha señalado anteriormente, corresponden al conjunto de cuatro regiones y no a todo el país. Se presume que el nivel general de la mortalidad del país debe ser algo superior al que reflejan las tasas de las cuatro regiones, Por esta razón las muertes esperadas serán inferiores a las reales;

(c) las muertes registradas, especialmente en las jurisdicciones que fueron eliminadas del análisis en la construcción de las tablas de vida, están afectadas por omisión, mucho más, aparentemente, en 1947, que en 1960. Con secuentemente, el número de muertes registradas estaría también por debajo de1 número real.

70. Debido a las razones anteriores, y además a que un valor esperado, en sentido estadístico, no tiene que coincidir con uno registrado, el total de muertes de ambos orígenes, obtenido de aplicar a toda la población censada en 1947 y 1960 las tasas de mortalidad de las cuatro regiones, no coincidió con el total dado por los registros para esos años: fue ligeramente superior (161.615 fueron las muertes esperadas, 156.621 las registradas en 1947) en un caso, y ligeramente inferior (172.043 frente a 176.662) en el otro. E1 último resultado está reflejando, seguramente, 1a excepcional omisiôn censal que se produjo en 1960 .

71. Si se efectúa un cálculo burdo, consistente en ajustar los datos registrados en proporción a las diferencias encontradas en toda la población en uㅡ no y otro año, y tal ajuste se aplica a los totales registrados de muertes según origen, puede sacarse la conclusióm de que las muertes esperadas, en la población nacida en el país, son inferiores a las registradas tanto en 1947 como en 1960. Lo contrario, claro está, sucede con las defunciones de población nacida en el exterior: las registradas son menores que las espera das. Si estos resultados son aceptados la diferencia de mortalidad según origen de la población conservaría en años recientes el mismo sentido obser vado en 1913-1915 y con anterioridad: sería menor en la población nacida en el exterior que en la nacida en el país.

72. Sería poco juicioso, creemos, sacar tal conclusión del análisis que se deja esbozado porque tenemos dudas acerca de la calidad con que se declara el origen de la población y la sospecha de que cuando se desconoce el lugar de nacimiento de un muerto se le asigna preferentemente la condición de naci do en el país. Por otra parte, los resultados alcanzados en relación con los datos de 1947 y 1960 están afectados por las limitaciones mencionadas anteriormente.

73. Hay además otro elemento de juicio que hace dudar de la conclusión de que la población nacida en el exterior tiene una mortalidad menor en años re cientes. Tal es el análisis que puede hacerse para la Provincia de Buenos Aires en torno a 1947 basado en las muertes anuales clasificadas por sexo, origen y edad -información disponible en este caso-. Las tasas muestran que no hay una diferencia clara en la mortalidad de ambos sectores de la población. Aunque se trata de un caso aislado, que puede no representar la situa ción de todo el país, no deja de ser significativo. En épocas pasadas, en 
1913-1915, cuando la diferencia de mortalidad por origen era un fenómeno bien establecido, no se producían excepciones como la indicada.

74. Por otra parte, 1a diferencia del nivel de la mortalidad por origen de la población reflejaba en el pasado, seguramente, una situación social muy diferente entre los nacidos en el país y los extranjeros. A la luz de indicadores derivados de los censos, la población extranjera tenía por ejemplo, un nivel educativo superior a la nacida en el país; natural era que su mortalidad fuera inferior. Según los censos más recientes, en cam bio, la situación ha cambiado y resultaría, por lo tanto, extraño que esa diferencia en la mortalidad se conservara con el sentido apuntado.

75. Resumiendo las conclusiones de esta sección: la mortalidad de la población nacida en el exterior fue en el pasado -claramente hasta 19131915- inferior a la correspondiente a la población nacida en el país. Fal ta información fehaciente para estudiar esta diferencia en épocas recientes. Algunos indicios burdamente elaborados hacen pensar que la diferencia persiste; otras comprobaciones - las estadísticas de la Provincia de Buenos Aires en 1947-parecen indicar que esa diferencia no existe ya. Nada definitivo por lo tanto, se puede sacar como conclusión. 


\section{PARTE SEGUNDA}



En esta Segunda Parte se describen los procedimientos utilizados en la cons trucción de un conjunto de tablas de mortalidad y se presentan los resultados. Se asigna gran importancia a esta elaboración porque, por una parte, la tabla de vida constituye el instrumento más apropiado y usual para medir la mortalidad de una población y, por la otra, falta en el país un conjunto de tablas, resultado de una labor sistemática, que permita la comparación de la mortalidad entre regiones y/o a lo largo del tiempo, Aunque existe un buen número de tablas de vida para el país y algunas provincias o ciudades, son insuficientes o inapropiadas si se desea efectuar comparaciones como las indicadas.

Consta esta parte de cuatro capítulos: en el III se hace una breve presentación de los dos procedimientos utilizados en la elaboración de las tablas de mortalidad, comparando datos de dos censos, uno de ellos, relacionando datos de registros con información del censo, el otro. El capítulo IV se ocupa de la elaboración de las tablas intercensales para los períodos 1869-1895 y 1895-1914, en tanto que el siguiente, el capítulo $V$, trata de la construcción de tablas basadas en datos de registros de defunciones de las épocas 19131915, 1946-1948 y 1959-1961 en torno a los años de los censos de población de 1914, 1947 y 1960. Finalmente, en el capítulo VI se presentan los resultados: un conjunto de 75 tablas de mortalidad para las cinco épocas consideradas. En la medida en que los datos básicos lo permitían, se elaboraron tablas de vida por sexo, región u origen de la población. 

En esta Segunda Parte se describen los procedimientos utilizados en la cons trucción de un conjunto de tablas de mortalidad y se presentan los resultados, Se asigna gran importancia a esta elaboración porque, por una parte, la tabla de vida constituye el instrumento mâs apropiado y usual para medir la mortalidad de una población $y$, por la otra, falta en el país un conjunto de tablas, resultado de una labor sistemâtica, que permita la comparación de la mortalidad entre regiones y/o a lo largo del tiempo, Aunque existe un buen número de tablas de vida para el país y algunas provincias o ciudades, son insuficientes o inapropiadas si se desea efectuar comparaciones como las indicadas.

Consta esta parte de cuatro capítulos: en el III se hace una breve presentación de los dos procedimientos utilizados en la elaboración de las tablas de mortalidad, comparando datos de dos censos, uno de ellos, relacionando datos de registros con información del censo, el otro. El capítulo IV se ocupa de la elaboración de las tablas intercensales para los períodos 1869-1895 y 1895-1914, en tanto que el siguiente, el capítulo $\mathrm{V}$, trata de 1a construcción de tablas basadas en datos de registros de defunciones de las épocas 19131915, 1946-1948 y 1959-1961 en torno a los años de los censos de población de 1914, 1947 y 1960. Finalmente, en el capítulo VI se presentan los resultados: un conjunto de 75 tablas de mortalidad para las cinco épocas consideradas. En la medida en que los datos básicos lo permitían, se elaboraron tablas de vida por sexo, región u origen de la población. 

Capítulo III

LOS DOS PROCEDIMIENTOS UTILIZADOS EN LA ELABORACION DE TABLAS DE VIDA

1. La medición de la mortalidad según la edad, la variable más comúnmente empleada en demografía y en las ciencias actuariales, se efectúa mediante un instrumento denominado tabla de mortalidad. Su elaboración se inicia ge neralmente siguiendo uno de estos dos caminos:

a) dividiendo el número de muertes ocurridas en un año por 1a población cen sada a mediados del año, clasificadas tanto una como la otra según la edad. Se obtiene, de ese modo, una medida directa de la mortalidad: la tasa anual por edad.

b) calculando 1a proporción que representan los sobrevivientes al final de un período intercensal, con respecto al total al comienzo del período, de una cohorte de personas -esto es, individuos nacidos en un mismo intervalo de años- registrada en dos censos, estableciéndose así lo que se denomina "relación de supervivencia" de la que se derivan medidas directas de la mor talidad.

La aplicación del primer procedimiento se justifica cuando la información so bre defunciones, proveniente de los registros civiles, tiene una calidad similar a la derivada del censo de población.

La validez del segundo método está condicionada a que la información que utị liza, obtenida de dos censos, sea comparable, principalmente en cuanto a cobertura, y a que la población investigada no haya experimentado migraciones durante el período intercensal.

2. Puede advertirse que es indispensable disponer de información censal pa ra aplicar tanto uno como el otro procedimiento: en el primer caso se requie re un censo y datos de muertes ocurridas en uno o varios años en torno a la fecha del censo; en el segundo, dos censos. La información debe ser compara ble y verificarse, en el segundo procedimiento, la hipótesis de que la pobla ción es cerrada, esto es no afectada por migraciones en el período intercensal. El segundo procedimiento of rece la ventaja de no requerir información proporcionada por los registros de muertes. Es esta una característica impor tante ya que no es común disponer de datos fehacientes sobre las muertes ocurridas en un año, especialmente si el análisis se remonta a épocas lejanas.

3. Cuando se dispone de información de buena calidad ell primer procedimiento es el que se utiliza invariablemente, ya que las tasas de mortalidad según la edad calculadas directamente son más precisas que las que pueden deducirse por el otro método, no sólo porque en la realidad ninguna población es estric tamente cerrada $y$, por lo tanto, no se cumple rigurosamente uno de los supues tos, sino también porque la derivación de tasas de mortalidad a partir de re- 
laciones de supervivencia es un procedimiento burdo frente al de la medición directa.

4. E1 inconveniente principal que impide la aplicación generalizada del pri mer procedimiento es que, frecuentemente, los registros de muertes no son completos. Tampoco lo es el recuento de población. Sin embargo, la enumera ción censal es menos defectuosa, por lo general, que el registro de defunció nes, de lo que resulta que las tasas de mortalidad calculadas relacionando muertes registradas con población enumerada en un censo resultan, con frecuen cia, inferiores a su valor real.

5. E1 empleo del segundo procedimiento se justifica en los casos en que no existen registros de muertes de calidad aceptable y siempre que las migracio nes no constituyan un factor de perturbación importante. Los resultados que se obtengan por este camino deben ser considerados siempre con reserva.

6. Las consideraciones anteriores, de valor general, servirán para explicar la razón por la cual el estudio de la mortalidad en la Argentina, más particu larmente, la elaboración de tablas de vida de diferentes épocas, se hizo distinguiendo dos períodos: el anterior a 1914, que comprende los dos períodos intercensales 1869-1895 y 1895-1914, y el que se inicia en 1914, época a partir de la cual se considera que los registros de defunciones son razonablemente completos en una parte importante del territorio nacional como parajustificar la ap1i cación del procedimiento de medir la mortalidad relacionando información de regis tros con datos censales.

Epocas anteriores a 1914

7. Los dos primeros censos nacionales fueron levantados en 1869 y 1895 . No había en esa época registros civiles organizados que proporcionaran información razonablemente completa sobre las muertes de calidad similar a la de los censos. Conviene recordar que los registros civiles de las distintas provincias se establecieron recién en la década de 1880 a 1890 y no se dispone de estadísticas sobre defunciones publicadas a nivel nacional sino desde 1911. Por imperio de las circunstancias, consecuentemente, debe recurrirse al método que se apoya en las relaciones de supervivencia intercensales para derivar tablas de vida para esas épocas remotas.

8. Como se dijo anteriormente la aplicación de ese método requiere que la in formación de los dos censos que se relacionan sea comparable y que la población no haya sufrido efectos de migraciones a lo largo del período analizado. En el caso de la Argentina ninguna de las dos condiciones se cumple satisfac toriamente en los períodos que deben estudiarse, esto es, 1869-1895 y 18951914: hay indicios claros de que los censos no fueron de calidad semejante (véase Referencias, 8); la población estuvo abierta a importante corrientes migratorias, Deberá empezarse por admitir, entonces, que ante esta situación no deben esperarse resultados precisos del estudio que se emprende, más aún $s i$ se tiene en cuenta que no contribuye ciertamente a facilitar el análi sis el hecho de que la amplitud de los períodos intercensales analizados sea muy extendida; más de 25 años median entre el primero y el segundo censo; 
cerca de 20 entre el de 1895 y 1914. Sólo la necesidad imperiosa de tener alguna idea sobre el nivel probable de la mortalidad de la época puede explicar y justificar que hayamos proseguido adelante en la elaboración de información tan poco apropiada para el análisis.

9. Es interesante especular sobre los posibles errores en la estimación de la mortalidad intercensal que pueden haberse cometido por no cumplir 1a informaciôn básica con los requerimientos señalados. La falta de comparabilidad de los censos no puede establecerse en forma terminante aunque, co mo se dijo anteriormente, hay indicios de que la calidad de la información (a la luz de lo que permiten comprobar las declaraciones de edad y sexo) mejoró con el tiempo. Es posible que la calidad esté asociada con la inte gridad del censo, que es 10 que más importa a los efectos de medir la mortalidad.

No hay duda que 1a integridad mejoró entre 1869 y 1895; el primer censo, por ejemplo, excluyó del recuento los territorios nacionales en tanto que el segundo los tomó en cuenta. Aunque la población total allí censada es muy escasa frente a la del país en conjunto, la falta de comparabilidad de los datos, en razón de haber sido el segundo recuento mäs completo que el primero, es un hecho innegable. Si los tres primeros censos han sido progresivamente más y más completos con el tiempo, las relaciones de supervivencia calculadas con datos observados debieron haber resultado superiores a la realidad $\mathrm{y}$, consecuentemente, el nivel estimado de mortalidad haber sido subestimado.

10. Como se ha dicho anteriormente, el método exige que la población haya permanecido cerrada durante el período intercensal que se investiga. No es esto ciertamente verdadero para la población total de la Argentina que reci bió, en los dos primeros períodos intercensales, importantes contingentes $\overline{\mathrm{de}}$ inmigrantes y que estuvo afectada también por el retorno de gran número de ellos, Puede admitirse, sin embargo, que la población nacida en el país debió experimentar en menor medida los efectos de tales movimientos migratorios, aunque no debe descartarse que hayan tenido significación.

Es razonable pensar que el sentido de las corrientes migratorias de las perso nas nacidas en el país fue negativo durante 1869 y 1914 , período que comprende los dos primeros intervalos entre censos. Debieron haber sido más los individuos que salieron del país y que fueron censados en 1869 o 1895 como argentinos nativos, que los que reingresaron durante esos períodos intercensales habiendo estado ausentes en ocasión de alguno de esos censos. Sólo una peque ña cantidad de personas, en términos absolutos y relativos, pudo dar origen a la inmigración, o mejor dicho retorno, de argentinos nativos; en tanto que eran muchos, especialmente en términos relativos, los que pudieron emigrar. Entre los argentinos nativos, fundamentalmente entre aquellos unidos por vínculos familiares con la población no nativa, debió haber sido muy frecuente el caso de emigración; tanto quizá como lo era para la población inmigrante, que retornaba a sus países de origen.

Algunos datos estadísticos, aunque derivados de registros de entradas y salidas que merecen muchos reparos, pueden servir para dar órdenes de magnitud y 
sobre todo ilustrar la significación que tenían los movimientos de retorno de los inmigrantes. En los 24 años que van de 1871 a 1894 entraron cerca de 2.2 millones de individuos; salieron 1.3 millones; entre 1895 y 1914 un período de 20 años que aproximadamente corresponde con el intercensal, ingresaron cerca de 5.2 millones; egresaron 3.1 millones (véase Referencias, 9).

Puede también especularse -ante la carencia de datos que puedan probarloque la emigración de mujeres nativas haya sido más importante que la de los varones en razón de que entre los inmigrantes predominaban los hombres con edades propicias para casarse. Si muchos de ellos contrajeron matrimonio en el país y lo hicieron, en parte, con argentinas nativas, y si posterior mente algunos de ellos retornaron a sus países de origen acompañados por sus familias (mujer e hijos argentinos nativos) la emigración de mujeres nativas debió superar a la de hombres, entre los que no cabe suponer que se producía un hecho similar. Como dato interesante en apoyo de esos supuestos cabe señalar que cerca de 170 por ciento de los inmigrantes eran varones y en $2 / 3$ partes solteros.

Se deja registrado este razonamiento porque, como se verá más adelante, al relacionar el número de mujeres censadas en 1914 con el correspondiente, a la misma cohorte, enumerada en 1895, se obtienen valores muy bajos para ser aceptables como expresión de las relaciones de supervivencia de una cohorte. Esos valores quedan por debajo de 1 os obtenidos para los varones en tramos de vida adulta. Aunque es admisible que en cierto tramo de la vida -dado el alto nivel de la mortalidad de la época- la mortalidad masculina fuera inferior a la femenina y, consecuentemente, las relaciones de supervivencia masculinas mayores que las femeninas, no parece razonable aceptar ni el interva lo de edades en que se produce esa diferencia de los valores según sexo, ni la importancia relativa de ella. En el procedimiento de medición de la mortalidad a través de relaciones de supervivencia las emigraciones producen e1 mismo efecto que las muertes. Si las salidas de argentinos superaron a las entradas, en consecuencia, se cometió un error en el sentido de exagerar el nivel de 1 a mortalidad intercensal.

11. Resumiendo 1o dicho en los puntos anteriores: ante la necesidad de con tar con estimaciones de niveles posibles de la mortalidad en los períodos an teriores a 1914, época a partir de la cual se cuenta con registros de muertés que permiten elaborar tablas de vida, sobre bases razonablemente firmes, se re currió al procedimiento de estimar la mortalidad para períodos intercensales comparando información de dos censos, los de 1869 y 1895 , en primer lugar; los de 1895 y 1914, en segundo término. Se tienen indicios, según se ha visto, de que los censos no son comparables, lo que debe tomarse como un 11amado de aten ción sobre la limitación de los resultados de la elaboración. Además, el procedimiento requiere que la población analizada no haya sufrido migraciones durante el período intercensal. A fin de satisfacer en forma aproximada esta condición se realiza el estudio exclusivamente con la población que en los cen sos declaró haber nacido en el país reconociendo, sin embargo, que no es tampoco un conjunto cerrado. Es posible que la falta de comparabilidad de los censos, en cuanto a cobertura, contribuya a que los niveles de mortalidad estimados sean inferiores a la realidad -si es que la cabalidad de los censos fue me 
jorando con el tiempo. Las migraciones que afectaron a la población nativa, posiblemente en una mayor medida a las mujeres que a los varones, durante los períodos intercensales pueden hacer, por el contrario, que los niveles de mortalidad estimados hayan sido exagerados. No podemos, en consecuencia, decir en qué sentido las estimaciones elaboradas pueden diferir de la realidad. Cabe señalar que se trata de estimaciones sólo aproximadas que procuran ilustrar acerca de cuál pudo ser la mortalidad durante las últimas déca das del siglo XIX.

12. En el capítulo IV se describen los métodos utilizados para derivar las tablas de vida intercensales 1869-1895 y 1895-1914 por sexo de 1a población nacida en el país. En base a ellas y con información obtenida sobre la dife rencia de la mortalidad según el lugar de nacimiento, Argentina o exterior, conocida para el período 1913-1915, se elaboraron tablas de mortalidad según sexo para la población total, nacida o no en el país y finalmente una ta bla de vida general, para ambos sexos y ambos orígenes (Argentina o exterior). Estos últimos resultados, derivados de otros que como se ha señalado, pueden aceptarse sólo con grandes reparos, son aun más conjeturales que los primeros. No por eso, creemos, son menos útiles. Sirven el propósito de dar una versión posible de la mortalidad de la población total de la Argen tina. Estimaciones, basadas en otras informaciones, derivadas por otros pro cedimientos, podrán compararse con las que se presentan a fin de establecer semejanzas o diferencias que servirán para confirmar o desechar las estimaciones aquí elaboradas.

\section{Epocas: 1914 y posteriores}

13. A partir de 1914 las tablas de mortalidad que se elaboran, con datos de los censos levantados en 1914, 1947 y 1960, están basadas en información pro porcionada por los registros de muertes anuales. No quiere esto decir que a partir de ese año las estadísticas de defunciones comienzan a ser completas en todo el país. Se sabe que existen errores de omisión que afectan tanto a las muertes registradas, como a las poblaciones enumeradas en los censos. No se conoce, sin embargo, la importancia de esos errores a través de una medición directa.

14. Por fuerza de las circunstancias, no disponer de resultados de mediciones directas, se recurre a procedimientos indirectos para detectar y estimar omisiones de los registros y censos. Los resultados de esta tarea, puede an ticiparse, son solamente aproximados, poco satisfactorios.

15. Tales procedimientos aproximados se aplican tanto a los datos relativos a la población, denominador de las tasas de mortalidad, como a las estadísti cas de muertes, que constituyen el numerador. En general se procura establecer coherencia entre la información de ambas fuentes buscando que las tasas de mortalidad resultantes reflejen la realidad sin pretender que aisladamente cada uno de los dos datos, población y muertes, sea correcto. Para el pro pósito de medir la mortalidad es indiferente que ambos sean exactos o estén, los dos en igual medida, afectados por error, dentro de cada grupo de pobla- 
ción estudiado. Mucho se especula con esto último (véase Referencias, 10) es decir, con suponer que las omisiones en los registros de muertes tienen igual importancia relativa que las omisiones de personas enumeradas en un censo y, consecuentemente, que las tasas obtenidas por cociente están 1ibres de error. Nosotros también hacemos ese supuesto, después de eliminar de la investigación algunas provincias con datos presumiblemente muy deficientes y de ajustar los datos del censo de 1960 a fin de hacerlo comparable con los datos de los registros.

16. En el Anexo III se describe el procedimiento utilizado para seleccionar un conjunto de jurisdicciones, compuesto por la Ciudad de Buenos Aires y 9 provincias, que designaremos por comodidad "10 provincias", cuyos registros de defunciones se consideran de calidad comparable con la de la in formación censal de 1914 y 1947. Con respecto al censo de 1960, son tan claros los indicios de que su calidad fue inferior a la de 1947, que creemos justificado modificar los resultados en la medida necesaria para hacer los comparables con éste y, consecuentemente, con la información de muertes registradas. No es esta una elaboración propia de este estudio: se aceptan los argumentos y conclusiones de un trabajo elaborado por un organismo oficial (véase Referencias, 2).

17. El conjunto de las 10 provincias está constituido por: la ciudad de Buenos Aires y la provincia de Buenos Aires, que forman la región que deno minamos BUENOS AIRES (BA); Santa Fe, Córdoba y Entre Ríos, que constituyeñ la región CENTRO LITORAL (CL); Mendoza y San Juan, integrantes de CUYO (CY) y Tucumán, Salta y Jujuy, que definen la región que llamamos NOROESTE (NO). En el Cuadro III-1 se muestra la importancia que la población de estas 10 provincias ha tenido en el total del país a través de los datos censales, sin corregir, de 1914, 1947 y 1960. Puede observarse que representan más del 80 por ciento del total. Por esta razón y también por simplicidad, de signaremos como ARGENTINA (RA) a la unión de las cuatro regiones constituí das por las 10 provincias aunque es dudoso que representen la mortalidad de todo el país. Es razonable suponer que el nivel de mortalidad general sea superior al que corresponde al conjunto de provincias seleccionado, ya que la población excluida debe tener niveles de vida inferiores a la media y, consecuentemente, mayor mortalidad. En el Capítulo II se elaboró una es timación acerca de cuál pudo haber sido la mortalidad argentina a través del tiempo, medida por la tasa bruta anual de mortalidad, y se hicieron con jeturas sobre la mortalidad de las provincias excluidas en la elaboración de las tablas de vida.

18. El Capítulo $V$ se ocupa de la elaboración de las tablas de vida para las épocas de los censos de 1914, 1947 y 1960. E1 conjunto de tablas elaboradas con información del censo de 1914 es el más numeroso porque la información básica permitió construir tablas distinguiendo el origen de la población, es to es, si el lugar de nacimiento era la Argentina o el exterior. Como ademâs se investiga la mortalidad según sexo y región, el conjunto de tablas de vida para el período 1913-1915 se compone de 35. Los conjuntos de tablas elaboradas para épocas en torno a los censos de 1947 y 1960 están integrados por sólo 15 cada uno, ya que en estos casos sólo se pudo investigar la morta lidad según sexo y región. 
Cuadro III-1

Importancia de la población de 10 provincias en el total del país a través de los censos de 1914, 1947 y 1960

\begin{tabular}{cccc}
\hline $\begin{array}{c}\text { Año del } \\
\text { censo }\end{array}$ & \multicolumn{2}{c}{ Población } & Porcentaje de \\
10 provincias & Total del \\
país & $\begin{array}{c}\text { peccionadas } \\
\text { en el total }\end{array}$ & 84.3 \\
1914 & 6.650 .525 & 7.885 .237 & 82.7 \\
1947 & 13.143 .598 & 15.893 .827 & 83.9 \\
1960 & 16.781 .568 & 20.010 .539 & 8 \\
\hline
\end{tabular}



Capítulo IV

ESTIMACION DEL NIVEL DE LA MORTALIDAD POR SEXO, EN LOS PERIODOS 1869-1895 y $1895-1914$

1. Según se ha visto en el capítulo anterior la estimación del nivel de la mortalidad correspondiente a las épocas más lejanas, 1869-1895 y 18951914, se apoya en el procedimiento de establecer relaciones de superviven cia intercensales correspondientes a personas de una misma cohorte -esto es, individuos nacidos en un mismo intervalo de años-. Se recurre a este método, que produce resultados sólo aproximados a la realidad, porque no existe información acerca de las muertes anuales ocurridas en los años en torno a la fecha de los dos primeros censos, el de 1869 y el de 1895 .

2. Procedimientos similares al que se utiliza aquí, en el sentido de ba sarse como éste únicamente en información censal, han sido utilizados por diferentes autores cuando las circunstancias lo imponían. Los casos más notables de la literatura demográfica son posiblemente el cálculo de tablas de vida para los períodos 1911-21 y 1931-41 por $\mathrm{K}$. Davis para la India (véase Referencias, 13) y la estimación de la mortalidad de la población natural de Brasil, en el período 1940-50, realizada por G. Mortara (véase Referencias, 14).

3. Los procedimientos empleados por nosotros, sin embargo, no coinciden con los utilizados por esos autores. Siguen el camino recorrido por varios demógrafos del CELADE, particularmente un trabajo reciente de Aréva 1o (véase Referencias, 15) y otros de Merlo y Ortega (véase Referencias, $16 \mathrm{y}$ 17). Lo que distingue a nuestro procedimiento de otros es que la fun ción básica de la tabla de vida que se utiliza para la elaboración es la relación de supervivencia por cinco años, relativa a un tramo también quin quenal de edades, que simbolizamos así: ${ }_{5} \mathrm{P}(\mathrm{x})$ queriendo expresar, con más precisión: $5 \mathrm{P}(\mathrm{x}, \mathrm{x}+4)={ }_{5} \mathrm{~L}_{\mathrm{x}+5} / 5_{5} \mathrm{~L}_{\mathrm{x}}$.

4. Aunque parece casi innecesario repetirlo una vez más, las tablas de vida que resultan de este tipo de elaboración constituyen sólo estimaciones plausibles del nivel de la mortalidad, no medidas precisas. Están afectadas por un posible amplio margen de error. Deben ser utilizadas, con secuentemente, con cautela. Pese a sus limitaciones creemos que estimaciō nes como las que aquí presentamos constituyen valiosos elementos para la difícil tarea de describir tendencias demográficas del pasado.

5. El capítulo se divide en forma natural en dos partes principales: 1a primera se refiere a la estimación del nivel de la mortalidad en el perío do 1869-1895; 1a segunda se ocupa de la elaboración correspondiente al lap so 1895-1914. En la derivación de valores "observados" de tasas de supervivencia para plazos de cinco años existe un problema técnico, de asignación de edad, que conviene considerar antes de entrar a examinar la estima 
ción del primer período, pues constituyó una tarea común, previa a la ela boración de las estimaciones de los dos períodos. Se lo analiza, por $10^{-}$ tanto, a continuación.

Asignación de edad a las relaciones de supervivencia por cinco años

6. Si una población es cerrada, esto es, no afectada por migraciones, y se cuenta con los resultados de dos censos separados entre sí por un perío do de $n$ años, entonces las personas censadas con edades entre $x+n$ y $x+n+5$ en el segundo de los dos censos, que representamos mediante el símbolo $5^{\mathrm{N} \dot{\mathrm{x}}+\mathrm{n}}$ son las que sobreviven de $5 \mathrm{~N}_{X}$, es decir, los individuos que a la época del primer censo tenían edades comprendidas entre $\mathrm{x}$ y $x+5$. La relación de supervivencia, por tramos quinquenales de edad, entre los dos censos separados por $\mathrm{n}$ años la escribimos ${ }_{\mathrm{n}} \mathrm{P}(\mathrm{x})$ y vale, evidentemente:

$$
\mathrm{n}^{\mathrm{p}}(\mathrm{x})=5^{\mathrm{N}} \mathrm{x}^{\mathrm{N}} \mathrm{n} / 5^{\mathrm{N}} \mathrm{x}
$$

7. Se refiere, claro está, a un plazo de $\mathfrak{n}$ años. Hay ventajas, tanto para ajustar los valores observados cuanto para derivar de las relaciones de su pervivencia ajustadas las otras funciones de la tabla de vida, en que las relaciones estén referidas a un plazo de cinco años, en lugar de a uno de $\underline{n}$, es decir, de cualquier extensión. Para transformar una relación de supervivencia por $\mathrm{n}$ años en una por 5 conviene imaginar a la primera como ex presión de una probabilidad relativa a un acontecimiento compuesto de $n$ eventualidades anuales $\mathrm{y}$, consecuentemente, como un producto de $\mathrm{n}$ relaciones de supervivencia de un año. La raíz de orden $n$ de ${ }_{n} P(x)$, en consecuencia, constituye una estimación del valor de una relación de supervivencia por un año y la potencia quinta de ese valor anual expresa una relación de supervi vencia por cinco años. En otras palabras, la raíz de orden $n / 5$ de ${ }_{n} P(x)$ proporciona una estimación del valor que puede tomar la relación de supervi vencia por cinco años, para un intervalo de edades quinquenal indeterminado. Podemos escribir, por lo tanto:

$$
5^{\mathrm{P}(\mathrm{y})}=\sqrt[\mathrm{n} / 5]{{ }_{n} \mathrm{P}(\mathrm{x})} \text { siendo } \mathrm{y} \text { la edad más joven de } 1 \text { gru }
$$
po quinquenal, por ahora indeterminada, correspondiente a la relación de sú pervivencia por cinco años y x la edad más joven, conocida, correspondienté a la relación de supervivencia por $\mathrm{n}$ años, derivada de información de dos censos.

8. Se presenta pues el problema de asignar una edad a la relación quinquenal de supervivencia definida en el punto anterior, es decir, estimar el va lor de y. Para investigar este punto se recurrió a la información contenida en seis tablas de vida argentinas, referidas a los años 1914, 1946-48 y 1959-61 (véase Referencias, 18, 19 y 20).

Para cada una de las tres épocas mencionadas se contaba con dos tablas, una para cada sexo, En cada uno de esos seis casos fue posible calcular va lores de ${ }_{n} \mathrm{P}(\mathrm{x})$ para $\mathrm{n}=20$ y $\mathrm{n}=25$ (se eligieron esos plazos porque los 
períodos intercensales que deberán analizarse son aproximadamente de esa ex tensión: 19 años, el comprendido entre 1895 y 1914; 25 el que media entre 1869 y 1895; si se miden los períodos en años enteros).

9. Se computó después la raíz de orden $\mathrm{n} / 5$ de los valores hallados y los resultados, asimilables, según se ha visto, a relaciones de supervivencia por cinco años, fueron comparados con un juego de valores ${ }_{5} \mathrm{P}(\mathrm{x})$ que también se elaboró para cada tabla. Fue posible, de esa comparación, estimar la edad que correspondía a cada valor derivado de ${ }_{n} \mathrm{P}(\mathrm{x})$ y estudiar cómo variaban tales asignaciones de edad en. función de la edad inicial, el sexo, la época de la tabla y el valor de $n$, el plazo intercensal.

10. Pudo establecerse, en primer lugar, que poco variaba, y en forma no sis temática, la edad estimada según la época de la tabla (asociada, en este caso, a variaciones muy importantes en el nivel de la mortalidad) o el sexo. Variaba claramente, en cambio, en función de la edad inicial en el cálculo de ${ }_{n} P(x)$ y del valor de $n$. Puede observarse esto analizando los valores pre sentados en el Cuadro IV-1*. Aparecen allí, para cada grupo quinquenal de edades iniciales, que se simboliza con $\mathrm{x}$ (1a edad inicia1) las edades mínima $\mathrm{y}$ máxima asignadas a las relaciones de supervivencia por cinco años, los valores promedios de los seis hallados y, finalmente, los valores ajustados que, como puede verse examinando el cuadro, difieren muy poco de los promedios y están comprendidos entre el mínimo y el máximo de cada caso (salvo una excep ción).

11. Un ejemplo numérico podrá servir para ilustrar lo anterior. Conforme con la tabla de vida para el sexo masculino, 1914, la relación de superviven cia por 20 años que corresponde al grupo de edad inicial 20-24 años vale 0.84028 . La raíz de orden $20 / 5$ de este valor equivale a 0.95743. Este valor, tomado como el de una relación de supervivencia por cinco años, corres ponde, según la misma tabla de vida, a una edad de 29.6. Cálculos similares, hechos con las otras cinco tablas, condujeron a edades estimadas de: 28.1 29.529 .629 .2 y 28.2. Como se ve, los valores extremos fueron: 28.1 el mínimo y 29.6 el máximo. E1 promedio de los seis valores vale 29.1 y el valor ajustado, que se adopta en este estudio 28.6, está comprendido entre los valores extremos.

12. Es de interés señalar que, exceptuando los tres primeros grupos de edades considerados en el Cuadro IV-1 los valores correspondientes al resto mues tran muy poca dispersión - lo que se evidencia por la proximidad entre los valores mínimo y máximo. Es oportuno adelantar que en los análisis que siguen, si bien se utiliza la asignación de edades que da el Cuadro IV-1 para todos los grupos de edad, solamente importan las que se refieren a edades superiores a los 15 años ya que, por otras razones, diferentes al problema de la asignación de la edad a las relaciones de supervivencia, los valores calculados para grupos de edades más jóvenes a partir de datos censales son dejados de lado en el cómputo de los valores de las tablas de vida. El procedimiento de asignación de edad expuesto en esta sección se emplea realmente, en consecuencia, sólo en el tramo de vida (edades superiores a una inicial de 15) para el cual los resultados son satisfactorios.

* Los cuadros y gráficos de los capitulos IV a VI van al final de cada capitulo. 
13. En conclusión: el análisis anterior, que se concreta en el Cuadro IV-1, muestra que es pequeño el error que puede cometerse al asignar una edad a la relaciôn de supervivencia por cinco años derivada de otra calculada para pla zos de 20 a 25 años, aceptada la validez general de un análisis basado en seis tablas de vida.

Elaboración de tablas de vida por sexo para el período $1869-1895$ de la población nacida en la Argentina

14. E1 procedimiento de derivar una tabla de vida de relaciones de supervi vencia intercensales por edad exige que la población investigada no haya su frido los efectos de migraciones entre los dos censos que se comparan. Con e1 propósito de cumplir aproximadamente con ese requisito el estudio de la mortalidad entre 1869 y 1895 se basa en información relativa a la población nacida en el país. Tal como se dijo en el Capítulo III esta población no ha estado libre de movimientos migratorios aunque, indudablemente, han tenido $\underline{u}$ na incidencia mucho menor que en el total afectado por fuertes corrientes mí gratorias de extranjeros. Es oportuno recordar, una vez más, que la falta de comparabilidad estricta entre los censos que se utilizan, los de 1869 y 1895 , en este caso, pueden explicar muchas de las irregularidades que se advierten en los datos observados. Cuando se examinen y utilicen los resultados de la elaboración que aquí se describe deberán tenerse presentes estas ob servaciones.

15. El material censal utilizado en los cálculos está constituido por:

(a) resultados oficiales del censo de 1869 [ total de población clasificada por sexo y lugar de origen (véase Referencias, 21)];

(b) distribución por edades de la población nacida en la Argentina, obtenida de la muestra elaborada con información del censo de 1869 por el Centro de In vestigaciones Sociales del Instituto Torcuato Di Tella (véase Referencias, $2 \overline{2}$ );

(c) resultados oficiales del censo de 1895 sobre población clasificada por sexo, origen y edad (véase Referencias, 23).

16. Decisiones de importancia secundaria, previas a la elaboración de los datos, fueron tomadas en relación con:

(a) la cohorte de personas enumeradas con menos de 5 años de edad de 1869 . Se decidió no utilizar la información sobre este grupo en razón de que es notorio que está afectada por una fuerte omisión;

(b) las personas que no declararon edad en el censo de 1895 fueron distribuidas entre los diferentes grupos de edad en proporción al número de individuos censa dos con edad declarada. Tal problema no se presentó con los datos de 1869 ya que la distribución por edades elaborada en base a la muestra había ya eliminado esa categoría. Llama la atención que en los datos publicados de los censos de 1869 y 1895 no aparecen casos de personas con lugar de nacimiento no declarado 
[ Lattes supone (véase Referencias, 8) que los que compilaron el censo posi blemente consideraron a estas personas como nacidas en la Argentinal;

(c) el plazo intercensal, que medido con precisión excede $10 s 25$ años, fue tomado como si hubiera sido exactamente de esa extensión.

(d) el último grupo considerado fue el que corresponde a personas con edades 70-74 en 1869, 95-99 en 1895, es decir, no se tomó en cuenta la información de personas mayores de esas edades. No era posible agruparlas en grupos quinquenales.

17. E1 primer paso consistió en calcular las relaciones de supervivencia intercensales, por 25 años en este caso, tal como aparece indicado en el Cuadro IV-2. A partir de ellas, conforme con lo expuesto anteriormente, se derivaron relaciones de supervivencia por 5 años referidas a edades asigna das a cada grupo, con arreglo a la norma establecida en el Cuadro IV-1. Los valores obtenidos que aparecen también en el Cuadro IV-2 fueron representados en los gráficos IV-1 y IV-2 relativos a la población masculina y femenina respectivamente. Se los designa valores "observados".

18. El examen de los datos del Cuadro IV-2 y los gráficos mencionados pone de relieve la existencia de graves deficiencias en la información censal que se analiza. En efecto, resulta inadmisible que la función examinada va ríe según la edad con la irregularidad que muestran los valores observados. Pese a ello puede advertirse una tendencia general decreciente de los valores con el aumento de la edad -como era dable esperar- y que, en general, las relaciones de supervivencia de los varones son inferiores a las obtenidas para las mujeres, lo que refleja una mayor mortalidad masculina. Llama, sin embargo, la atención que las relaciones de supervivencia en el tramo de edades adultas jóvenes son frecuentemente muy bajas entre las mujeres, infe riores a las correspondientes a los varones, Como se ha señalado antes pue de deberse esta situación a emigración femenina durante el período intercen sal. Otra conclusión que puede sacarse de un primer examen es que la variāa ción de las relaciones de supervivencia observadas es más irregular entre las mujeres que entre los varones, lo que es coherente con lo que se sabe acerca de la calidad de los datos censales, diferente según los sexos. La declaración de edad de la población masculina fue mejor hecha que la de la femenina (véase Referencias, 8).

19. Como elemento de comparación se disponía de una tabla de vida para la Ciudad de Buenos Aires, referida al año 1887, elaborada por Kern (véase Referencias, 18). Hay indicios de que en la época estudiada (1869-1895) 1a mortalidad urbana era superior a la rural. En el año 1887, además, hubo una epidemia de cólera en la ciudad de Buenos Aires, lo que seguramente contribu ye a exagerar el nivel de mortalidad reflejado en la tabla mencionada. Por estas razones, porque la información sobre muertes de la ciudad puede estar indebidamente aumentada por defunciones de personas no residentes en la ciü dad (véase Referencias, 24) y además porque en la elaboración de los datos sobre muertes en el primer año de vida la tabla de Kern exagera la mortalidad infantil al considerar como muertes correspondientes a ese tramo a un 
número de casos que aparentemente corresponden a nacidos muertos, se consi dera que el nivel de mortalidad reflejado en la tabla comentada debe superar al nivel medio del país en el período 1869-1895. Pese a todas esas ra zones, que señalan que la tabla de vida para la Ciudad de Buenos Aires de 1887 no es apropiada para representar la mortalidad del país, ella constituye sin duda un elemento muy valioso de comparación con los datos observa dos y con los datos que se ajusten. En el Cuadro IV-3 aparecen valores de las relaciones de supervivencia elaborados con la tabla de vida citada.

Mortalidad masculina 1869-1895. Población nacida en 1a Argentina

20. Después de varios intentos de ajustamiento de los valores observados de varones y de mujeres, recurriendo a procedimientos mecánicos y gráficos, se decidió adoptar el resultado obtenido al ajustar la información relativa a los varones entre las edades de 20 y 60 años mediante un polinomio de segundo grado, por el método de mínimos cuadrados. Los valores resultantes, que eran muy parecidos a los que podían obtenerse mediante otros ajustamien tos, son aproximados a los que corresponden a la tabla de Kern para la Ciudad de Buenos Aires de 1887 y caen dentro del intervalo de valores de dos tablas modelo de mortalidad de las Naciones Unidas: las que corresponden a una esperanza de vida al nacer (ambos sexos) de 30.0 y 32.5 años (véase Referencias, 25). Puede verse esa interesante aproximación observando los va lores que aparecen en el conjunto designado "relaciones ajustadas" en el Cuadro IV-3 y el Gráfico IV-1 entre las edades 30 y 60 años. Se presentan allí los valores de las relaciones de supervivencia de las tablas modelo men cionadas. Se decidió, en vista de esto, adoptar los valores resultantes de $\overline{1}$ ajustamiento mencionado dentro de este tramo de vida y buscar, con ayuda de las tablas modelo de mortalidad y otros elementos disponibles, la forma de completar la serie de relaciones de supervivencia.

21. Antes de pasar a tratar estos puntos es oportuno señalar aquí que un es tudio realizado con tablas de vida existentes para la Argentina, referidas $\bar{a}$ los años 1914, 1947 y 1960, había mostrado que la relación de supervivencia por 5 años, calculada para grupos quinquenales de edad, se aproxima, con razo nable precisión, a un polinomio de segundo grado en el tramo de vida indicado (30-60 años). No queremos afirmar que con tal simplicidad puede describir se en todos los casos la variación de una función muy compleja, como lo es la relación de supervivencia; sólo señalar que, dentro de la aproximación burda con que trabajamos, por imposición de la deficiencia de los datos, utilizar un polinomio de segundo grado para ajustar datos observados, afectados por gruesos errores, no debe introducir perturbaciones, en particular, significar la imposición de una excesiva regularidad.

22. Los valores correspondientes a las edades 20 y 25 dados por el polinomio de ajustamiento parecieron muy altos, en comparación con los que daban las ta blas modelo de mortalidad. Se prefirió desecharlos y estimarlos por otro medio.

23. Para completar la tabla de vida masculina, aceptada la validez de los valores de relaciones de supervivencia obtenidas entre las edades 30 y 60 , se 
contaba con:

(a) ecuaciones de regresiôn, que permiten çalcular el valor de la relación de supervivencia para el grupo de edades $x, x+4$ en funciôn de la conocida para $x+5, x+9$ (véase Referencias, 17);

(b) la tabla de mortalidad de la Ciudad de Buenos Aies de 1887 cuyos valores, en el tramo 30-60 años, son muy próximos a los ajustados, aunque se considera, como se dice más arriba, que esta tabla exageraría el nivel de la mortalidad del país, especialmente en el primer año de vida;

(c) tablas modelo de las Naciones Unidas, dos de las cuales, enmarcan los valores ajustados entre los 20 y los 55 años.

24. En relación con los tramos iniciales de la tabla, la parte sin duda más difícil de estimar satisfactoriamente, la regreșión produjo los valores de relaciones supervivencia más altos y la tabla de vida de la ciudad de Buenos Aires de 1887, los más bajos. Se pensó que la solución de esti mar la parte inicial de la tabla de vida en base al modelo de las Naciones Unidas ofrecía la mejor solución al producir una estimación intermedia, que se alejaba tanto de los valores más altos, obtenidos por regre. sión, como de los más bajos, sospechosos de exagerar la mortalidad, de la tabla de 1887. Se adoptó, en consecuencia, un nivel de mortalidad intermedio a los dos modelos mencionados entre las edades 0 y 25 años. En la in terpolación entre esos dos modelos se tuvo en cuenta que los valores ajusta dos, en el tramo de edades 30-60 años se aproximaban bastante más a la tabla modelo correspondiente, a una esperanza de vida de 32.5 que a la de 30.0 años.

25. Los valores finales de la tabla, correspondientes al tramo de edades superiores a los 60 años, se estimaron también después de haber explorado diferentes caminos. En este caso las tablas modelo de las Naciones Unidas aparentemente exageraban la mortalidad -tasas de supervivencia muy bajas-; la tabla de Kern, para la Ciudad de Buenos Aires de 1887, mostraba valores relativamente altos, y la ecuación de regresión (véase Referencias, 16) pro ducía estimaciones de las relaciones de supervivencia mayores aún, aunque próximas a las de la tabla de Kern. Se optó por los resultados de la regre sión para ser consecuentes con el supuesto de que la mortalidad de la Ciudad de Buenos Aires de 1887 era posiblemente superior a la media del país en 1869-1895.

26. La serie completa de relaciones de supervivencia por 5 años, y tramos quinquenales de edad, que fue adoptada como representativa de la mortalidad del período 1869-1895, de la población masculina nacida en la Argentina, aparece en el Cuadro IV-3 y el Gráfico IV-1 junto con la información que se utilizó en su elaboración. En ese Cuadro y en el Gráfico se designa a este conjunto de relaciones como serie "ajustadas". Merece destacarse que los valores observados correspondientes a los grupos de edades más avanzadas son muy altos y superan a los de cualquiera de las tablas de vida utilizadas, así como también a los valores ajustados. Creemos que no reflejan la reali dad. 
27. Quedan ahora dos problemas por resolver: calcular una serie similar a la anterior representativa de la mortalidad femenina y derivar, de las series de relaciones de supervivencia, las otras funciones de una tabla de vi da, Estos temas se consideran en los puntos que siguen, en el orden indicá do.

Mortalidad femenina 1869-1895. Población nacida en la Argentina

28. La mayor irregularidad que mostraban las relaciones de supervivencia observadas en la población femenina, Cuadro IV-2 y Gráfico IV-2, frente a las de los hombres, imposibilitó un ajustamiento satisfactorio siguiendo un procedimiento similar al empleado en el caso de la población masculina. Por otra parte, disponiendo ya de una serie aceptada de relaciones de supervivencia masculinas se presenta la posibilidad de basar en ella la estimación de la ley femenina de mortalidad, utilizando alguna información o hipótesis acerca de la diferencia de mortalidad según el sexo. Una razón más para jus tificar este procedimiento es que, como se ha señalado anteriormente, las re laciones de supervivencia observadas para las mujeres, en ciertos tramos de edades adultas jóvenes, son muy bajas. Se piensa que pueden estar reflejan do el efecto de una emigración, selectiva por sexo, producida en el períodó intercensal.

29. Como se dijo más arriba, el examen de los datos observados muestra que, salvo el tramo de edades aludido en el pärrafo anterior, las relaciones de su pervivencia femeninas son mayores que las masculinas, lo que es una prueba de que su mortalidad es menor. Otros indicios indirectos de esa diferencia de mortalidad por sexo son proporcionados por resultados censales: 1a proporción de huérfanos maternos es muy inferior a la de huérfanos de padre, la proporción de viudos es ampliamente menor a la de viudas (véase Capítulo II). Es pues razonable suponer que la mortalidad general de las mujeres en la época estudiada era inferior a la de los hombres. Difícil es establecer una medida de esa diferencia. Las irregularidades que muestran las relaciones de supervivencia, así como la sospecha de que en el caso de las mujeres tales relacio nes pueden estar afectadas por emigraciones producidas durante e1 período intercensal, dificultan la utilización de esos valores para elaborar en base a ellos la serie ajustada de relaciones de supervivencia femenina,

30. Para resolver el problema se echó mano nuevamente a las tablas modelo de vida de las Naciones Unidas que presentan también hipotéticas diferencias de mortalidad según los sexos y el nivel de la mortalidad. La justificación de recurrir a estos modelos se basa en los resultados de estudios sobre diferen cias de mortalidad por sexo, basados en datos de registros, de la época 191315, en torno a 1914. Puede concluirse de ese análisis que las diferencias que suponen las tablas modelo se adaptan, con razonable aproximación, a los datos argentinos de 1914 (véase Capítulo VII). Aceptando esa conclusión y suponien do que puede también ser válida para el período 1869-1895, es que se adopta como nivel de mortalidad femenino el que, según los modelos de tablas de vida de las Naciones Unidas, corresponde a la tabla ya adoptada para los varones. Las relaciones de supervivencia femeninas adoptadas, que se designan "ajusta- 
das", aparecen en e1 Cuadro IV-3 y son representadas en el Gráfico IV-2. Se presentan en este último, además, las relaciones de supervivencia observadas de hombres y mujeres.

31. Parece casi innecesario llamar la atención sobre el hecho de que la decisión adoptada para estimar la mortalidad femenina en el período 18691895, que se acaba de exponer, resta toda significación, como valor obser vado, a la diferencia que resulta entre las estimaciones de mortalidad se gún sexo, Es un hecho aceptado, por el cúmulo de indicadores, que la mor talidad femenina era menor; 10 que es conjetural es la medida asignada a esa diferencia.

Cálculo de las funciones de las tablas de vida por sexo, 1869-1895, poblaciôn nacida en la Argentina

32. Un conjunto ajustado de relaciones de supervivencia según la edad, pa ra cada sexo, esto es, la serie completa de valores $5 \mathrm{P}(\mathrm{x})$, no implica valo res determinados de las tasas de mortalidad por edad, es decir ${ }_{5} \mathrm{q}_{\mathrm{x}}$. Además, la función $5^{P(x)}$ está referida a un amplio tramo de vida, 10 años en nuestro caso, en que utilizamos grupos quinquenales de edad. Dos valores sucesivos de esta función cubren, por lo tanto, un tramo de vida en común. Así, por ejemplo, 5P(20), que mide la probabilidad de sobrevivir cinco años de los componentes del grupo de edades 20-24 al comienzo del quinquenio, tiene en común el tramo de vida 20-24 con la tasa $5 \mathrm{P}(15)$, y 25-29, con ${ }_{5}^{\mathrm{P}}(25)$.

33. Para pasar del conjunto de valores $5^{P}(x)$ a las probabilidades de morir en tramos quinquenales de edad, ${ }_{5} q_{x}$ se utilizzó nuevamente el repertorio de tablas modelo de vida de las Naciones Unidas (véase Referencias, 25). Para cada valor de ${ }_{5} \mathrm{P}(\mathrm{x})$ se determinaron las dos probabilidades de morir que co rrespondían, conforme con esos modelos, es decir: ${ }_{5} q_{x}$ y $5 q_{x+5}$, y que están implícitas en la tasa de supervivencia.

34. De acuerdo con lo dicho en el párrafo anterior cada probabilidad de muerte, $5 q_{X}$, fue estimada dos veces: en función del valor de $5 P(x-5)$ y tam biên de ${ }_{5} \mathrm{P}(\mathrm{x})$, es decir, las dos tasas de supervivencia que cubren el tramo de vida $x, x+5$. Se dispuso, por 1o tanto," de dos valores, que no resultaron muy diferentes entre sí -como podría haberse anticipado teniendo en cuenta que los valores de $5^{\mathrm{P}(\mathrm{x})}$ ajustados o se aproximaban a los de las ta blas modelo de vida, según se vio, o resultaron de una interpolación entre dos de ellas en el tramo de vida limitado por las edades 0 y 60 años. Un promedio de ambos valores fue lo que se adoptó finalmente como valor de la probabilidad de morir. En la determinación de 1a probabilidad 5975 intervino solamente una relación de supervivencia, ${ }_{5} \mathrm{P}(70)$.

35. Una vez obtenido el conjunto de valores de la función $5 q_{x}$ (además de $\mathrm{q}_{\mathrm{o}} \mathrm{y}$ 4q1) la probabilidad de que una persona que alcanza la edad $\mathrm{x}$ muera an tes de cumplir la edad $x+5$, la tarea que siguió, para obtener las demás funciones de la tabla de vida, se desarrolló por procedimientos ampliamente conocidos. 
36. La función de sobrevivientes a la edad exacta $x$, que se designa $1_{x} y$ las muertes en el tramo de vida $x, x+n$, que se representan ${ }_{n} d_{x}$, resultan definidas por las relaciones:

$1_{x+n}=1_{x}-1_{x} \cdot q_{x}$ empezando $\operatorname{con} 1_{0}=100,000$

$n^{d}=1_{x} \cdot q_{x}$

37. E1 cómputo del tiempo vivido entre las edades $\mathrm{x} y \mathrm{x}+\mathrm{n}$ se hizo:

${ }_{5} \mathrm{~L}_{\mathrm{o}}=500.000 \mathrm{P}_{\mathrm{b}}$ siendo $\quad \mathrm{P}_{\mathrm{b}}={ }_{5} \mathrm{~L}_{\mathrm{o}} / 5 . \mathrm{I}_{\mathrm{o}}$

${ }_{1} \mathrm{~L}_{\mathrm{o}}=0.351_{0}+0.651_{1} \quad$ (adoptándose e1 factor de separación $\mathrm{f}_{\mathrm{o}}=0.35$ )

$4^{L_{1}}=5^{\mathrm{L}}{ }_{0}-{ }_{1} \mathrm{~L}_{0}$

$5_{x}^{L}=5^{P(x-5)} \cdot 5_{x-5}^{L} \quad$ para $x=5,10, \ldots \ldots, 75$

$\omega^{\mathrm{L}} \mathrm{L}_{80}={ }_{5} \mathrm{~L}_{75} \cdot{ }_{5}^{\mathrm{P}(75+) /\left(1-{ }_{5} \mathrm{P}(75+)\right) \text { siendo }}{ }_{5}^{\mathrm{P}(75+)}=\mathrm{T}_{80} / \mathrm{T}_{75}$

38. El tiempo vivido entre las edades $\mathrm{x}$ y w se calculó:

$T_{x}={ }_{5}^{L}{ }_{x}+{ }_{5} L_{x+5}+\ldots .+{ }_{\infty}^{L} 80$

y la esperanza de vida a la edad $x, \stackrel{\circ}{e}_{x}$, así:

$\stackrel{\circ}{e}_{x}=T_{x} / 1_{x}$

39. Las tablas de vida consideradas en los puntos anteriores, es decir, re presentativas del nivel de mortalidad, por sexo, para el período intercensal 1869-1895 de 1a población nacida en la Argentina, aparecen el Capítulo VI.

Elaboración de tablas de vida por sexo para el período 1895-1914 de la población nacida en la. Argentina

40. Parece innecesario repetir aquí lo dicho más arriba en torno a las limita ciones que tiene la elaboración de una tabla de vida a partir de relaciones de supervivencia intercensales por edades: la información de los dos censos difícilmente es estrictamente comparable, la población no permanece cerrada sino que experimenta migraciones durante el período intercensal. Es oportuno, empe ro, tener presente esas advertencias pues son aplicables a 1a información del período que analizamos ahora limitado por los años 1895 y 1914 . El censo de este último año, según lo muestran diferentes indicadores, tuvo una calidad su perior al levantado en 1895, lo que autoriza a pensar que su cobertura fue tam bién más completa. La población nacida en la Argentina, que se toma como una 
mejor aproximación a una población cerrada que la población total, debió seguramente estar afectada por migraciones internacionales que acompañaban a las fuertes corrientes constituidas por extranjeros. Se sabe, por lo tan to, que con los datos disponibles será posible derivar sólo una estimación burda del nivel de la mortalidad.

41. El material básico utilizado, la población nacida en la Argentina clasificada por sexo y edad, fue obtenida de las publicaciones oficiales de los censos nacionales de 1895 y 1914.

42. Antes de elaborarse el material fueron tomadas estas decisiones:

(a) no considerar la cohorte de personas censadas con edades 0-4 en 1895, ya que era evidente que estaba afectada por una fuerte omisión;

(b) distribuir los casos de individuos con edad no declarada entre los diferentes grupos de edad en proporción al número de individuos censados con edad conocida;

(c) el plazo intercensal, que medido rigurosamente supera los 19 años, fue to mado como si hubiera sido de esa extensión exacta;

(d) el último grupo de edades considerado fue el que corresponde a personas con edades 75-79 en 1895, 94-98 en 1914, desechándose 1a información relativa a edades superiores.

43. En el Cuadro IV-4 se muestra el cálculo de las relaciones de supervivencia intercensal: en primer lugar para el plazo de 19 años, y luego para el de 5 años. Aparece también la edad asignada a estas últimas. Se utilizaron, pa ra este propósito, los resultados derivados del Cuadro IV-1 (1as relaciones elaboradas en ese Cuadro para el plazo de 20 años fueron aplicadas, por aproximación, al caso considerado que es de 19 años). E1 conjunto obtenido de ta sas de supervivencia, para grupos quinquenales de edad y plazo de 5 años que se denominan "tasas observadas" aparece representado en el Gráfico IV-3, población masculina, y en el Gráfico IV-4, población femenina.

44. El examen de estos gráficos muestra que la variación de los valores obser vados en el período $1895-1914$ es más regular que la registrada en el primer pe ríodo intercensal, 1869-1895, especialmente en el caso de los varones, aunque no está exenta de bruscas oscilaciones, que reflejan errores de los datos básicos. Además, tal como aparecía también en los gráficos relativos a aquel in tervalo, los valores correspondientes a los grupos de edades más avanzadas son relativamente muy altos, lo que se pone en evidencia cuando se los compara con relaciones de supervivencia derivadas de tablas de vida. Los conocidos errores censales relacionados con la declaración de la edad de los ancianos son seguramente la causa de esta tendencia, que no consideramos real.

45. Además de los valores observados correspondientes al período intercensal 1895-1914, los Gráficos IV-3 y IV-4 presentan las relaciones de supervivencia, por 5 años y tramos quinquenales de edad, correspondientes a dos tablas de vida 
argentinas, entre las cuales puede esperarse que se ubique la que corresponde al período estudiado y que intentamos construir, En efecto, es razonable esperar que el nivel de la mortalidad en el período 1895-1914 sea inferior, esto es, esté representado por relaciones de supervivencia mayo res, al del período 1869-1895, y sea superior, con relaciones de supervivencia inferiores, al de 1a época 1913-1915. Sostenemos esto porque se sa be que la mortalidad ha bajado sostenidamente a través deltiempo, 1o que puede comprobarse comparando las relaciones de supervivencia observadas en los períodos 1869-1895 y 1895-1914, ambas referidas a un período uniforme de 5 años. Los valores numéricos de las tasas de supervivencia por 5 años representadas en los gráficos, de las tablas de vida de 1869-1895 y 19131915, de la población nacida en la Argentina, por sexo, aparecen en el Cuadro IV-5.

46. Puede observarse, examinando con cuidado el gräfico relativo a la po blación masculina, que la franja limitada por los valores de las tablas de vida que se utilizan como elementos de comparación, de 1869-1895 y 19131915, describe con bastante fidelidad, aunque, claro está, con poca preci sión, la tendencia y el nivel de los valores observados correspondientes a 1895-1914. En el caso de la población femenina, en cambio, no sucede otro tanto: dicha franja de valores está, por lo general, por encima de los valores observados, especialmente en el tramo de edades adultas jóvenes, 1o que afirma la presunción de que las relaciones de supervivencia femeninas observadas están afectadas por emigración de población en el período anali zado. En vista de estas comprobaciones se sacó la conclusión de que los datos observados de la población masculina, debidamente ajustados, podrían tomarse como representativos de la mortalidad de la época estudiada, 18951914. En cambio, tal como sucedió cuando se estudió la mortalidad del prí mer intervalo intercensal, en razón de que la información censal femenina es muy deficiente y de que tal población pudo estar afectada por fuertes emigraciones, se desechó la idea de estimar su mortalidad sobre la base de la información dada por los censos sobre el número de mujeres censadas en 1895 y 1914.

Mortalidad masculina 1895-1914. Población nacida en la Argentina

47. Se hicieron varios intentos de ajuste de los datos observados de la po blación masculina, antes de llegar a la versión que se adoptó como represen tativa del nivel de la mortalidad del período 1895-1914. Merece destacarse entre ellos el que consistió en repetir el procedimiento utilizado para el período 1869-1895, es decir, ajustar mediante un polinomio de segundo grado los valores correspondientes a las edades del tramo 20-60 años y, a partir de las relaciones de supervivencia obtenidas estimar las correspondientes a los tramos inicial y final de la tabla. Ese procedimiento, sin embargo, pro dujo valores que, aunque representaban con satisfactoria exactitud el nivel y la tendencia de los observados en el intervalo de edades indicado, eran le vemente superiores a los que era dable esperar teniendo en cuenta el nivel de la mortalidad de la población masculina, nacida en el país, en el período 1913-1915. Había naturalmente dos formas extremas de resolver ese conflicto: 
desechando ya sea los valores estimados para el período intercensal, o los correspondientes a la êpoca del censo de 1914, que se basan en registros de muertes. Se prefirio lo primero ya que, como se ha dicho en otra parte de este informe, el procedimiento de derivar una tabla de vida a través de re laciones de supervivencia intercensales es siempre un expediente extremo, cuyo empleo se justifica sólo si no es posible construir la tabla de vida en base a datos de registros. Se prefiere, por lo tanto, la información proveniente de estadísticas de defunciones. Cabe, sin embargo, hacer la ob servación de que un error en la declaración sobre lugar de nacimiento -por ejemplo, haber tratado como defunciones de argentinos a muertes de inmigran tes- pudo haber conducido a que la tabla de vida de la población nativa del período 1913-1915 haya exagerado la mortalidad. No hay prueba de que ese tipo de error se haya producido, pero merece ser tenido en cuenta como una posibilidad.

48. Finalmente, la tabla de vida resultante de promediar las probabilidades de morir por edades de las tablas de vida de 1869-1895 y 1913-1915, pro dujo una sucesión de valores de relaciones de supervivencia quinquenales que no sólo daban una versión posible de las correspondientes a la ley de mortalidad intercensal, sino que además eran muy próximos a los obtenidos mediante el ajustamiento mencionado en el punto anterior, salvo en aquellas edades para las cuales los valores de ese ajustamiento resultaban inaceptables. Se decidió, en consecuencia, recurrir a este recurso simple, que pro ducía resultados satisfactorios, sin dejar de reconocer que otras interpola ciones entre las tablas consideradas como límites podrían también haber con ducido a valores igualmente aceptables. Las relaciones de supervivencia ajustadas para el período 1895-1914, sexo masculino, aparecen en el Cuadro IV-5 y se representan en el Gráfico IV-3.

\section{Mortalidad femenina 1895-1914. Población nacida en la Argentina}

49. Por razones tambiên de simplicidad y consecuentes con la decisión adop tada en relación con la tabla de varones, se elaboró la tabla de mortalidad femenina promediando las probabilidades de morir, por edades, de las tablas correspondientes a los períodos 1869-1895 y 1913-1915, de la población naci da en la Argentina, Las relaciones de supervivencia resultantes de esta ela

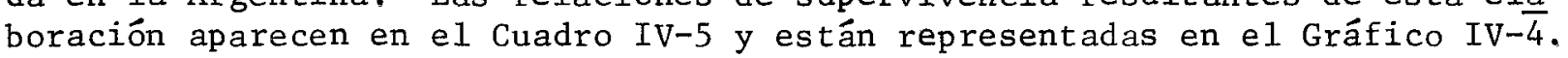

Resumen

50. Resumiendo, las tablas de mortalidad de la población nacida en la Argen tina, por sexo, para el período intercensal 1895-1914, resultaron, conforme con 10 dicho en los puntos anteriores, de un promedio de las probabilidades de morir para los tramos de vida: 0, 1-4 y los grupos quinquenales 5-9, 1014, ... hasta 75-79, de las correspondientes a las tablas ya elaboradas para los períodos 1869-1895 y 1913-1915. La estimación correspondiente al grupo de edades superiores a los 80 años se basó también en un promedio de la tasa central de mortalidad de ese grupo. 
51. La derivación de las funciones de las tablas de vida, en función de los valores promediados, siguió los procedimientos habituales descritos anterior mente al considerarse la elaboración de las tablas de mortalidad del primer período intercensal. Las tablas resultantes aparecen en el Capítulo VI.

Tablas de vida de la población total, nacida en la Argentina o en el exterior, por sexo y para ambos sexos, Períodos intercensales 1869-1895 y 1895-1914

52. Como resultado de la elaboración descrita en los puntos anteriores se cuenta con tablas de mortalidad por sexo y período intercensal, 1869-1895 y 1895-1914, de la población nacida en la Argentina: cuatro tablas en total.

53. Esa información no es representativa seguramente del nivel de la mortalidad general del país ya que no toma en cuenta 1 a población nacida en el ex tranjero y que habitaba en la Argentina. Ese sector tenía una importancia relativamente grande, y creciente con el tiempo, en el total y su mortalidad era generalmente menor a la correspondiente a la población nativa.

54. Aunque se tienen indicios de la existencia de:esa diferencia en el nivel de la mortalidad según el origen de la población (véase Referencias, 24) por indicadores derivados de los censos de 1869 y 1895, así como también por tablas de vida elaboradas con datos referentes a la Ciudad de Buenos Aires de 1887 (véase Referencias, 6) es sólo con la información de 1914 que puede medirse a nivel nacional, con razonable exactitud, la importancia de la diferencia de mortalidad entre la población nacida en la Argentina y en el exte rior, según la edad y el sexo.

55. La información censal de 1914, así como también la proporcionada por los registros de muertes del período 1913-1915, permiten el cálculo de tasas de mortalidad por sexo, grupos de edad y origen de la población, esto es, pobla ción nacida en la Argentina y en el exterior. Dada la escasa significación que tenía la población inmigrante en los grupos de edades más bajas, el estü dio de la diferencia de mortalidad por origen se limita a la población mayor de 5 años. Para este sector fue posible establecer la diferencia entre la tasa anual de mortalidad por sexo y grupos de edad de la población nacida en la Argentina y la correspondiente tasa de la población nacida en el exterior. Tales diferencias son siempre positivas, esto es, en cada grupo de sexo y edad considerado la mortalidad de la población nativa supera a la de la inmigrante, salvo en el primer grupo de edad considerado ( $5-9$ años) en el caso de los varones, excepción que posiblemente carece de significación, y salvo también en la población de edades muy avanzadas: 1a mayor de 75 años en la po blación masculina, y de 80 años, en la femenina.

56. Esa información, relativa como queda dicho al período 1913-1915, sirvió de base para la estimación que se elaboró acerca de la mortalidad de la pobla ción nacida en el exterior correspondiente a los dos primeros períodos intercensales. Se hizo el supuesto que las diferencias en las tasas de mortalidad de 1913-1915, por edad y sexo entre la población nacida en la Argentina y en el exterior existieron también, invariablemente, a lo largo de los dos primeros 
periodos intercensales. Aceptado este supuesto, que se formula ante la fal ta de datos adecuados para establecer la diferencia de mortalidad por origen con datos propios de las épocas consideradas, resulta tarea sencilla de rivar las tasas de mortalidad de la población inmigrante en funciôn de las estimadas previamente para la población nacida en el país. Estos resultados no tienen otro propósito que elaborar con ellos, y las tasas relativas a la población nacida en la Argentina, una tabla de vida de la población total, nativa e inmigrante, para cada sexo y cada uno de los dos períodos intercen sales, 1869-1895 y 1895-1914.

57. Con 1a finalidad mencionada se estableció la distribución de la población nacida en la Argentina y en el exterior dentro de cada grupo de edad, sexo y época-intercensal, utilizando información proporcionada por los cen sos levantados en 1869, 1895 y 1914. Esas distribuciones aplicadas a las tasas obtenidas por origen, según 1o indicado en el punto anterior, dentro de cada grupo de edad, sexo y época intercensal, proporcionaron la tasa pro medio buscada. Se obtuvo pues un conjunto de tasas por edad, para cada sexo y cada período intercensal, que sirvieron de base a la elaboración de las ta blas de vida que se presentan. Como se ha señalado antes, el tramo de vida entre las edades 0 y 5 años de estas tablas de vida no difiere de las construidas para la población nacida en el país.

58. Por un procedimiento similar, es decir, calculando la distribución por sexo de la población total (nativa e inmigrante) dentro de cada grupo de edad y época intercensal, fue posible derivar; a partir de las tasas de mortalidad por sexo (ambos orígenes) valores promedios correspondientes a la población. de ambos sexos. Se lograron así las tablas de mortalidad, de po blación total, esto es de ambos sexos y ambos orígenes, para 1869-95 y 1895-1914.

59. Las tablas de vida de población total (ambos orígenes) por sexo y para ambos sexos resultantes se presentan en el Capítulo VI.

60. Las tablas de mortalidad cuya elaboración se describe en los puntos ante riores, representativas hipotéticamente de la mortalidad general, esto es, de la población total que habitaba en la Argentina cualquiera que fuera su lugar de nacimiento, tienen sólo un valor conjetural. E1 supuesto de que la diferencia de las tasas de mortalidad de la población, según origen, calculada para 1913-1915, vale también para épocas anteriores, no tiene fundamento sólido co mo para otorgar a las tablas resultantes otra significación que las de un supuesto razonable. 
Cuadro IV -1

Edades ( $y$ ) estimadas y ajustadas a las que corresponde la función ${ }^{\mathrm{P}}(\mathrm{y})$, calculada a partir de ${ }_{n} \mathrm{P}(\mathrm{x})$ mediante la extracción de 1 a raíz de orden $\mathrm{n} / 5$, conforme con seis tablas de mortalidad argentina y dos valores de $n(20$ y 25$)$

\begin{tabular}{|c|c|c|c|c|c|c|c|c|}
\hline \multirow[b]{3}{*}{$\underline{x}$} & \multirow[b]{3}{*}{ minimo } & \multicolumn{3}{|c|}{$\mathrm{n}=20$} & \multicolumn{4}{|c|}{$n=25$} \\
\hline & & \multicolumn{2}{|c|}{ Estimad as } & \multirow[t]{2}{*}{ Ajustadas } & \multicolumn{3}{|c|}{ Estimadas } & \multirow[t]{2}{*}{ Ajustadas } \\
\hline & & máximo & promedio & & mínimo & máximo & promedio & \\
\hline 5 & 11.7 & 13.0 & 12.5 & 12.5 & 13.0 & 15.7 & 14.0 & 14.0 \\
\hline 10 & 15.0 & 17.2 & 15.7 & 15.7 & 17.5 & 19.5 & 18.5 & 18.5 \\
\hline 15 & 22.6 & 25.0 & 23.5 & 23.6 & 25.9 & 27.8 & 27.1 & 26.8 \\
\hline 20 & 28.1 & 29.6 & 29.1 & 28.6 & 30.7 & 32.5 & 32.1 & 31.8 \\
\hline 25 & 32.8 & 34.3 & 33.7 & 33.6 & 36.1 & 37.2 & 36.8 & 36.8 \\
\hline 30 & 38.1 & 38.8 & 38.5 & 38.6 & 41.3 & 41.9 & 41.8 & 41.8 \\
\hline 35 & 43.3 & 43.7 & 43.6 & 43.6 & 46.5 & 47.2 & 46.8 & 46.8 \\
\hline 40 & 48.4 & 49.1 & 48.7 & 48.6 & 51.4 & 52.1 & 51.8 & 51.8 \\
\hline 45 & 53.2 & 53.8 & 53.6 & 53.6 & 56.4 & 57.0 & 56.7 & 56.8 \\
\hline 50 & 58.4 & 58.7 & 58.6 & 58.6 & 61.8 & 62.1 & 61.9 & 61.8 \\
\hline 55 & 63.6 & 63.9 & 63.7 & 63.6 & 66.9 & 67.2 & 67.0 & 66.8 \\
\hline 60 & 68.6 & 69.0 & 68.8 & 68.6 & 71.7 & 72.2 & 71.9 & 71.8 \\
\hline 65 & 73.4 & 73.8 & 73.6 & 73.6 & 76.4 & 77.1 & 76.8 & 76.8 \\
\hline 70 & 78.3 & 78.8 & 78.6 & 78.6 & 81.2 & 82.1 & 81.7 & 81.8 \\
\hline 75 & 83.2 & 83.8 & 83.6 & 83.6 & 86.1 & 87.4 & 86.8 & 86.8 \\
\hline
\end{tabular}


Cuadro IV-2

Población nacida en la Argentina. Cálculo de relaciones de supervivencia por cinco años según sexo y grupos quinquenales de edad para el período 1869-1895 a partir de la población censada en 1869 y 1895

\begin{tabular}{|c|c|c|c|c|c|}
\hline \multirow{2}{*}{\multicolumn{2}{|c|}{1869}} & \multirow{2}{*}{\multicolumn{2}{|c|}{1895}} & \multirow{2}{*}{$\begin{array}{l}\text { Relación de supervivencia } \\
\text { intercensal por: }\end{array}$} & \multirow{3}{*}{$\begin{array}{l}\text { Edad } \\
\text { inicial } \\
\text { asignada } \\
\text { de1_grupo }\end{array}$} \\
\hline & & & & & \\
\hline $\begin{array}{l}\text { Inicia } 1 \\
\text { del_grupo }\end{array}$ & Poblacion & $\begin{array}{l}\text { Inıcial } \\
\text { _ele1_grupgo. }\end{array}$ & Poblacion & 25 años & \\
\hline $\mathrm{y}$ & $5^{N(y)}$ & $y+25$ & $5^{N(y+25)}$ & $25^{P(y)}=5^{P(x)}$ & $\mathrm{x}$ \\
\hline
\end{tabular}

\begin{tabular}{rrrrrrr} 
Varones & \multicolumn{7}{c}{} & & & \\
5 & 136.648 & 30 & 76.716 & 0.561413 & 0.890955 & 14.0 \\
10 & 110.923 & 35 & 75.096 & 0.677010 & 0.924951 & 18.5 \\
15 & 69.558 & 40 & 48.217 & 0.693191 & 0.929332 & 26.8 \\
20 & 57.615 & 45 & 44.253 & 0.768081 & 0.949032 & 31.8 \\
25 & 58.561 & 50 & 29.154 & 0.497840 & 0.869797 & 36.8 \\
30 & 42.975 & 55 & 20.504 & 0.477115 & 0.862442 & 41.8 \\
35 & 34.639 & 60 & 17.131 & 0.494558 & 0.868646 & 46.8 \\
40 & 28.720 & 65 & 7.997 & 0.278447 & 0.774371 & 51.8 \\
45 & 23.379 & 70 & 6.825 & 0.291929 & 0.781726 & 56.8 \\
50 & 18.476 & 75 & 2.983 & 0.161453 & 0.694400 & 61.8 \\
55 & 9.527 & 80 & 2.651 & 0.278262 & 0.774267 & 66.8 \\
60 & 11.085 & 85 & 798 & 0.071989 & 0.590817 & 71.8 \\
65 & 3.853 & 90 & 692 & 0.179600 & 0.709351 & 76.8 \\
70 & 3.870 & 95 & 273 & 0.070543 & 0.588424 & 81.8 \\
Mujeres & & & & & & \\
5 & 125.776 & 30 & 85.194 & 0.677347 & 0.925043 & 14.0 \\
10 & 96.803 & 35 & 75.642 & 0.781401 & 0.951864 & 18.5 \\
15 & 86.291 & 40 & 56.415 & 0.653776 & 0.918514 & 26.8 \\
20 & 69.648 & 45 & 39.495 & 0.567066 & 0.892744 & 31.8 \\
25 & 66.862 & 50 & 33.839 & 0.506102 & 0.872666 & 36.8 \\
30 & 50.881 & 55 & 19.319 & 0.379690 & 0.823922 & 41.8 \\
35 & 38.110 & 60 & 21.482 & 0.563684 & 0.891676 & 46.8 \\
40 & 36.734 & 65 & 9.298 & 0.253117 & 0.759738 & 51.8 \\
45 & 22.927 & 70 & 9.724 & 0.424129 & 0.842364 & 56.8 \\
50 & 21.789 & 75 & 3.816 & 0.175134 & 0.705787 & 61.8 \\
55 & 10.173 & 80 & 4.436 & 0.436056 & 0.847047 & 66.8 \\
60 & 12.704 & 85 & 1.321 & 0.103983 & 0.635905 & 71.8 \\
65 & 4.314 & 90 & 1.230 & 0.285118 & 0.778045 & 76.8 \\
70 & 5.774 & 95 & 479 & 0.082958 & 0.607816 & 81.8 \\
& & & & & \\
\hline
\end{tabular}


Cuadro IV-3

Relaciones de supervivencia por cinco años según sexo y grupos quinquenales de edad:

(A) ajustadas de la población nacida en la Argentina para el período 18691895, sexo masculino

(B) de la tabla de vida de Kern, sexo masculino, de la Ciudad de Buenos Ai res, 1887

(C) de dos tablas modelo de las Naciones Unidas, sexo masculino, con esperanza de vida al nacer, para ambos sexos, equivalente a 30.0 y 32.5 años

(D) ajustadas de la población nacida en la Argentina para el período 18691895, sexo femenino

\begin{tabular}{|c|c|c|c|c|c|}
\hline$\overline{\text { Edad }}$ & & $\overline{\text { Val }}$ & & & Mujeres \\
\hline inicia1 & Argentina & Tabla de & Tabla mo- & Tabla mo- & Argentina \\
\hline grupo & ajustadas & As. 1887 & $E(0)=30.0$ & $E(0)=32.5$ & ajustadas \\
\hline Nacimientos & 0.7210 & 0.6957 & 0.7058 & 0.7248 & 0.7406 \\
\hline 0 & 0.8700 & 0.8081 & 0.8577 & 0.8731 & 0.8700 \\
\hline 5 & 0.9596 & 0.9521 & 0.9556 & 0.9606 & 0.9568 \\
\hline 10 & 0.9621 & 0.9649 & 0.9590 & 0.9629 & 0.9577 \\
\hline 15 & 0.9478 & 0.9468 & 0.9444 & 0.9487 & 0.9435 \\
\hline 20 & 0.9368 & 0.9366 & 0.9326 & 0.9379 & 0.9313 \\
\hline 25 & 0.9299 & 0.9302 & 0.9245 & 0.9313 & 0.9232 \\
\hline 30 & 0.9209 & 0.9186 & 0.9130 & 0.9218 & 0.9168 \\
\hline 35 & 0.9031 & 0.8985 & 0.8957 & 0.9068 & 0.9067 \\
\hline 40 & 0.8796 & 0.8767 & 0.8722 & 0.8857 & 0.8945 \\
\hline 45 & 0.8502 & 0.8560 & 0.8440 & 0.8594 & 0.8742 \\
\hline 50 & 0.8151 & 0.8287 & 0.8086 & 0.8251 & 0.8467 \\
\hline 55 & 0.7741 & 0.7846 & 0.7626 & 0.7798 & 0.8091 \\
\hline 60 & 0.7273 & 0.7239 & 0.7011 & 0.7182 & 0.7610 \\
\hline 65 & 0.6524 & 0.6436 & 0.6139 & 0.6312 & 0.6859 \\
\hline 70 & 0.5503 & 0.5345 & 0.5023 & 0.5202 & 0.5799 \\
\hline 75 y más & 0.3814 & 0.3410 & 0.3136 & 0.3284 & 0.4018 \\
\hline
\end{tabular}


Cuadro IV-4

Población nacida en la Argentina. Cálculo de relaciones de supervivencia por cinco años según sexo y grupos quinquenales de edad para el período 1895-1914, a partir de la población censada en 1895 y 1914.

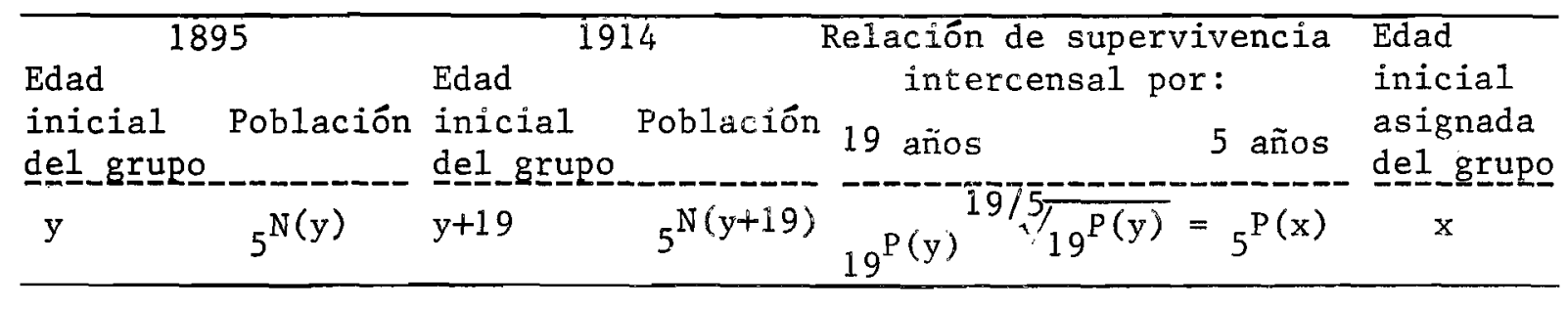

\section{Varones}

$$
5
$$

10

15

20

25

30

35

40

45

50

55

60

65

70

75

Mujeres

5

10

15

20

25

30

35

40

45

50

55

60

65

70

75

$\begin{array}{rr}260.340 & 24 \\ 199.125 & 29 \\ 145.155 & 34 \\ 118.923 & 39 \\ 102.722 & 44 \\ 76.716 & 49 \\ 75.096 & 54 \\ 48.217 & 59 \\ 44.253 & 64 \\ 29.154 & 69 \\ 20.504 & 74 \\ 17.131 & 79 \\ 7.997 & 84 \\ 6.825 & 89 \\ 2.983 & 94\end{array}$

$250.107 \quad 24$

$181.556 \quad 29$

$168.040 \quad 34$

$135.964 \quad 39$

$114.231 \quad 44$

$85.194 \quad 49$

$75.642 \quad 54$

$56.415 \quad 59$

$39.495 \quad 64$

$33.839 \quad 69$

$19.319 \quad 74$

$21.482 \quad 79$

$9.298 \quad 84$

$9.724 \quad 89$

$3.816 \quad 94$
211.937

144.212

0.814078

120.388

0.724228

0.829375

95.973

0.807018

72.8850 .709536

$53.872 \quad 0.702226$

$41.916 \quad 0.558166$

$29.471 \quad 0.611216$

$16.983 \quad 0.383771$

11.083

0.380154

6.608

4.126

0.322279

1.815

0.240850

1.000

0.226960

473

0.146520

0.158565

223.680

139.835

123.159

94.592

69.359

55.214

36.706

32.661

17.278

15.120

7.930

6.772

2.741

2.185

872
0.894337

0.770203

0.732915

0.695714

0.6071 .182

0.648097

0.485260

0.578942

0.437473

0.446822

0.410477

0.315241

0.294795

0.224702

0.228512
0.947308

0.918597

0.951961

0.945140

0.913657

0.911171

0.857747

0.878488

0.777224

0.775288

0.742315

0.687546

0.676882

0.603252

0.615927

0.971040

0.933598

0.921484

0.908940

0.876958

0.892138

0.826727

0.866036

0.804478

0.808966

0.791104

0.738013

0.725104

0.675105

0.678097
12.5

15.7

23.6

28.6

33.6

38.6

43.6

48.6

53.6

58.6

63.6

68.6

73.6

78.6

83.6

\section{5}

15.7

23.6

28.6

33.6

38.6

43.6

48.6

53.6

58.6

63.6

68.6

73.6

78.6

83.6 


\section{Cuadro IV-5}

Relaciones de supervivencia por cinco años $5^{\mathrm{P}}(\mathrm{x})$ ajustadas de la población nacida en la Argentina, por sexo y grupos quinquenales de edad, de tres épocas: 1869-1895, 1895-1914 y 1913-1915

\begin{tabular}{|c|c|c|c|c|c|c|}
\hline $\begin{array}{l}\text { Edad } \\
\text { inicial }\end{array}$ & & Varones & & & Mujeres & \\
\hline grupo & 1869-1895 & $1895-1914$ & $1913-1915$ & $1869-1895$ & $1895-1914$ & $1913-1915$ \\
\hline Nacimientos & 0.7210 & 0.7846 & 0.8565 & 0.7406 & 0.7988 & 0.8659 \\
\hline 0 & 0.8700 & 0.9144 & 0.9513 & 0.8700 & 0.9152 & 0.9516 \\
\hline 5 & 0.9596 & 0.9715 & 0.9826 & 0.9568 & 0.9697 & 0.9832 \\
\hline 10 & 0.9621 & 0.9704 & 0.9796 & 0.9577 & 0.9667 & 0.9760 \\
\hline 15 & 0.9478 & 0.9561 & 0.9648 & 0.9435 & 0.9523 & 0.9617 \\
\hline 20 & 0.9368 & 0.9455 & 0.9540 & 0.9313 & 0.9417 & 0.9521 \\
\hline 25 & 0.9299 & 0.9395 & 0.9493 & 0.9232 & 0.9352 & 0.9472 \\
\hline 30 & 0.9209 & 0.9291 & 0.9384 & 0.9168 & 0.9278 & 0.9400 \\
\hline 35 & 0.9031 & 0.9123 & 0.9219 & 0.9067 & 0.9189 & 0.9310 \\
\hline 40 & 0.8796 & 0.8893 & 0.8998 & 0.8945 & 0.9076 & 0.9212 \\
\hline 45 & 0.8502 & 0.8624 & 0.8746 & 0.8742 & 0.8903 & 0.9061 \\
\hline 50 & 0.8151 & 0.8304 & 0.8449 & 0.8467 & 0.8652 & 0.8831 \\
\hline 55 & 0.7741 & 0.7915 & 0.8071 & 0.8091 & 0.8299 & 0.8493 \\
\hline 60 & 0.7273 & 0.7428 & 0.7594 & 0.7610 & 0.7816 & 0.8037 \\
\hline 65 & 0.6524 & 0.6762 & 0.7003 & 0.6859 & 0.7151 & 0.7451 \\
\hline 70 & 0.5503 & 0.5881 & 0.6255 & 0.5799 & 0.6249 & 0.6705 \\
\hline 75 y más & 0.3814 & 0.4274 & 0.4757 & 0.4018 & 0.4526 & 0.5053 \\
\hline
\end{tabular}



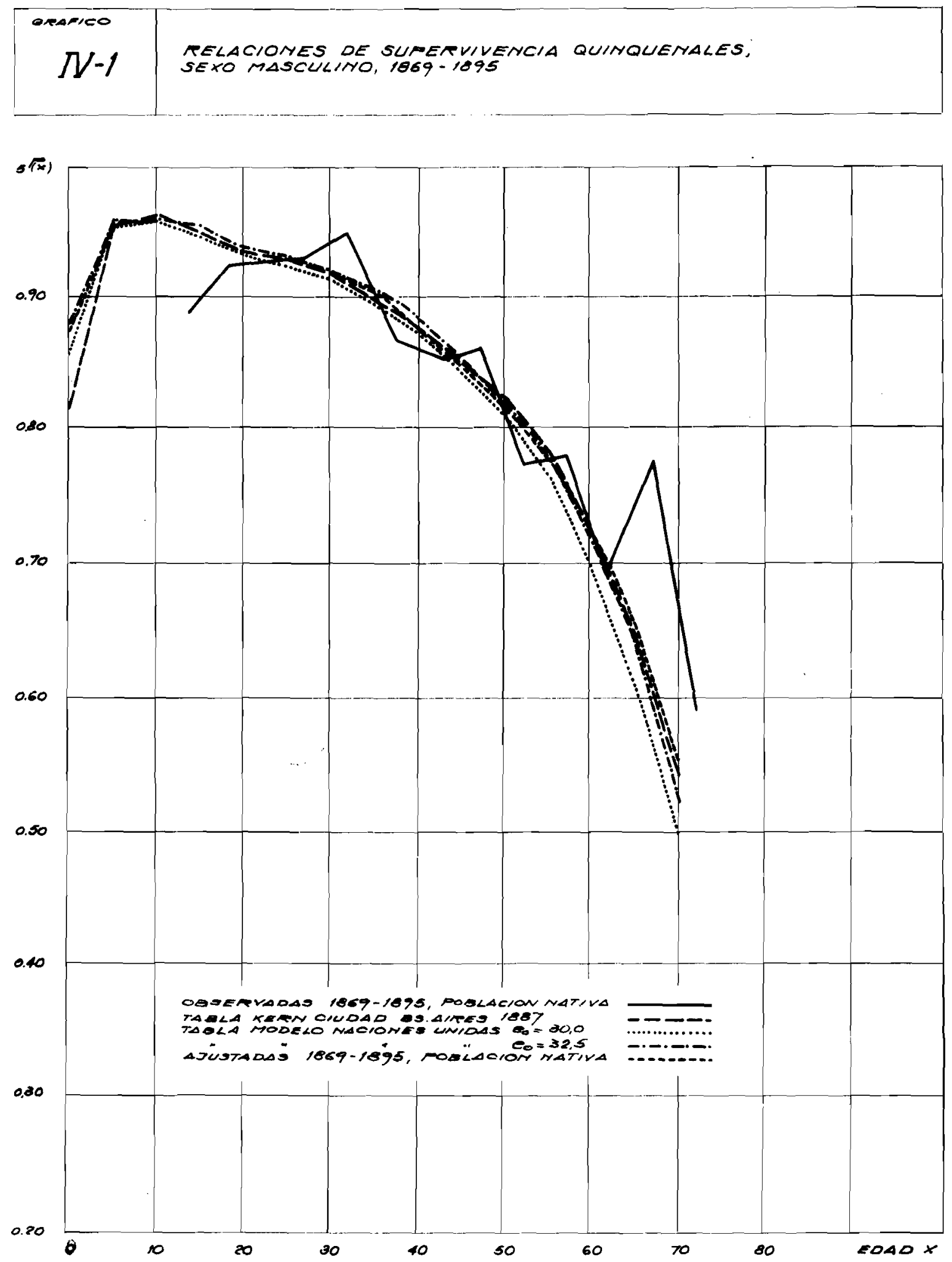

FUEMTE: CUAONO W.2 Y M.9. 


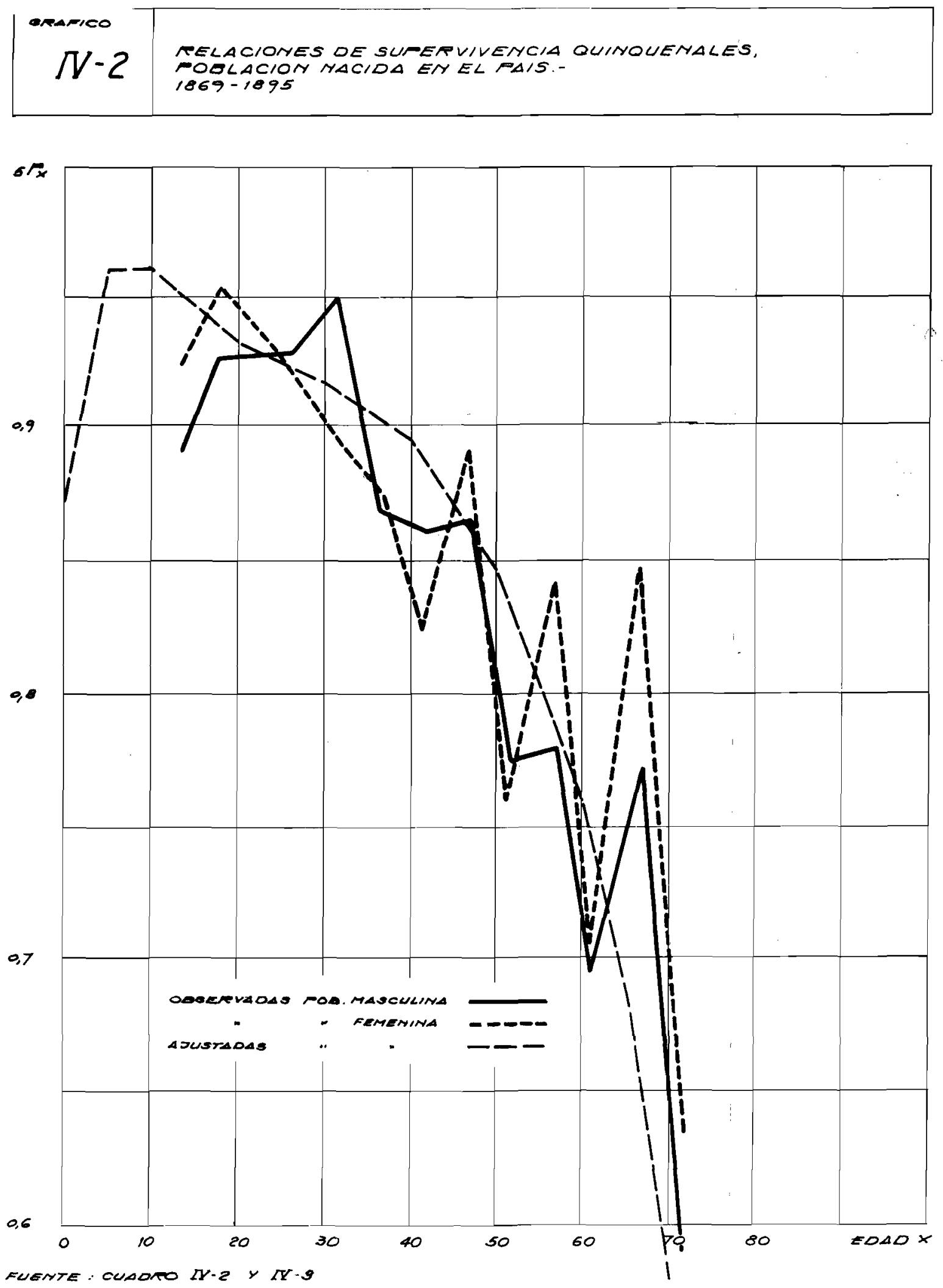




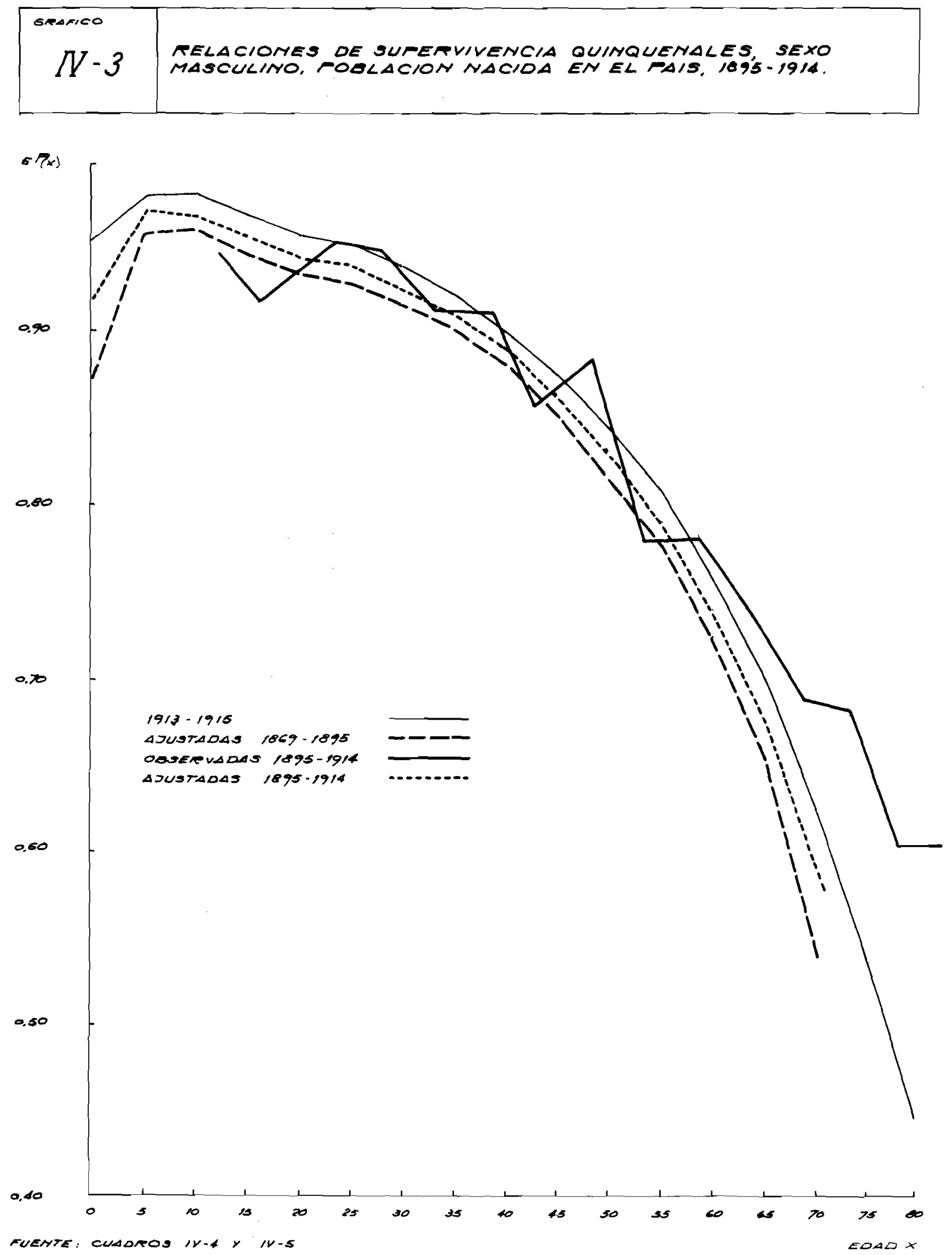



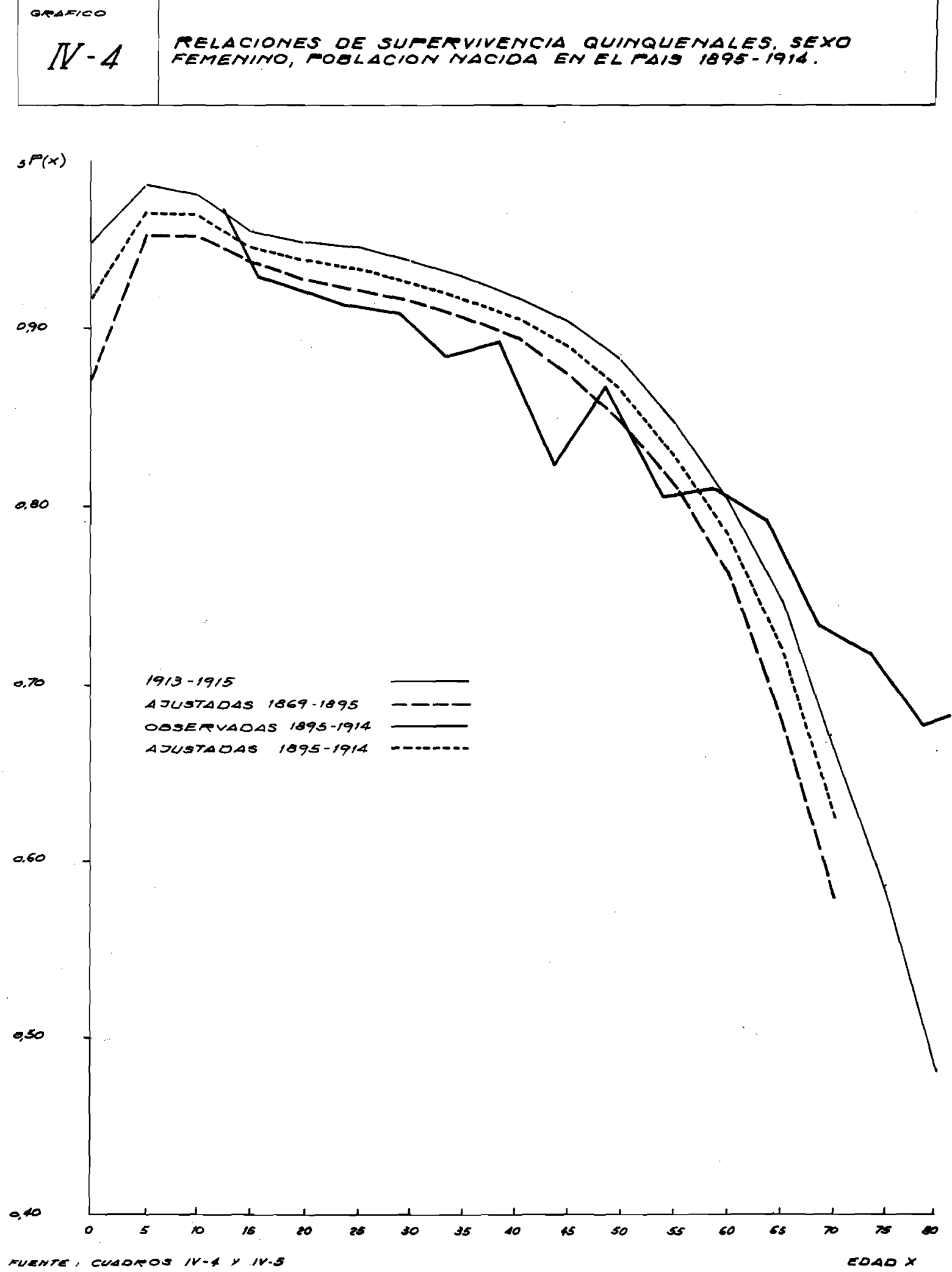
Capítulo V

LAS TABLAS DE MORTALIDAD DE 1913-1915, 1946-1948 y 1959-1961

1. E1 año 1914 marca el momento inicial de cualquier estudio del nivel de la mortalidad en el país que se apoye sobre bases estadísticas serias. Pa ra ese año se cuenta, por primera vez, con un censo de población e informa ción de registros de muertes razonablemente buenos, en provincias donde vi vía la mayoría de la población. Lo siguen 1947 y 1960 , años en los que se levantaron los censos nacionales posteriores al de 1914. Es lamentable la falta de información censal intermedia a nivel nacional durante el período comprendido entre 1914 y 1947 porque el estudio del proceso de descenso de la mortalidad se ve seriamente dificultado.

2. Las tablas de mortalidad se construyen con información de tres años en torno al año en que se levantó cada censo: 1913-1915, 1946-1948 y 19591961. Se procura, con los promedios de tres años, lograr resultados que no estén sujetos a variaciones accidentales, como podrían acaso estarlo los que se apoyaran en la información de sólo un año.

3. La clasificación del material estadístico básico permitió que las tablas de mortalidad de 1913-1915 se elaboraran no sólo por región y sexo, lo que también se hizo para las épocas 1946-1948 y 1959-1961, sino también por ori gen, esto es, según que la población hubiera nacido en la Argentina o en e1 exterior. Los resultados muestran que el nivel de la mortalidad según el ori gen de la población variaba notablemente: era, generalmente, mayor para los nacidos en el país. Los datos sobre defunciones de las épocas más recientes no permiten, desgraciadamente, una elaboración similar.

4. La construcción de las tablas de vida que se describe en los puntos que siguen se divide, atendiendo a los procedimientos empleados en la elaboración, en tres partes relativas a otros tantos tramos de vida: la inicial, que comprende los dos primeros años de vida: la intermedia, que abarca desde la edad 2 hasta la de 80,85 o 90, según los casos, y la final, que se inicia con estas últimas edades. Es conveniente conservar esa separación pues se facilita la exposición del trabajo realizado. En cada una de las tres partes se exami nará la elaboración de las tablas de las tres épocas mencionadas pudiendo adé lantarse que los procedimientos utilizados en la construcción de las tablas fueron similares en todos los casos. Contribuye esto a que los resultados sean comparables.

Fuentes de datos y ajustes del material básico

5. En el Anexo IV se detallan las fuentes de las que se extrajeron los datos relativos a nacimientos, muertes y población que se utilizaron en la elaboración de las tablas de mortalidad. También allí se indican los ajustes intro- 
ducidos a la información básica con el propósito de hacerla coherente entre sí. Los ajustes principales se relacionan con la corrección de nacimientos por omisión y el ajuste de las cifras censales de 1960, a fin de hacerlas comparables con las de los registros de muertes,

El tramo inicial de las tablas de vida

6. Los censos de población suministran, con frecuencia, muy deficiente información sobre los niños de 0 y 1 años de edad; se producen generalmente serias omisiones. Un ejemplo ilustrativo servirá para dar una idea de la importancia del error: en el censo de 1914, los niños censados en la provin cia de Buenos Aires con edades entre 2 y 4 años cumplidos fueron 63.503 como promedio por edad. Los censados con edades 0 y 1 alcanzaron apenas a 61.828 y 55.300 respectivamente. En una población creciente, como era la que se considera, el número de personas según la edad tiende a disminuir a medida que ésta aumenta y valores como los indicados resultan inaceptables. Si en la medición de la mortalidad se utilizara información censal con defectos como el señalado se cometería un error sistemático en el sentido de exagerarla.

7. En lugar de emplear los resultados censales relativos a las edades 0 y I se prefirió, siguiendo prácticas que son bastante difundidas en la elabo ración de tablas de vida (véase Referencias, 10) utilizar información prove niente de los registros de nacimientos y de muertes a fin de estimar la población de esas edades en los períodos estudiados. Este procedimiento, por otra parte, fue también seguido por los autores de las tablas construidas más recientemente en la Argentina (véase Referencias, 19 y 20).

8. Se presenta un primer problema: los registros de nacimientos también es tán afectados por omisiones, aunque, por lo general, de una importancia relativa menor a la del censo de población en las edades 0 y 1 . Este asunto ha sido investigado en un trabajo anterior del Centro de Investigaciones So ciales (véase Referencias, 12) en el que se elaboraron correcciones por omi sión de las series anuales de nacimientos registrados por provincia y sexo en el período 1911-1947. Los detalles del procedimiento utilizado para 1le gar a ese ajuste deben consultarse en el trabajo citado. Baste sólo decir aquí que el método consiste en elaborar, a partir de datos censales -excluyendo generalmente la población censada con edades 0 y $1-$ y de estadísticas de muertes según la edad, estimaciones del número anual de nacimientos. Es tos resultados, por lo general, son más altos que los dados por los registros. Se atribuye la diferencia a omisión en los registros de nacimientos. Posiblemente una interpretación correcta es que la diferencia mencionada es el exceso de omisión de los registros de nacimientos por sobre la omisión general que afecta no sólo a los nacimientos sino también a las muertes y a la población enumerada en el censo. Lo que se logra, eliminando ese exceso de omisión de nacimientos, es que los datos de las tres fuentes, es decir, registro de nacimientos, registro de muertes y censo, resulten coherentes entre sí. 
9. Una relaciôn entre nacimientos estimados -por el método mencionado en el punto anterior- y registrados proporciona un factor de ajuste de los nacimien tos, por omisiôn. Aplicando ese factor a los nacimientos registrados se obtiene una serie presumiblemente corregida por omisión en el sentido señalado en el pârrafo precedente. El trabajo citado proporciona los nacimientos ya ajustados de varios años que se necesitan para la elaboración de las tablas de vida (1911-1915 y 1944-1947). Los nacimientos ajustados correspondientes a los otros años que también se requieren, esto es 1948 y 1957-1961, fueron obtenidos aplicando el mismo procedimiento utilizado en ese trabajo, con ligeras mo dificaciones o adaptaciones que impusieron los datos básicos que debían elabo rarse.

10. E1 método seguido en la elaboración de las probabilidades de morir de los dos primeros años de vida, que forman la parte inicial de las tablas de mortalidad, las probabilidades que se designan $\mathrm{q}_{\mathrm{o}} \mathrm{y} \mathrm{q}_{1}$ con la notación habitual, se rá ilustrado con un ejemplo. Se referirá a la población masculina, de la región BUENOS AIRES, constituida por la Capital Federal y la Provincia de Buenos Aires, período 1913-1915.

11. En el Cuadro V-1 figura la información básica utilizada, esto es, la serie anual de nacimientos, corregidos por omisión, entre los años 1911 y 1915 , y, pa ra los mismos años, la serie de muertes con 0 y 1 años de edad.

12. E1 procedimiento que se utiliza supone que la población menor de los 2 años de edad, nacida dentro de cada región, no está sujeta a migraciones, esto es, no recibe inmigraciones desde afuera de la región, ni está alterada por emigraciones de niños nacidos en la región. Este supuesto, desde luego, es falso ya que la población es abierta, está sujeta a migraciones. Sin embargo, es seguramente muy poco importante el movimiento migratorio de la población con edades in feriores a los 2 años $y$, en alguna medida, es dable esperar que se produzcan com pensaciones entre niños muertos fuera de la región de los emigrados y defunciones, dentro de la región, de niños inmigrantes.

13. Aceptado el supuesto de que 1a población investigada, menor de 2 años, es cerrada se hace necesario, a fin de llegar a establecer las probabilidades bus cadas, seguir la evolución de las generaciones anuales de nacimientos, esto es, e1 número de nacimientos ocurridos durante un año en la región considerada, a 10 largo del período que se investiga, 1913-1915, y en tanto esas generaciones vivieron dentro del tramo de vida limitado por las edades 0 y 2, Para esto es ne cesario contar con las muertes anuales clasificadas no sólo por edad sino también por cohorte, es decir, por año de nacimiento. Esta información no es proporcionada directamente por los datos de los registros. Puede, sin embargo, es timarse con razonable exactitud si se dispone de información de las muertes según edad detallada -tramos menores a un año-. Por ejemplo, en el caso del primer año de vida: muertes con menos de 1 día, con más de 1 día y menos de 1 sema na, etc. Haciendo el supuesto de que las defunciones se distribuyen uniformemente a lo largo del año es fácil estimar cuántas de ellas, en cada grupo de edad, pueden corresponder a nacimientos ocurridos durante el año que se conside ra y cuántas otras a los del año anterior. Así, si las muertes de menores de $\overline{1}$ día se distribuyen uniformemente en el año, una parte equivalente a $1 / 365$ del 
total debió ocurrir cada día. Como sólo las que se produjeron el $1^{\circ}$ de enero pudieron provenir en parte de nacimientos del año anterior y en parte del año considerado, se toma la mitad de ellas, esto es, $1 / 730$ del total de las muertes anuales de menores de 1 día como la cantidad atribuible a nacimientos del año anterior. El complemento de esa fracción, 729/730 aplicado al total de las muertes de menores de un día proporciona las que corresponden a nacimien tos del año analizado. Un análisis similar, para cada uno de los grupos de edad en que se clasifican las muertes de menos de un año, permite calcular el total de defunciones que pueden atribuirse a nacimientos del año anterior $y$ del año considerado. E1 cociente entre las muertes asignadas a nacimientos del año anterior y el total de defunciones define lo que se denomina "factor de separación" de las muertes.

14. Con la notación usual, el total de muertes de edad $x$ en el año $z$ se escribe $D_{x}^{Z}$. Este total se descompone en los dos subconjuntos mencionados en el párrafo anterior, que se escriben $\alpha^{\mathrm{D}} \mathrm{D}_{\mathrm{x}}^{\mathrm{Z}} \mathrm{y}_{\delta} \mathrm{D}_{\mathrm{x}}^{\mathrm{Z}}$. E1 primero, $\alpha^{\mathrm{D}} \mathrm{D}_{\mathrm{x}}$, representa e1 número de muertes de personas con edâd $x$, ocurridas durante ${ }^{x} l$ año $z$, que ha bían alcanzado a cumplir la edad $x$ durante ese año. En particular, si $x=0$, representa las defunciones de niños que mueren en el mismo año civil en que nacen. E1 segundo, $\delta \mathrm{D}_{\mathrm{x}}^{2}$, representa el número de muertes de personas con edad $x$, ocurridas durante $\mathrm{e}^{\mathrm{I}}$ año $\mathrm{z}$, que alcanzaron $\mathrm{la}$ edad $\mathrm{x}$ durante $\mathrm{el}$ año civil anterior al de la muerte, que es el que se está considerando. Cumplieron la edad $x$ en el año $z-1$. Con esta notación, el factor de separación, que se es cribe $\mathrm{f}_{\mathrm{X}}^{Z}$ queda definido así:

$$
f_{x}^{z}=\delta D_{x}^{z} / D_{x}^{z}
$$

15. La información disponible acerca de la edad detallada de las muertes per mitió estimar la partición de las muertes anuales de la edad 0 en los dos sub conjuntos que se han definido, tal como queda explicado anteriormente. No fue posible, sin embargo, hacer lo propio con las muertes de edad l, ya que las estadísticas no suministran la información necesaria para ello. Se utili zó, para ese fin, un factor de separación de las muertes de edad 1 , empleado frecuentemente (véase Referencias, 10). Su valor, empleado uniformemente en todo el trabajo, es 0.41 . En el Cuadro $V-1$, se presenta, para el ejemplo que se analiza, la partición de las muertes anuales de edad 0 y 1 en los dos subconjuntos definidos anteriormente.

16. Con el material anterior, reproducido en el citado Cuadro V-1, se está en condiciones de elaborar un diagrama de Lexis, tal como aparece en el Grá fico V-1. Facilita esto el cálculo de los valores necesarios para determinar las probabilidades de supervivencia y de muerte de la tabla de vida y ayuda a interpretar fácilmente el significado de esas relaciones. En el dia grama de Lexis tal como se presenta en el Gráfico V-1 se indica, en el eje horizontal, 1a escala de tiempo; en el vertical, la correspondiente a las edades. En la primera aparecen cada uno de los años que van desde 1911 hasta 1915. Además se han destacado los momentos que dividen los años, señalándolos 
con la fecha 31 de diciembre. De un modo similar, en el eje de las edades se han señalado tramos de vida. Así por ejemplo $(0,1)$, relativo a personas con más de 0 año y menos de 1 , y también las edades exactas que limitan esos tramos: 0,1 y 2. En los cuadrados definidos por un año, en la escala de tiempo, y un intervalo anual de vida, en la de las edades, aparecen las muertes divididas en los dos subconjuntos definidos anteriormente: 1 as $\alpha^{D}$ en un triángulo inferior: las $\delta^{D}$ en el superior. Con esta disposición es fácil ahora, siguiendo una diagonal, calcular la forma en que una cohorte anual de nacimientos se va reduciendo con el tiempo por efecto de la morta lidad. Asî, de 66.225 niños nacidos durante $1913,4.286$ murieron ese mismo año $y$, consecuentemente, la diferencia $66.225-4.286=61.939$ son los que sobrevivieron al final del año 1913 (vêase el Gráfico V-1). Este núme ro se indica en la franja vertical que separa el año 1913 del año 1914 y a la altura correspondiente al tramo de vida $(0,1)$ ya que, en ese momento, los integrantes de la cohorte analizada tenían edades comprendidas dentro de ese intervalo. Durante el año 1914, conforme con el Gráfico V-1, 2.163 individuos, integrantes de la cohorte analizada, murieron antes de cumplir la edad de 1 año. De los 61.939 que iniciaron con vida el año 1914, 61.939 - $2.163=59.776$ llegaron a cumplir, durante el año 1914, la edad exacta 1 . Aparecen indicados, por esa razón, sobre el año 1914 en la escala del tiem po y a la altura que marca la edad exacta 1 año. Por un razonamiento simi lar puede deducirse que 865 mueren en 1914 antes de 1 legar al final del año y después de haber cumplido la edad 1 y que, consecuentemente, 58.911 sobreviven al final de 1914 con edades, en ese momento, comprendidas en el intervalo $(1,2)$. E1 diagrama determina cuändo cada una de las cohortes anuales estudiadas alcanza la edad 2 , ya que el propósito de esta elaboración es calcular probabilidades de morir y sobrevivir hasta esa edad, o cuändo las cohortes más jóvenes alcanzan el final del año 1915 (con edades cumplidas 0 y 1). Empleando una notación que es usual, el número de perso nas que alcanzan una edad exacta $x$, durante un año $z$, se escribe $E_{X}^{Z}$, en tan to que el símbolo que se utiliza para representar a los que están vivos al final del año $z$, con edades comprendidas entre los límites $x, x+1$, es $N_{x}^{Z}$ (véase Referencias, 10).

17. Para construir una tabla de vida del período trienal 1913-1915, no interesa el comportamiento separado de cada cohorte anual de nacimientos, sino la experiencia combinada de todas las cohortes que vivieron, durante e1 período considerado, en los tramos de vida 0,1 y 1,2 . Se combina, por 10 tanto, la información de varias cohortes de la forma siguiente:

$$
\begin{aligned}
& E_{x}=E_{x}^{1913}+E_{x}^{1914}+E_{x}^{1915} \\
& N_{x}^{\prime}=N_{x}^{1913}+N_{x}^{1914}+N_{x}^{1915} \\
& N_{x}^{\prime \prime}=N_{x}^{1912}+N_{x}^{1913}+N_{x}^{1914}
\end{aligned}
$$

y se definen las siguientes probabilidades de supervivencia: 
$\alpha^{p_{x}}=N_{x}^{\prime} / E_{x}$ probabilidad de una persona de sobrevivir desde el momento del año en que alcanza la edad $x$-durante el período 19131915- hasta el final de ese mismo año

$\delta^{P}=E_{x+1} / N^{\prime \prime}$ probabilidad de una persona, con edad alcanzada $x$ al comien zo de un año, de llegar con vida a cumplir la edad $x+1$ durante el perído 1913-1915.

E1 producto de ambas probabilidades representa la de sobrevivir del aniversario $\mathrm{x}$ al $\mathrm{x}+1$ conforme con $1 \mathrm{a}$ experiencia de mortalidad del período 1913-1915. Se escribe

$\mathrm{p}_{\mathrm{X}}=\alpha^{\mathrm{p}_{\mathrm{x}}} \cdot \delta^{\mathrm{p}} \mathrm{x}$

E1 complemento de esta probabilidad es la de morir $\mathrm{q}_{\mathrm{x}}$

$q_{x}=1-p_{x}$

18. En el Cuadro V-2 aparecen los valores numéricos que toman las funcio nes presentadas anteriormente en el ejemplo ilustrativo. En las tablas de mortalidad que se reproducen, en el Capítulo VI, figuran los valores de $\mathrm{q}_{0}$ y $q_{1}$ de las tablas de mortalidad para los períodos 1913-1915, 1946-1948 y 1959-1961 que fueron calculados siguiendo el procedimiento expuesto. Cuando se elaboraron tablas de mortalidad para ambos sexos se sumaron los valores de las funciones $E, N^{\prime}$ y $N^{\prime \prime}$ correspondientes a los varones y mujeres y con ellos se obtuvieron las probabilidades buscadas.

19. Finalmente, es oportuno recordar una vez más, que no se hizo el inten to de medir la mortalidad de la población nacida en el exterior a lo largo del tramo de vida considerado ya que su número es muy escaso. Por razones de simplicidad y comodidad las tablas de vida de la población nacida en el exterior se completaron en su primera parte -tramo de edades menores de 5 a ños, no sólo menores de 2 años- con las funciones de las tablas de la pobla ción nacida en la Argentina. No tienen, por lo tanto, ningún valor como me dida propia de la mortalidad en ese tramo de vida de la población inmigrante.

El tramo intermedio de las tablas de vida

20. Con esta denominación se designa el extenso intervalo que va desde los 2 años hasta la edad con que se inicia el grupo final: 80,85 o 90 años, se gún los casos. Este grupo final se considera aparte. En el tramo intermedio la información de muertes y de población está agrupada en tramos quinque nales a partir de la edad de 5 años. Hay además un grupo inicial, de tres años de amplitud, formado por los niños en el intervalo 2-4 años cumplidos.

21. E1 primer paso de la elaboración consistió en calcular las tasas anuales de mortalidad para esos intervalos, dentro de cada una de las clases 
resultantes de clasificar a la población y las muertes por región, sexo y origen. La clasificación por origen se limitó, como se dijo ya anteriormente, a la información relativa a la época 1913-1915. Las tasas resulta ron de dividir el número promedio anual de muertes, registradas en tres a ños alrededor del año del censo, por el número de personas censadas. La población se tomó al momento del censo, sin ningún ajuste que procurara estimarla a mediados del año censal, punto central de los tres años consi derados con la información de muertes. Se consideró que tal ajuste tenía importancia secundaria en razón de que las fechas censales fueron en 1914 y 1947 muy próximas a mediađoos del año y de que el ajuste por omisión de la población censal en 1960 hace ilusorio cualquier refinamiento como el mencionado.

22. Las tasas resultantes, se denominan "observadas" y son asimilables a las tasas centrales de mortalidad de una tabla de vida, $\mathrm{n}_{\mathrm{x}}$, ya que éstas resultarían de un câlculo similar efectuado con la población estacionaria de la tabla. E1 problema que se plantea es decidir si los valores observados deben ser ajustados, para eliminar irregularidades que puedan afectarlos, o si, por el contrario, pueden tomarse como representativos de las tasas centrales de mortalidad de una tabla de vida.

23. Las tasas correspondientes a los primeros grupos de edad considerados presentaron la forma típica de variar: bajaban claramente entre el grupo 2-4 y 5-9, seguían descendiendo al pasar de este grupo al siguiente, 10-14, -salvo algún caso excepcional en el que se mantenía el valor sin variacióny a partir de este grupo comenzaban a aumentar.

24. Los resultados obtenidos para el grupo de edades 2-4 en 1a población nacida en el exterior, en la época 1913-1915, hizo aconsejable eliminar del análisis esas tasas -seguramente afectadas por errores accidentales origina dos en el tamaño reducido de la población considerada- y, consecuentemente, iniciar el estudio de la mortalidad de la población nacida en el exterior a la edad de 5 años. Por razones prácticas, sin embargo, las tablas de vida relativas a este sector de población comienzan, como las de la población na cida en el país, a la edad 0. En el tramo de edades $0-5$ se asigna a la población nacida en el exterior la mortalidad que corresponde a la nacida en la Argentina de la misma región y sexo. Al procederse de este modo se 1ogra que el número de sobrevivientes a la edad 5, 1a función $1_{5}$, sea igual en ambas tablas de vida- la de nacidos en la Argentina y la de nacidos en el ex terior- lo que facilita la comparación entre ellas.

25. Después de un examen cuidadoso de las tasas de mortalidad relativas a los primeros grupos de edad, en vista de la variación plausible que mostra ban o, dicho de otro modo, ante la falta de evidencias de que hubiera irre gularidades en tales tasas, se decidió adoptarlas, sin modificación, como representativas de las de una tabla de vida. Son, por 1o tanto, las que a parecen como función $\mathrm{m}_{\mathrm{x}}$, la tasa central de mortalidad, en las tablas de vida que figuran en el Capitulo VI.

26. E1 ajustamiento de las tasas observadas comenzó a partir de los grupos 
de edad 20-24 o posteriores, según los casos, cuando aparecieron irregulari dades obvias en la variación de las tasas según la edad, como puede observar se en los Cuadros V-3, V-4 y V-5 y los Gráficos V-2 a V-5. En estos casos se procedió a ajustar las tasas observadas mediante un procedimiento gráfico.

27. En el ajustamiento realizado en todos los casos se mantuvo el nivel gene ral observado de la mortalidad, esto es, si algunas tasas observadas se eleva ban al ajustarlas, otras se reducían de modo tal que el número de muertes esperadas -resultado de aplicar las tasas ajustadas a la población clasificada por edad- sumaran igual número de defunciones que el observado dentro del tra mo de vida en el que se ajustaban las tasas; salvo diferencias de una o dos muertes, sin significación, No se pretende que las muertes esperadas resulten ajustadas por este procedimiento, sino que tengan el mismo tipo de error que los datos de población. De ese modo las tasas, cociente de muertes y población, describen una marcha regular con el crecer de la edad.

28. Un juicio sobre la importancia de los ajustamientos introducidos en las tasas puede formarse observando los Gráficos V-2 a V-5 que muestran, en escala logarítmica -a fin de facilitar tanto la representación como el examen de la variación de las tasas- los valores observados y los ajustados correspondientes a las 16 series básicas correspondientes a la época 1913-1915. Las tasas correspondientes a los períodos 1946-1948 y 1959-1961 no se presentan gráfica mente porque los ajustamientos fueron de muy poca importancia y, consecuentemente, de menor interés. Las tasas observadas y las ajustadas para los tres períodos se presentan en los Cuadros V-3, V-4 y V-5. Para uniformar la presen tación de los cuadros y los gráficos los grupos de edades considerados arrancan con el grupo 20-24 aunque, frecuentemente, el ajustamiento comienza en eda des superiores, 10 que puede comprobarse al notar que las tasas observadas y las ajustadas coinciden en muchos casos.

29. Como puede apreciarse observando los gráficos y los valores numéricos que aparecen en los cuadros los ajustes tienen, en general, mayor importancia en los grupos de edad avanzada que en los otros grupos. E1 tamaño reducido de la población de esas edades, unido a los mayores errores por mala declaración de edad, pueden explicar la necesidad de ajustamientos más severos en esos casos.

30. A1 ajustar datos pueden cometerse dos errores típicos: de exceso o insuficiencia de ajustamiento. Hemos procurado no caer en ninguno de ellos aunque hemos temido más al primero que al segundo. Nuestro propósito es medir fielmente el nivel general de la mortalidad observado antes que obtener tablas de vida con funciones muy regulares, apropiadas para usos más exigentes que los del análisis demogräfico. Se ha procurado, por lo tanto, sólo eliminar los errores notorios en las tasas observadas, sin imponer una regularidad forzada, ante el peligro de que resultara excesiva.

31. Como puede comprobarse examinando los Cuadros V-3 a V-5 los ajustamientos se han efectuado en las categorías que resultan de la clasificación más fina de la población: 16 en el caso del período 1913-1915, que resultan de clasificar la población por región ( 4 clases), sexo (2) y origen (2), y 8 , en cada una 
de las épocas 1946-1948 y 1959-1961, que resultan de cruzar los datos por región (4) y sexo (2). En total se cuenta, por lo tanto, con 32 series a justadas de tasas de mortalidad. El problema siguiente es componer nuevas tablas que resultan de unir las clases elementales que se han definido.

32. Las tasas de mortalidad correspondientes a la unión de clases resulta ron de sumar las muertes esperadas, computadas en base a la población y las tasas ajustadas de las clases elementales y dividirlas por la suma de las poblaciones de las mismas clases. Estos cómputos se efectuaron para cada grupo de edad. Las tasas resultantes mostraron una variación regular con la edad, razón por la cual se las considerô como tasas ajustadas. Es opor tuno señalar que en algunos casós del período 1913-1915 al unirse información de población nacida en la Argentina y en el exterior -con niveles de mortalidad a veces muy diferentes- se obtuvieron resultados que mostraron una variación decreciente en ciertós tramos de edades adultas jóvenes. Véa se, por ejemplo, cómo la tasa de mortalidad de la población masculina región BUENOS AIRES, época 1913-1915, baja de 6.54 por mil, en el grupo 2024 , a 6.41 por mil en el grupo siguiente en tanto que, en las dos tablas que se utilizaron para su elaboración, lạ de varones nacidos en la Argentí na y la correspondiente a los nacidos en el exterior, los valores de la ta sa son crecientes: 8.28 y 8.50 en la primera, 5.06 y 5.28 en la segunda (véase en el Capítulo VI la información completa de las 3 tablas). Tenden cias como las del ejemplo se consideran reales $y$, en consecuencia, no se modifican los valores obtenidos.

33. Las tasas ajustadas de las 32 tablas básicas, de las clases elementales, y las correspondientes a las 33 que se derivaron de ellas por unión de clases, constituyen la información necesaria para proseguir con el cómputo de las otras funciones de la tabla de mortalidad. Antes de pasar a la des cripción de ese punto es oportuno considerar la elaboración realizada con las tasas del tramo final de las tablas de vida.

\section{E1 tramo final de las tablas de vida}

34. Es común que la elaboración de la parte final de las tablas de vida pre sente problemas particulares derivados de:

(a) la escasa población con edades muy elevadas, especialmente en el pasado, 1o que hace que las tasas observadas de mortalidad estén sujetas a fuertes oscilaciones;

(b) los gruesos errores de declaración de edades de estas personas, tanto en los censos como en los registros de muertes, que contribuyen a alterar las ta sas observadas, alejándolas de los valores reales.

35. Estos inconvenientes se presentaron cuando se examinaron las tasas correspondientes a edades avanzadas de los diversos grupos de población estudia dos en las tres épocas. Los problemas, sin embargo, no tuvieron la misma importancia en cada una de ellas. Varios factores contribuyeron a que los incon 
venientes fueran mayores en la elaboración de los datos relativos a 19131915, menores cuando se trabajó con los de 1946-1948 y prácticamente inexistentes -o más propiamente, no evidentes- tratándose del período 19591961 .

36. Antes de pasar a describir los ajustes efectuados a 1a información relativa a muertes de personas de edad avanzada, parece oportuno plantear la pregunta de si se justifica la realización de esos ajustes, que pueden a veces parecer excesivos, especialmente los practicados con la infor maciôn de 1913-1915. Podría cuestionarse su utilidad cuando los valores resultantes dependen con frecuencia más del criterio de ajustamiento empleado que de lo que muestran las estadísticas de los registros. La jus tificación de proceder a realizarlos está dada por la necesidad de disponer de los valores de las últimas edades a fin de completar el cómputo de algunas funciones de la tabla de vida. Interesa que tales valores fí nales sean coherentes con los que corresponden a los grupos de edad que les preceden inmediatamente. No se pretende, sin embargo, que las tasas ajustadas relativas a las edades más avanzadas sean una medida adecuada de la mortalidad y no debe dárseles a ellas el mismo crédito que a las correspondientes a los otros intervalos de edad.

37. Aunque la información disponible para 1913-1915 permitía calcular ta sas de mortalidad por grupos quinquenales hasta los 100 años de edad se prefirió reunir en un solo grupo la información relativa a los mayores de 90 años, debido a que la escasez del número y los errores de declaración de edad -mayores en 1914 que en los períodos posteriores-hacían de una va lidez ilusoria el análisiṣ más detallado. El número de personas y, consecuentemente de muertes, en muchas clases era muy reducido, aun cuando se hiciera el agrupamiento indicado (mayores de 90). Debe recordarse que la mortalidad del período 1913-1915 se analiza clasificando a la población en 16 clases que resultan de dividirla según región, sexo y origen. A ese ni vel, aunque se reúna en una categoría a todos los individuos mayores de 90 años, los números suelen ser muy pequeños (en cuatro casos, por ejemplo, las personas censadas fueron menos de 100). No es de extrañar, por lo tan to, que dada la escasa población y teniendo presente los gruesos errores que se cometen en la declaración de la edad de personas ancianas (en los censos y en los registros de muertes) surgieran valores observados de tasas de mortalidad excesivamente altos a veces o sospechosamente bajos otras ve ces. Para remediar estos desvíos se procedió a redistribuir las muertes ré gistradas entre las 16 clases elementales en que se clasifica la población en forma tal que la tasa de mortalidad correspondiente al grupo de más de 90 años resultara coherente con la tasa ajustada, de cada una de las 16 cla ses elementales, del grupo 85-89 años, esto es $5^{\mathrm{m}_{85}}$.

38. Se calculó, en primer lugar, el valor de las tasas de mortalidad obser vadas correspondiente al grupo de personas de más de 90 años, que designamos m90, para cada una de las 16 clases de población (resultantes de la cla sificación cruzada por región, sexo y origen). Se determinó, por el método de mínimos cuadrados, una recta de regresión que usando como variable la tasa adoptada $5^{\mathrm{m}_{85}}$ ajustaba los valores observados de $\mathrm{m}_{90}$. En este ajustamiento 
intervinieron doce pares de valores $\left(5^{m_{85}} \mathrm{y}\right.$ a $\left.\mathfrak{m}_{90}\right)$ habiéndose excluido de la elaboración los cuatro correspondientes a poblaciones con menos de 100 indi viduos. La aplicación de las tasas ajustadas, determinadas por esa relación lineal, a la población con más de 90 años produjo un número de muertes esperadas que sumadas resultaron inferiores a las observadas ( 971 en lugar de 1001). Se aumentaron entonces las tasas en la medida necesaria a fin de 1ograr un número esperado de muertes similar al observado. Las tasas así aumen tadas fueron las que se tomaron como valores ajustados. En el Cuadro V-6 apa rece el número observado de muertes de más de 90 en cada clase de población estudiada y junto a él el nümero de muertes esperado resultante de aplicar a la población las tasas ajustadas. El efecto del ajustamiento, como se dijo anteriormente, es redistribuir el total de muertes observadas de más de 90 años entre las 16 clases elementales de población a fin de regularizar el comportamiento de la tasa $\mathrm{m}_{90}$ frente al de la tasa ajustada $5^{\mathrm{m}} 85^{\text {. }}$

39. Un procedimiento similar se aplicó a los datos de 1946-1948. Esta vez el número de categorías fue sólo de 6: la combinación de 3 regiones (excluida CUYO) y 2 sexos. Los valores observados y ajustados del número de muertes se dan también en el Cuadro V-6 mencionado anteriormente.

40. Si los valores de la tasa de mortalidad final (grupos de más de 90 años) para seis tablas de vida de 1946-1948 fueron ajustados pareció adecuado también hacer 10 propio con los datos de las dos tablas de la región de CuYo, que presentaban una tasa final para el grupo de más de 80 años. Pudo observar se que esos valores, tal como resultaban de la observación, eran excesivamente elevados en comparación con la tasa del grupo de edades inmediatamente anterior, especialmente si se tenía en cuenta el comportamiento de las tasas de iguales edades en otras regiones. Se creyó conveniente, en consecuencia, modificar los valores observados en la región CUYO reemplazándolos por otros que resultaron de estimar las tasas para personas mayores de 80 años en base a las ajustadas para el grupo de edades 75-79, teniendo en cuenta la tendencia observada en las tres regiones para las cuales se contaba con información más detallada, Como resultado de esta modificación, de importancia secundaria, el número de muertes observadas en la región de CUYo con más de 80 años se redujo de 300 a 237, en el caso de los varones; de 342 a 317 en el de las mujeres.

41. En las tablas correspondientes al período 1959-1961 no se ajustaron los valores observados de las tasas de mortalidad correspondientes a la población mayor de 85 años. Se tomó esa decisión porque:

(a) la población considerada era bastante mayor que en los otros períodos debido esto no sólo a que la población en 1960 había crecido con respecto a la de los censos anteriores, sino también a que el grupo final considerado fue de edades superiores a los 85 años en 1960, en tanto que en los casos anteriores por contarse con información más detallada, se formó un grupo final con los in dividuos de más de 90 años (excepto en el caso de la región cuYo en 1946-1948); $\mathrm{y}$

(b) las tasas observadas para el grupo final, edades superiores a los 85 años, 
resultaron en todas las categorías, claramente superiores, y por lo tanto coherentes, con las ajustadas correspondientes al grupo de edades 80-84.

Elaboración de las tablas abreviadas de mortalidad en función de los datos elaborados para los diferentes tramos de vida

42. Se cuenta ahora, como resultado de las elaboraciones descritas en los puntos que anteceden, con la siguiente información relativa a los diferentes tramos de vida:

(a) con las probabilidades de morir durante el primer y segundo año de vida, esto es, $\mathrm{q}_{0} \mathrm{y}_{\mathrm{l}}$. La información de las muertes de menores de un año, clasi ficadas según año de nacimiento, utilizada para el cómputo de $q_{0}$ y $q_{1}$, per mitió el cómputo de un valor promedio, por región, sexo y época, del factor de separación de las muertes de edad 0 . Ese factor es necesario, según se verá más adelante, en el cálculo del tiempo vivido ( $L_{0}$ ) en la tabla de vi da. En el Cuadro V-7 se presentan los factores de separación de la edad 0 , No fue posible, según se indicó oportunamente (punto 15 de este capítu1o) ob tener valores propios del factor de separación de la edad 1, también necesario para el cálculo del tiempovivido $\left(\mathrm{L}_{1}\right)$. Se adoptó, tal como se señaló anteriormente, e1 valor uniforme 0.41 ;

(b) con las tasas anuales de mortalidad asimilables, despúes del ajustamiento, a las tasas centrales de mortalidad de una tabla de vida para grupos desde los 2 años de edad hasta los 80,85 o 90 según los casos. Estas tasas están dadas para un intervalo de tres años, en el primer grupo considerado, $3^{\mathrm{m}_{2}}$, y para tramos quinquenales a partir de 1 a edad de 5 años, $5^{\mathrm{m}} \mathrm{x}$;

(c) con las tasas adoptadas para el grupo abierto final que corresponde a: (i) las edades de más de 90 años $\left(\mathrm{m}_{90}\right)$ en las tablas de 1913-1915 y 19461948 (salvo las de la región de ra las que se cuenta con tasas para el grupo abierto final de más de 80 años $\left(\mathrm{m}_{80}\right)$.

(ii) las edades de más de 85 años $\left(m_{\infty} 85\right)$ en las tablas de 1959-1961.

43. Con la información indicada en el punto anterior se está en condiciones de elaborar una tabla abreviada de mortalidad. El primer paso consiste en es timar las probabilidades de muerte, $\mathrm{n}^{\mathrm{q}} \mathrm{x}$, a partir de las tasas anuales de mor talidad, $\mathrm{m}_{\mathrm{x}}$, en el tramo intermedio ${ }^{\mathrm{n}} \mathrm{x}$ de edades. Salvo el caso del intervalo $2-4$, e ${ }^{n}$ el que la amplitud es de tres años, los otros considerados fueron uniformemente de cinco años. Los valores de las probabilidades de morir en fun ción de las tasas centrales de mortalidad se obtuvieron mediante la relación sī guiente, establecida empíricamente por Reed y Merrell (véase Referencias, 26).

$$
n^{q} x=1-e^{-n} \cdot n_{x}-0.008 \cdot n^{3} \cdot n^{2} x
$$

en la que la letra $n$ representa la amplitud del intervalo de edades (2 o 5 en nuestro caso). La probabilidad de morir que corresponde a la tasa anual del grupo abierto final es obviamente 1. Se logró, por lo tanto, un conjunto de 
de valores de probabilidades de morir que cubrieron toda la extensión de la tabla de vida. Obsérvese que el procedimiento empleado no define el valor de la edad extrema de vida de cada tabla, que se designa usualmente con $\omega$.

44. E1 cálculo del resto de las funciones se hizo por procedimientos bien conocidos, A partir de un valor inicial $1=100.000$ se computaron las muer tes ocurridas en un tramo de vida $x, x+n$ mediante la relación:

$$
n d_{x}=1_{x}-1_{x} \cdot q_{x}
$$

$y$, posteriormente, el número de sobrevivientes:

$$
1_{x+n}=1_{x}-n_{x}
$$

45. E1 tiempo vivido, en los diferentes tramos de vida, se calculó también por procedimientos diferentes según se contara o no con el valor de la tasa central de mortalidad. En los primeros dos años, cuando esa tasa no era co nocida, el tiempo vivido, $\mathrm{L}_{\mathrm{x}}$ se computó con 1 a ayuda de los factores de sé paración, mencionados anteriormente. En el caso de la edad 0 los valores a parecen en el Cuadro V-7 y se designan $f_{0}$. Para la edad 1 se adoptó el valor 0.41 como se indicó oportunamente. 'Se 10 representa $f_{1}$. Con estos factores el tiempo vivido se calculó según las siguientes relaciones:

$$
\begin{aligned}
& { }_{1} L_{0}=f_{0} \cdot 1_{0}+\left(1-f_{0}\right) \cdot 1_{1} \\
& L_{1} L_{1}=f_{1} \cdot 1_{1}+\left(1-f_{1}\right) \cdot 1_{2}
\end{aligned}
$$

A partir de 1 a edad 2 se contaba con tasas centrales de mortalidad, $\mathrm{n}_{\mathrm{x}}$. En estos casos consecuentemente, el cálculo del tiempo vivido se hizo directamente:

$$
\mathrm{n}_{\mathrm{x}}^{\mathrm{L}}=\mathrm{nd}_{\mathrm{x}} / \mathrm{n}_{\mathrm{x}}
$$

y, en particular: $\cos _{\omega 90}=\mathrm{T}_{90}={ }_{\infty} \mathrm{d}_{90} / \mathrm{m}_{90}=1_{90} / \mathrm{m}_{90}$ (o expresiones similares en los casos en que el grupo abierto final se inicia a los 80 o 85 años).

46. El cálculo del tiempo vivido por la generación de la tabla de vida a partir de la edad $x$ se hizo:

$$
\mathrm{T}_{\mathrm{x}}={ }_{\mathrm{n}} \mathrm{L}_{\mathrm{x}}+{ }_{\mathrm{n}^{\mathrm{L}} \mathrm{x}+\mathrm{n}}+\cdots
$$

$y$ el de la esperanza de vida a la edad $x$ :

$$
\stackrel{\circ}{e}_{x}=T_{x} / 1_{x}
$$


47. Se completó la tabla de vida con el cómputo de las tasas centrales de mortalidad correspondientes a los dos primeros años:

$$
\begin{aligned}
& 1_{0}^{m_{0}}=1_{0}^{d_{0} / L_{0}} \\
& 1_{1}^{m_{1}}=1_{1}^{d_{1}} / 1_{1}^{L_{1}}
\end{aligned}
$$

48. Todos los cálculos, a partir de la información básica detallada en el punto 42, fueron realizados por un computador. Los resultados son presentados en el Capítulo VI.

Comparación de las tablas de mortalidad elaboradas con otras ya existentes

49. Parece interesante cerrar este capítulo dedicado a las tablas de vida elaboradas para épocas censales a partir de 1914, con una comparación entre los resultados alcanzados y los derivados de otras tablas de vida ya existentes, construidas por diferentes autores y representativas de la mortali dad del país en conjunto. En el Cuadro V-8 se presentan los índices seleć cionados, derivados de diferentes tablas, que permiten el cotejo mencionado.

50. Antes de comentar esos valores es oportuno señalar las principales ra zones, que se pueden adelantar, por las que los valores de los dos juegos de tablas que se comparan, las existentes y las que se elaboran en este tra bajo, pueden diferir entre sí.

51. En primer lugar la cobertura geográfica no es la misma. Para nosotros ARGENTINA significa, como se explicó oportunamente, la unión de las cuatro regiones que definimos por suma de provincias. Ese sector, como lo muestra el Cuadro III-1, representa entre el 80 y el 85 por ciento de la población del país en los años censales, con poca variación. La población no considerada vive en provincias menos desarrolladas que la media del país, con re gistros de muertes presumiblemente deficientes (razón por la cual fueron e $\bar{x}$ cluidas de nuestra elaboración), y con un nivel de mortalidad que seguramente es mayor a la media de la Argentina.

52. Las tablas de 1914, elaboradas por Kern (véase Referencias, 18) que se utilizan como término de comparación con las del período 1913-1915, conside raron solamente las muertes producidas en 1914, no un promedio anual del trienio 1913-1915 como las nuestras. Además hay entre esas tablas y las elaboradas en este trabajo diferencias en cuanto a los procedimientos de cons trucción, especialmente enlo que atañe a los primeros años de vida: las tablas de Kern se apoyan en los resultados del censo, las nuestras en los registros corregidos de nacimientos y de muertes.

53. Las tablas de Camisa 1946-1948 (véase Referencias, 19) y de Ortega 19591961 (véase Referencias, 20) puede decirse que también cubren a la población total del país, pues sólo excluyeron a la de las provincias de Catamarca, For mosa y La Rioja, cuyo peso relativo en el total es muy pequeño. En estos 
casos los procedimientos de construcción empleados coinciden prácticamente con los de este trabajo y, como aquí, se tomó también un promedio de tres años de muertes en torno al año de los censos de 1947 y 1960 . Por estas razones cabe esperar una mayor semejanza entre estas tablas y las elaboradas en este trabajo que entre las de Kern de 1914 y las nuestras de 19131915 .

54. E1 examen de los índices del Cuadro V-8 permite concluir que en gene ral los valores de las tablas existentes y las nuevas son muy próximos en tre sí, como podrá juzgarlo el lector. Las diferencias más notables, como se anticipó en los puntos antericres, se producen en los tramos inicia les de vida entre las tablas de Kern de 1914, tanto la de hombres como Ia de mujeres, y las del período 1913-1915 elaboradas en este documento. Creemos que en buena parte esa diferencia (las tablas de Kern muestran una mortalidad mayor en los primeros años de vida) proviene de haberse utiliza do la población censada con edades 0 y 1 en 1914 -que, a nuestro juicio, estuvo afectada por fuerte omisión- en lugar de los nacimientos y muertes de la época como se hizo en este trabajo. Un defecto en el número de per sonas tiende a exagerar las tasas de mortalidad. Para edades superiores a los 35 años las diferencias entre las tablas de Kern de 1914 y las nues tras son pequeñas y pueden explicarse por la diferente cobertura geográfi ca y los diferentes métodos empleados en la elaboración. En menor medida por haber tomado las muertes de un solo año (las tablas de Kern) o un pro medio de tres (las nuestras).

55. La comparación entre los valores de las tablas elaboradas por Camisa para 1946-1948 y Ortega 1959-1961 y las que se construyen en este trabajo muestra que las diferencias son pequeñas aunque sistemáticamente -salvo alguna excepción- los indices de este trabajo señalan un nivel de mortali dad ligeramente inferior al de las tablas existentes. Opinamos que esto puede deberse a la diferente cobertura geográfica de las tablas. Las pro vincias excluidas por nosotros, aunque con registros de muertes defectuosas, suelen mostrar niveles de tasas de mortalidad superiores a la media. Es pues razonable encontrar resultados como los que aparecen en el Cuadro $\mathrm{V}-8$.

56. Los comentarios anteriores pueden servir para poner en evidencia la ventaja de haber construido las tablas de este estudio, a partir de tablas regionales, ya que se obtienen índices nacionales (unión de las cuatro regiones) coherentes con los regionales. No podría hacerse otro tanto a par tir de las tablas nacionales existentes sin tener que afrontar muy serios obstáculos que se presentarían cuando se analizaran sus componentes geográ ficos a nivel de provincias o regiones. Aunque de menor importancia es también conveniente disponer de tablas estrictamente comparables en el tiempo -por haberse utilizado en su elaboración la misma base geográfica y análogos métodos de construcción. Estas ventajas permitirán los estudios de diferencias en la mortalidad en el tiempo y entre regiones que forman parte del Capítulo VII. 
Cuadro V-1

Datos básicos y muertes anuales estimadas por generación utilizados en la construcción del tramo inicial de la tabla de vida de la región BUENOS AIRES, varones, período 1913-1915

\begin{tabular}{|c|c|c|c|c|c|c|}
\hline Información & Símbolo & & & $\overline{\text { Año }(z)}$ & & \\
\hline & & 1911 & 1912 & 1913 & 1914 & 1915 \\
\hline $\begin{array}{l}\text { Nacimientos anuales corregi- } \\
\text { dos por omisión }\end{array}$ & $z_{E_{0}}$ & 60.863 & 65.076 & 66.225 & 66.553 & 63.081 \\
\hline Muertes registradas según eda & & & & & & \\
\hline edad 0 & $z_{D(0)}$ & 6.985 & 6.964 & 6.499 & 6.265 & 6.149 \\
\hline edad 1 & $z_{D}(1)$ & 1.689 & 1.783 & 1.711 & 1.466 & 1.877 \\
\hline Muertes por edad y generación & & & & & & \\
\hline $\begin{array}{c}\text { edad } 0-\text { nacidos en el mismo } \\
\text { año } \underline{z}\end{array}$ & ${ }^{z} \mathrm{D}(0)$ & 4.533 & 4.506 & 4.286 & 4.102 & 3.915 \\
\hline $\begin{aligned} \text { edad } 0 \text { - } & \text { nacidos en el año an } \\
& \text { terior } \underline{z-1}\end{aligned}$ & $z_{\delta} D(0)$ & 2.452 & 2.458 & 2.213 & 2.163 & 2.234 \\
\hline $\begin{array}{c}\text { edad } 1 \text { - cumplieron } 1 \text { año en } \\
\text { el año } \underline{z}\end{array}$ & $\alpha^{z} D(1)$ & 997 & 1.052 & 1.010 & 865 & 1.107 \\
\hline $\begin{array}{c}\text { edad } 1 \text { - cumplieron un año en } \\
\text { e1 año } \underline{z-1}\end{array}$ & $\delta^{\mathrm{D}} \mathrm{D}(1)$ & 692 & 731 & 701 & 601 & 770 \\
\hline
\end{tabular}


Cuadro V-2

Cálculo de las probabilidades de supervivencia y muerte de las edades 0 y 1 . Región BUENOS AIRES, Varones, 1913-1915

\begin{tabular}{|c|c|c|}
\hline \multirow[t]{2}{*}{ Función } & \multicolumn{2}{|c|}{ Edad (x) } \\
\hline & $x=0$ & $x=1$ \\
\hline $\mathrm{E}_{\mathrm{X}}$ & 195.859 & 178.350 \\
\hline$E_{x+1}$ & 178.350 & 167.006 \\
\hline $\mathrm{N}^{\prime} \mathrm{x}$ & 183.556 & 175.368 \\
\hline$N^{\prime \prime} x$ & 184.960 & 169.078 \\
\hline$\alpha^{\mathrm{px}}$ & 0.93718 & 0.98328 \\
\hline${ }_{\delta}^{\mathrm{px}}$ & 0.96426 & 0.98775 \\
\hline $\mathrm{p}_{\mathrm{x}}$ & 0.90369 & 0.97123 \\
\hline$q_{x}$ & 0.09631 & 0.02877 \\
\hline
\end{tabular}


Cuadro $V-3$

Tasas anuales de mortalidad observadas y ajustadas por grupos quinquenales de edad según sexo, origen y región. Epoca: 1913-1915

\begin{tabular}{|c|c|c|c|c|c|c|c|c|}
\hline \multirow{3}{*}{$\begin{array}{l}\text { Grupo } \\
\text { de } \\
\text { edad }\end{array}$} & \multicolumn{4}{|c|}{ Origen: Argentina } & \multicolumn{4}{|c|}{ Origen: Exterior } \\
\hline & \multicolumn{2}{|c|}{ Varones } & \multicolumn{2}{|c|}{ Mujeres } & \multicolumn{2}{|c|}{ Varones } & \multicolumn{2}{|c|}{ Mujeres } \\
\hline & $\begin{array}{c}\text { Obser- } \\
\text { vada } \\
\end{array}$ & $\begin{array}{l}\text { Ajus } \\
\text { tada }\end{array}$ & $\begin{array}{c}\text { Obser- } \\
\text { vada } \\
\end{array}$ & $\begin{array}{l}\text { Ajus } \\
\text { tada }\end{array}$ & $\begin{array}{l}\text { Obser- } \\
\text { vada } \\
\end{array}$ & Ajus & $\begin{array}{l}\text { Obser- } \\
\text { vada }\end{array}$ & $\begin{array}{l}\text { Ajus } \\
\text { tada } \\
\end{array}$ \\
\hline & \multicolumn{8}{|c|}{$\begin{array}{l}\text { Región: BUENOS AIRES } \\
\text { (por mil) }\end{array}$} \\
\hline $20-24$ & 8.28 & 8.28 & 8.52 & 8.52 & 5.06 & 5.06 & 4.85 & 4.85 \\
\hline $25-29$ & 8.17 & 8.50 & 8.70 & 8.70 & 5.28 & 5.28 & 4.94 & 5.10 \\
\hline $30-34$ & 9.99 & 10.40 & 9.42 & 9.42 & 6.08 & 6.20 & 6.25 & 5.75 \\
\hline $35-39$ & 12.96 & 12.90 & 10.92 & 10.92 & 8.20 & 8.10 & 6.87 & 6.70 \\
\hline $40-44$ & 15.86 & 16.50 & 13.36 & 12.80 & 10.62 & 10.70 & 7.55 & 8.20 \\
\hline $45-49$ & 22.53 & 21.00 & 14.40 & 15.00 & 15.74 & 14.50 & 10.12 & 10.00 \\
\hline $50-54$ & 27.42 & 27.40 & 19.25 & 19.50 & 19.54 & 20.40 & 12.18 & 12.45 \\
\hline $55-59$ & 38.39 & 36.00 & 25.93 & 25.93 & 28.23 & 28.60 & 17.56 & 17.05 \\
\hline $60-64$ & 48.62 & 48.20 & 35.42 & 35.42 & 41.44 & 40.20 & 26.02 & 25.75 \\
\hline $65-69$ & 65.29 & 65.00 & 49.83 & 48.80 & 55.40 & 57.10 & 36.79 & 38.90 \\
\hline $70-74$ & 88.31 & 89.80 & 65.56 & 68.30 & 80.61 & 81.80 & 59.51 & 59.15 \\
\hline $75-79$ & 131.89 & 126.00 & 100.91 & 95.60 & 121.02 & 119.40 & 91.89 & 90.50 \\
\hline $80-84$ & 168.75 & 176.75 & 125.00 & 133.80 & 170.58 & 174.30 & 138.48 & .138 .50 \\
\hline $85-89$ & 259.40 & 248.00 & 195.48 & 187.50 & 261.72 & 255.00 & 216.22 & 211.90 \\
\hline
\end{tabular}

Región: CENTRO LITORAL (por mil)

$\begin{array}{rrrrrrrrr}20-24 & 8.83 & 8.83 & 9.40 & 9.40 & 4.45 & 4.33 & 4.90 & 4.90 \\ 25-29 & 9.55 & 9.55 & 10.06 & 10.45 & 4.46 & 4.70 & 4.75 & 4.95 \\ 30-34 & 10.80 & 11.20 & 12.41 & 12.05 & 5.49 & 5.40 & 5.82 & 5.50 \\ 35-39 & 14.89 & 14.25 & 13.45 & 13.80 & 6.67 & 6.75 & 7.32 & 6.35 \\ 40-44 & 19.39 & 19.30 & 16.62 & 15.75 & 9.46 & 9.10 & 7.22 & 7.60 \\ 45-49 & 24.36 & 24.50 & 18.43 & 17.90 & 12.04 & 12.35 & 9.36 & 9.50 \\ 50-54 & 29.06 & 29.20 & 19.65 & 21.25 & 17.30 & 17.15 & 10.79 & 11.80 \\ 55-59 & 37.37 & 37.35 & 26.27 & 27.30 & 23.48 & 24.00 & 15.66 & 15.50 \\ 60-64 & 48.33 & 48.05 & 36.51 & 36.25 & 36.60 & 34.00 & 24.90 & 22.90 \\ 65-69 & 64.75 & 61.95 & 51.35 & 48.25 & 48.91 & 49.00 & 34.93 & 34.60 \\ 70-74 & 74.68 & 80.15 & 63.21 & 64.40 & 69.63 & 72.00 & 50.15 & 54.00 \\ 75-79 & 111.85 & 103.80 & 97.64 & 86.30 & 104.33 & 106.60 & 77.45 & 84.50 \\ 80-84 & 119.39 & 134.45 & 106.16 & 116.05 & 152.33 & 158.80 & 135.89 & 133.00 \\ 85-89 & 185.29 & 175.00 & 165.64 & 157.00 & 234.66 & 238.00 & 213.39 & 210.00 \\ & & & & & & & & \end{array}$


Cuadro V-3 (Continuación)

Tasas anuales de mortalidad observadas y ajustadas por grupos quinquenales de edad según sexo, origen y región. Epoca: 1913-1915

\begin{tabular}{|c|c|c|c|c|c|c|c|c|}
\hline \multirow{3}{*}{$\begin{array}{l}\text { Grupo } \\
\text { de } \\
\text { edad }\end{array}$} & \multicolumn{4}{|c|}{ Origen: Argentina } & \multicolumn{4}{|c|}{ Origen: Exterior } \\
\hline & \multicolumn{2}{|c|}{ Varones } & \multicolumn{2}{|c|}{ Mujeres } & \multicolumn{2}{|c|}{ Varones } & \multicolumn{2}{|c|}{ Mujeres } \\
\hline & $\begin{array}{l}\text { Obser- } \\
\text { vada }\end{array}$ & Ajus & $\begin{array}{l}\text { Obser- } \\
\text { vada }\end{array}$ & Ajus & $\begin{array}{l}\text { Obser- } \\
\text { vada }\end{array}$ & Ajus & $\begin{array}{l}\text { Obser- } \\
\text { vada }\end{array}$ & Ajus \\
\hline & \multicolumn{8}{|c|}{$\begin{array}{l}\text { Región: CUYO } \\
\text { (por mil) }\end{array}$} \\
\hline $20-24$ & 11.50 & 11.50 & 10.08 & 10.10 & 5.78 & 5.78 & 6.06 & 6.06 \\
\hline $25-29$ & 11.60 & 12.00 & 11.40 & 11.75 & 6.17 & 6.17 & 6.50 & 6.50 \\
\hline $30-34$ & 12.68 & 13.65 & 13.98 & 14.00 & 6.52 & 6.90 & 7.69 & 7.20 \\
\hline $35-39$ & 17.62 & 17.10 & 16.60 & 16.25 & 8.82 & 8.95 & 6.50 & 8.00 \\
\hline $40-44$ & 24.49 & 23.25 & 18.10 & 18.90 & 12.37 & 11.80 & 9.71 & 9.25 \\
\hline $45-49$ & 29.01 & 29.50 & 21.18 & 21.25 & 16.07 & 15.65 & 10.10 & 11.05 \\
\hline $50-54$ & 36.77 & 36.70 & 25.69 & 26.80 & 18.93 & 21.10 & 14.39 & 14.50 \\
\hline $55-59$ & 44.47 & 45.00 & 38.79 & 36.25 & 31.60 & 28.95 & 19.78 & 20.30 \\
\hline $60-64$ & 53.23 & 56.00 & 51.16 & 49.00 & 38.62 & 40.10 & 31.66 & 29.55 \\
\hline $65-69$ & 71.94 & 70.00 & 71.49 & 66.40 & 52.71 & 55.85 & 46.15 & 43.15 \\
\hline $70-74$ & 87.95 & 89.10 & 87.66 & 90.15 & 84.09 & 78.20 & 71.65 & 65.00 \\
\hline $75-79$ & 131.99 & 115.50 & 133.82 & 122.50 & 125.71 & 109.65 & 114.29 & 97.50 \\
\hline $80-84$ & 141.79 & 152.35 & 144.97 & 166.75 & 140.19 & 154.10 & 116.88 & 150.30 \\
\hline \multirow[t]{2}{*}{$85-89$} & 218.18 & 201.00 & 228.07 & 227.00 & 233.33 & 216.70 & 184.21 & 233.60 \\
\hline & \multicolumn{8}{|c|}{$\begin{array}{l}\text { Región: NOROESTE } \\
\text { (por mil) }\end{array}$} \\
\hline $20-24$ & 13.52 & 12.60 & 12.95 & 12.95 & 7.55 & 7.00 & 8.81 & 7.70 \\
\hline $25-29$ & 11.95 & 13.00 & 14.69 & 14.69 & 7.31 & 7.35 & 7.29 & 7.90 \\
\hline $30-34$ & 15.33 & 14.50 & 16.61 & 16.61 & 7.21 & 8.40 & 9.19 & 8.50 \\
\hline $35-39$ & 16.91 & 16.85 & 18.92 & 17.75 & 10.17 & 10.20 & 9.99 & 9.35 \\
\hline $40-44$ & 21.53 & 21.35 & 19.11 & 19.15 & 13.86 & 13.00 & 9.05 & 10.50 \\
\hline $45-49$ & 26.37 & 27.20 & 22.47 & 21.75 & 16.88 & 17.15 & 13.45 & 12.20 \\
\hline $50-54$ & 34.43 & 33.75 & 23.48 & 25.90 & 20.42 & 22.75 & 9.52 & 14.80 \\
\hline $55-59$ & 40.67 & 39.30 & 33.91 & 31.45 & 29.95 & 30.25 & 15.22 & 18.50 \\
\hline $60-64$ & 40.65 & 45.85 & 38.27 & 39.05 & 43.74 & 40.35 & 26.97 & 24.10 \\
\hline $65-69$ & 54.27 & 53.45 & 54.15 & 49.60 & 55.25 & 54.10 & 43.48 & 33.50 \\
\hline $70-74$ & 61.81 & 64.90 & 60.04 & 64.50 & 79.05 & 72.75 & 42.68 & 47.60 \\
\hline $75-79$ & 92.22 & 80.85 & 91.80 & 84.80 & 110.17 & 98.25 & 75.95 & 68.00 \\
\hline $80-84$ & 91.04 & 103.35 & 94.51. & 112.80 & 114.94 & 133.10 & 107.69 & 97.90 \\
\hline $85-89$ & 142.28 & 131.00 & 148.26 & 150.00 & 181.82 & 180.35 & 142.86 & 141.00 \\
\hline
\end{tabular}


Cuadro V-4

Tasas anuales de mortalidad observadas y ajustadas por grupos quinquenales de edad según sexo y región. Epoca: 1946-1948

\begin{tabular}{|c|c|c|c|c|c|c|c|c|}
\hline \multirow{2}{*}{$\begin{array}{l}\text { Grupo } \\
\text { de } \\
\text { edad }\end{array}$} & \multicolumn{2}{|c|}{ Varones } & \multicolumn{2}{|c|}{ Mujeres } & \multicolumn{2}{|c|}{ Varones } & \multicolumn{2}{|c|}{ Mujeres } \\
\hline & $\begin{array}{c}\text { Obser- } \\
\text { vada }\end{array}$ & $\begin{array}{l}\text { Ajus } \\
\text { tada }\end{array}$ & $\begin{array}{c}\text { Obser- } \\
\text { vada }\end{array}$ & $\begin{array}{l}\text { Ajus } \\
\text { tada }\end{array}$ & $\begin{array}{c}\text { Obser- } \\
\text { vada }\end{array}$ & $\begin{array}{l}\text { Ajus } \\
\text { tada }\end{array}$ & $\begin{array}{c}\text { Obser- } \\
\text { vada }\end{array}$ & $\begin{array}{l}\text { Ajus } \\
\text { tada }\end{array}$ \\
\hline
\end{tabular}

Región: BUENOS AIRES

Región: CENTRO LITORAL

$\begin{array}{rrrrrrrrr}20-24 & 2.67 & 2.57 & 2.29 & 2.29 & 2.91 & 2.91 & 2.92 & 2.92 \\ 25-29 & 2.59 & 2.70 & 2.29 & 2.29 & 3.20 & 3.20 & 3.14 & 3.14 \\ 30-34 & 2.97 & 2.97 & 2.43 & 2.43 & 3.75 & 3.75 & 3.18 & 3.27 \\ 35-39 & 4.33 & 4.33 & 3.06 & 3.06 & 4.83 & 4.83 & 4.15 & 4.11 \\ 40-44 & 6.69 & 6.69 & 4.17 & 4.17 & 6.82 & 6.82 & 5.15 & 5.25 \\ 45-49 & 10.95 & 10.95 & 5.97 & 5.97 & 10.61 & 10.31 & 7.04 & 7.13 \\ 50-54 & 16.73 & 16.73 & 9.14 & 9.14 & 15.61 & 15.47 & 10.42 & 9.86 \\ 55-59 & 24.44 & 24.28 & 13.37 & 13.37 & 21.47 & 23.00 & 13.87 & 14.86 \\ 60-64 & 35.26 & 34.97 & 20.34 & 20.34 & 34.73 & 33.71 & 23.73 & 23.51 \\ 65-69 & 49.22 & 50.35 & 32.14 & 32.14 & 47.17 & 48.58 & 33.78 & 35.06 \\ 70-74 & 70.98 & 72.50 & 49.72 & 49.72 & 71.52 & 70.39 & 55.25 & 52.28 \\ 75-79 & 107.07 & 104.41 & 80.65 & 78.99 & 104.67 & 101.12 & 78.74 & 77.96 \\ 80-84 & 147.19 & 150.35 & 121.60 & 125.60 & 144.52 & 144.52 & 125.18 & 116.25 \\ 85-89 & 233.58 & 216.06 & 201.71 & 199.70 & 205.08 & 205.59 & 157.91 & 173.64\end{array}$

Región: CUYO

\begin{tabular}{rrrrrrrrr}
$20-24$ & 2.93 & 2.75 & 3.02 & 3.02 & 5.66 & 5.66 & 6.44 & 6.44 \\
$25-29$ & 3.06 & 3.20 & 3.39 & 3.28 & 6.45 & 6.19 & 7.54 & 7.26 \\
$30-34$ & 4.19 & 3.95 & 3.23 & 3.63 & 5.72 & 6.74 & 7.24 & 7.76 \\
$35-39$ & 4.61 & 4.95 & 4.96 & 4.62 & 8.74 & 8.05 & 9.22 & 8.67 \\
$40-44$ & 7.51 & 7.50 & 6.23 & 6.46 & 9.71 & 10.47 & 9.57 & 9.98 \\
$45-49$ & 12.11 & 11.54 & 9.24 & 8.95 & 15.29 & 13.88 & 12.06 & 11.99 \\
$50-54$ & 19.27 & 17.22 & 12.91 & 12.82 & 19.78 & 19.11 & 14.34 & 14.92 \\
$55-59$ & 22.85 & 25.44 & 15.99 & 17.89 & 24.81 & 26.67 & 17.75 & 20.06 \\
$60-64$ & 37.27 & 36.49 & 29.42 & 26.04 & 39.08 & 38.23 & 32.90 & 28.22 \\
$65-69$ & 50.13 & 51.85 & 38.06 & 37.77 & 53.93 & 55.33 & 39.87 & 39.81 \\
$70-74$ & 66.22 & 73.38 & 53.99 & 54.77 & 86.09 & 80.48 & 59.50 & 58.46 \\
$75-79$ & 113.45 & 103.75 & 76.65 & 79.77 & 114.48 & 118.21 & 80.53 & 83.66 \\
$80-84$ & & & & & 168.67 & 167.00 & 128.28 & 120.95 \\
$85-89$ & & & & & 214.83 & 236.41 & 159.46 & 174.87 \\
\hline
\end{tabular}


Cuadro V-5

Tasas anuales de mortalidad observadas y ajustadas por grupos quinquenales de edad según sexo y región. Epoca: 1959-1961

\begin{tabular}{|c|c|c|c|c|c|c|c|c|}
\hline \multirow{2}{*}{$\begin{array}{l}\text { Grupo } \\
\text { de } \\
\text { Edad }\end{array}$} & \multicolumn{2}{|c|}{ Varones } & \multicolumn{2}{|c|}{ Mujeres } & \multicolumn{2}{|c|}{ Varones } & \multicolumn{2}{|c|}{ Mujeres } \\
\hline & $\begin{array}{c}\text { Obser- } \\
\text { vada }\end{array}$ & $\begin{array}{l}\text { Ajus } \\
\text { tada }\end{array}$ & $\begin{array}{c}\text { Obser- } \\
\text { vada }\end{array}$ & $\begin{array}{l}\text { Ajus } \\
\text { tada }\end{array}$ & $\begin{array}{c}\text { Obser- } \\
\text { vada }\end{array}$ & $\begin{array}{l}\text { Ajus } \\
\text { tada. }\end{array}$ & $\begin{array}{c}\text { Obser- } \\
\text { vada }\end{array}$ & Ajus \\
\hline
\end{tabular}

Región: BUENOS AIRES

Regiōn: CENTRO LITORAL

$\begin{array}{rrrrrrrrr}20-24 & 1.65 & 1.65 & 1.03 & 1.03 & 1.67 & 1.67 & 1.09 & 1.09 \\ 25-29 & 1.88 & 1.88 & 1.21 & 1.21 & 2.07 & 1.98 & 1.43 & 1.43 \\ 30-34 & 2.28 & 2.28 & 1.44 & 1.44 & 2.34 & 2.43 & 1.81 & 1.81 \\ 35-39 & 3.07 & 3.07 & 1.74 & 1.74 & 3.23 & 3.23 & 2.13 & 2.19 \\ 40-44 & 4.69 & 4.69 & 2.48 & 2.48 & 4.90 & 4.90 & 3.06 & 3.13 \\ 45-49 & 7.87 & 7.87 & 3.91 & 3.91 & 8.01 & 8.01 & 4.86 & 4.52 \\ 50-54 & 12.64 & 12.64 & 5.70 & 5.70 & 12.48 & 12.48 & 6.92 & 6.87 \\ 55-59 & 19.11 & 19.11 & 8.83 & 8.83 & 18.78 & 18.78 & 10.66 & 10.59 \\ 60-64 & 28.98 & 27.99 & 13.92 & 13.92 & 28.88 & 27.69 & 16.04 & 16.39 \\ 65-69 & 40.48 & 41.05 & 22.73 & 22.85 & 41.30 & 41.29 & 25.65 & 25.48 \\ 70-74 & 56.74 & 59.89 & 37.13 & 37.71 & 57.56 & 60.40 & 40.62 & 40.35 \\ 75-79 & 86.08 & 86.93 & 63.05 & 62.21 & 86.29 & 87.58 & 62.83 & 64.57 \\ 80-84 & 134.53 & 123.69 & 103.56 & 102.67 & 132.06 & 126.99 & 103.95 & 103.31\end{array}$

Región: CUYO

Región: NOROESTE

$\begin{array}{rrrrrrrrr}20-24 & 1.71 & 1.71 & 1.47 & 1.47 & 2.84 & 2.84 & 2.90 & 2.90 \\ 25-29 & 2.13 & 2.13 & 1.72 & 1.72 & 3.68 & 3.68 & 3.54 & 3.54 \\ 30-34 & 2.69 & 2.62 & 1.81 & 1.81 & 3.95 & 3.95 & 4.13 & 4.13 \\ 35-39 & 3.27 & 3.51 & 2.36 & 2.36 & 5.03 & 5.03 & 5.04 & 4.89 \\ 40-44 & 5.37 & 5.23 & 3.38 & 3.38 & 6.58 & 6.76 & 5.88 & 6.04 \\ 45-49 & 8.66 & 8.75 & 5.11 & 5.11 & 9.81 & 9.44 & 7.76 & 7.75 \\ 50-54 & 13.32 & 13.58 & 8.06 & 8.06 & 13.84 & 13.92 & 10.51 & 10.50 \\ 55-59 & 21.28 & 20.92 & 12.35 & 12.35 & 21.74 & 21.47 & 14.97 & 14.95 \\ 60-64 & 30.65 & 31.18 & 19.22 & 19.14 & 33.43 & 32.31 & 22.56 & 21.98 \\ 65-69 & 44.12 & 45.27 & 30.70 & 30.32 & 48.05 & 48.31 & 34.11 & 32.95 \\ 70-74 & 64.85 & 65.39 & 47.86 & 48.02 & 65.48 & 70.08 & 49.93 & 49.88 \\ 75-79 & 92.82 & 93.55 & 74.00 & 76.07 & 103.16 & 101.60 & 77.81 & 77.73 \\ 80-84 & 151.34 & 130.77 & 123.00 & 120.50 & 150.98 & 148.27 & 110.18 & 121.37\end{array}$


Cuadro V-6

Número de muertes de más de 90 años de edad observado y ajustado en las clases de población estudiadas en 1913-1915 y 1946-1948

\begin{tabular}{|c|c|c|}
\hline Clases (regiōn, sexo, origen) & Observadas & Ajustadas \\
\hline \multicolumn{3}{|l|}{$1913-1915$} \\
\hline $\begin{array}{l}\text { BUENOS AIRES, Varones, ARGENTINA } \\
\text { BUENOS AIRES, Mujeres, ARGENTINA } \\
\text { BUENOS AIRES, Varones, EXTERIOR } \\
\text { BUENOS AIRES, Mujeres, EXTERIOR, } \\
\text { CENTRO LITORAL, Varones, ARGENTINA } \\
\text { CENTRO LITORAL, Mujeres, ARGENTINA } \\
\text { CENTRO LITORAL, Varones, EXTERIOR } \\
\text { CENTRO LITORAL, Mujeres, EXTERIOR } \\
\text { CUYO, Varones, ARGENTINA } \\
\text { CUYO, Mujeres, ARGENTINA } \\
\text { CUYO, Varones, EXTERIOR } \\
\text { CUYO, Mujeres, EXTERIOR } \\
\text { NOROESTE, Varones, ARGENTINA } \\
\text { NOROESTE, Mujeres, ARGENTINA } \\
\text { NOROESTE, Varones, EXTERIOR } \\
\text { NOROESTE, Mujeres, EXTERIOR }\end{array}$ & $\begin{array}{r}52 \\
140 \\
82 \\
96 \\
80 \\
224 \\
28 \\
41 \\
30 \\
53 \\
9 \\
8 \\
53 \\
95 \\
5 \\
5\end{array}$ & $\begin{array}{r}64 \\
130 \\
82 \\
106 \\
85 \\
178 \\
28 \\
46 \\
28 \\
50 \\
9 \\
5 \\
69 \\
114 \\
4 \\
4\end{array}$ \\
\hline Total & 1.001 & 1.002 \\
\hline \multicolumn{3}{|l|}{$1946-1948$} \\
\hline $\begin{array}{l}\text { BUENOS AIRES, Varones } \\
\text { BUENOS AIRES, Mujeres } \\
\text { CENTRO LITORAL, Varones } \\
\text { CENTRO LITORAL, Mujeres } \\
\text { NOROESTE, Varones } \\
\text { NOROESTE, Mujeres }\end{array}$ & $\begin{array}{r}434 \\
877 \\
175 \\
407 \\
48 \\
184\end{array}$ & $\begin{array}{r}463 \\
803 \\
174 \\
455 \\
50 \\
180\end{array}$ \\
\hline Total & 2.125 & 2.125 \\
\hline
\end{tabular}


Cuadro V-7

Factores de separación de las muertes de menores de un añol por sexo y regiones para las diferentes épocas censales

\begin{tabular}{|c|c|c|c|c|c|c|c|c|c|}
\hline Región & $1913-15$ & $\begin{array}{l}\text { Varones } \\
1946-48 \\
\end{array}$ & 1959-61 & 1913-15 & $\begin{array}{l}\text { Mujeres } \\
1946-48 \\
\end{array}$ & 1959-61 & $\begin{array}{r}\text { An } \\
1913-15 \\
\end{array}$ & $\begin{array}{l}\text { bos Sexo } \\
1946-48 \\
\end{array}$ & $\begin{array}{l} \\
1959-6\end{array}$ \\
\hline RA & & & & & & & & 98 & \\
\hline BA & & & & & 0 . & & & 68 & 63 \\
\hline CL & 2 & & & & 0. & & 0.323 & 0.321 & 0.281 \\
\hline$C Y$ & 0.327 & 0.314 & 0.297 & 0.348 & 0.3 & & 0.337 & 0.320 & 0.303 \\
\hline NO & 0.321 & 0.287 & 0.300 & 0.335 & 0.306 & 0.321 & 0.328 & 0.296 & 0.310 \\
\hline
\end{tabular}

a/ Proporción de las muertes totales atribuida a nacimientos ocurridos en el año anterior.

Nota:

Los factores de separación se elaboran con información detallada de 1a edad de las muertes y suponiendo que ocurren uniformemente a lo largo del año. Las fuentes son las indicadas anteriormente para cada época censal. 
Cuadro V-8

Comparación entre índices seleccionados de tablas de mortalidad existentes para la Argentina y los correspondientes a las que se elaboran en este trabajo

\begin{tabular}{|c|c|c|c|c|c|c|}
\hline \multirow[t]{2}{*}{ Tabla de mortalidad } & \multicolumn{6}{|c|}{ Indices seleccionados } \\
\hline & $\stackrel{\mathrm{e}}{\mathrm{o}}_{\mathrm{o}}$ & $q_{0}$ & $4^{q} 1$ & $15^{q_{35}}$ & $15^{q_{50}}$ & $\stackrel{\circ}{e}_{65}$ \\
\hline $\begin{array}{l}\text { Kern } 1914 \text { - varones } \\
\text { RA V 1913-1915 }\end{array}$ & $\begin{array}{l}46.93 \\
47.59\end{array}$ & $\begin{array}{l}0.13615 \\
0.12100\end{array}$ & $\begin{array}{l}0.07106 \\
0.06575\end{array}$ & $\begin{array}{l}0.28466 \\
0.29281\end{array}$ & $\begin{array}{l}0.37039 \\
0.38285\end{array}$ & $\begin{array}{l}11.07 \\
11.03\end{array}$ \\
\hline Kern 1914 - mujeres & 48.86 & 0.12201 & 0.07011 & 0.28200 & 0.28641 & 12.24 \\
\hline RA M 1913-1915 & 49.72 & 0.11100 & 0.06475 & 0.28417 & 0.29206 & 12.77 \\
\hline Camisa 1946-1948 varones & 58.63 & 0.07557 & 0.02234 & 0.16157 & 0.30918 & 11.62 \\
\hline RA V 1946-1948 & 59.09 & 0.07216 & 0.02031 & 0.15869 & 0.31587 & 11.67 \\
\hline Camisa 1946-1948 mujeres & 62.95 & 0.06712 & 0.02264 & 0.13032 & 0.20928 & 13.96 \\
\hline RA M 1946-1948 & 63.59 & 0.06304 & 0.02004 & 0.12455 & 0.20585 & 13.79 \\
\hline Ortega 1959-1961 varones & 63.16 & 0.06146 & 0.01468 & 0.11729 & 0.25208 & 12.66 \\
\hline RA V 1959-1961 & 63.68 & 0.05918 & 0.01258 & 0.11273 & 0.26120 & 12.90 \\
\hline Ortega 1959-1961 mujeres & 68.87 & 0.05356 & 0.01501 & 0.07887 & 0.15180 & 15.80 \\
\hline RA M 1959-1961 & 69.53 & 0.05104 & 0.01275 & 0.07094 & 0.14505 & 15.51 \\
\hline
\end{tabular}

Fuentes:

Referencias (18), (19), (20) -al final de esta publicación-y Capítulo VI. 
ESCALA DE EOAD

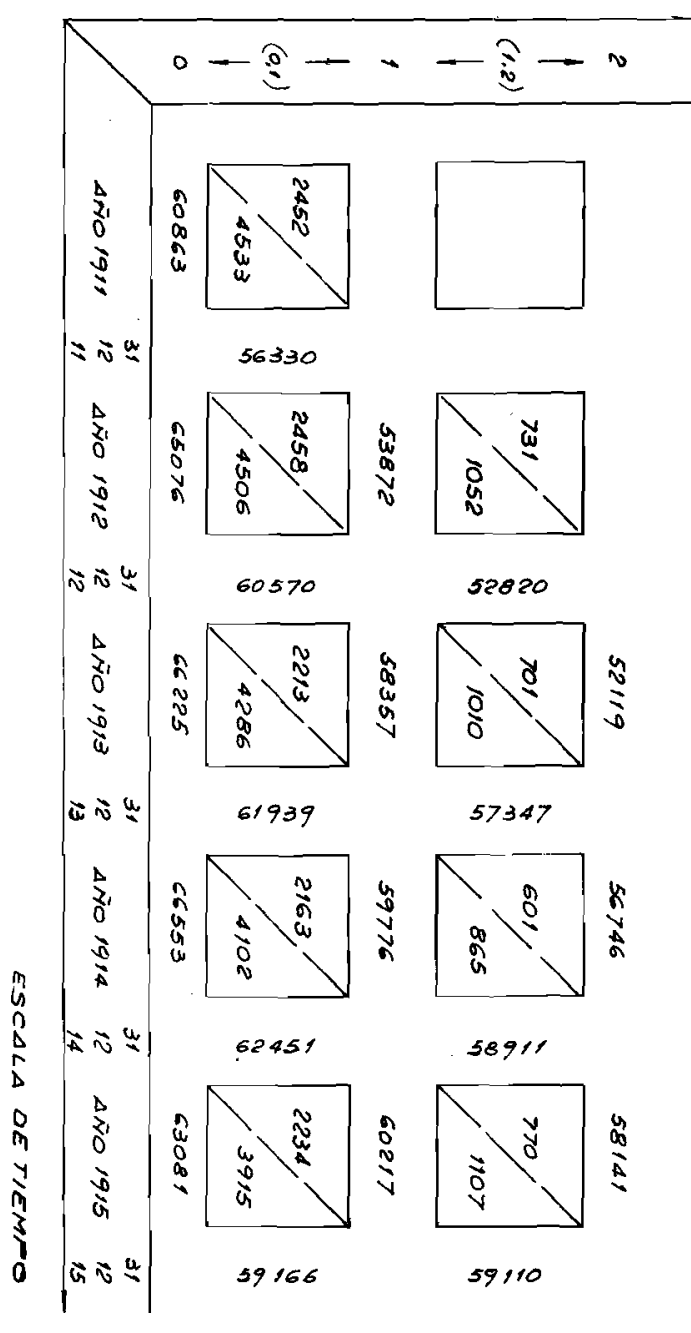




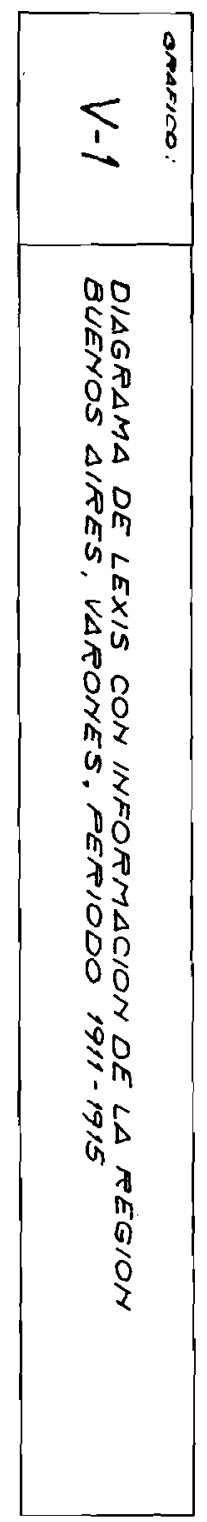




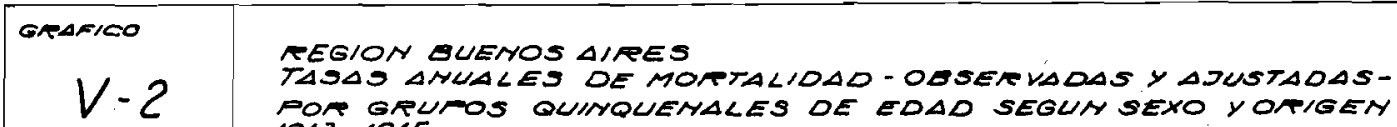
PON GRUROS QUIMQLEMALES DE EDAD SEGUN SEXO YOTIGEN $1913-1915$

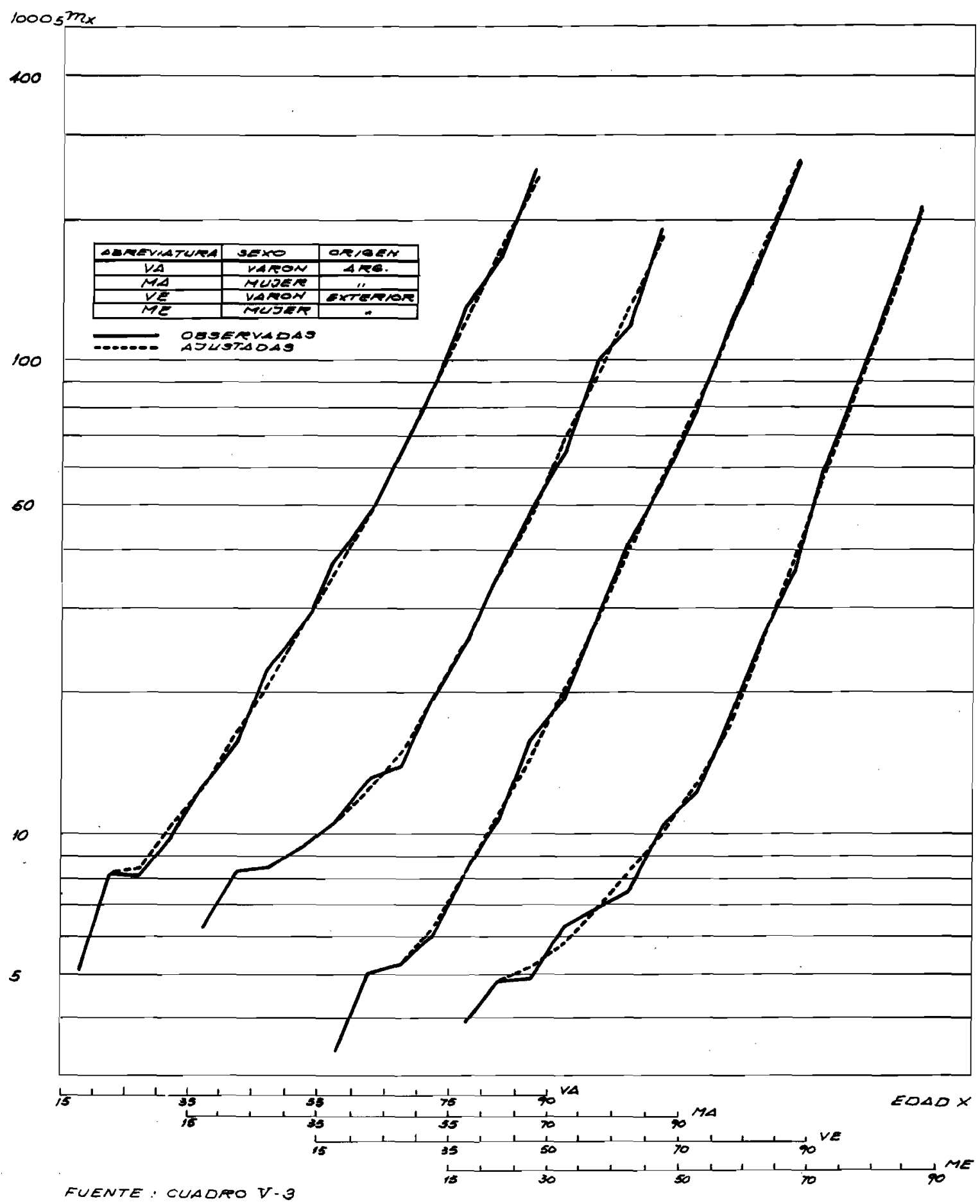




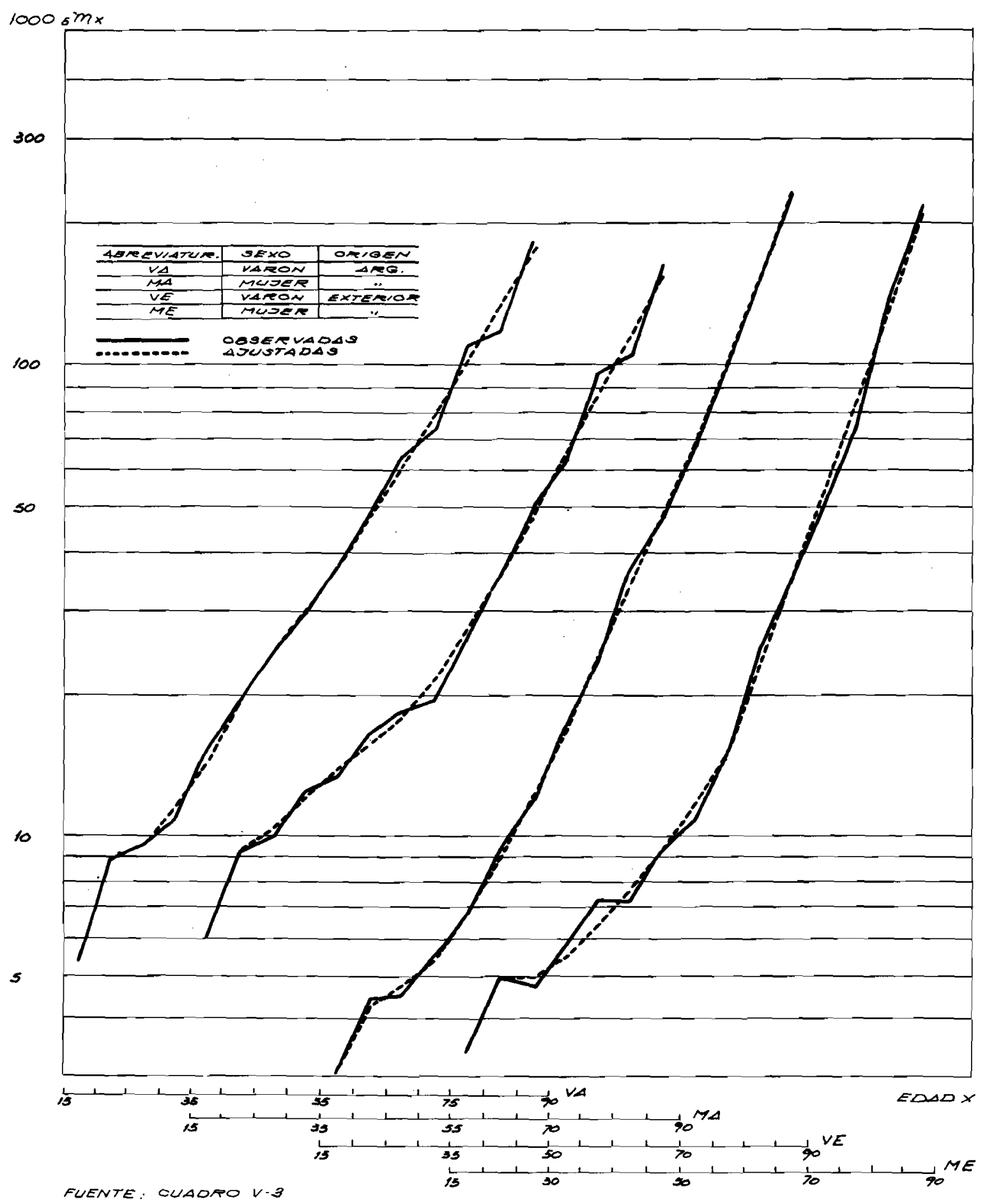




\begin{tabular}{|c|c|}
\hline $1 /-4$ & 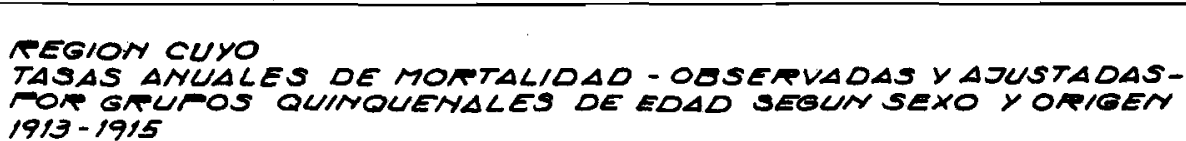 \\
\hline
\end{tabular}

$1000 \mathrm{sm}_{x}$

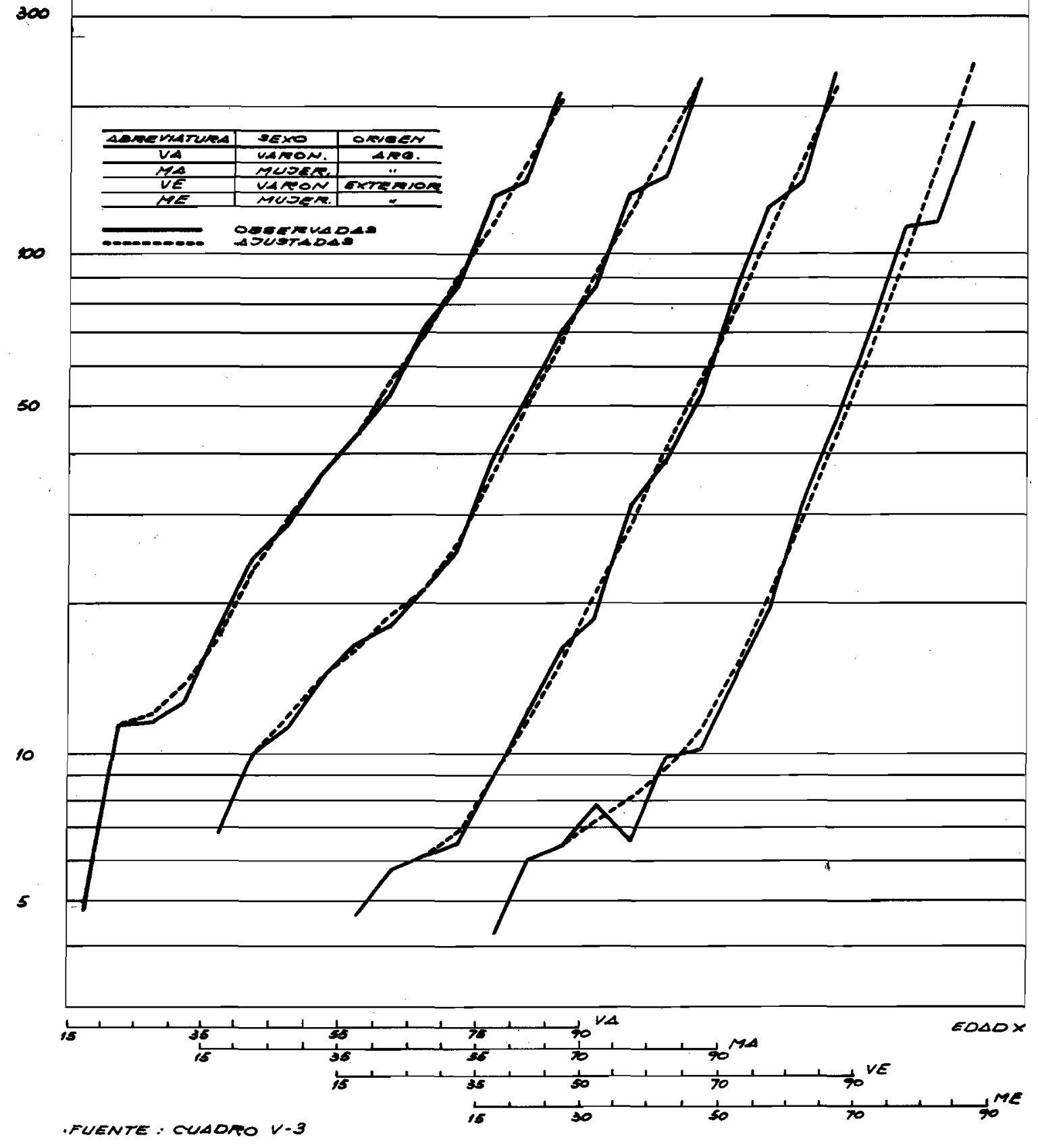




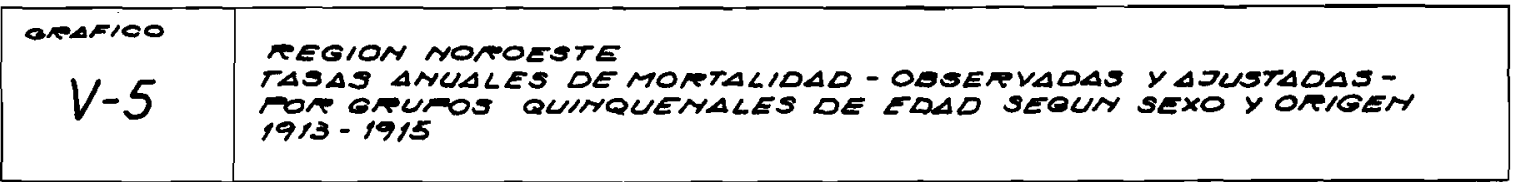

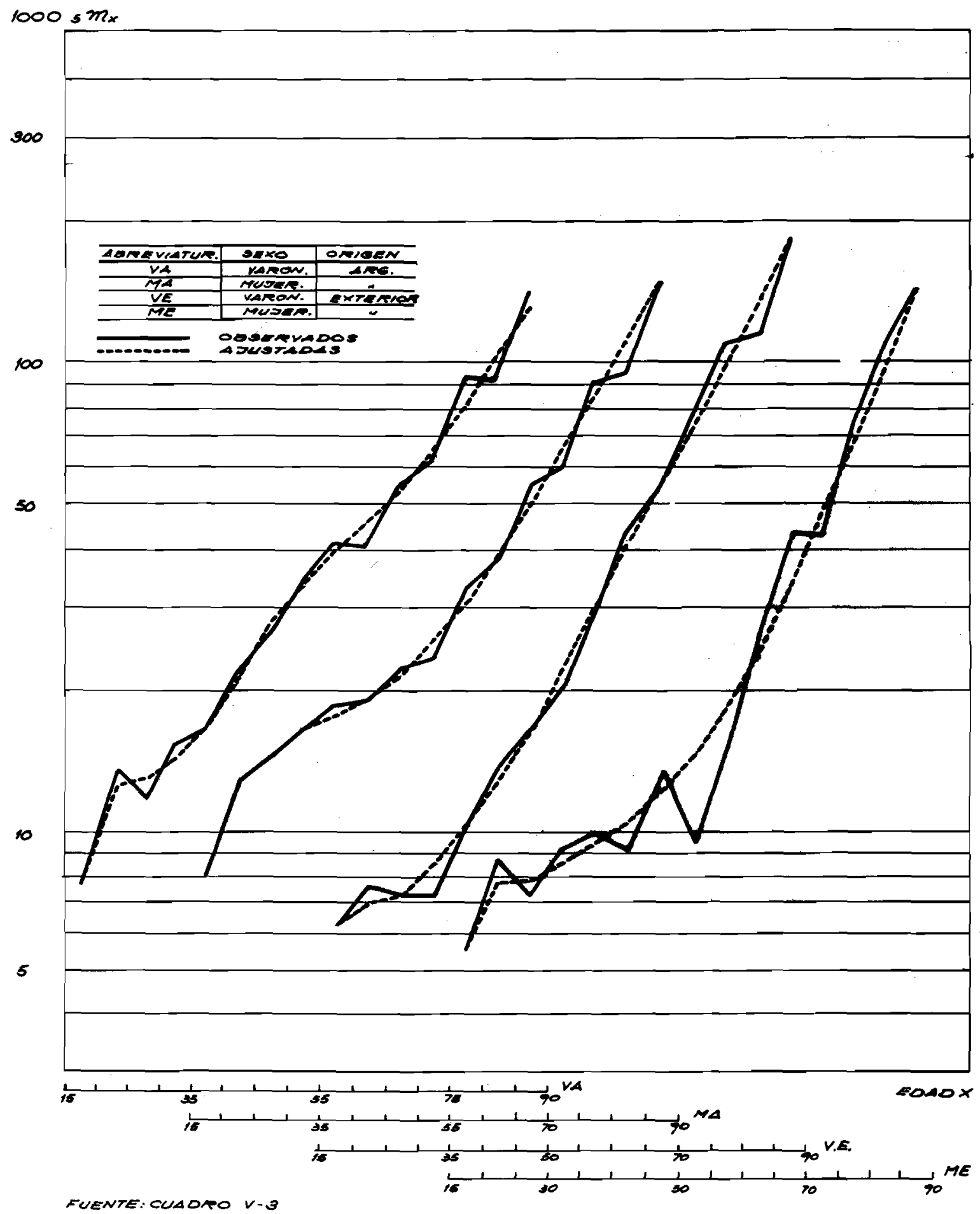



Capitulo VI

LAS TABLAS ABREVIADAS DE MORTALIDAD ELABORADAS EN ESTE TRABAJO

1. Se presentan aquí las tablas de mortalidad que se han construido siguiendo los procedimientos descritos en los capítulos anteriores de esta Parte Segunda.

2. A fin de facilitar la interpretación de las funciones que se tabulan en el Cuadro VI-1 que sigue se compara la representación convencional de las mis mas con la que se ha empleado en este estudio, adaptada a las posibilidades del computador.

Cuadro VI-1

Funciones de las tablas abreviadas de mortalidad que se tabulan. Notación convencional y la adoptada en este trabajo en la presentación de las tablas

Tasa anual (o central) de mortalidad en el tramo de vida $x, x+n$

$$
\mathrm{n}^{\mathrm{m}} \mathrm{x} \quad \mathrm{M}(\mathrm{X}, \mathrm{N})
$$

Probabilidad de morir entre las edades $x$ y $x+n$ de una persona en el momento en que alcanza con vida $1 \mathrm{a}$ edad $\mathrm{x}$

$\begin{array}{ll}n^{q} x & Q(X, N) \\ I_{x} & L(X) \\ n^{d} x & D(X, N)\end{array}$

Número de sobrevivientes a $1 \mathrm{a}$ edad $\mathrm{x}$ de una generación inicial de 100.000 nacidos vivos

Muertes entre las edades $x$ y $x+n$ de la generación de la tabla de vida

Tiempo vivido por la generación en el tramo de vida $x, x+n$

$$
n^{L} x
$$

Tiempo vivido por la generación a partir de la edad $\mathbf{x}$

$\begin{array}{ll}\mathrm{T}_{\mathrm{x}} & \mathrm{T}(\mathrm{X}) \\ \mathrm{o}_{\mathrm{x}} & \mathrm{E}(\mathrm{X})\end{array}$

Esperanza de vida a la edad $\mathrm{x}$

3. En el Cuadro VI-2 se presenta un Indice de las 75 tablas construidas en e1 que aparece la indicación de la región, sexo, origen y época que definen cada tabla de mortalidad, su título abreviado y la página en donde se repro duce. 
Cuadro VI-2

Indice de las tablas abreviadas de mortalidad elaboradas en este trabajo

\begin{tabular}{|c|c|c|c|c|c|c|}
\hline Regiōn & Sexo & Origen & Epoca & & $\begin{array}{c}\text { Título } \\
\text { abreviado }\end{array}$ & Pág. \\
\hline ARGENTINA & Ambos sexos & & $1869-1895$ & $\mathrm{RA}$ & $1869-1895$ & 105 \\
\hline ARGENTINA & Varones & & $1869-1895$ & RA V & $1869-1895$ & 105 \\
\hline ARGENTINA & Mujeres & & $1869-1895$ & RA M & [ $1869-1895$ & 106 \\
\hline ARGENTINA & Varones & Argentina & $1869-1895$ & RA V & 1869-1895 & A 106 \\
\hline ARGENTINA & Mujeres & Argentina & $1869-1895$ & RA M & [ 1869-1895 & A 107 \\
\hline ARGENTINA & Ambos sexos & & $1895-1914$ & $\mathrm{RA}$ & $1895-1914$ & 107 \\
\hline ARGENTINA & Varones & & $1895-1914$ & RA V & 1895-1914 & 108 \\
\hline ARGENTINA & Mujeres & & $1895-1914$ & RA M & 1895-1914 & 108 \\
\hline ARGENTINA & Varones & Argentina & $1895-1914$ & RA V & 1895-1914 & A 109 \\
\hline ARGENTINA & Mujeres & Argentina & $1895-1914$ & RA $\mathrm{M}$ & $1895-1914$ & A 109 \\
\hline ARGENTINA & Ambos sexos & & $1913-1915$ & $\mathrm{RA}$ & $1913-1915$ & 110 \\
\hline ARGENTINA & Varones & & $1913-1915$ & RA V & 1913-1915 & 110 \\
\hline ARGENTINA & Mujeres & & $1913-1915$ & RA M & [ 1913-1915 & 111 \\
\hline ARGENTINA & Varones & Argentina & $1913-1915$ & $\mathrm{RA} \mathrm{V}$ & $1913-1915$ & A 111. \\
\hline ARGENTINA & Mujeres & Argentina & $1913-1915$ & RA M & 1913-1915 & A 112 \\
\hline ARGENTINA & Varones & Exterior & $1913-1915$ & RA V & $1913-1915$ & E 112 \\
\hline ARGENTINA & Mujeres & Exterior & $1913-1915$ & RA M & $1913-1915$ & E 113 \\
\hline ARGENTINA & Ambos sexos & & $1946-1948$ & $\mathrm{RA}$ & $1946-1948$ & 113 \\
\hline ARGENTINA & Varones & & $1946-1948$ & RA V & $1946-1948$ & 114 \\
\hline ARGENTINA & Mujeres & & $1946-1948$ & RA M & 1946-1948 & 114 \\
\hline ARGENTINA & Ambos sexos & & $1959-1961$ & $\mathrm{RA}$ & $1959-1961$ & i15 \\
\hline ARGENTINA & Varones & & $1959-1961$ & $\mathrm{RA} \mathrm{V}$ & $1959-1961$ & 115 \\
\hline ARGENTINA & Mujeres & & $1959-1961$ & RA M & 1959-1961 & 116 \\
\hline
\end{tabular}

(continúa) 
Cuadro VI-2 (continuación)

Indice de las tablas abreviadas de mortalidad elaboradas en este trabajo

\begin{tabular}{|c|c|c|c|c|c|c|c|}
\hline Región & & Sexo & Origen & Epoca & & $\begin{array}{l}\text { Título } \\
\text { abreviado }\end{array}$ & Pág. \\
\hline BUENOS & AIRES & Ambos sexos & & $1913-1915$ & $\mathrm{BA}$ & $1913-1915$ & 1i\% \\
\hline BUENOS & AIRES & Varones & & 1913-1915 & BA V & $1913-1915$ & 117 \\
\hline BUENOS & AIRES & Mujeres & & $1913-1915$ & BA M & 1913-1915 & 118 \\
\hline BUENOS & AIRES & Varones & Argentina & $1913-1915$ & $\mathrm{BA} V$ & 1913-1915 & A 118 \\
\hline BUENOS & AIRES & Mujeres & Argentina & $1913-1915$ & $\mathrm{BA} \mathrm{M}$ & 1913-1915 & A $11 \mathrm{~S}$ \\
\hline BUENOS & AIRES & Varones & Exterior & $1913-1915$ & $\mathrm{BA} \mathrm{V}$ & $1913-1915$ & E 119 \\
\hline BUENOS & AIRES & Mujeres & Exterior & $1913-1915$ & $\mathrm{BA} \mathrm{M}$ & I 1913-1915 & E $1: 0$ \\
\hline BUENOS & AIRES & Ambos sexos & & $1946-1948$ & BA & $1946-1948$ & 120 \\
\hline BUENOS & AIRES & Varones & & $1946-1948$ & $\mathrm{BA} \mathrm{V}$ & $1946-1948$ & 121 \\
\hline BUENOS & AIRES & Mujeres & & $1946-1948$ & $B A M$ & $1946-1948$ & 121 \\
\hline BUENOS & AIRES & Ambos sexos & & $1959-1961$ & BA & $1959-1961$ & 122 \\
\hline BUENOS & AIRES & Varones & & $1959-1961$ & $\mathrm{BA} \mathrm{V}$ & 1959-1961 & 122 \\
\hline BUENOS & AIRES & Mujeres & & $1959-1961$ & BA $\mathrm{M}$ & $1959-1961$ & 123 \\
\hline CENTRO & LITORAL & Ambos sexos & & $1913-1915$ & CL & $1913-1915$ & 123 \\
\hline CENTRO & LITORAL & Varones & & $1913-1915$ & CL V & $1913-1915$ & 124 \\
\hline CENTRO & LITORAL & Mujeres & & $1913-1915$ & CL $\mathrm{M}$ & 1 1913-1915 & 124 \\
\hline CENTRO & LITORAL & Varones & Argentina & $1913-1915$ & $\mathrm{CL} \mathrm{V}$ & $1913-1915$ & A 125 \\
\hline CENTRO & LITORAL & Mujeres & Argentina & $1913-1915$ & CL $\mathrm{M}$ & $1913-1915$ & A 125 \\
\hline CENTRO & LITORAL & Varones & Exterior & $1913-1915$ & $\mathrm{CL} \mathrm{V}$ & 1913-1915 & E 126 \\
\hline CENTRO & LITORAL & Mujeres & Exterior & $1913-1915$ & CL $M$ & 1 1913-1915 & E 126 \\
\hline CENTRO & LITORAL & Ambos sexos & & $1946-1948$ & $\mathrm{CL}$ & $1946-1948$ & 127 \\
\hline CENTRO & LITORAL & Varones & & $1946-1948$ & $\mathrm{CL} \mathrm{V}$ & $1946-1948$ & 127 \\
\hline CENTRO & LITORAL & Mujeres & & $1946-1948$ & CL M & $1946-1948$ & 128 \\
\hline CENTRO & LITORAL & Ambos sexos & & $1959-1961$ & $\mathrm{CL}$ & $1959-1961$ & 128 \\
\hline CENTRO & LITORAL & Varones & & $1959-1961$ & CL V & $1959-1961$ & 129 \\
\hline CENTRO & LITORAL & Mujeres & & $1959-1961$ & $C L M$ & 1 1959-1961 & 129 \\
\hline
\end{tabular}

(continúa) 
Cuadro VI-2 (continuación)

Indice de las tablas abreviadas de mortalidad elaboradas en este trabajo

\begin{tabular}{|c|c|c|c|c|c|c|}
\hline Región & Sexo & Origen & Epoca & & $\begin{array}{c}\text { Título } \\
\text { abreviado }\end{array}$ & Pág. \\
\hline CUYO & Ambos sexos & & $1913-1915$ & $\mathrm{CY}$ & $1913-1915$ & 130 \\
\hline CUYO & Varones & & $1913-1915$ & $\mathrm{CY}$ & V 1913-1915 & 130 \\
\hline CUYO & Mujeres & & $1913-1915$ & CY I & M 1913-1915 & 131 \\
\hline CUYO & Varones & Argentina & $1913-1915$ & CY & V 1913-1915 & A 131 \\
\hline CUYO & Mujeres & Argentina & $1913-1915$ & $\mathrm{CY}$ & M 1913-1915 & A 132 \\
\hline CUYO & Varones & Exterior & $1913-1915$ & CY & V 1913-1915 & E 132 \\
\hline CUYO & Mujeres & Exterior & $1913-1915$ & CY I & M 1913-1915 & E 133 \\
\hline CUYO & Ambos sexos & & $1946-1948$ & $\mathrm{CY}$ & $1946-1948$ & 133 \\
\hline CUYO & Varones & & $1946-1948$ & $\mathrm{CY}$ & V 1946-1948 & 134 \\
\hline CUYO & Mujeres & & $1946-1948$ & $\mathrm{CY}$ & M 1946-1948 & 134 \\
\hline CUYO & Ambos sexos & & $1959-1961$ & $\mathrm{CY}$ & $1959-1961$ & 135 \\
\hline CUYO & Varones & & $1959-1961$ & $\mathrm{CY}$ & V 1959-1961 & 135 \\
\hline CUYO & Mujeres & & $1959-1961$ & CY 1 & M 1959-1961 & 136 \\
\hline NOROESTE & Ambos sexos & & $1913-1915$ & NO & $1913-1915$ & 136 \\
\hline NOROESTE & Varones & & $1913-1915$ & NO & $\nabla 1913-1915$ & 137 \\
\hline NOROESTE & Mujeres & & $1913-1915$ & No 1 & M 1913-1915 & 137 \\
\hline NOROESTE & Varones & Argentina & $1913-1915$ & No & V 1913-1915 & A 138 \\
\hline NOROESTE & Mujeres & Argentina & $1913-1915$ & No 1 & M 1913-1915 & A 138 \\
\hline NOROESTE & Varones & Exterior & $1913-1915$ & No & V 1913-1915 & E 139 \\
\hline NOROESTE & Mujeres & Exterior & $1913-1915$ & NO 1 & M 1913-1915 & E 139 \\
\hline NOROESTE & Ambos sexos & & $1946-1948$ & NO & $1946-1948$ & 140 \\
\hline NOROESTE & Varones & & $1946-1948$ & NO & V 1946-1948 & 140 \\
\hline NOROESTE & Mujeres & & $1946-1948$ & NO 1 & M 1946-1948 & 141 \\
\hline NOROESTE & Ambos sexos & & $1959-1961$ & NO & $1959-1961$ & 141 \\
\hline NOROESTE & Varones & & $1959-1961$ & No & V 1959-1961 & 142 \\
\hline NOROESTE & Mujeres & & $1959-1961$ & No 1 & M 1959-1961 & 142 \\
\hline
\end{tabular}


REGION : ARGENTINA

SEXO : AMBOS SEXOS

EPOCA : 1869-1895

\begin{tabular}{|c|c|c|c|c|c|c|c|c|}
\hline $\mathrm{X}$ & $N$ & $M(X, N)$ & $Q(\dot{X}, N)$ & $L(X)$ & $D(X, N)$ & $L(X, N)$ & $T(X)$ & $E(X)$ \\
\hline 0 & 1 & 0.27368 & 0.23235 & 100000 & 23235 & 84897 & 3285832 & 32.86 \\
\hline 1 & 4 & 0.04136 & 0.15107 & 76765 & 11597 & 280383 & 3200935 & 41.70 \\
\hline 5 & 5 & 0.01013 & 0.04949 & 65168 & 3225 & 317778 & 2920552 & 44.82 \\
\hline 10 & 5 & 0.00676 & 0.03328 & 61943 & 2061 & 304562 & 2602774 & 42.02 \\
\hline 15 & 5 & 0.00919 & 0.04499 & 59882 & 2694 & 292675 & 2298212 & 38.38 \\
\hline 20 & 5 & 0.01175 & 0.05719 & 57188 & 3271 & 277763 & 2005537 & 35.07 \\
\hline 25 & 5 & 0.01289 & 006257 & 53917 & 3374 & 261150 & 1727774 & 32.05 \\
\hline 30 & 5 & 0.01380 & 0.06685 & 50543 & 3379 & 244268 & 1466624 & 29.02 \\
\hline 35 & 5 & 0.01582 & 0.07628 & 47164 & 3598 & 226825 & 1222356 & 25.92 \\
\hline 40 & 5 & 0.01857 & 0.08898 & 43566 & 3877 & 198137 & 995531 & 22.85 \\
\hline 45 & 5 & 0.02321 & 0.11005 & 39689 & 4368 & 187525 & 797394 & 20.09 \\
\hline 50 & 5 & 0.02936 & 0.13727 & 35321 & 4849 & 164483 & 609869 & 17.27 \\
\hline 55 & 5 & 0.03743 & 0.17184 & 30472 & 5236 & 139270 & 445386 & 14.62 \\
\hline 60 & 5 & 0.04923 & 0.22009 & 25236 & 5554 & 112295 & 306116 & 12.13 \\
\hline 65 & 5 & 0.06585 & 0.28365 & 19682 & 5583 & 84452 & 193821 & 9.84 \\
\hline 70 & 5 & 0.09519 & 0.38431 & 14099 & 5418 & 56950 & 109369 & 7.76 \\
\hline 5 & 5 & 0.13970 & 0.51228 & 8681 & 4447 & 32288 & 52419 & 6.04 \\
\hline 30 & W & 0.21032 & 1.00000 & 4234 & 4234 & 20131 & 20131 & 5 \\
\hline
\end{tabular}

REGION : ARGENTINA

SEXO : VARONES

EPOCA : $1869-1895$

$\begin{array}{lllllllll}X & N & M(X, N) & Q(X, N) & L(X) & D(X, N) & L(X, N) & T(X) & E(X)\end{array}$

\begin{tabular}{rrrrrrrrr}
\hline 0 & 1 & 0.28917 & 0.24342 & 100000 & 24342 & 84178 & 3259711 & 32.60 \\
1 & 4 & 0.04114 & 0.15024 & 75658 & 11367 & 276322 & 3175533 & 41.97 \\
5 & 5 & 0.00999 & 0.04882 & 64291 & 3139 & 313608 & 2899211 & 45.10 \\
10 & 5 & 0.00637 & 0.03139 & 61152 & 1920 & 300960 & 2585603 & 42.28 \\
15 & 5 & 0.00869 & 0.04259 & 59232 & 2523 & 289853 & 2284643 & 38.57 \\
20 & 5 & 0.01111 & 0.05415 & 56709 & 3071 & 275867 & 1994790 & 35.18 \\
25 & 5 & 0.01193 & 0.05804 & 53638 & 3113 & 260408 & 1718923 & 32.05 \\
30 & 5 & 0.01279 & 0.06210 & 50525 & 3138 & 244780 & 1458515 & 28.87 \\
35 & 5 & 0.01513 & 0.07307 & 47387 & 3463 & 228278 & 1213735 & 25.61 \\
40 & 5 & 0.01861 & 0.08916 & 43924 & 3916 & 209830 & 985457 & 22.44 \\
45 & 5 & 0.02438 & 0.11529 & 40008 & 4613 & 188507 & 775627 & 19.39 \\
50 & 5 & 0.03128 & 0.14562 & 35395 & 5154 & 164090 & 587120 & 16.59 \\
55 & 5 & 0.04113 & 0.18726 & 30241 & 5663 & 137047 & 423030 & 13.99 \\
60 & 5 & 0.05323 & 0.23584 & 24578 & 5796 & 108400 & 285983 & 11.64 \\
65 & 5 & 0.07076 & 0.30149 & 18782 & 5663 & 79753 & 177583 & 9.45 \\
70 & 5 & 0.10146 & 0.40405 & 13119 & 5301 & 52343 & 97830 & 7.46 \\
75 & 5 & 0.14626 & 0.52890 & 7818 & 4135 & 28752 & 45487 & 5.82 \\
80 & $\mathrm{~W}$ & 0.22008 & 1.00000 & 3683 & 3683 & 16735 & 16735 & 4.54
\end{tabular}


REGION : ARGENTINA

SEXO : MUJERES

EPOCA : 1869-1895

$\begin{array}{lllllllll}\mathrm{X} & \mathrm{N} & \mathrm{M}(\mathrm{X}, \mathrm{N}) & \mathrm{Q}(\mathrm{X}, \mathrm{N}) & \mathrm{L}(\mathrm{X}) & \mathrm{D}(\mathrm{X}, \mathrm{N}) & \mathrm{L}(\mathrm{X}, \mathrm{N}) & \mathrm{T}(\mathrm{X}) & \mathrm{E}(\mathrm{X})\end{array}$

\begin{tabular}{rrrrrrrrr}
\hline 0 & 1 & 0.25770 & 0.22073 & 100000 & 22073 & 85653 & 3331508 & 33.32 \\
1 & 4 & 0.04159 & 0.15192 & 77927 & 11839 & 284647 & 3245855 & 41.65 \\
5 & 5 & 0.01027 & 0.05015 & 66088 & 3314 & 322155 & 2961208 & 44.81 \\
10 & 5 & 0.00715 & 0.03517 & 62774 & 2208 & 308350 & 2639053 & 42.04 \\
15 & 5 & 0.00973 & 0.04757 & 60566 & 2881 & 295628 & 2330703 & 38.48 \\
20 & 5 & 0.01248 & 0.06064 & 57685 & 3498 & 279680 & 2035075 & 35.28 \\
25 & 5 & 0.01407 & 0.06812 & 54187 & 3691 & 261707 & 1755395 & 32.40 \\
30 & 5 & 0.01511 & 0.07298 & 50496 & 3685 & 243268 & 1493688 & 29.58 \\
35 & 5 & 0.01666 & 0.08018 & 46811 & 3753 & 224672 & 1250420 & 26.71 \\
40 & 5 & 0.01852 & 0.08875 & 43058 & 3821 & 205738 & 1025748 & 23.82 \\
45 & 5 & 0.02188 & 0.10406 & 39237 & 4083 & 185977 & 820010 & 20.90 \\
50 & 5 & 0.02705 & 0.12714 & 35154 & 4469 & 164598 & 634033 & 18.04 \\
55 & 5 & 0.03352 & 0.15526 & 30685 & 4764 & 141515 & 469435 & 15.30 \\
60 & 5 & 0.04536 & 0.20456 & 25921 & 5302 & 116350 & 327920 & 12.65 \\
65 & 5 & 0.06110 & 0.26599 & 20619 & 5484 & 89385 & 211570 & 10.26 \\
70 & 5 & 0.08912 & 0.36463 & 15135 & 5519 & 61877 & 122185 & 8.07 \\
75 & 5 & 0.13335 & 0.49567 & 9616 & 4766 & 36165 & 60308 & 6.27 \\
80 & W & 0.20089 & 1.00000 & 4850 & 4850 & 24143 & 24143 & 4.98
\end{tabular}

REGION : ARGENTINA SEXO : VARONES EPOCA: 1869-1895 ORIGEN : ARGENTINA

\begin{tabular}{rrrrrrrrr}
$\mathrm{X}$ & $\mathrm{N}$ & $\mathrm{M}(\mathrm{X}, \mathrm{N})$ & $\mathrm{Q}(\mathrm{X}, \mathrm{N})$ & $\mathrm{L}(\mathrm{X})$ & $\mathrm{D}(\mathrm{X}, \mathrm{N})$ & $\mathrm{L}(\mathrm{X}, \mathrm{N})$ & $\mathrm{T}(\mathrm{X})$ & $\mathrm{E}(\mathrm{X})$ \\
\hline 0 & 1 & 0.28917 & 0.24342 & 100000 & 24342 & 84178 & 3145220 & 31.45 \\
1 & 4 & 0.04114 & 0.15024 & 75658 & 11367 & 276322 & 3061042 & 40.46 \\
5 & 5 & 0.00997 & 0.04864 & 64291 & 3127 & 313635 & 2784720 & 43.31 \\
10 & 5 & 0.00644 & 0.03168 & 61164 & 1938 & 300964 & 2471085 & 40.40 \\
15 & 5 & 0.00907 & 0.04435 & 59226 & 2627 & 289557 & 2170121 & 36.64 \\
20 & 5 & 0.01243 & 0.06026 & 56599 & 3411 & 274442 & 1880564 & 33.23 \\
25 & 5 & 0.01369 & 0.06618 & 53188 & 3520 & 257097 & 1606122 & 30.20 \\
30 & 5 & 0.01533 & 0.07379 & 49668 & 3665 & 239075 & 1349025 & 27.16 \\
35 & 5 & 0.01805 & 0.08640 & 46003 & 3975 & 220164 & 1109950 & 24.13 \\
40 & 5 & 0.02280 & 0.10786 & 42028 & 4533 & 198830 & 889786 & 21.17 \\
45 & 5 & 0.02889 & 0.13474 & 37495 & 5052 & 174891 & 690956 & 18.43 \\
50 & 5 & 0.03622 & 0.16601 & 32443 & 5386 & 148692 & 516065 & 15.91 \\
55 & 5 & 0.04576 & 0.20497 & 27057 & 5546 & 121199 & 367373 & 13.58 \\
60 & 5 & 0.05679 & 0.24768 & 21511 & 5328 & 93820 & 246174 & 11.44 \\
65 & 5 & 0.07341 & 0.30952 & 16183 & 5009 & 68235 & 152354 & 9.41 \\
70 & 5 & 0.10203 & 0.40648 & 11174 & 4542 & 44517 & 84119 & 7.53 \\
75 & 5 & 0.14332 & 0.52936 & 6632 & 3511 & 24498 & 39602 & 5.97 \\
80 & $\mathrm{~W}$ & 0.20663 & 1.00000 & 3121 & 3121 & 15104 & 15104 & 4.84
\end{tabular}




\begin{tabular}{rrrrrrrrr}
$\mathrm{X}$ & $\mathrm{N}$ & $\mathrm{M}(\mathrm{X}, \mathrm{N})$ & $\mathrm{Q}(\mathrm{X}, \mathrm{N})$ & $\mathrm{L}(\mathrm{X})$ & $\mathrm{D}(\mathrm{X}, \mathrm{N})$ & $\mathrm{L}(\mathrm{X}, \mathrm{N})$ & $\mathrm{T}(\mathrm{X})$ & $\mathrm{E}(\mathrm{X})$ \\
\hline & & & & & & & \\
\hline 0 & 1 & 0.25770 & 0.22073 & 100000 & 22073 & 85653 & 3254836 & 32.55 \\
1 & 4 & 0.04159 & 0.15192 & 77927 & 11839 & 284647 & 3169183 & 40.67 \\
5 & 5 & 0.01030 & 0.05019 & 66088 & 3317 & 322161 & 2884536 & 43.65 \\
10 & 5 & 0.00728 & 0.03575 & 62771 & 2244 & 308244 & 2562375 & 40.82 \\
15 & 5 & 0.01007 & 0.04913 & 60527 & 2974 & 295205 & 2254131 & 37.24 \\
20 & 5 & 0.01328 & 0.06428 & 57553 & 3700 & 278526 & 1958926 & 34.04 \\
25 & 5 & 0.01522 & 0.07331 & 53853 & 3948 & 259391 & 1680400 & 31.20 \\
30 & 5 & 0.01669 & 0.08007 & 49905 & 3996 & 239470 & 1421009 & 28.47 \\
35 & 5 & 0.01848 & 0.08836 & 45909 & 4057 & 219546 & 1181539 & 25.74 \\
40 & 5 & 0.02061 & 0.09802 & 41852 & 4102 & 199062 & 961993 & 22.99 \\
45 & 5 & 0.02416 & 0.11396 & 37750 & 4302 & 178061 & 762931 & 20.21 \\
50 & 5 & 0.02967 & 0.13810 & 33448 & 4619 & 155661 & 584870 & 17.49 \\
55 & 5 & 0.03687 & 0.16856 & 28829 & 4859 & 131798 & 429209 & 14.89 \\
60 & 5 & 0.04799 & 0.21351 & 23970 & 5118 & 106638 & 297411 & 12.41 \\
65 & 5 & 0.06376 & 0.27447 & 18852 & 5174 & 81152 & 190773 & 10.12 \\
70 & 5 & 0.09127 & 0.37143 & 13678 & 5080 & 55662 & 109621 & 8.01 \\
75 & 5 & 0.13412 & 0.50346 & 8598 & 4329 & 32278 & 53959 & 6.28 \\
80 & $\mathrm{~W}$ & 0.19690 & 1.00000 & 4269 & 4269 & 21681 & 21681 & 5.08
\end{tabular}

REGION : ARGENTINA

SEXO : AMBOS SEXOS

EPOCA : 1895-1914

\begin{tabular}{rrrrrrrrr}
$\mathrm{X}$ & $\mathrm{N}$ & $\mathrm{M}(\mathrm{X}, \mathrm{N})$ & $\mathrm{Q}(\mathrm{X}, \mathrm{N})$ & $\mathrm{L}(\mathrm{X})$ & $\mathrm{D}(\mathrm{X}, \mathrm{N})$ & $\mathrm{L}(\mathrm{X}, \mathrm{N})$ & $\mathrm{T}(\mathrm{X})$ & $\mathrm{E}(\mathrm{X})$ \\
\hline & & & & & & & & \\
\hline 0 & 1 & 0.19650 & 0.17424 & 100000 & 17424 & 88674 & 4003811 & 40.04 \\
1 & 4 & 0.02909 & 0.10817 & 82576 & 8932 & 307082 & 3915137 & 47.41 \\
5 & 5 & 0.00683 & 0.03362 & 73644 & 2476 & 362030 & 3608055 & 48.99 \\
10 & 5 & 0.00494 & 0.02442 & 71168 & 1738 & 351495 & 3246025 & 45.61 \\
15 & 5 & 0.00728 & 0.03579 & 69430 & 2485 & 340938 & 2894530 & 41.69 \\
20 & 5 & 0.00958 & 0.04686 & 66945 & 3137 & 326882 & 2553592 & 38.14 \\
25 & 5 & 0.01007 & 0.04920 & 63808 & 3139 & 311193 & 2226710 & 34.90 \\
30 & 5 & 0.01096 & 0.05344 & 60669 & 3242 & 295240 & 1915517 & 31.57 \\
35 & 5 & 0.01294 & 0.06281 & 57427 & 3607 & 278117 & 1620277 & 28.21 \\
40 & 5 & 0.01549 & 0.07475 & 53820 & 4023 & 259043 & 1342160 & 24.94 \\
45 & 5 & 0.01934 & 0.09251 & 49797 & 4607 & 237467 & 1083117 & 21.75 \\
50 & 5 & 0.02448 & 0.11573 & 45190 & 5230 & 212875 & 845650 & 18.71 \\
55 & 5 & 0.03183 & 0.14799 & 39960 & 5914 & 185015 & 632775 & 15.84 \\
60 & 5 & 0.04253 & 0.19302 & 34046 & 6572 & 153800 & 447760 & 13.15 \\
65 & 5 & 0.05799 & 0.25421 & 27474 & 6984 & 119910 & 293960 & 10.70 \\
70 & 5 & 0.08300 & 0.34419 & 20490 & 7052 & 84820 & 174050 & 8.49 \\
75 & 5 & 0.12086 & 0.46147 & 13438 & 6201 & 51688 & 89230 & 6.64 \\
80 & $\mathrm{~W}$ & 0.19277 & 1.00000 & 7237 & 7237 & 37542 & 37542 & 5.19
\end{tabular}




\begin{tabular}{rrrrrrrrr}
$\mathrm{X}$ & $\mathrm{N}$ & $\mathrm{M}(\mathrm{X}, \mathrm{N})$ & $\mathrm{Q}(\mathrm{X}, \mathrm{N})$ & $\mathrm{L}(\mathrm{X})$ & $\mathrm{D}(\mathrm{X}, \mathrm{N})$ & $\mathrm{L}(\mathrm{X}, \mathrm{N})$ & $\mathrm{T}(\mathrm{X})$ & $\mathrm{E}(\mathrm{X})$ \\
\hline & & & & & & & & \\
\hline & 1 & 0.20669 & 0.18221 & 100000 & 18221 & 88156 & -3947559 & 39.48 \\
1 & 4 & 0.02904 & 0.10800 & 81779 & 8832 & 304153 & 3859403 & 47.19 \\
5 & 5 & 0.00675 & 0.03323 & 72947 & 2424 & 358675 & 3555250 & 48.74 \\
10 & 5 & 0.00473 & 0.02339 & 70523 & 1650 & 348490 & 3196575 & 45.33 \\
15 & 5 & 0.00680 & 0.03347 & 68873 & 2305 & 338603 & 2848085 & 41.35 \\
20 & 5 & 0.00909 & 0.04451 & 66568 & 2963 & 325432 & 2509482 & 37.70 \\
25 & 5 & 0.00940 & 0.04599 & 63605 & 2925 & 310713 & 2184050 & 34.34 \\
30 & 5 & 0.01036 & 0.05058 & 60680 & 3069 & 295727 & 1873337 & 30.87 \\
35 & 5 & 0.01264 & 0.06139 & 57611 & 3537 & 279213 & 1577610 & 27.38 \\
40 & 5 & 0.01590 & 0.07665 & 54074 & 4145 & 260008 & 1298397 & 24.01 \\
45 & 5 & 0.02071 & 0.09875 & 49929 & 4930 & 237320 & 1038389 & 20.80 \\
50 & 5 & 0.02672 & 0.12568 & 44999 & 5655 & 210857 & 801069 & 17.80 \\
55 & 5 & 0.03576 & 0.16479 & 39344 & 6483 & 180513 & 590212 & 15.00 \\
60 & 5 & 0.04713 & 0.21170 & 32861 & 6957 & 146913 & 409699 & 12.47 \\
65 & 5 & 0.06374 & 0.27585 & 25904 & 7146 & 111655 & 262786 & 10.14 \\
70 & 5 & 0.09026 & 0.36837 & 18758 & 6910 & 76515 & 151131 & 8.06 \\
75 & 5 & 0.13011 & 0.48700 & 11848 & 5770 & 44815 & 74616 & 6.30 \\
80 & $\mathrm{~W}$ & 0.20395 & 1.00000 & 6078 & 6078 & 29801 & 29801 & 4.90
\end{tabular}

REGION : ARGENTINA

SEXO : MUJERES

EPOCA : 1895-1914

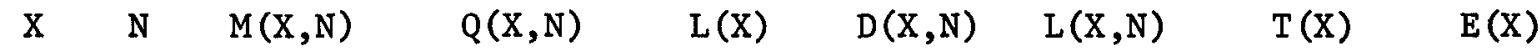

\begin{tabular}{rrrrrrrrr}
\hline 0 & 1 & 0.18592 & 0.16587 & 100000 & 16587 & 89218 & 4067486 & 40.67 \\
1 & 4 & 0.02913 & 0.10833 & 83413 & 9036 & 310158 & 3978268 & 47.69 \\
5 & 5 & 0.00692 & 0.03405 & 74377 & 2533 & 365553 & 3668110 & 49.32 \\
10 & 5 & 0.00515 & 0.02545 & 71844 & 1828 & 354650 & 3302557 & 45.97 \\
15 & 5 & 0.00782 & 0.03840 & 70016 & 2689 & 343357 & 2947907 & 42.10 \\
20 & 5 & 0.01021 & 0.04987 & 67327 & 3358 & 328240 & 2604550 & 38.69 \\
25 & 5 & 0.01097 & 0.05349 & 63969 & 3422 & 311290 & 2276310 & 35.58 \\
30 & 5 & 0.01178 & 0.05733 & 60547 & 3471 & 294058 & 1965020 & 32.45 \\
35 & 5 & 0.01335 & 0.06474 & 57076 & 3695 & 276142 & 1670962 & 29.28 \\
40 & 5 & 0.01495 & 0.07223 & 53381 & 3856 & 257265 & 1394820 & 26.13 \\
45 & 5 & 0.01759 & 0.08447 & 49525 & 4183 & 237168 & 1137555 & 22.97 \\
50 & 5 & 0.02152 & 0.10243 & 45342 & 4644 & 215100 & 900387 & 19.86 \\
55 & 5 & 0.02735 & 0.12846 & 40698 & 5228 & 190420 & 685287 & 16.84 \\
60 & 5 & 0.03773 & 0.17310 & 35470 & 6140 & 162000 & 494867 & 13.95 \\
65 & 5 & 0.05200 & 0.23103 & 29330 & 6776 & 129710 & 332867 & 11.35 \\
70 & 5 & 0.07543 & 0.31808 & 22554 & 7174 & 94835 & 203157 & 9.01 \\
75 & 5 & 0.11122 & 0.43361 & 15380 & 6669 & 60227 & 108322 & 7.04 \\
80 & $\mathrm{~W}$ & 0.18112 & 1.00000 & 8711 & 8711 & 48095 & 48095 & 5.52
\end{tabular}


REGION : ARGENTINA SEXO : VARONES EPOCA : 1895-1914 ORIGEN : ARGENTINA

\begin{tabular}{rrrrrrrrr}
$\mathrm{X}$ & $\mathrm{N}$ & $\mathrm{M}(\mathrm{X}, \mathrm{N})$ & $\mathrm{Q}(\mathrm{X}, \mathrm{N})$ & $\mathrm{L}(\mathrm{X})$ & $\mathrm{D}(\mathrm{X}, \mathrm{N})$ & $\mathrm{L}(\mathrm{X}, \mathrm{N})$ & $\mathrm{T}(\mathrm{X})$ & $\mathrm{E}(\mathrm{X})$ \\
\hline & & & & & & & & \\
0 & 1 & 0.20669 & 0.18221 & 100000 & 18221 & 88156 & 3761265 & 37.61 \\
1 & 4 & 0.02904 & 0.10800 & 81779 & 8832 & 304153 & 3673109 & 44.92 \\
5 & 5 & 0.00672 & 0.03305 & 72947 & 2411 & 358708 & 3368956 & 46.18 \\
10 & 5 & 0.00481 & 0.02375 & 70536 & 1675 & 348492 & 3010248 & 42.68 \\
15 & 5 & 0.00727 & 0.03568 & 68861 & 2457 & 338163 & 2661756 & 38.65 \\
20 & 5 & 0.01079 & 0.05251 & 66404 & 3487 & 323302 & 2323593 & 34.99 \\
25 & 5 & 0.01164 & 0.05656 & 62917 & 3559 & 305688 & 2000291 & 31.79 \\
30 & 5 & 0.01335 & 0.06459 & 59358 & 3834 & 287205 & 1694603 & 28.55 \\
35 & 5 & 0.01614 & 0.07758 & 55524 & 4308 & 266850 & 1407398 & 25.35 \\
40 & 5 & 0.02075 & 0.09863 & 51216 & 5051 & 243452 & 1140548 & 22.27 \\
45 & 5 & 0.02647 & 0.12414 & 46165 & 5731 & 216498 & 897096 & 19.43 \\
50 & 5 & 0.03311 & 0.15289 & 40434 & 6182 & 186715 & 680598 & 16.83 \\
55 & 5 & 0.04181 & 0.18926 & 34252 & 6483 & 155052 & 493883 & 14.42 \\
60 & 5 & 0.05253 & 0.23215 & 27769 & 6447 & 122728 & 338831 & 12.20 \\
65 & 5 & 0.06781 & 0.28989 & 21322 & 6181 & 91157 & 216103 & 10.14 \\
70 & 5 & 0.09127 & 0.37157 & 15141 & 5626 & 61640 & 124946 & 8.25 \\
75 & 5 & 0.12497 & 0.47613 & 9515 & 4530 & 36250 & 63306 & 6.65 \\
80 & $\mathrm{~W}$ & 0.18425 & 1.00000 & 4985 & 4985 & 27056 & 27056 & 5.43
\end{tabular}

REGION : ARGENTINA SEXO : MUJERES EPOCA : 1895-1914 ORIGEN : ARGENTINA

\begin{tabular}{rrrrrrrrr}
$X$ & $N$ & $M(X, N)$ & $Q(X, N)$ & $L(X)$ & $D(X, N)$ & $L(X, N)$ & $T(X)$ & $E(X)$ \\
\hline & & & & & & & \\
0 & 1 & 0.18592 & 0.16587 & 100000 & 16587 & 89218 & 3909839 & 39.10 \\
1 & 4 & 0.02913 & 0.10833 & 83413 & 9036 & 310158 & 3820621 & 45.80 \\
5 & 5 & 0.00696 & 0.03419 & 74377 & 2543 & 365527 & 3510463 & 47.20 \\
10 & -5 & 0.00531 & 0.02619 & 71834 & 1881 & 354468 & 3144936 & 43.78 \\
15 & 5 & 0.00827 & 0.04052 & 69953 & 2834 & 342680 & 2790468 & 39.89 \\
20 & 5 & 0.01134 & 0.05516 & 67119 & 3702 & 326340 & 2447788 & 36.47 \\
25 & 5 & 0.01272 & 0.06166 & 63417 & 3910 & 307310 & 2121448 & 33.45 \\
30 & 5 & 0.01411 & 0.06813 & 59507 & 4054 & 287400 & 1814138 & 30.49 \\
35 & 5 & 0.01592 & 0.07657 & 55453 & 4246 & 266650 & 1526738 & 27.53 \\
40 & 5 & 0.01797 & 0.08601 & 51207 & 4404 & 245025 & 1260088 & 24.61 \\
45 & 5 & 0.02093 & 0.09945 & 46803 & 4655 & 222377 & 1015063 & 21.69 \\
50 & 5 & 0.02579 & 0.12115 & 42148 & 5106 & 197975 & 792686 & 18.81 \\
55 & 5 & 0.03253 & 0.15040 & 37042 & 5571 & 171283 & 594711 & 16.06 \\
60 & 5 & 0.04277 & 0.19320 & 31471 & 6080 & 142155 & 423428 & 13.45 \\
65 & 5 & 0.05706 & 0.24969 & 25391 & 6340 & 111105 & $281273 .$. & 11.08 \\
70 & 5 & 0.07954 & 0.33173 & 19051 & 6320 & 79455 & 170168 & 8.93 \\
75 & 5 & 0.11278 & 0.43991 & 12731 & 5600 & 49655 & 90713 & 7.13 \\
80 & $\mathrm{~W}$ & 0.17368 & 1.00000 & 7131 & 7131 & 41058 & 41058 & 5.76
\end{tabular}


REGION : ARGENTINA

SEXO :-AMBOS SEXOS

EPOCA : 1913-1915

$X \quad N \quad M(X, N) \quad Q(X, N) \quad L(X) \quad D(X, N) L(X, N) \quad T(X) \quad E(X)$

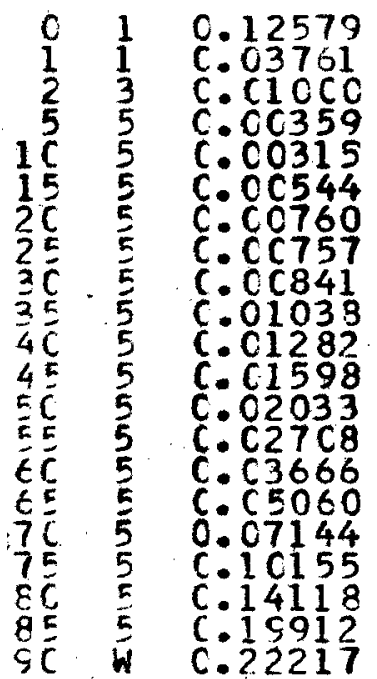

0.11612
0.03679
0.02958
$C .01780$
0.01564
$C .02686$
0.03734
$C .03720$
0.04125
$C .05068$
0.06224
0.07703
0.09703
0.12727
$C .16860$
0.22552
0.30393
$C .40433$
0.51608
0.64486
1.00000

100000

88388

85136

82618

81147

79878

77732

74829

72046

69074

65573

61492

56755

51248

44725

37184

28798

20045

11940

5778

2052

1612
3252
2518
1471
1269
2146
2903
2783
2972
3501
4081
4737
5507
6523
7541
8386
8753
8105
6162
3726
2052

92313 251800 409749 402857 394486 381974 367635 353389 337283 318331 296433 270881 240879 205701

165731

122522

79813

43646

18712

4849840
4757527
4671058
4419258
4009509
3606652
3212166
2830192
2462557
2109168
1771885
1453554
1157121
886240
645361
439660
273929
151407
71594
27948
9236

48.50

53.83

54.87

53.49

49.41

45.15

$41 \cdot 32$

$34: 18$

30.53

$27 \cdot 02$

$20 \cdot 39$

17.29

$14 \cdot 43$

11.82

9.51

6.00

4.84

4.84

BEGION . ARGENTINA

SEXO_:-VARQNES

EPOCA :-1213-1215

$X N \quad N(X, N) \quad C(X, N) \quad L(X) \quad D(X, N) L(X, N) \quad T(X) \quad E(X)$

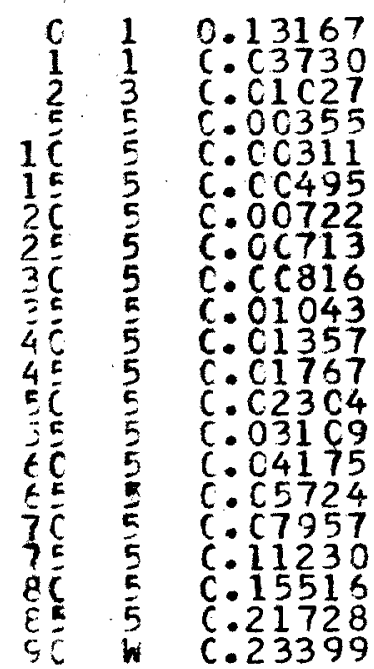

0.12100

0.03650

0.03036

C. 01761

0.01544

0.02447

0.03551

0.03507

0.04004

0. 0500 ?

6. 06577

0. C 8485

0.10927

0.14490

0.18982

c. 25134

0.33248

0.43679

0.55061

0.67813
1.00000
100000

87900

84692

82121

79429

77485

74734

72113

69225

65700

61379

56171

50032

42788

34666

23053

17324

9757

4385

1411
12100

3208

1446

1246

1944

2751

2821

2888

3525

4321

5208

6139

7244

8122

8713

8629

7567

5372

2974

141.1
91893

86007

250341

407324

400643

392727

381025

367602

353922

337967

318423

294737

266450

233001

194539

152210

108445

67382

34622

13687

6030
4758986

4667093

4581086

4330745

3923421

3522778

3130051

2749026

2381424

2027502

1689535

1371112

1076375

809925

576924

382385

230166

121721

54339

19717
6030

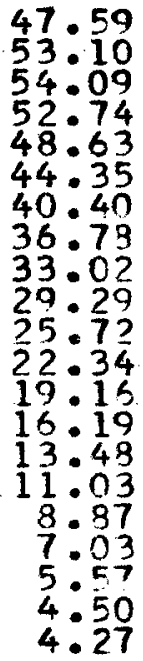


REGION : ARGENTINA

SEXO : MUJERES

EPOCA : 1913-1915

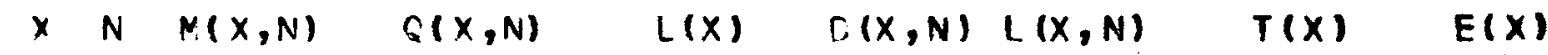

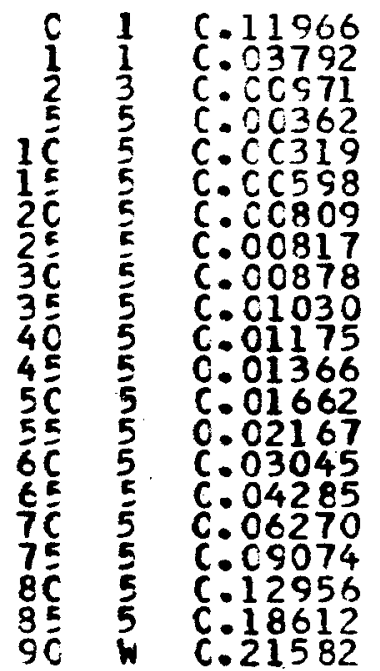

0.11100

0.03709

0.02873

0.01795

0.01583

0.02949

C. 03971

0.04009

0.04302

0.05030

0.05719

0.06619

0.07999

0.10311

0.14202

0.19433

0.2719 .3

0.36994

0.48551

0. 61 c11
100000

88900

85603

83144

81652

80359

77989

74892

71890

68797

65337

61601

57523

52921

47464

40723

32800

23886

15050

7743

2949
11100 3297

2459

1492

1293

2370

3097

3002

3460

3736

4078

4602

5457

6741

7914

8923

8836

7307

4794
$9 ? 763$ 253244 412155 405329 396321 382818 367442 352278 335922 298536 276895

251823

221379

184691

142313

97377

56399

25758
$4972020 \quad 49.72$

$4879257 \quad 54.89$

$4792302 \quad 55.98$

$4539058 \quad 54.59$

$4126903 \quad 50.54$

$3721574 \quad 46 \cdot 31$

$3325253 \quad 42 \cdot 64$

204243539.29

$2574993 \quad 35.82$

222271532.31

$1886793 \quad 28.88$

156883525.47

1270299

903404

$741581 \quad 15: 62$

$520202 \quad 12.77$

$335511 \quad 10.23$

$193198 \quad 8.09$

$95821 \quad 5 \cdot 37$

39422

13664

4.69

REGION : ARGENTINA_SEXO_: VARONES_EPOCA : 1913-1915 ORIGEN : ARGENTINA

$x \quad N \quad M(X, N) \quad Q(x, N) \quad L(X) \quad D(X, N) L(X, N) \quad T(X) \quad E(X)$

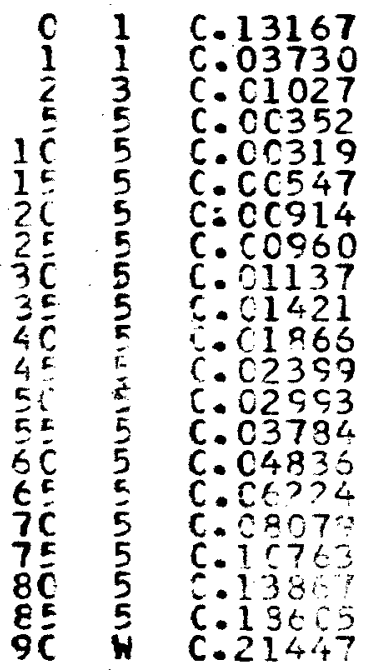

$\begin{array}{rrr}0.12100 & 100000 & 12100 \\ C .03650 & 87900 & 3208 \\ 0.03036 & 84692 & 2571 \\ 0.01746 & 82121 & 1434 \\ \text { C. } 01583 & 80687 & 1278 \\ 0.02701 & 79409 & 2145 \\ 0.04475 & 77264 & 3458 \\ 0.04695 & 73806 & 3465 \\ 0.05539 & 70341 & 3896 \\ C .06877 & 66445 & 4570 \\ C .08940 & 61875 & 5531 \\ 0.11355 & 56344 & 6398 \\ 0.13976 & 49946 & 6981 \\ 0.17356 & 42965 & 7457 \\ \text { C. } 21662 & 35508 & 7692 \\ C .27026 & 27816 & 7518 \\ 0.33667 & 20298 & 6834 \\ 0.42290 & 13464 & 5694 \\ 0.50962 & 7770 & 3960 \\ 0.61897 & 3810 & 2358 \\ 1.00000 & 1452 & 1452\end{array}$

91893
86007
250341
407386
400527
392130
378337
360938
342656
321605
296400
266694
233244
197067
159057
120790
84590
52903
28557
12674
6770

4490684

4398791

4312784

4062443

3655057

3254430

2862291

2483954

2123016

1780360

1458755

1162346

895652

662408

465341

306284

185494

100904

48001

19444

6770
44.91

50.04

50.92

49.47

$45 \cdot 30$

47.08

33.66

30.18

26.79

23.58

20.63

$17 \cdot 93$

13.11

$11.01 \frac{1}{9}$

7.49

6.18

$\frac{5}{4.66}$ 
REGION_:ARGENTINA_SEXO_:_MUERES__EPOCA__1913-1915_ORIGEN :-ARGENTINA

$\times N M(X, N) \quad Q(X, N) \quad L(X) \quad D(X, N) L(X, N) \quad T(X) \quad E(X)$

\begin{tabular}{|c|c|c|c|c|c|c|}
\hline $\begin{array}{l}1 \\
1 \\
3 \\
5 \\
5 \\
5 \\
5 \\
5 \\
5 \\
5 \\
5 \\
5 \\
5 \\
5 \\
5 \\
5 \\
5\end{array}$ & $\begin{array}{l}C .11966 \\
C .03792 \\
C . C C 971 \\
C . C C 367 \\
C .00335 \\
C .00548 \\
C . C C 941 \\
C .01024 \\
C .01154 \\
C . C 1336 \\
C .01533 \\
C . C 1759 \\
C .02151 \\
C .02821 \\
C . C 3768 \\
C . C 5045 \\
C .06814 \\
C .09272 \\
C .12500 \\
C .17120\end{array}$ & $\begin{array}{l}0.11100 \\
0.03709 \\
0.02873 \\
0.01820 \\
0.01662 \\
0.03192 \\
0.04604 \\
0.05001 \\
0.05619 \\
0.06478 \\
0.07400 \\
0.08494 \\
0.10419 \\
0.13224 \\
0.17289 \\
0.22492 \\
0.29202 \\
0.37637 \\
0.47394 \\
0.58741 \\
1.00000\end{array}$ & $\begin{array}{r}100000 \\
88900 \\
85603 \\
83144 \\
81631 \\
80274 \\
77712 \\
74134 \\
70426 \\
66459 \\
62162 \\
57563 \\
52674 \\
47186 \\
40946 \\
33867 \\
26249 \\
18584 \\
11590 \\
6108 \\
2520\end{array}$ & $\begin{array}{l}11100 \\
3297 \\
2450 \\
1513 \\
1357 \\
2562 \\
3578 \\
3708 \\
3957 \\
4306 \\
4600 \\
4889 \\
5488 \\
5240 \\
7079 \\
7618 \\
7665 \\
6994 \\
5482 \\
3588 \\
2520\end{array}$ & $\begin{array}{l}53 \\
55 \\
44 \\
62 \\
75 \\
71 \\
34 \\
09 \\
04 \\
05 \\
65 \\
71 \\
79 \\
98 \\
72 \\
01 \\
89 \\
31 \\
56\end{array}$ & $\begin{array}{l}85 \\
30 \\
86 \\
24 \\
49 \\
78 \\
44 \\
35 \\
41 \\
36 \\
71 \\
00 \\
21 \\
23 \\
51 \\
50 \\
51 \\
30 \\
74 \\
16\end{array}$ \\
\hline
\end{tabular}

REGION_:ARGENTINA_SEXO_:_VARONES__EPOCA_: 1913-1915 ORIGEN :-_EXTERIOR

$X N M(x, N) \quad O(x, N) \quad L(X) \quad E(X, N) L(X, N) \quad T(X) \quad E(X)$

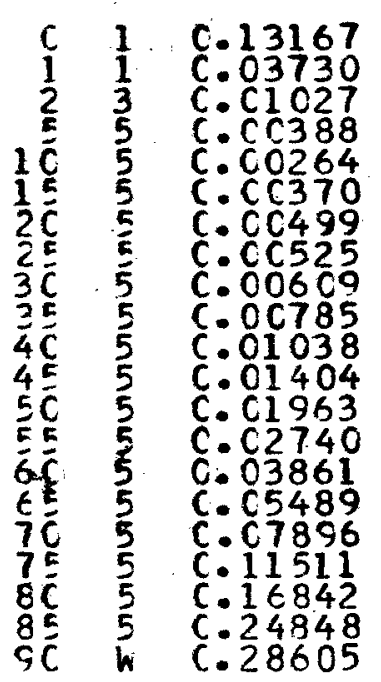

0.12100

0.03650

C. 03036

0.01923

0.01312

0.01834

0.02467

0.02594

C. 03003

C. 05068

0.06798

0. 09384

0.12868

0.17679

0.24230

0.33037

0.44501

0.58124

0.72859

1.00000
100000 87000

84692

82121

80542

79485

78027

76102

74128

69130
65627

61166

55426

48294

39756

30123

20171

11195

4688

1272
12100 3208

2571

1579

1057
1458

1925

2226

3503

4461

5740

7132

8538

9633

9952

8976

6507

3416

1272
91893 86007 250341 406959 400379 394054 385772

376000

365517

353121

337476

317735

292410

260292

221134

175496

126039

77978

38636
13748

4447
4975434

4883541

4797534
4547193

4140234

3739855

3345801

2584029

2218512

1865391

1527915

1210180

917770
657478

436344

260948

134809

56831

18195
4447

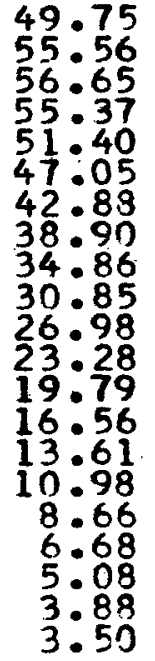


REGION : ARGENTINA SEXO: MUJERES EPOCA : 1913-1915 ORIGEN : EXTERIOR

$\times N M(X, N) \quad Q(X, N) \quad L(X) \quad D(X, N) L(X, N) \quad T(X) \quad E(X)$

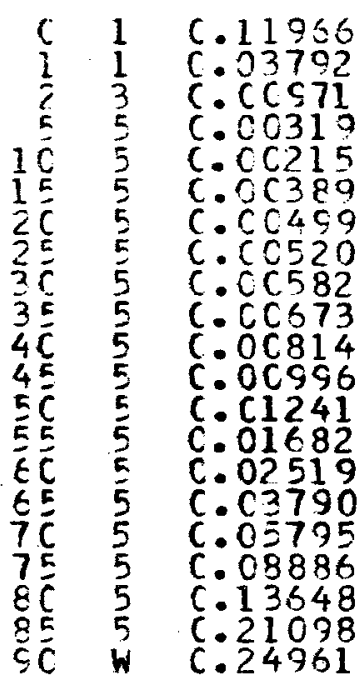

100000

88900

85603

83144

81828

80953

79392

77434

75445

73279

70851

68021

64710

60807

55386

49241

40682

30346

19307

9578

3190

11100
3297
2459
1316
875
1561
1958
1989
2166
2428
2830
3311
3903
4021
6645
8559
10336
11039
9729
6388
3190

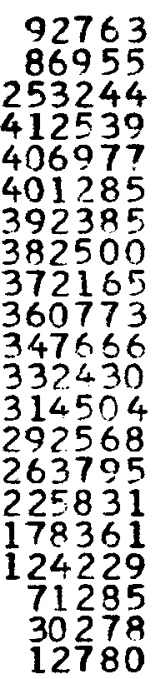

92763
86955

253244

406977

401285

382500

372165

347656

314504

292568

263705

178361

24229
71285

30278
12780
5355313

5262550

5175595

4922351

4509812
4102835

3701550

2926665

2554500

2193727

1846061

1513631

906559

642764

416933

238572

114343

43058

12780
53.55

59.20

60.46

55.11

50.68

$46 \cdot 6 ?$

$38: 79$

34.86

30.96

27.14

$23 \cdot 39$

16.22

13.05

10.25

5.92

4.50

4.01

REGION : ARGENTINA

SEXO : AMBOS SEXOS

EPOCA : 1946-1948

$X N \quad N(X, N) \quad G(X, N)$

$L(x)$

$\Gamma(X, N)\llcorner(X, N)$

$D(x)$

$E(x)$

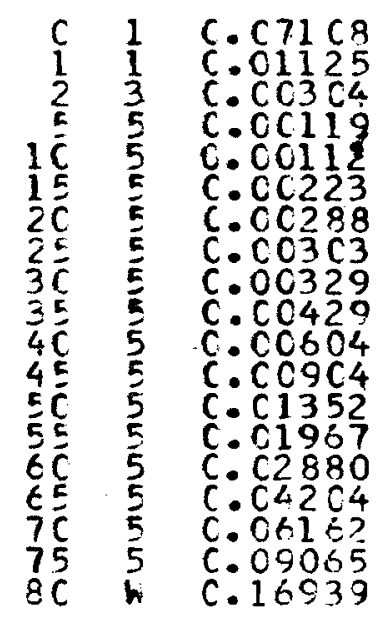

0.06770

0.01118

0.00908

0.00593

0.00559

0.01109

0.01430

C. 01504

0.01633

0.02124

C. 02978

0.04427

C. 06554

0.09402

0.13483

ก. 19101

0.26794

0.36964

1. 00000

$\begin{array}{rr}100000 & 6770 \\ 93230 & 1042 \\ 92188 & 837 \\ 91351 & 542 \\ 90809 & 507 \\ 90302 & 1002 \\ 89300 & 1277 \\ 88023 & 1324 \\ 86699 & 1415 \\ 85284 & 1811 \\ 83473 & 2486 \\ 80987 & 3585 \\ 77402 & 5073 \\ 72329 & 6800 \\ 65529 & 8835 \\ 55694 & 10829 \\ 45865 & 12289 \\ 33576 & 12411 \\ 21165 & 21165\end{array}$

95247
93615
275379
45562
452679
449327
443403
436964
430091
422145
411589
396571
375222
345704
306771
257588
109432
136911
124948

6107998

to12751

5920136

5644807

5189345

4736666

4287339

3843936

3406972

2076881

2554736

2143147

1746576

1371354

1025650

461291

261859

124948
61.08

64.49

64.22

$57: 15$

52.45

48.01

$39: 30$

34.91

30.61

22.55

18.95

$15: 65$

10.06

$7: 80$
5.90 


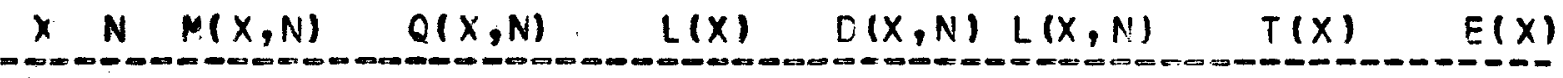

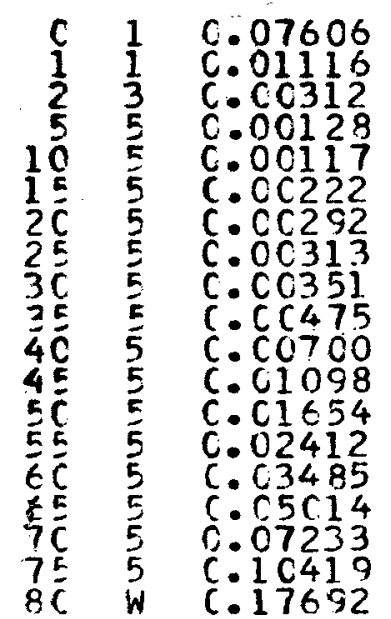

0.072 .16

0.01109

C. 00638

0.00583

0.01104

0.01450

0.01554

0.01741

C. 02349

0.03444

C. 05353

0.07962

0.11413

C. 16093

C. 22370

0.30711

C. 41246

1. 00000

$\begin{array}{rr}100000 & 7216 \\ 92784 & 1029 \\ 91755 & 855 \\ 90900 & 580 \\ 90320 & 527 \\ 89793 & 992 \\ 88801 & 1288 \\ 87513 & 1360 \\ 86153 & 1500 \\ 84653 & 1989 \\ 82644 & 2847 \\ 79817 & 4273 \\ 75544 & 6015 \\ 69529 & 7935 \\ 61594 & 9912 \\ 51682 & 11561 \\ 40121 & 12321 \\ 27800 & 11466\end{array}$

$16334 \quad 16334$

94877
92177
274038
453125
450427
446847
441996
434505
427359
418737
406714
389162
363664
328980
284419
230574
170344
110049
92324

5009409

5722355

548317

4905192

4544765

4097918

3656822

3222317

2794967

2376230

1969516

1580354

887710

603291

372717

92324
$57 \cdot 09$
$62: 67$
$62: 37$
$59: 94$
$55: 31$
$50: 61$
$46: 15$
$41: 79$
$37: 49$
$33: 02$
$28: 75$
$24: 68$
$20: 92$
$17: 50$
$14: 41$
$11: 67$
$0: 29$
$7: 28$
$5: 65$

REGION : ARGENTINA

SEXO : MUJERES

EPOCA : 1946-1948

$X N N(X, N) \quad Q(X, N) \quad L(X) \quad D(X, N) L(X, N) \quad T(X) \quad L(X)$

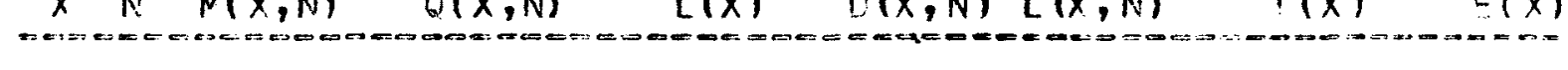

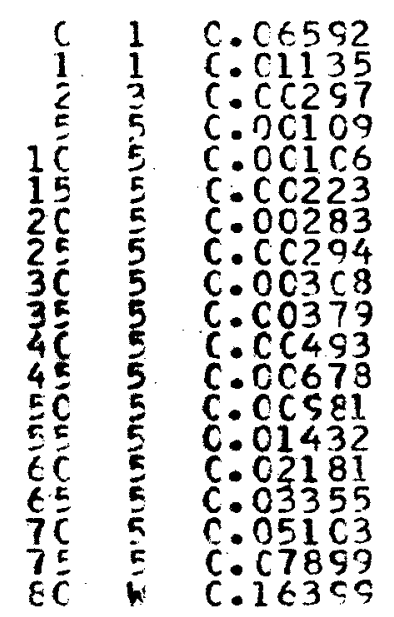

114

$\begin{array}{rrr}0.06304 & 100000 & 6304 \\ 0.01127 & 93696 & 1056 \\ 0.00887 & 92640 & 822 \\ 0.00544 & 91818 & 499 \\ 0.00529 & 91319 & 483 \\ 0.01109 & 90836 & 1008 \\ 0.01406 & 89828 & 1263 \\ 0.01460 & 88565 & 1293 \\ 0.01529 & 87272 & 1335 \\ \text { C. } 01879 & 85937 & 1614 \\ 0.02437 & 84323 & 2055 \\ 0.03338 & 82268 & 2746 \\ C .04796 & 79522 & 3814 \\ \text { C. } 06929 & 75708 & 5246 \\ \text { C. } 10374 & 70462 & 7310 \\ C .15539 & 63152 & 9813 \\ 0.22721 & 53339 & 12119 \\ C .33048 & 41220 & 13622 \\ 1.00000 & 27598 & 27598\end{array}$

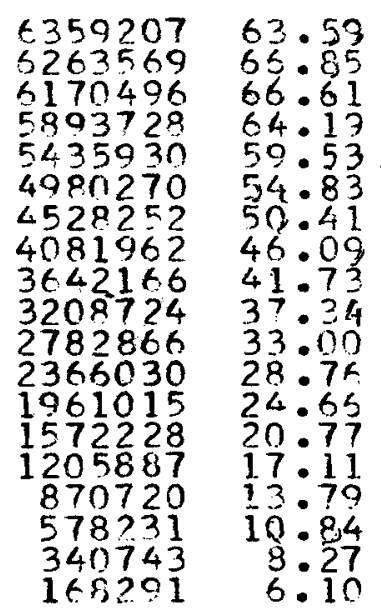

95639 276768 457798 455660 452018 446290 439796 433442 425858 416836 405015 388787 366341 335167 292489 237488 172452 168201

政


REGION__ARGENTINA

SEXO :-AMBOS_SEXOS

EPOCA : 1959-1961

$\times N \quad M(X, N) \quad C(X, N) \quad L(X) \quad C(X, N) L(X, N) \quad T(X) \quad E(X)$

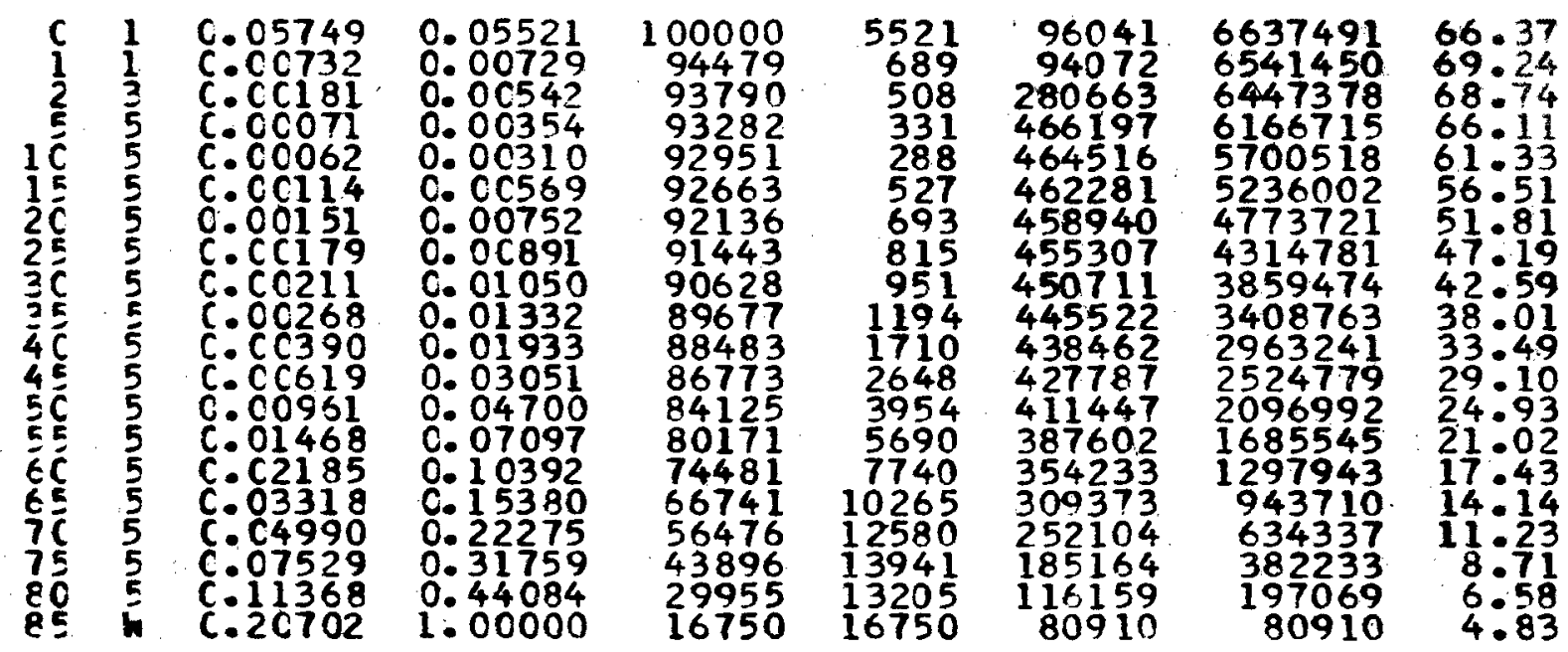

REGION : ARGENTINA

SEXO : VARONES

EPOCA : 1959-1961

$X \quad N \quad M(X, N) \quad O(X, N) \quad L(X) \quad C(X, N) L(X, N) \quad T(X) \quad E(X)$

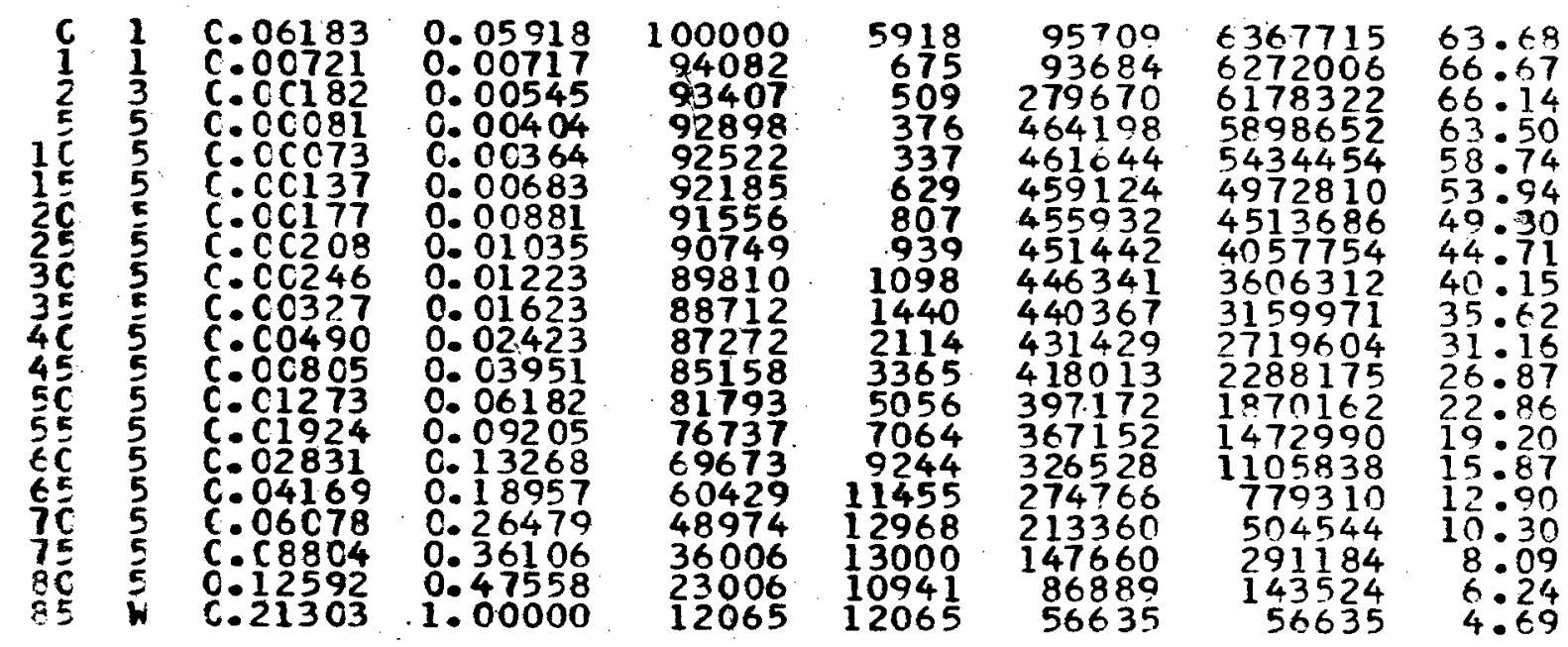




$\times \quad N \quad M(X, N) \quad G(X, N) \quad L(X) \quad r(X, N) L(X, N) \quad T(X) \quad E(X)$

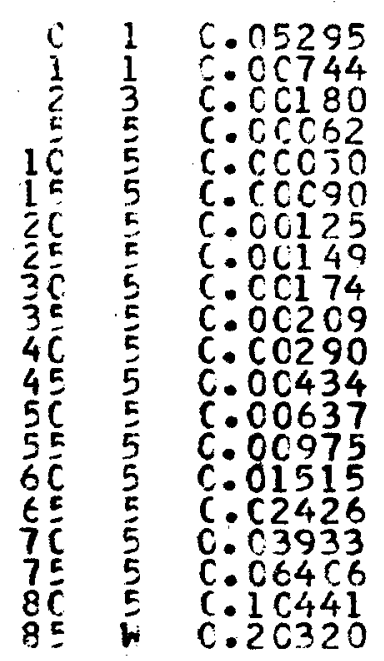

$0.05104 \quad 100000$

C. $00741 \quad 94896$

c. 00539

0.00310

0.06250

C. 00449

0.00623

0.00742

C. 00867

0.01040

0.01440

0.02148

C. 03139

0. 0476 ?

0.07316

C.11475

0.17979

0.27704

C. 41313

1. 00000
94193

93686

93396

93163

92745

92167

91483

scto0

30747

88454

86554

83837

79840

73999

65507

53729

38844

22726
$5104 \quad 96391$

$703 \quad 94481$

507

200

233

418

578

6.84

703

943

1293

1900

2717

3997

5841

$8<92$

11778

14885

16048

22796
281667
467942

466000

464445

462400

459060

255747

451198

44586 ?

437788

426531

409749

385545

350041
299466 23234.0

$15370 ?$

112105

$\begin{array}{ll}6952558 & 69.53 \\ 6856167 & 72: 25 \\ 5761686 & 71: 79 \\ 6480019 & 63: 17 \\ 6012277 & 64: 37 \\ 5546277 & 59: 53 \\ 5081832 & 54: 79 \\ 4619432 & 50.17 \\ 4160372 & 45: 48 \\ 3704625 & 40: 85 \\ 3253429 & 36: 25 \\ 2807567 & 31: 74 \\ 2367779 & 27: 39 \\ 1943248 & 23: 18 \\ 1533299 & 19: 20 \\ 1147754 & 15: 51 \\ 797713 & 12: 18 \\ 438247 & 9.27 \\ 265887 & 6: 144 \\ 112185 & 4.92\end{array}$


REGION : BUENOS AIRES

SEXXO_:AMBOS_SEXOS

EPOCA :-1913-1915

$\times \quad N \quad M(X, N) \quad Q(X, N) \quad L(X) \quad D(X, N) L(X, N) \quad T(X) \quad E(X)$

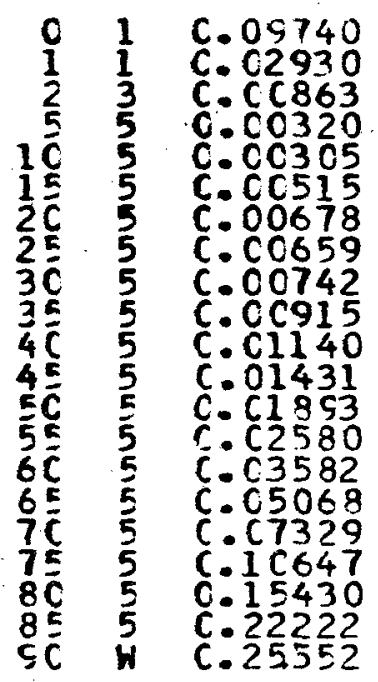

C. 09166

C. 02880

0.02557

0.01588

0. 01514

C. 02545

0.03338

c. 03246

0.03647

C. 04480

0.05553

0.06924

0.09063

C. 12161

C. 16505

C. 22583

C. 31052

C. 41940

C. 54256

C. 68666

1.00007
100000

90834

88218

85962

84597

83316

81196

78486

75939

73169

69891

66010

61439

55870

49076

40976

31722

21872

5733
9166

2616

2256

1365

1281

2120

2710

2547

2770

3278

3881

4571

5569

6794

8100

9254

9850

9173

6966

3937
94106 89291 261414 426563 420000

411651

399705

386495

373315

358251

340439

319427

294189

263333

226131

182597

134398

86156

45146

17717

7029

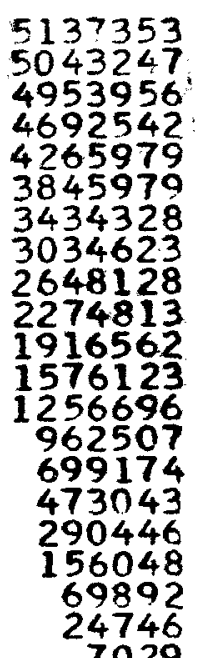

5043247

4692542

3845979

3434328

3034623

2274813

1916562

1576123

256696

699174

473043

290446
156048

24746

7029

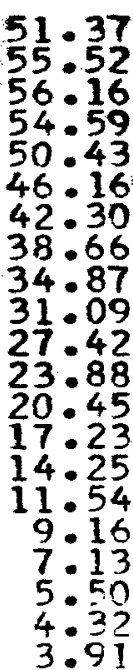

REGION : BUENOS AIRES

SEXO : VARONES

EPOCA : 1913-1915

$\times N M(X, N)$

$Q(X, N)$

$L(x)$

$D(X, N) L(X, N)$

$T(x)$

$E(x)$

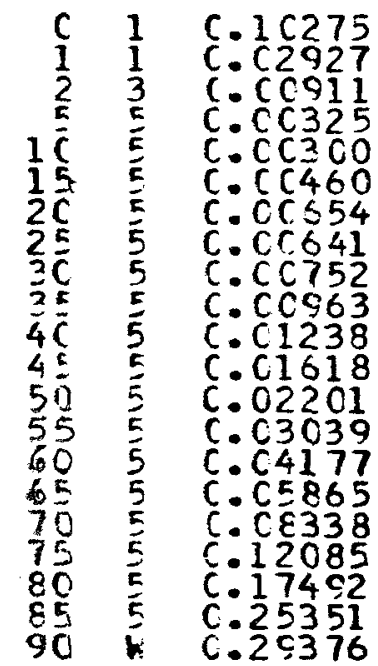

0. 09831

C. 02377

0.02598

C. 01613

0.01490

0.02276

C. 03221

0.03158

C. 03696

C. 04710

0.06017

0.07796

0.10464

0.14176

C. 18990

0.25673

0. 34548

C. 46144

C. 59554

0.73600
1.00000
100000

90369

87769

85401

82772

$808 \mathrm{~B}$

78282

75810

73008

69570
65384

653887

53978

46326

37529

27894

18257

9833

3977

1050
9631

2600

2368

1377

1252

1884

2472

3438

4186

5097

6309

7652

8797

9635

9637

8424
5856

2927
93730

88835

259934

423692

417333

409565

398471

385647

372606

357009

338126

315019

286642

251793

$21) 606$

164280

115579

69706

33478
11546

11546
3574
5007171

4913441

4824606

4564672

4140980

3723647

3314082

2915611

2529964

2157358
1800249

1462223

860562

608759

398163

232883

118304

48598

15120
50.07

$54 \cdot 37$

54.97

53.45

49.28

44.99

40.97

$37 \cdot 24$

29.55

$25: 89$

$22 \cdot 36$

15.04

13.14

10.61

9.39

5.48

4.04

3.80
3.40 
REGION : BUENOS AIRES

SEXO : MUJERES

EPOCA: 1913-1915

$X \quad N \quad M(X, N) \quad Q(X, N) \quad L(X) \quad D(X, N) L(X, N) \quad T(X) \quad E(X)$

$\begin{array}{ll}C & 1 \\ 1 & 1 \\ 2 & 3 \\ 5 & 5 \\ 1 C & 5 \\ 1 C & 5 \\ 1 C C & 5 \\ 2 C & 5 \\ 3 C & 5 \\ 3 E & 5 \\ 4 C & 5 \\ 4 c & 5 \\ 5 C & 5 \\ 5 E & 5 \\ 6 C & 5 \\ 65 & 5 \\ 7 C & 5 \\ 75 & 5 \\ 8 C & 5 \\ 8 C & 5 \\ 9 C & W\end{array}$

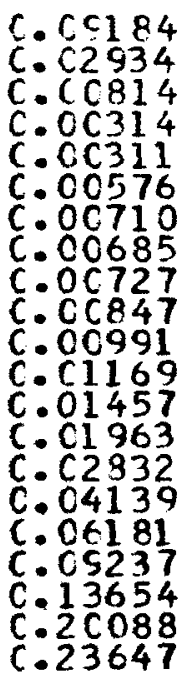

C. 08579

C. 02884

0.02414

0.01559

0.01544

C. 02842

0.03493

0.03372

0.03575

0.04153

0.04844

0.05690

0.07046

0.09384

C. 13273

0.18833

0.26866

0.37524

0.50408

:. 6 6 8322

1. 00000
100000

91321

88687

86546

85197

83832

81498

78652

76000

73283

70239

66837

63034

58593

53095

46048

37376

27335

8469

2979

8679
2634
2141
1349
1315
2384
2846
2652
2717
3044
3402
3803
4441
5498
7047
8672
0041
10257
8609
5490
2979

94498

89767

263022

429618

422830

413889

400845

387153

373728

359386

343200

325321

304804

28008 ?

248835

200519

162449

111043

63051

12598

$\begin{array}{rr}5323058 & 53 \cdot 23 \\ 5228560 & 57: 25 \\ 5138793 & 57: 94 \\ 4875771 & 56: 34 \\ 4446153 & 52.19 \\ 4023323 & 47.96 \\ 3609434 & 44.29 \\ 3208580 & 40.79 \\ 2821436 & 37.12 \\ 2447708 & 33.40 \\ 2088322 & 29.73 \\ 1745037 & 26: 11 \\ 1419711 & 22.52 \\ 1114907 & 19.03 \\ 834825 & 15: 72 \\ 585990 & 12.73 \\ 376471 & 10.07 \\ 214022 & 7.83 \\ 102979 & 6.03 \\ 39928 & 4.71 \\ 12598 & 4.23\end{array}$

REGION: BUENOS AIRES _SEXO:_VARONES _ EPOCA: 1913-1915 ORIGEN: ARGENTINA

$\times N \quad M(x, N) \quad Q(X, N) \quad L(X) \quad E(X, N) L(X, N) \quad T(X) \quad E(X)$

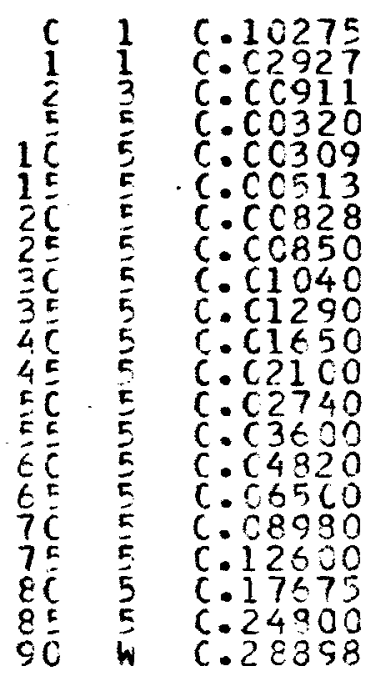

0.09631

0.02877

0.02698

0.01538

0.01534

0.02535

0.04062

0.04158

0.05077

0.06252

c. 07944

0.10007

0.12868

$0.165 \mathrm{B1}$

0. 21598

0.28052

C. 36636

ก. 47580

C. 5,0948

C. 72788

1. 00000

$\begin{array}{rr}100000 & 9631 \\ 90369 & 2600 \\ 87769 & 2368 \\ 85401 & 1356 \\ 84045 & 1280 \\ 82756 & 2098 \\ 80658 & 3276 \\ 77382 & 3225 \\ 74157 & 3765 \\ 70392 & 4408 \\ 65984 & 5242 \\ 60742 & 6079 \\ 54663 & 7034 \\ 47629 & 7897 \\ 39732 & 8581 \\ 31151 & 8738 \\ 22413 & 8222 \\ 14191 & 6752 \\ 7439 & 4460 \\ 2979 & 2168 \\ 811 & 811\end{array}$

4748792

4655062

4566227
4306293

3882543

3465391

3056424

2660772

2281360

1919341

1577636

1259939

970463

713748

494387

316358

181927

90368

36781

11548

2806
$47 \cdot 49$
$51: 51$
$52: 03$
$50: 42$
$46: 20$
$41: 87$
$37: 89$
$34: 39$
$30: 76$
$27: 27$
$23: 91$
$20: 74$
$17: 75$
$14: 99$
$12: 44$
$10: 16$
$8: 12$
$6: 37$
$4: 94$
$3: 88$
$3: 46$ 
REGION: BUENOS AIRES SEXO: MUJERES EPOCA: 1913-1915 ORIGEN: ARGENTINA

$\therefore N M(X, N) \quad O(X, N) \quad L(X) \quad D(X, N) L(X, N) \quad T(X) \quad E(X)$

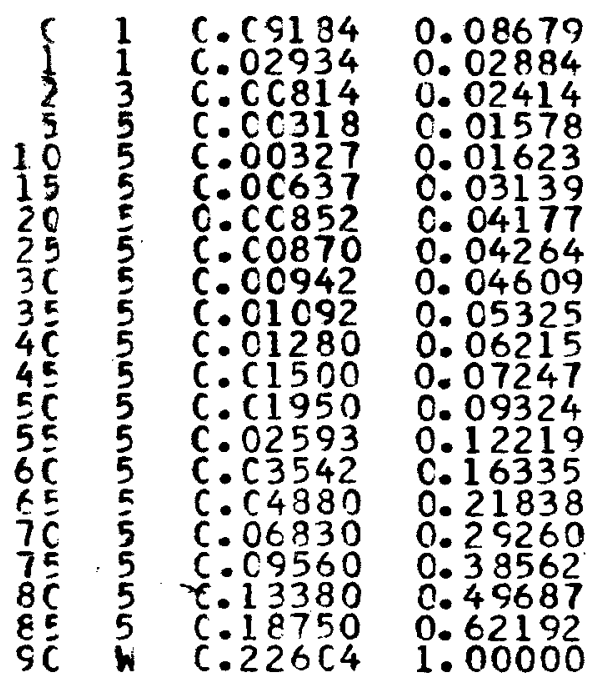

$\begin{array}{rrr}100000 & 8679 & 94498 \\ 91321 & 2634 & 89767 \\ 88687 & 2141 & 263022 \\ 86546 & 1366 & 429560 \\ 85180 & 1382 & 422630 \\ 83798 & 2630 & 412873 \\ 81168 & 3391 & 398005 \\ 77777 & 3316 & 381150 \\ 74461 & 3432 & 36431 \\ 71029 & 3782 & 346337 \\ 67247 & 4179 & 326484 \\ 63068 & 4570 & 304667 \\ 58498 & 5454 & 279692 \\ 53044 & 6481 & 249942 \\ 46563 & 7606 & 214737 \\ 38957 & 8507 & 174324 \\ 30450 & 8910 & 130454 \\ 21540 & 8306 & 86883 \\ 13234 & 6576 & 49148 \\ 6658 & 4141 & 22085 \\ 2517 & 2517 & 11135\end{array}$

$5051724 \quad 50.52$

$4957226 \quad 54.28$

$4867459 \quad 54.88$

460443753.20

$\begin{array}{ll}4174877 & 49.01 \\ 3752247 & 44.78\end{array}$

$3339374 \quad 41 \cdot 14$

$2560219 \quad 34.38$

$2195888 \quad 30.92$

$\begin{array}{ll}1849551 & 27: 50 \\ 1523067 & 24: 15\end{array}$

$1218400 \quad 20 \cdot 83$

$938708 \quad 17.70$

$688766 \quad 14.79$

$474029 \quad 12.17$

$299705 \quad 9.94$

1692517.86

$823686: 23$

$33220 \quad 4.97$

111354.42

REGION: BUENOS AIRES SEXO: VARONES EPOCA: 1913-1915 ORIGEN: EXTERIOR

$\times N \quad M(x, N) \quad Q(x, N) \quad L(x) \quad C(x, N) \quad L(X, N) \quad T(x) \quad E(x)$

\begin{tabular}{|c|c|c|c|c|c|c|}
\hline $\begin{array}{l}1 \\
1 \\
3 \\
5 \\
5 \\
5 \\
5 \\
5 \\
5 \\
5 \\
5 \\
5 \\
5 \\
5 \\
5 \\
5 \\
5\end{array}$ & 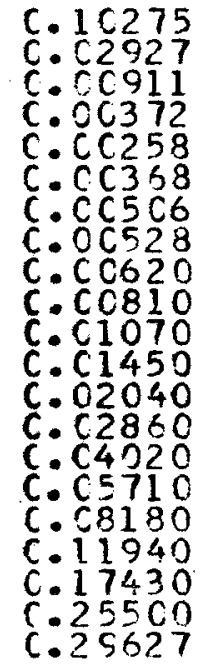 & $\begin{array}{l}C .09631 \\
0.02877 \\
0.02698 \\
C .01844 \\
0.01282 \\
0.01825 \\
C .02501 \\
0.02609 \\
0.03056 \\
0.03975 \\
0.05220 \\
0.07013 \\
0.09735 \\
C .13395 \\
0.18341 \\
C .25091 \\
0.34012 \\
0.45733 \\
0.50414 \\
0.73815 \\
1.00000\end{array}$ & $\begin{array}{r}100000 \\
90369 \\
87769 \\
85401 \\
83826 \\
82751 \\
81241 \\
79209 \\
77143 \\
74785 \\
71812 \\
68063 \\
63290 \\
57129 \\
49476 \\
40402 \\
30269 \\
19974 \\
10839 \\
4399 \\
1152\end{array}$ & $\begin{array}{l}9631 \\
2600 \\
2368 \\
1575 \\
1075 \\
1510 \\
2032 \\
2066 \\
2358 \\
2973 \\
3749 \\
4773 \\
6161 \\
7653 \\
9074 \\
10133 \\
10295 \\
9135 \\
6440 \\
3247 \\
1152\end{array}$ & $\begin{array}{r}937 \\
888 \\
2599 \\
4233 \\
4166 \\
4103 \\
4015 \\
3912 \\
3803 \\
3670 \\
3503 \\
3291 \\
3020 \\
2675 \\
2257 \\
1774 \\
1258 \\
765 \\
369 \\
127 \\
38\end{array}$ & $\begin{array}{l}141365 \\
047636 \\
958801 \\
698867 \\
275480 \\
858813 \\
448487 \\
046906 \\
655618 \\
275205 \\
908758 \\
557884 \\
228712 \\
926707 \\
650115 \\
433394 \\
255933 \\
130077 \\
53549 \\
16421 \\
3888\end{array}$ \\
\hline
\end{tabular}


REGION: BUENOS AIRES SEXO:_MUJERES EPOCA: 1913-1915 ORIGEN: EXTERIOR

$\times \quad N \quad M(X, N) \quad Q(X, N) \quad L(X) \quad E(X, N) L(X, N) \quad T(X) \quad E(X)$

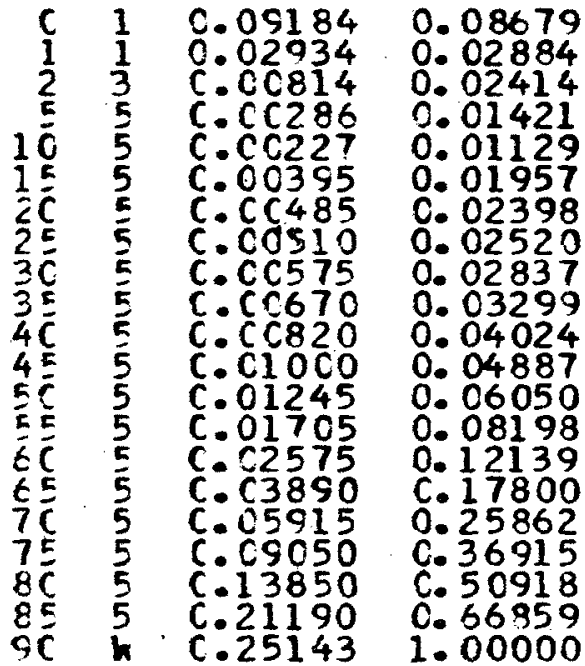

$100000 \quad 8679$ $91321 \quad 2634$ $88687 \quad 2141$ $86546 \quad 1220$ $85317 \quad 963$ $84354 \quad 1651$ $82703 \quad 1983$ $80720 \quad 2034$ $78686 \quad 2233$ 76453 73931 70956 67489 63406 58208 51142 42039 31167 19662 9650 3198
94498 89767 263022 429720 424229 417975 408866 398824 388348 376418 362905 346700 327952 304868 274408 234010 183804 127127 72289 30448 12719
$5568797 \quad 55.69$ $5474299 \quad 59.95$ $5384532 \quad 60.71$ $5121510 \quad 59.18$ $4691790 \quad 54.99$ $4267561 \quad 50.59$ $3849586 \quad 46.55$ $3440720 \quad 42.63$ $3041896 \quad 38.66$ $2653548 \quad 34.71$ $2277130 \quad 30.80$ $1914325 \quad 26.98$ $1567625 \quad 23 \cdot 23$ $1239673 \quad 19.55$ $934805 \quad 16.06$ $660397 \quad 12.91$ $426387 \quad 10.14$ 2425837.78 $115456 \quad 5: 87$ $43167 \quad 4.47$

$x N \quad M(X, N) \quad Q(X, N) \quad L(x) \quad D(X, N) L(X, N) \quad T(X) \quad E(X)$

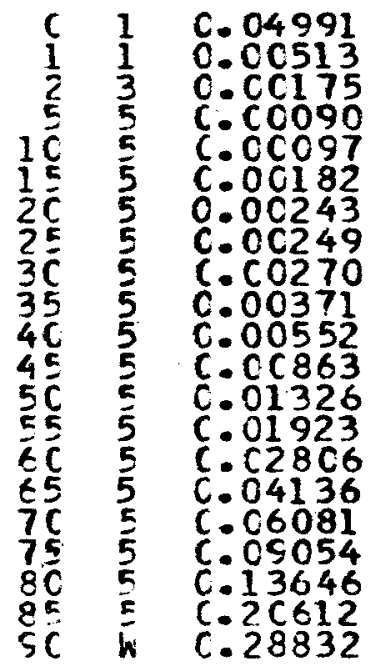

0.04815

0.00512

C. 00524

0.00449

0.00484

0.00906

0.01208

0.01238

0.01342

0.01839

0.02725

C. 04230

0. 06431

0.09201

C. 13159

0.18821

0. 26490

0.36928

0.50387

0.65805

1. 00000

$\begin{array}{rr}100090 & 4815 \\ 95185 & 487 \\ 94698 & 496 \\ 94202 & 423 \\ 93779 & 454 \\ 93325 & 846 \\ 92479 & 1117 \\ 91362 & 1131 \\ 90231 & 1211 \\ 89020 & 1637 \\ 87383 & 2381 \\ 85002 & 3596 \\ 81406 & 5236 \\ 76170 & 7008 \\ 69162 & 9101 \\ 60061 & 11304 \\ 48757 & 12916 \\ 35841 & 13235 \\ 22606 & 11391 \\ 11215 & 7380 \\ 3835 & 3835\end{array}$

6377461 6280986 6186088 5902659 5432659 4964618 4499783 4040112 3585895 3137376 2696136 2264795 1848109

1453237

1088806

491157

278758

132580 49105 13301
63.77

65.99

$65: 32$

57.93

48.66

44.22

39.74

$35: 24$

30.85

26.64

22.70

19.08

$15 \cdot 74$

10.07

7.78

35804

13301

5.86
4.38
3.47 


$\begin{array}{lllllll}X \quad N \quad M(X, N) \quad Q(X, N) \quad L(X) & C(X, N) L(X, N) & T(X) & E(X)\end{array}$

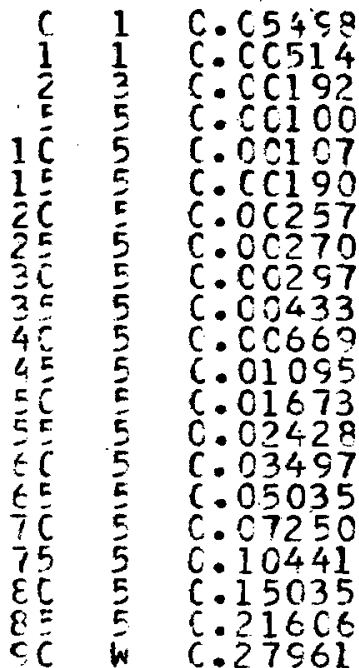

0.05283

0.0512

0.00499

D. $0 C 534$

0.00946

C. 01277

0.01342

0.02144

0.03294

C. 05339

C. 08050

0.11494

$0.1 \in 144$

0.?2453

C. 3 C 771

0.41313

C. 53900

0.67509

1. 0000 ón

$\begin{array}{rr}100000 & 5283 \\ 94717 & 485 \\ 94232 & 541 \\ 03691 & 467 \\ 93224 & 498 \\ 92726 & 877 \\ 91849 & 1173 \\ 90676 & 1217 \\ 89459 & 1319 \\ 88140 & 1899 \\ 86251 & 2841 \\ 83410 & 4453 \\ 78957 & 6356 \\ 72601 & 8338 \\ 64263 & 10375 \\ 53888 & 12099 \\ 41789 & 12859 \\ 28930 & 11952 \\ 16978 & 9151 \\ 7827 & 5291 \\ 2536 & 2536\end{array}$

96096
94431
281771
467000
465421
461579
456420
450741
444108
436259
424644
405687
270915
343410
296683
240798
177355
114472
60865
24489
9070

6131726
6035630 5941190

5650428

5192428

4727007

4265428

3800008

2358267

2014159

2477900

2053236

1646560

1266653

023243

626.50

385262

วกะด 96

94424

33559

9070
61.32

63.72

60.41

$55 \cdot 70$

50.98

42.01

37.54

33.06

28.73

24.62

$17: 45$

$14 \cdot 37$

$11 \cdot 63$

9.24

$5 \cdot 56$

3.58

REGION : BUENOS AIRES SEXO : MUJERES

EPOCA : $1946-1948$

$x N N(X, N) \quad G(X, N) \quad L(X) \quad D(X, N) L(X, N) \quad T(X) \quad E(X)$

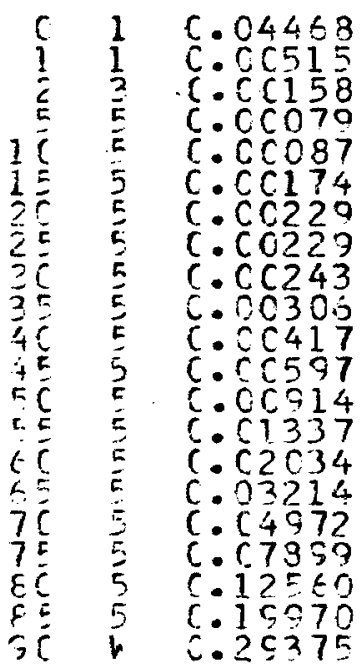

0.04328

0.0513

C. Cr 473

C. 00394

C. 00434

C. $0<867$

G. 0113n

0.01139

0. 01208

0.01519

C. 32055

0.02944

0.04475

C. 06483

0.14933

C. 22203

0.33048

0.47469

0.645 .97
100000

95672

35181

94731
04257

93047

93133

92072

01023

80923

$8672 B$

84174

80407

75194

67905

57758

44932

30083

15923
4329

491

450

374

410

?. 14

1081

1049

1100

1366

1829

2554

5213

7299

10139

12824

14840

14280

10298
96366

$9538 ?$

284610

473418

467816

463319

458079

452675

445405
438609

427806

389903

-58950

315464

257924

187986

113594

51117
6692578

$\leftarrow 585712$

6490330

5205520

5732102

$526083 \%$

470302 ?

432976

3971622

3418940

2972544

2533935

2106129

1693985

1304092

045232

$6>9768$

371844

183858

70164
19047
$66 \cdot 83$
$68: 84$
$68: 19$
$65: 51$
$67: 75$
$56: 00$
$51: 45$
$47: 03$
$42: 53$
$39: 02$
$33: 57$
$29: 22$
$25: 02$
$21: 07$
$17: 24$
$13: 92$
$19 \cdot 90$
$8: 29$
$6: 11$
$4: 44$
$3: 29$ 
REGION : BUENOS AIRES

SEXO : AMBOS SEXOS

EPOCA : 1959-1961

$x \quad N \quad M(X, N) \quad G(X, N) \quad L(X) \quad E(X, N) L(X, N) \quad T(X) \quad E(X)$

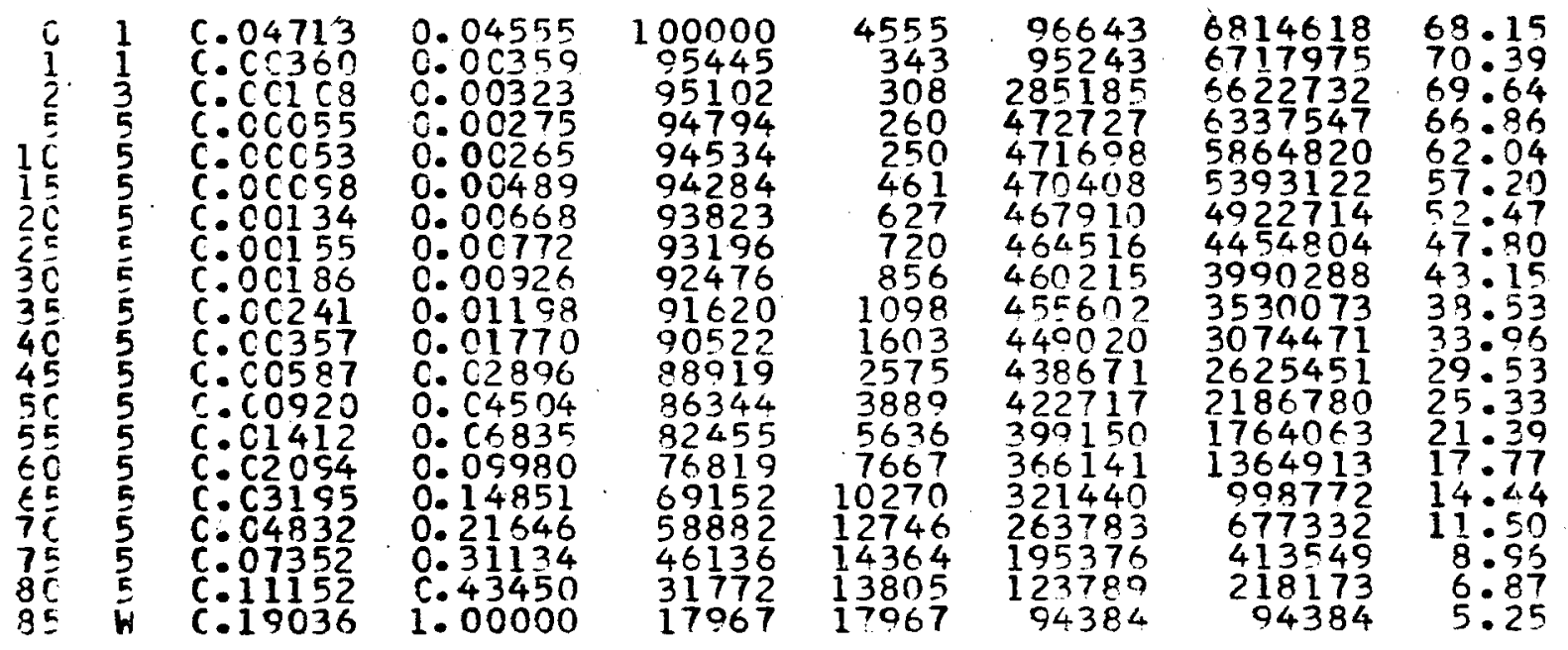

REGION : BUENOS AIRES

SEXO : VARONES

EPOCA : 1959-1961

$X \quad N \quad M(X, N) \quad C(X, N) \quad L(X) \quad[(X, N) L(X, N) \quad T(X) \quad E(X)$

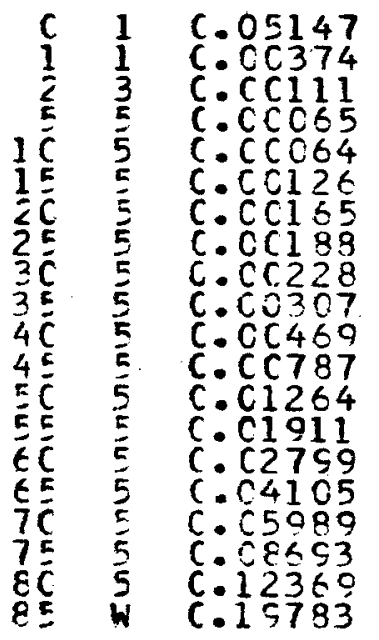

0.04957

C. 00373

C. 00332

0.00325

$0.0 \mathrm{c} 320$

$0.0 \mathrm{C628}$

C. C C 922

C. 0 C936

0.01134

C. 01524

0.02320

C. 03865

$0.0 \in 139$

0.09146

0.13129

0.18693

C. 26143

0.35738

1. 4.60000

$\begin{array}{rr}100000 & 4957 \\ 95043 & 355 \\ 94688 & 315 \\ 94373 & 306 \\ 94067 & 301 \\ 93766 & 589 \\ 93177 & 766 \\ 92411 & 865 \\ 91546 & 1038 \\ 90508 & 1380 \\ 89128 & 2068 \\ 87060 & 3364 \\ 83696 & 5138 \\ 78558 & 7185 \\ 71373 & 9370 \\ 62003 & 11590 \\ 50413 & 13179 \\ 37234 & 13307 \\ 23927 & 11231 \\ 12696 & 12696\end{array}$

355

315

301

766

865

1380

2068

3364

7185

9370
1590

3179

12696

96317
94834
283784
470769
470313
467460
464242
460106
455263
449511
440938
427446
406487
375981
334762
282339
220053
153077
90800
64176

6508658

6412341

6317507

6033723

5562954

5092641

4625181

4160939

3700833

3245570

2796059

2355121

1521188

1145207

810445

528106

308053

154976

64176
65.09

67.47

66.72

63.93

59.14

$54 \cdot 31$

49.64

45.03

35.86

$31 \cdot 37$

27.05

23.03

$19 \cdot 26$

13.07

13.48

8.27

6.48 
EPOCA : 1959-1961

$x \quad N \quad M(X, N) \quad Q(X, N) \quad L(X) \quad G(X, N) L(X, N) \quad T(X) \quad E(X)$

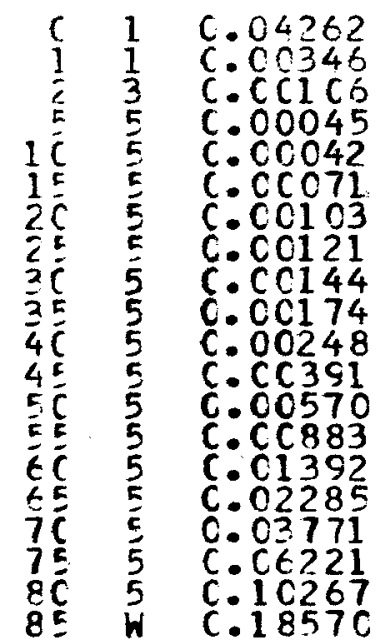

0.04134

C. 00345

0. 06318

C. 00225

0.00210

c. 00354

0.00514

0.00603

C. OC718

C. 0 C867

C. 01233

C. 01938

0. 02813

0.04326

C. 06741

0.10843

C. 173702

1. 00000
100000

95866

95535

95232

95018

04819

94483

93998

03431

92761

91957

90823

89063

86558

82813

77230

68850

56943

41560
4134

331

214

199

336

485

567

670

874

1134

1760

3745

5.583

8374

11913

15383

16048
24612

96986
95671
285849
47556
473810
473240
470814
468595
465278
462069
457258
450128
439474
424172
401078
364477
315911
247275
165073
132536

7167260

7070274

6.974603

6688754

6213198

5730389

$52 t \in 148$

4795274

$4326+79$

उ०E 1401

3209332

2042074

2491046

2052472

$162835 \%$

122727

$85079=$

544821

207600

33253 ?
71.47
$73: 75$
$73: 01$
$70: 24$
$55: 39$
$60: 53$
$55: 74$
51.01
$46: 31$
41.63
$36: 97$
$32: 39$
$27: 98$
$23: 71$
$19: 65$
$15: 29$
$12: 50$
$9: 57$
7.15
5.39

REGION : CENTRO LITORAL SEXO : AMBOS SEXOS

EPOCA : 1913-1915

$X N N(X, N) \quad Q(X, N) \quad L(X) \quad[(X, N) \quad L(X, N) \quad T(X) \quad E(X)$

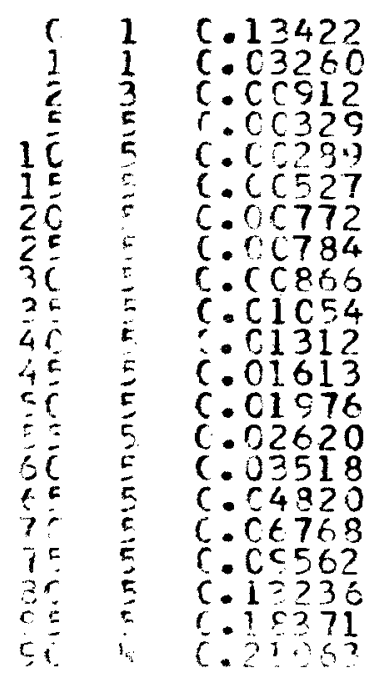

C. 12304

C. 03199

C. 02701

0.01633

C. 02503

0.03792

C. C3850

0.04245

C. 05144

0.06366

0.07772

0.04443

0.12338

0.16234

C. 21503

C. 29835

0.38568

0.49304

c. 61415

1. 00000

$\begin{array}{rr}100000 & 12304 \\ 87696 & 2805 \\ 84891 & 2293 \\ 82598 & 1349 \\ 81249 & 1166 \\ 80083 & 2085 \\ 77998 & 2958 \\ 75040 & 2889 \\ 72151 & 3063 \\ 69088 & 3554 \\ 65534 & 4172 \\ 61362 & 4769 \\ 56593 & 5344 \\ 51249 & 6323 \\ 44926 & 7293 \\ 37633 & 8128 \\ 20505 & 8557 \\ 20928 & 8075 \\ 12863 & 6342 \\ 6521 & 4005 \\ 2516 & 2516\end{array}$

91670 960 $<1$ 251425 410030 403460 395636 383161 353695 337192 317988 295660 270445 241336 207305 168631 126581

84449 47015 21901

11045
4874861 4783191 4697150 4445725 4035695
3632235 3236599 2053439 2484943 1704056 1475068 1180408 909963 468627 461322 292691

1大राin

O 1641 $337 / 6$ 11945
43.75 $54 \cdot 54$ $55 \cdot 33$
53.82 49.67 $45: 36$ 41.50 $38 \cdot C 3$ 34.44
30.85 27.39 20.86 $17: 76$ 14.89 $12: 26$ $9.5 ?$ $7 \cdot 93$ 6. ? 5 5.17 $\therefore .75$ 


$X N M(X, N) \quad Q(X, N) \quad L(X) \quad D(X, N) L(X, N) \quad T(X) \quad E(X)$

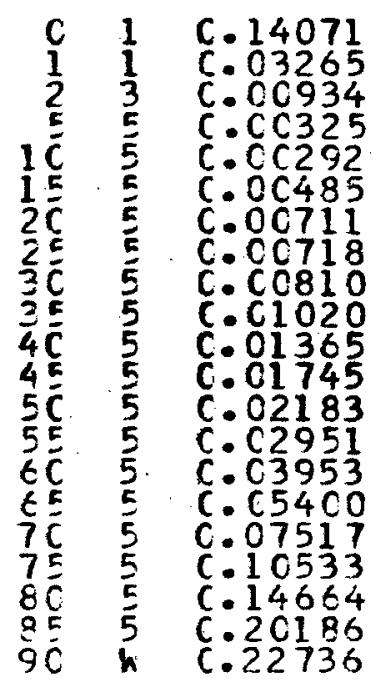

C. 12829

0.03203

0.02765

0.01613

0. 01450

0.02398

0.03497

0.03531

0.03975

0.04982

0.06615

0.08383

0.10383

0.13793

0.18062

0.23884

0.31716

C. 52985

0.65008

1. 00000

$\begin{array}{rr}100000 & 12829 \\ 87171 & 2792 \\ 84379 & 2333 \\ 82046 & 1323 \\ 80723 & 1171 \\ 79552 & 1908 \\ 77644 & 2716 \\ 74928 & 2646 \\ 72282 & 2873 \\ 69409 & 3458 \\ 65951 & 4362 \\ 61589 & 5163 \\ 56426 & 5859 \\ 50567 & 6975 \\ 43592 & 7874 \\ 35718 & 8531 \\ 27187 & 8623 \\ 18564 & 7721 \\ 10843 & 5745 \\ 5098 & 3314 \\ 1784 & 1784\end{array}$

91174
85524
249786
407077
401027
393402
381997
368524
354691
339020
319561
295874
268302
236361
199190
157981
114713
73303
39178
16417
7847

4801039

4709865

4624341

4374555

3967478

3566451

3173049

2791052

2422528

1728817

1409256

1113382

608629

409439

251458

63442

24264

7847
48.01

54.03

$54 \cdot 80$

49.15

44.83

40.87

37.25

$33 \cdot 51$

26.21

22.88

19.73

13.96

11.46

$9 \cdot 25$

$5 \cdot 85$

4.40

REGION : CENTRO LITORAL

SEXO : MUJERES

EPOCA : 1913-1915

$X \quad N \quad \sim(x, N$

$6(x, N)$

L. (x)

$D(X, N) L(X, N)$

$T(x)$

$E(x)$

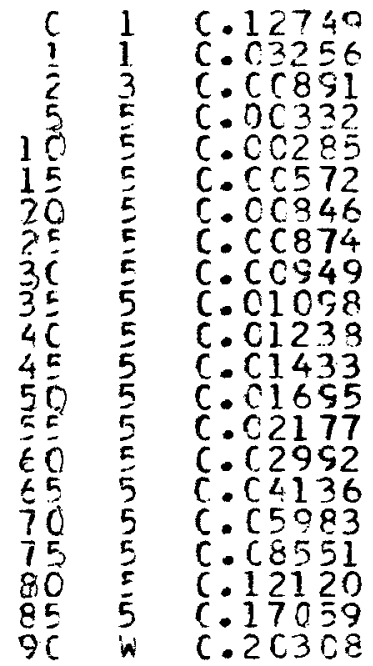

C. 11753
0.03194
0.02639
0.01147
0.01416
$C .02823$
0.04149
C. 04283
$C .04643$
0.05353
0.06017
0.06933
$C .02152$
0.10356
0.13972
0.18821
$C .26120$
$C .35255$
0.46243
0.58607
1.00000

100000

88247

85428

83173

81803

80645

78369

75118

71901

68563

64893

60989

56760

52133

46734

40204

32637

24112

15600

8391

3473

11753
2810
2255
1370
1158
2276
3251
3217
3338
3670
3904
4229
4627
5399
6530
7567
8525
8503
7218
4918
3473

92184 86584

253087
412651

406316

397902

384270
368078

351739
334244

315347

295115

272979

248002

218249

142487

99439

59554

28829

17102
40,67122

4874938

4788354

4535267

4122616

3716300

2318398

2934119

2566041

1880058

1269596
996617

748615

530365

347411
204924

105485

45931
17102
49.67

$55: 24$

$56 \cdot 05$

$50: 40$

46.08

42.34

35.69

$32: 30$

28.97

25.66

22. 27?

16.02

$13: 19$

$10 \cdot 64$

8.50

$6 \cdot 76$

4.92 
REGION: CENTRO LITORAL SEXO: VARONES EPOCA: 1913-1915 ORIGEN: ARGENTINA

$X N M(X, N) \quad Q(X, N) \quad L(X) \quad D(X, N) L(X, N) \quad T(X) \quad E(X)$

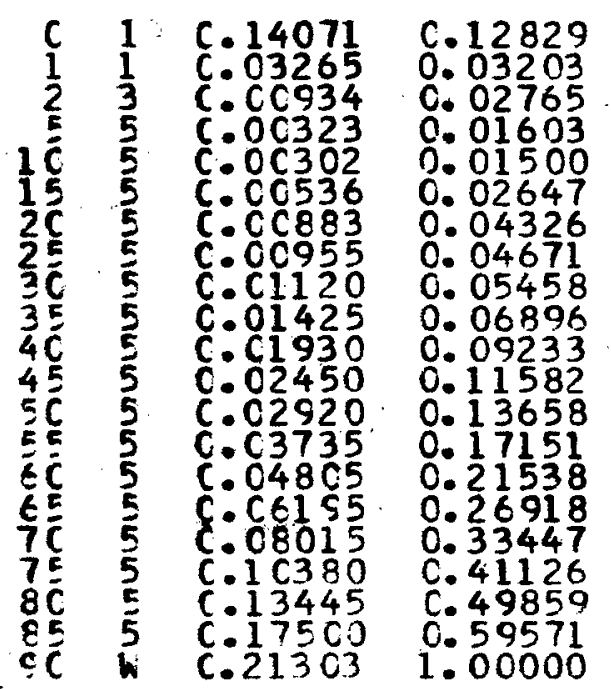

$\begin{array}{rr}100000 & 12829 \\ 87171 & 2792 \\ 84379 & 2333 \\ 82046 & 1315 \\ 80731 & 1211 \\ 79520 & 2105 \\ 77415 & 3349 \\ 74066 & 3460 \\ 70606 & 3854 \\ 66752 & 4603 \\ 62149 & 5738 \\ 56411 & 6534 \\ 49877 & 6812 \\ 43065 & 7386 \\ 35679 & 7685 \\ 27994 & 7535 \\ 20459 & 6843 \\ 13616 & 5600 \\ 8016 & 29997 \\ 4019 & 2394 \\ 1625 & 1625\end{array}$

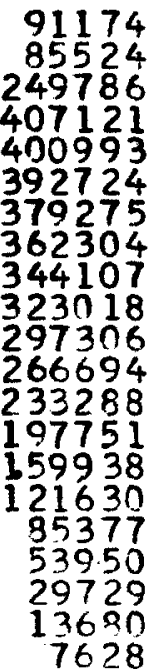

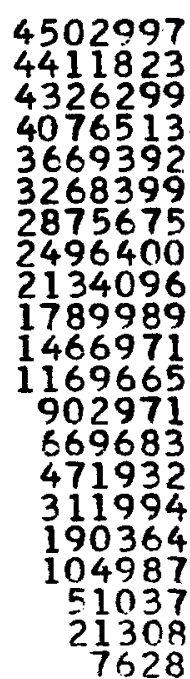

45.03

50.61

51.27

49.69

45.45

$41 \cdot 10$

$37 \cdot 15$

$33 \cdot 71$

$30 \cdot 23$

26.82

23.60

$20 \cdot 73$

$18 \cdot 10$

$15 \cdot 55$

$13 \cdot 23$

$11 \cdot 15$

$9 \cdot 30$

$7: 71$

$6 \cdot 27$

5.30

REGION:_CENTRO_LITORAL_SEXO:-MUJERES_-EPOCA: 1913-1915 ORIGEN:_ARGENTINA

$\times N \quad M(x, N) \quad Q(x, N) \quad L(X) \quad C(X, N) L(X, N) \quad T(X) \quad E(X)$

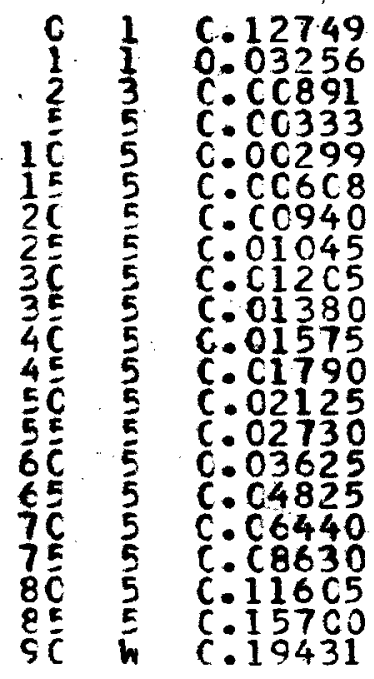

C. 11753

C. 03194

C. 02639

0.01652

0.01485

C. 02998

C. 04600

0.05101

0. 05861

C. 06685

$0.0759 t$

0.08590

0.10121

0.12824

0.16687

0.21618

0.27830

0.35529

C. 44773

0.55499
1.0000

$\begin{array}{rr}100000 & 11753 \\ 88247 & 2819 \\ 85428 & 2255 \\ 83173 & 1374 \\ 81799 & 1215 \\ 80584 & 2416 \\ 78168 & 3595 \\ 74573 & 3804 \\ 70769 & 4148 \\ 66621 & 4454 \\ 62167 & 4722 \\ 57445 & 4935 \\ 52510 & 5314 \\ 47196 & 6053 \\ 41143 & 6865 \\ 34278 & 7410 \\ 26868 & 7477 \\ 19391 & 6889 \\ 12502 & 5598 \\ 6904 & 3832 \\ 3072 & 3072\end{array}$

9218.4
86584 253087

412613

406355

397369

382447

364019

344232

322754

299810

275698

250071

221722

189370

153575

$11 \leqslant 103$

79826

48238

24408
15810
4736284 4644100 4557516 430442 ? 3891816 3485461 3088092 2705645 2341626

1997394

1674640

1374830

1099132

849061

627339

437960

284385

168282

88456

4ก 218

15810
$47 \cdot 36$
$52: 63$
$53: 35$
$51: 75$
$47: 58$
$43: 25$
$39: 51$
$36: 28$
$33: 09$
$29: 98$
$26: 94$
$23: 93$
$20: 93$
$17: 99$
$15: 25$
$12: 78$
$10: 59$
$8: 68$
$7: 08$
$5: 83$
$5: 15$ 
REGION:_CENTRO_LITORAL_SEXO___VARONES__EPOCA:_1913-1915___ORIGEN:_EXTERTOR

$\times N M(X, N) \quad Q(X, N) \quad L(X) \quad O(X, N) L(X, N) \quad T(X) \quad E(X)$

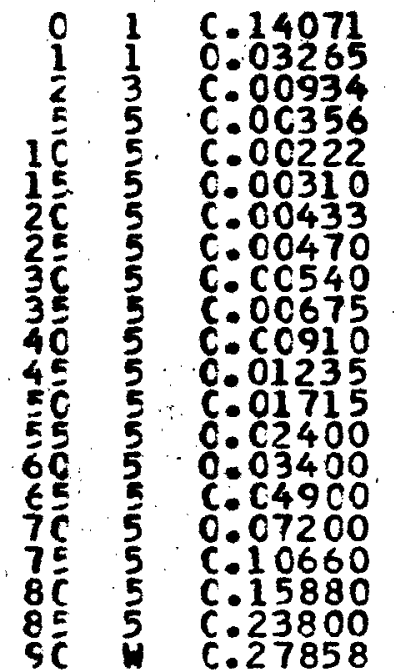

0.12829

0.03203

0. 02765

c. 01765

0.01104

0. 01539

0.02144

0.02325

0.02667

0.03323

0.04456

0.06003

0.08245

0.11359

0. 15731

0.21917

0.30593

0.41979

0. 55922

1. 71253
100000

87171

84379

82046

80597

79707

78480

76798

75013

73013

67442

63394

58167

51560

43449

33926

23547

13662

6022
12829

2792

2333

1449

890

1227

1682

1785

2000

2426

3145

4048

5227

6607

8111

9523

10379

9885

7640

4291

91174
85524
249786
407022
400901
395806
388453
379787
370370
359407
345604
327773
304791
275292
238559
194347
144153
92730
48111
18029
6214

5123823

5032649

4947125

4697339

4290317

3889416

3493610

3105157

2725370

2355000

1649989

1322216

1017435

742143

503584
309237

165084

72354

24243

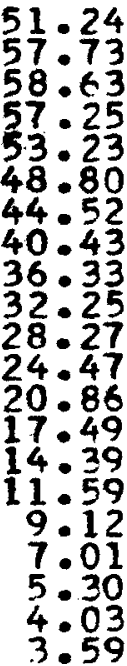

REGION: :CENTRO LITORAL_SEXO:_MUJERES_EROCA: I913-1915_ORIGEN:_EXTERIOR.

$X N M(X, N) \quad Q(X, N) \quad L(X) \quad D(X, N) L(X, N) \quad T(X) \quad E(X)$

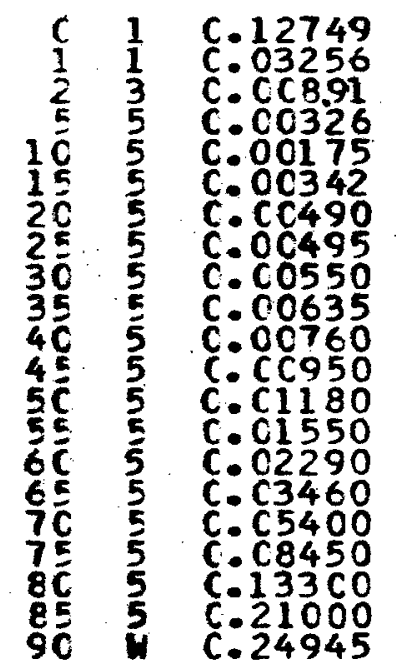

0.11753
0.03194
0.02639
0.01618
0.00871
0.01697
0.02423
0.02447
0.02715
0.03129
0.03734
0.04648
0.05742
0.07480
0.10866
0.15987
0.23884
0.34926
0.49474
0.66516
1.00000
100000

88247

85428

83173

81827

81114

79738

77806

75902

73841

71530

68859

65659

61889

57260

51038

42879

32638

21239

10731

11753
2819
2255
1346
713
1376
1932
1904
2061
2311
2671
3200
3770
4629
6222
8159
10241
11399
10508
7138
3593

92184
86584
253087
412883
407429
402339
394286
384647
374727
363937
351447
336842
319492
298645
271703
235809
189648
134899
79008
33090
14404

5437990
5345806
5259222
5006135
4593252
4185823
3783484
3389198
3004551
2629824
2285887
1914440
1577598
1258106
959461
687758
451949
262301
127402
48394
14404

54.38

60.58

61.56

60.19

56.13

51.60

47.45

$33 \cdot 56$

35.61

31.69

27.80

24.03

$20 \cdot 33$

13.48

10.54

8.04

6.00

4.51 
REGION: CENTRO LITORAL

SEXO_:AMBOS SEXOS

EPOCA

$x \quad N \quad M(X, N) \quad Q(X, N) \quad L(X) \quad C(X, N) L(X, N) \quad T(X) \quad E(X)$

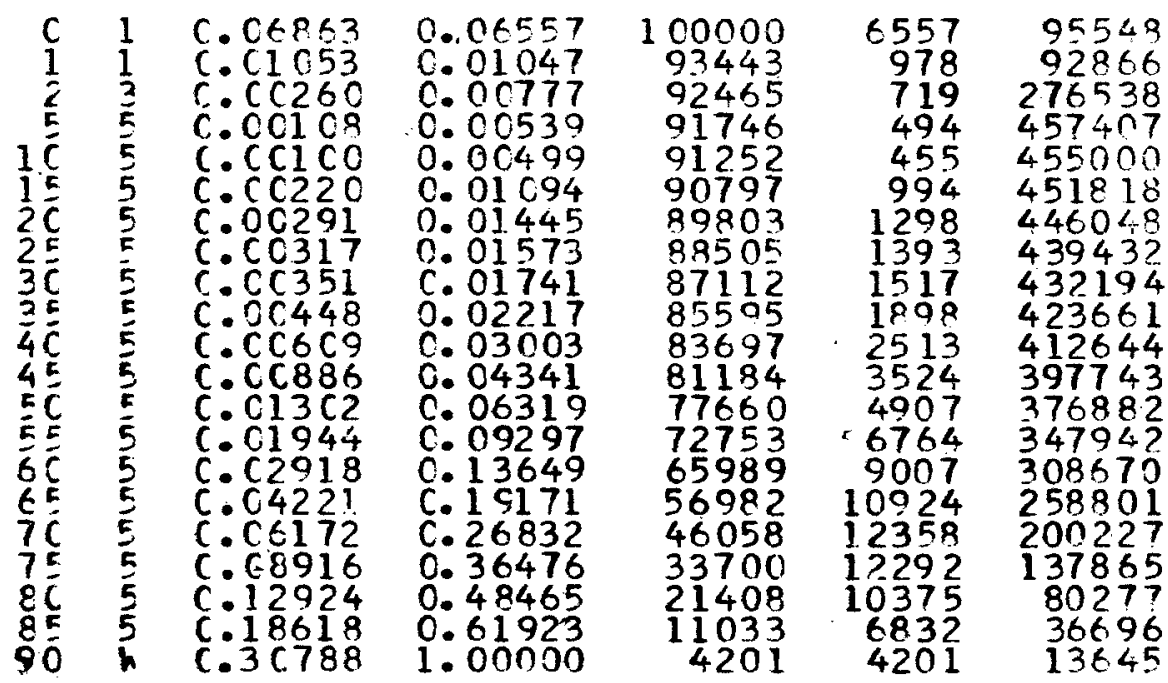

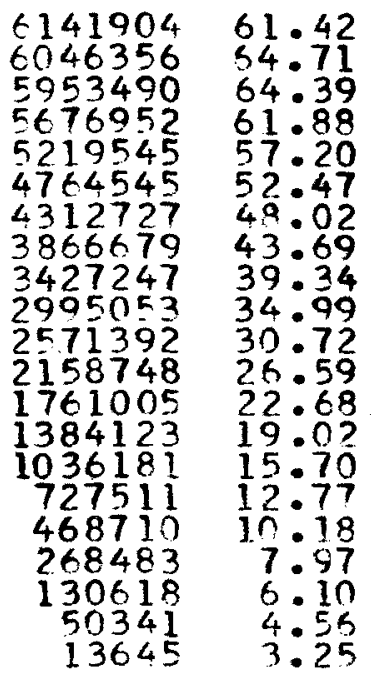

REGION : CENTRO LITORAL

SEXO : VARONES

EPOCA : $1946-1948$

$x N M(X, N) \quad Q(X, N) \quad L(X) \quad D(X, N) L(X, N) \quad T(X) \quad E(X)$

0.06969

0.01058

C. 00762

$0.0 \mathrm{C} 593$

$0.0 \mathrm{C5} 14$

0.01065

C. 01445

0.01588

C. 01859

0. 02388

0.03357

C. 05034

0. 0.7466

C. 1 C911

C. 15607

0.21750

C. 30016

0.40299

0.52455

1. 00000

$\begin{array}{rr}100000 & 6969 \\ 93031 & 984 \\ 92047 & 702 \\ 91345 & 542 \\ 90803 & 467 \\ 90336 & 962 \\ 89374 & 1292 \\ 88082 & 1399 \\ 86683 & 1611 \\ 85072 & 2032 \\ 83040 & 2788 \\ 80252 & 4060 \\ 76212 & 5690 \\ 70522 & 7694 \\ 62828 & 9806 \\ 63022 & 11532 \\ 41490 & 12454 \\ 29036 & 11701 \\ 17335 & 9093 \\ 8242 & 5416 \\ 2826 & 2826\end{array}$

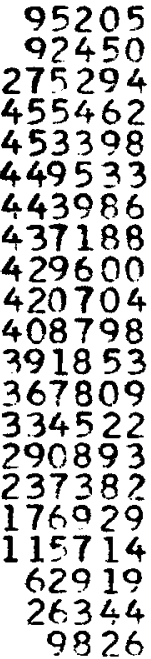

5975809

5880604

5788154

5512860

5057398

4604000

4154467

3710481

3273293

2843693

2422989

2014191

1622338

1254529

920007

629114

391732

214803

99089

36170

9826
$50.7 t$

63.21

$62 \cdot 88$

60.35

55.70

46.48

42.13

$37: 76$

33.43

$20: 18$

$25: 10$

$21 \cdot 29$

17.79

$14 \cdot 64$

11.87

9.44

7.40

$5 \cdot 72$

3.48 
RECTON : CENTRO LITORAL

SEXO : MUJERES

EPOCA : 1946-1948

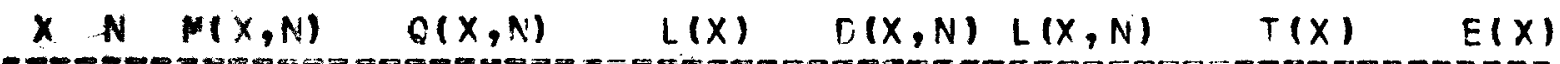

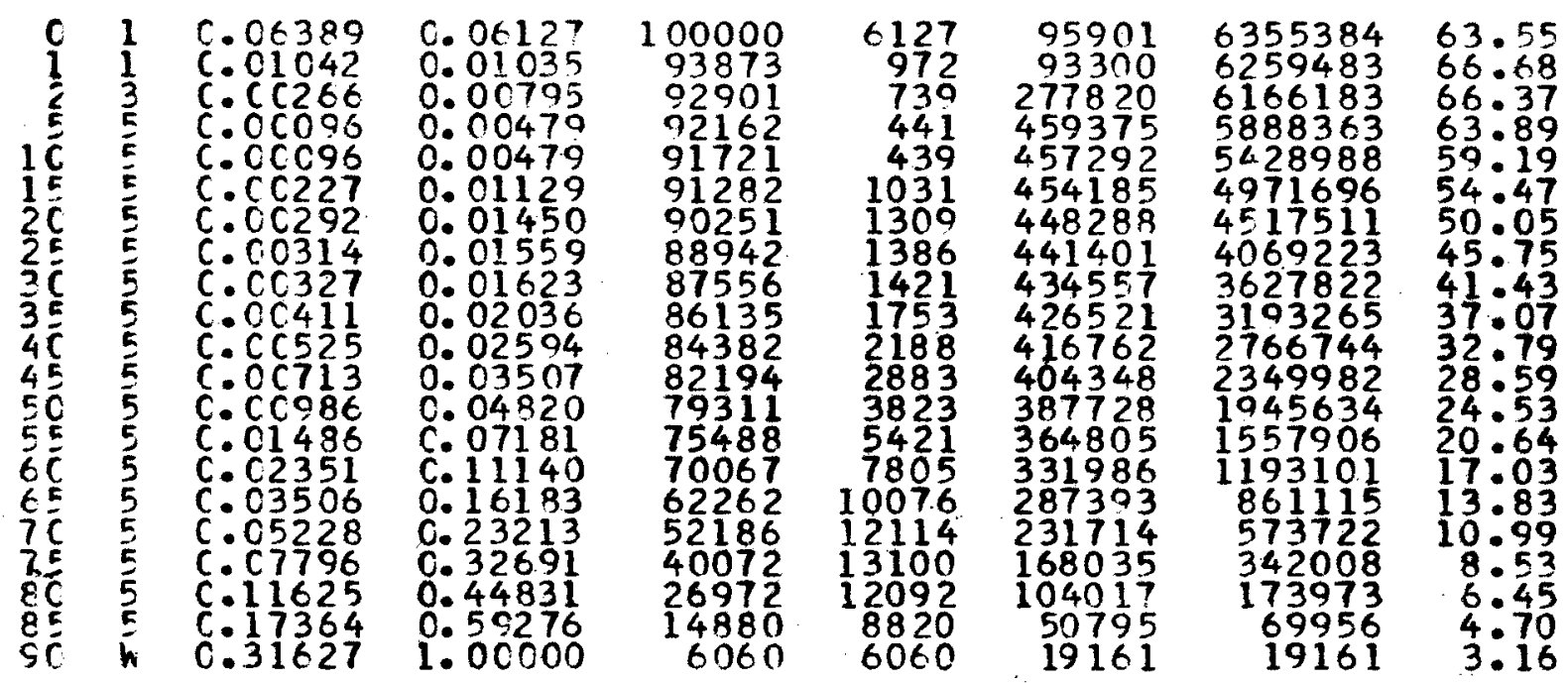

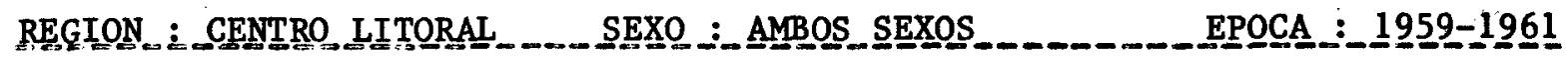

$X \quad N \quad M(X, N) \quad G(X, N) \quad L(X) \quad D(X, N) L(X, N) \quad T(X) \quad E(X)$

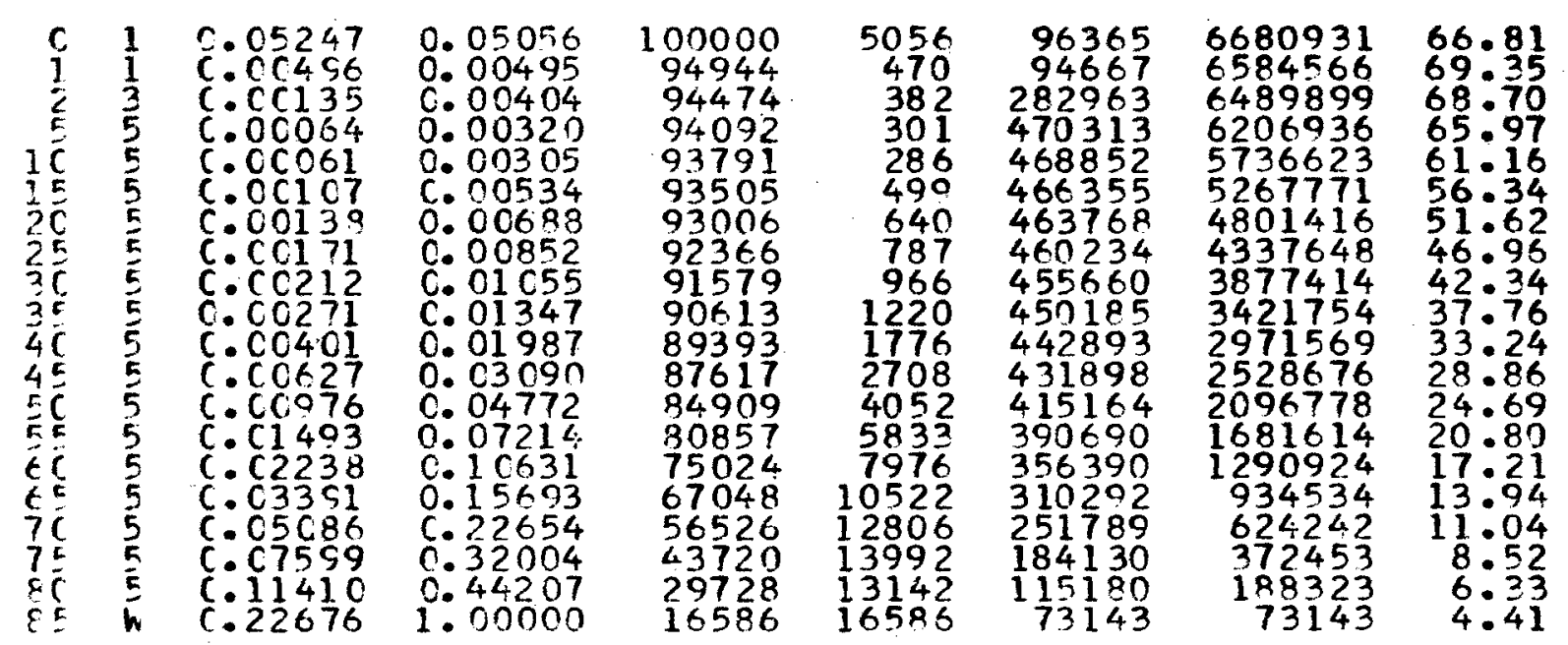


REGION : CENTRO LITORAL

SEXO : VARONES

EPOCA : 1959-1961

$x N \mu(x, N) \quad Q(X, N) \quad L(x) \quad D(X, N) L(X, N) \quad T(X) \quad E(X)$

$\begin{array}{ll}C & 1 \\ 1 & 1 \\ 2 & 3 \\ E & E \\ 1 C & 5 \\ 15 & 5 \\ 15 & 5 \\ 2 C & 5 \\ 2 E & 5 \\ 3 C & 5 \\ 35 & 5 \\ 4 C & 5 \\ 4 E & 5 \\ 5 C & 5 \\ 55 & 5 \\ E C & 5 \\ 6 E & 5 \\ 7 C & 5 \\ 7 E & 5 \\ 8 C & 5 \\ 8 E & 4\end{array}$
C. 05463

0.00493

0.00416

C. 00359

0.00359

0.00663

0.00832

0.00986

0.01208

0.01603

C. 02423

0.03932

0.06064

C. 12996

0.26335

1. 400000

$\begin{array}{rr}100000 & 5463 \\ 94537 & 466 \\ 94071 & 391 \\ 93680 & 337 \\ 93343 & 335 \\ 93008 & 617 \\ 92391 & 769 \\ 91622 & 903 \\ 90719 & 1096 \\ 89623 & 1437 \\ 88186 & 2136 \\ 86050 & 3384 \\ 82666 & 5013 \\ 77653 & 6985 \\ 70668 & 9184 \\ 61484 & 11554 \\ 49930 & 13149 \\ 36781 & 13224 \\ 23557 & 11272 \\ 12285 & 12285\end{array}$

96028
94262
281295
468056
465278
463910
460479
456061
451029
444892
435919
422472
401683
371938
331672
279826
217699
150993
88763
53267

06028

281295

465278

463910

460479

451029

444892

435919

401683

331672

279826

217699

88763
6435522

6339494

6245232

5963937

5495881

5030603

4566693

4106214

3650153

3199124

2754232

2318313

1895841

1122220

510722

293023

142030
$64 \cdot 36$

67.06

66.39

63.66

58.88

54.09

49.43

44.82

$40 \cdot 24$

$31 \cdot 23$

$26 \cdot .94$

$22 \cdot 93$

15.88

12.86

$10 \cdot 23$

$6 \cdot 03$

REGION__ GENTRQ IITORAL

SEXO_- MUJERES

EROCA_-1259-1961

$\times N \quad M(X, N) \quad C(x, N) \quad L(X) \quad C(X, N) L(X, N) \quad T(X) \quad E(X)$

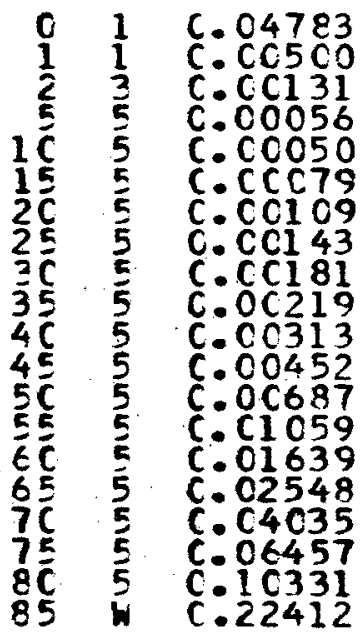

c. 04626

0.00498

$0.0 \mathrm{C} 392$

$0: 00280$

0.00250

$0.00394^{4}$

$0.0 C 544$

$0.0 C 713$

C. Cosol

0.01090

C. 01554

C. $C 2237$

0.03381

0.05168

C. $C 7893$

0.12019

C. 18403

C. 27893

0.4 C976

1. $00 \mathrm{COO}$
100000 95374

94899

94527

94263

94028

93657

93148

02484

91650

90651

89242

87246

84296

79940

73630

64780

52859

32115

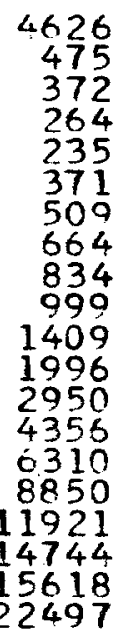

4626
475
372
264
235
371
509
664
834
990
1409
1996
2950
4356
0310
8850
1921
4744
5618
2497

96725
95094
283969
471429
470000
469620
466973
464336
460774
456164
450160
441593
420403
411332
384991
347331
295440
228342
151176
100379

6975231

6878506

6783412
6499443

6028014

5558014

5088394

4621421

4157085

3696311

3240147

2789987

2348394

1918991

1507659

1122668

479897

251555

100379
69.75

72.12

68.76

63.95

59.11

49.61

$44: 95$

40.33

35.74

31.26

26.92

22.75

18.86

$15 \cdot 25$

9.03

6.60

4.45 


$X \quad N \quad M(X, N) \quad Q(X, N) \quad L(X) \quad D(X, N) L(X, N) \quad T(X) \quad E(X)$

0.15733

0.06856

0.04218

0.02452

0.01662

0.02740

0.04494

0.04695

0.05211

0.06488

0.08032

C. 09894

0.12458

C. 20702

0.34855

0.44495

0.55789

0.68144

1. 0000n
100000

84267

78490

75179

73336

72117

70141

66989

63844

60517

56591

52046

41055

34397

27276

19939
12989

7210

3188

1016
15733
5777

3311

1843

1219

1976

3152

3145

3926

4545

5149

5842

6658

7121

6950

5779

4022

2172

1016
89569

80859

230732

371573

363881

356036

343355

327604

311517

293423

272319

248145

220703

189471

154905

118530

82453

50213

25419

9910

3943
$4144560 \quad 41.45$

$4054901 \quad 48.12$

$3974132 \quad 50.63$

$3743400 \quad 49.79$

$3371827 \quad 45.98$

$3007946 \quad 41.71$

$2651910 \quad 37.81$

$2308555 \quad 34.46$

198095131.03

$1669434 \quad 27.59$

137601124.32

$1103692 \quad 21.21$

$855547 \quad 18.24$

63484415.46

$445373 \quad 12.95$

$290468 \quad 10.65$

171938

89485

39272

3943

8.62

$5 \cdot 45$

4.45

3.89

REGION : CUYO

SEXO : VARONES

EPOCA : 1913-1915

$X N \quad N(X, N) \quad G(X, N)$

$L(x)$

$D(X, N) L(X, N)$

$T(x)$

$E(x)$

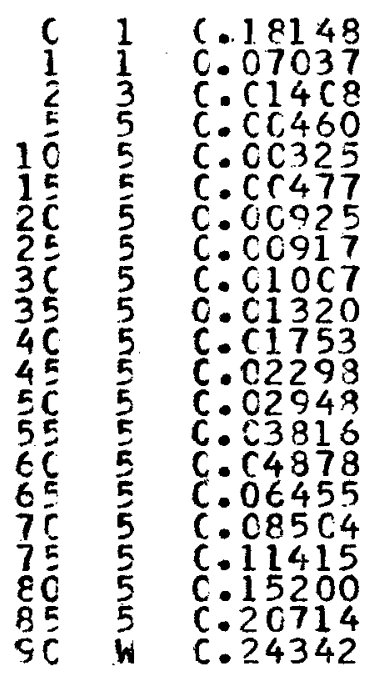

C. 16173

0.06757

C. 04140

0.02276

0.01613

C. 02359

0.04528

0. 04490

0.06403

0.08420

C. 10902

0.13780

0.17490

0.21830

0.27886

C. 35107

0.44221

0.54301
0.65993

1. 00000
100000

83827

78163

73222
72041

70342

67157
64142

64142
60986

57081

52275

46576

40158

33134

18678

12121

6761

3090

1051
16173

5664

3236

1705

1181

1699

3185

3015

3156

4806
5699

6418

7233

7223

6557

5360

3671

2039

1051
89116 80485 220830

363385

35610.5

344324

328790

313406

205233

274159

247908

217707

184067

148278

1.11899

77105

46956

24151

4318
4118487 4029371

3948886

3719056

3348404

2085019

2628834

2284510

1955720

1642314

1346481

824324
606617

422550
274272

162374
85269

38313

14162

4318
$41 \cdot 18$

$48: 07$

$50 \cdot 52$

49.64

45.73

$37: 37$

34.02

30.49

23.59

$20: 51$

15 .11

$12: 75$

8.69

7.03

5.67

4.58

4.11 


$x N M(X, N) \quad G(X, N) \quad L(X) \quad D(X, N) L(X, N) \quad T(X) \quad E(X)$

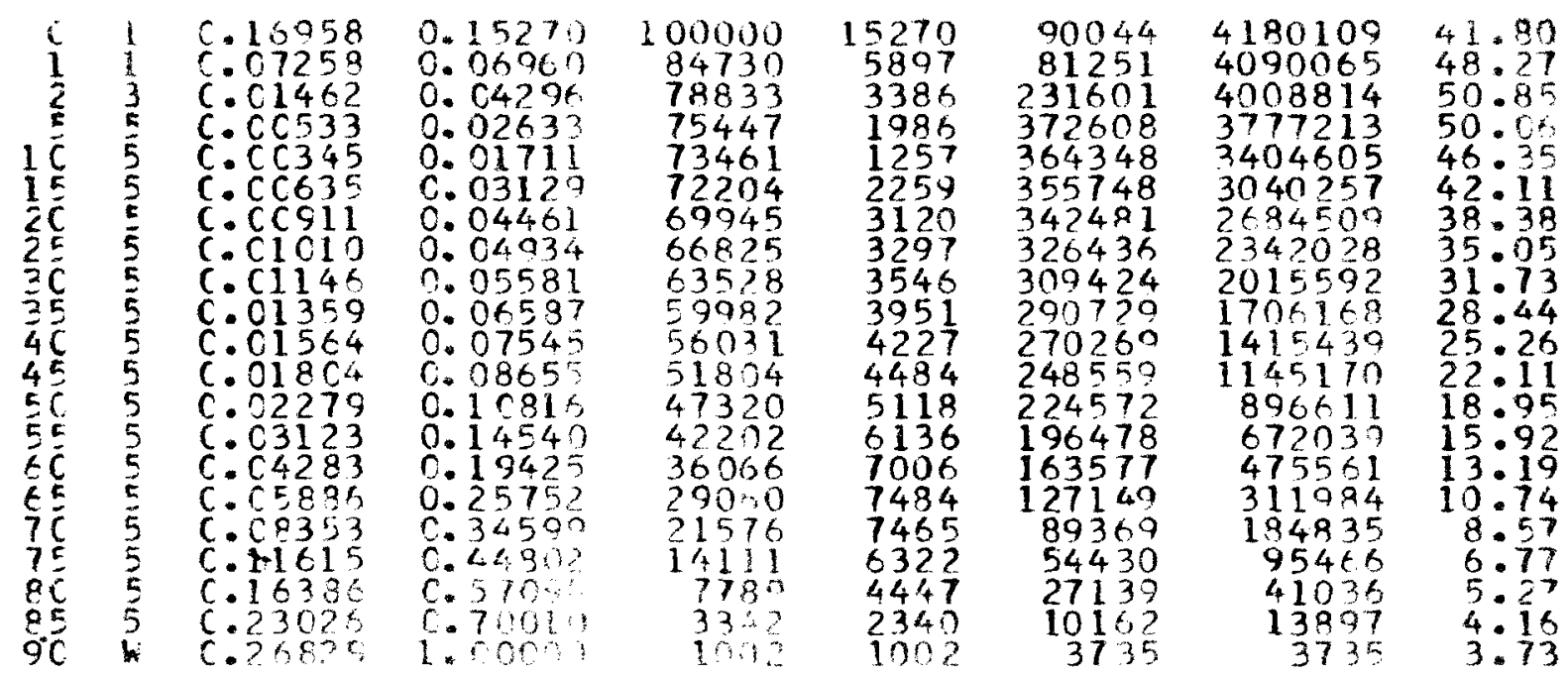

REGION : CUYO SEXO : VAKONES EPDCA : 1913-1913, ORIGEN : ARGENTINA

$\times N M(x, N) \quad(x, N) \quad[(x, \quad[(x, N)(x, N) \quad r(x) \quad E(x)$

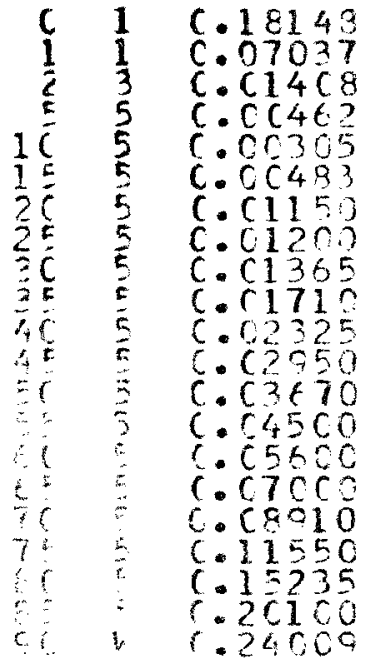

100000 33927

78163

$749 ? 7$

73214

72105

70383

66441

67563

58425

43622

41132

34190

27246
20528

14395

9147

$-166$

2. 311
16173 5664

3236

1713

$110^{\circ}$

1722

3942

3878

4139

4803

5911

6942

6944

6718

6133

5248

4091

2755

\&1?
89116 00485 229830 370779 363607 $\times 56522$ 342783 323167 303150 280877 254237 223017 $1891=5$ 154311

119064

87614

58000

35333

18087

7458 339 ?
3891770 3802654 3722169 3492339 3121560 2757953 2401431 2050649 1735481

1432331 1151454 674200 485045 330734 210770

123156 64256 28923 10940

$328 ?$
$38 \cdot 92$

47.62

46.61

$42 \cdot t 4$

38.25

$34 \cdot 12$

30.98

$27 \cdot 7$

$21 \cdot 47$

18.81

16.39

14.19

12.14

10.27

8.56

7.02

5.71

i. 89 


\begin{tabular}{|c|c|c|c|c|c|c|c|c|}
\hline \multicolumn{3}{|c|}{ REGION : CUYO } & \multicolumn{4}{|c|}{ EPOCA : 1913-1915 } & \multicolumn{2}{|c|}{ ORIGEN : ARGENTINA } \\
\hline$x$ & $N$ & $M(X, N)$ & $C(X, N)$ & $L(x)$ & $C(X, N)$ & $L(X, N)$ & $T(x)$ & $E(x)$ \\
\hline 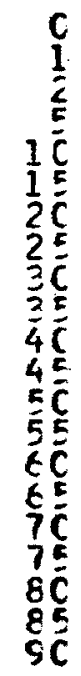 & $\begin{array}{l}1 \\
1 \\
3 \\
5 \\
5 \\
5 \\
5 \\
5 \\
5 \\
5 \\
5 \\
5 \\
5 \\
5 \\
5 \\
5 \\
5 \\
5 \\
5 \\
5 \\
4\end{array}$ & 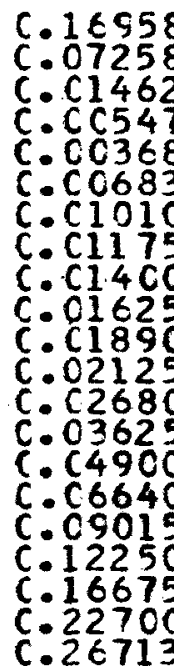 & $\begin{array}{l}0.15270 \\
0.06960 \\
C .04296 \\
0.02701 \\
0.01825 \\
0.03362 \\
0.04934 \\
0.05719 \\
0.06779 \\
0.07828 \\
0.09050 \\
0.10121 \\
0.12604 \\
0.16687 \\
0.21911 \\
0.28567 \\
0.36801 \\
0.46608 \\
C .57750 \\
0.69472 \\
1.00000\end{array}$ & $\begin{array}{r}100000 \\
84730 \\
78833 \\
75447 \\
73409 \\
72070 \\
69647 \\
66210 \\
62424 \\
58192 \\
53637 \\
48783 \\
43846 \\
38320 \\
31926 \\
24929 \\
17808 \\
11255 \\
6009 \\
2539 \\
775\end{array}$ & $\begin{array}{r}15270 \\
5897 \\
3386 \\
2038 \\
1339 \\
2423 \\
3437 \\
3786 \\
4232 \\
4555 \\
4854 \\
4937 \\
5526 \\
6394 \\
6997 \\
7121 \\
6553 \\
5246 \\
3470 \\
1764 \\
775\end{array}$ & $\begin{array}{r}900.44 \\
81251 \\
231601 \\
372578 \\
363859 \\
354758 \\
340297 \\
322213 \\
302286 \\
280308 \\
256825 \\
232329 \\
206194 \\
176386 \\
142796 \\
107244 \\
72690 \\
42825 \\
20810 \\
7771 \\
2901\end{array}$ & $\begin{array}{r}4007966 \\
3917922 \\
3836671 \\
3605070 \\
3232492 \\
2868633 \\
2513875 \\
2173578 \\
1851365 \\
1549079 \\
1268771 \\
1011946 \\
779617 \\
573423 \\
397037 \\
254241\end{array}$ & $\begin{array}{l}8 \\
4 \\
7 \\
8 \\
3 \\
0 \\
9 \\
3 \\
6 \\
2 \\
5 \\
4 \\
8 \\
6 \\
4 \\
0 \\
5 \\
0 \\
4 \\
0\end{array}$ \\
\hline
\end{tabular}

REGION_:CUYO SEXO_: VARONES EPOCA : 1913-1915 ORIGEN : EXTERIOR

$\times \quad N \quad M(X, N) \quad Q(x, N) \quad L(x) \quad C(X, N) \quad L(X, N) \quad T(X) \quad E(X)$

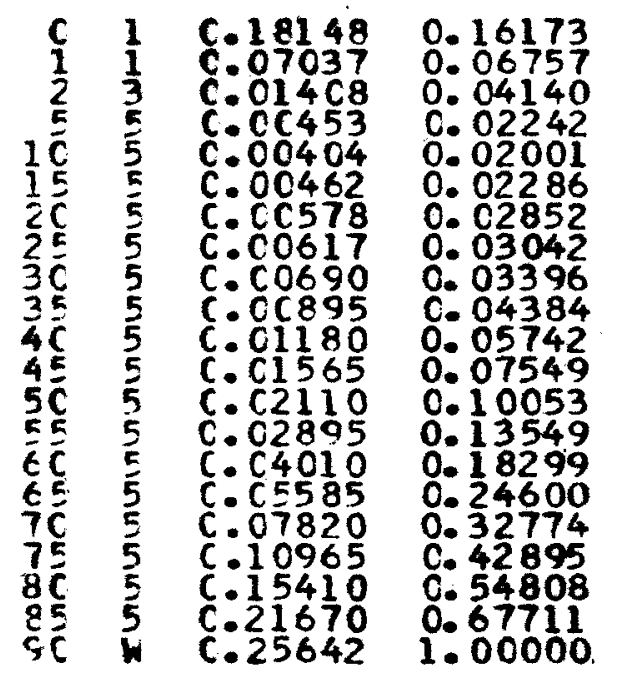

132

$\begin{array}{rrrrr}100000 & 16173 & 89116 & 4425177 & 44.25 \\ 83827 & 5664 & 80485 & 4336061 & 51: 73 \\ 78163 & 3236 & 229830 & 4255576 & 54.44 \\ 74927 & 1680 & 370861 & 4025746 & 53: 73 \\ 73247 & 1466 & 362871 & 3654885 & 49.90 \\ 71781 & 1641 & 355195 & 3292014 & 45.86 \\ 70140 & 2000 & 34601 & 2936810 & 41.87 \\ 68140 & 2073 & 335981 & 2590798 & 38.02 \\ 66067 & 2243 & 325073 & 2254817 & 34.13 \\ 63824 & 2798 & 312626 & 1929744 & 30.24 \\ 61026 & 3504 & 296949 & 1617118 & 26: 50 \\ 57522 & 4343 & 277508 & 1320169 & 22.95 \\ 53179 & 5346 & 253365 & 1042661 & 19.61 \\ 47833 & 6481 & 223859 & 789296 & 16: 50 \\ 41352 & 7567 & 188703 & 565427 & 13.67 \\ 33785 & 8311 & 148809 & 376724 & 11: 15 \\ 25474 & 8349 & 106755 & 227915 & 8: 95 \\ 17125 & 7346 & 66995 & 121150 & 7: 07 \\ 9779 & 5360 & 34783 & 54155 & 5: 54 \\ 4419 & 2992 & 13807 & 19372 & 4: 38 \\ 1427 & 1427 & 5565 & 5565 & 3.90\end{array}$


REGION : CUYO SEXO : MUJERES EPOCA_ 1913-1915 -

$X \quad N M(X, N) \quad Q(X, N) \quad L(X) \quad D(X, N) L(X, N) \quad T(X) \quad E(X)$

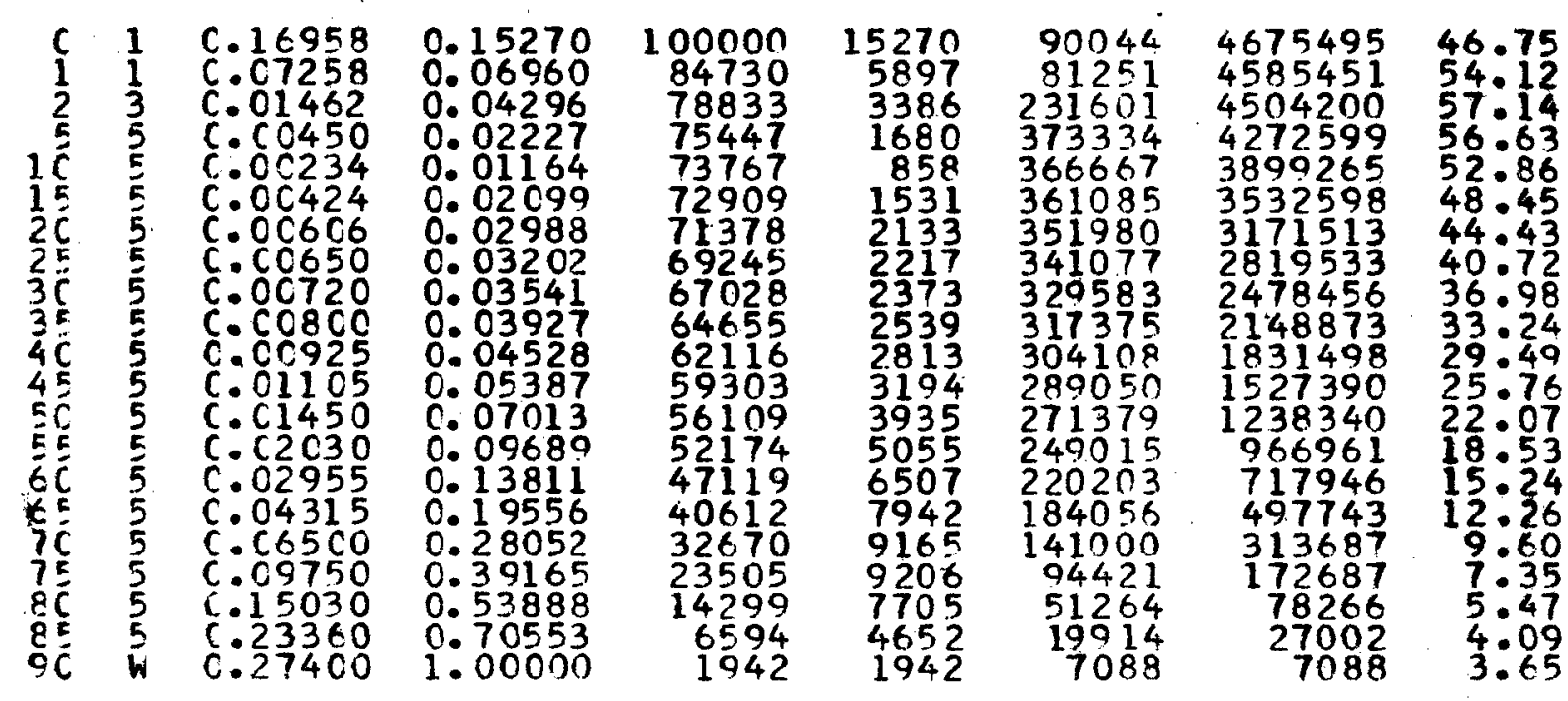

REGION : CUYO

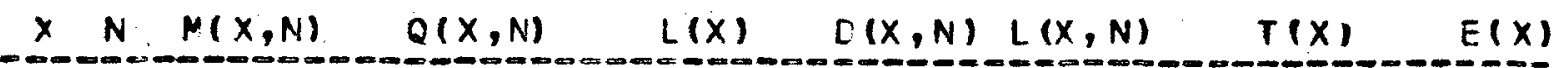

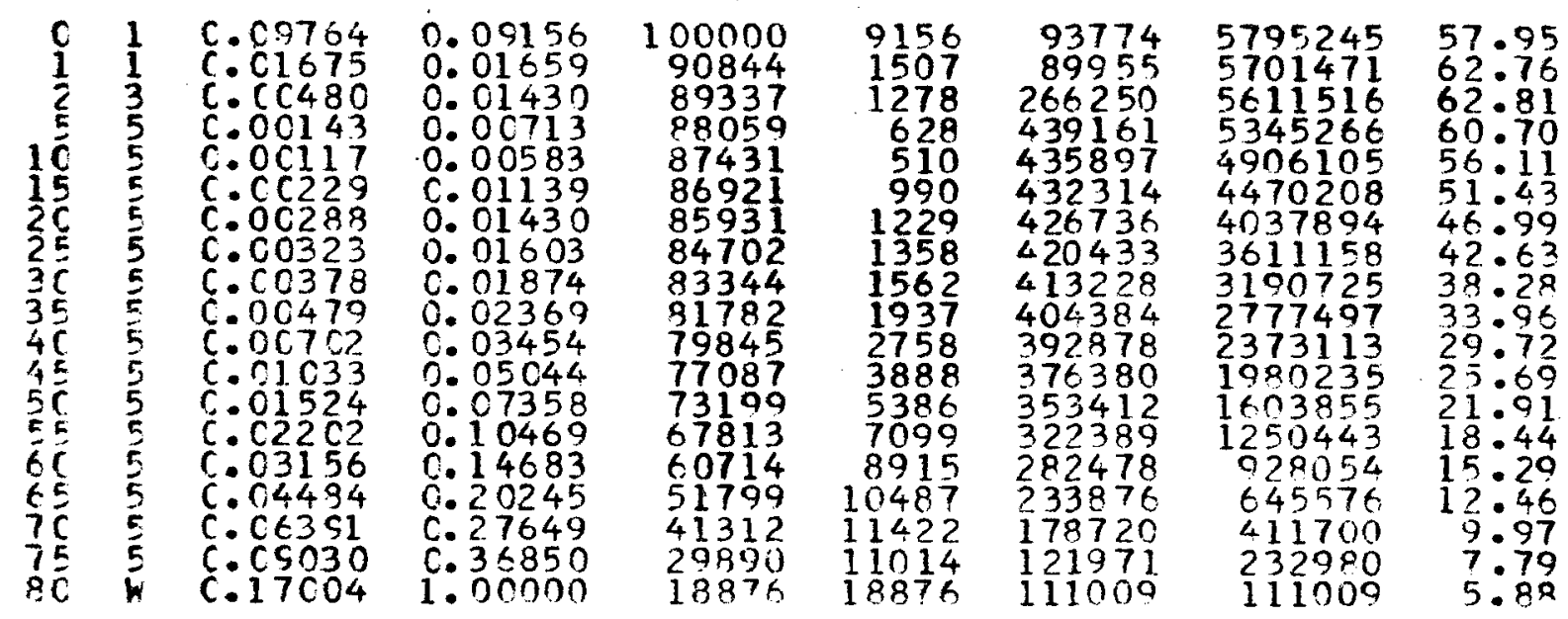




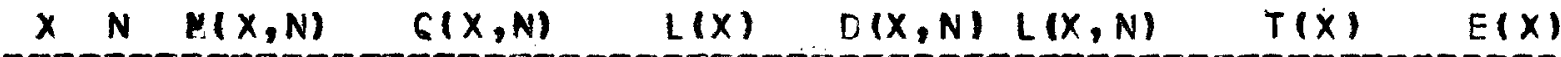

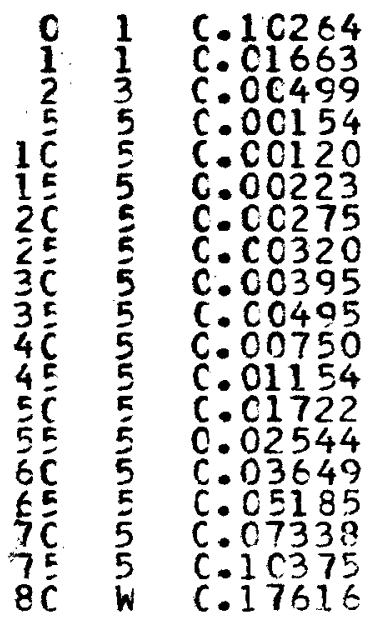

0.09589

0.01647

C. 01486

0. 0076 ?

0. 00598

0.01109

C. 01366

0.01588

0.01957

0.02447

0.03686

0.05619

C. 08277

C. 12001

0.16788

0. 23044

C. 31084

0.41111

1. 00000
100000

90411

88922

87600

86928

86408

85449

84281

82942

81319

79329

76405

$621 \frac{12}{66}$

58205

48433

37272

25686

15126

9589
1489
1322
672
520
959
1168
1339
1623
1990
2924
4293
5969
7938
9772
11161
11586
10560
15126

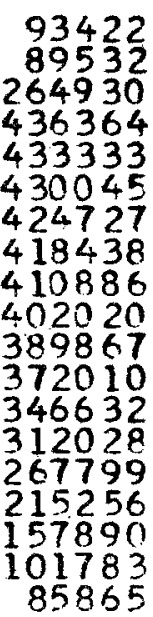

93422
89532
264930

436364

433333

430045

424727

410886

402020

389867

346632

267799

157890

85865
5652827

5559405

5469873

5204943

4768579

4335246

3905201

3480474

3062036

2651150

2249130

1859263

1487253

828593

345538

187648

85965
56.53

61.49

$61: 51$

54.86

50.17

45.70

$41 \cdot 30$

36.92

$2 \overline{8}: 35$

24.33

20.62

14.24

$11 \cdot 58$

$9 \cdot 27$

$7 \cdot 31$

REGION : CUYO

SEXO__ MUIERES

ERQCA. - 1946-1248

$\begin{array}{llllll}X \quad N \quad M(X, N) & Q(X, N) & L(X) & O(X, N) L(X, N) & T(X) & E(X)\end{array}$

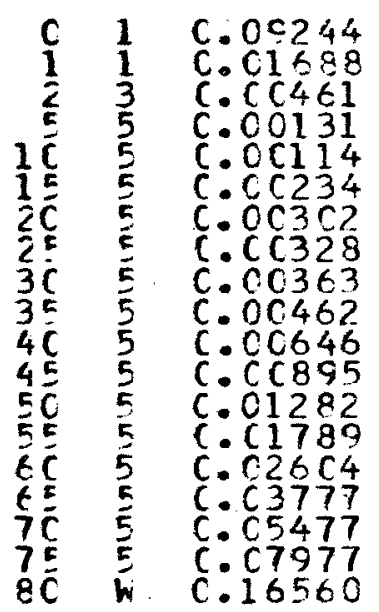

0.08702

0.01671

C. 01374

c. 00653

0.00589

C. $\Gamma 1164$

0.01500

0.01628

C. 01800

0.02286

C. 03182

c. 04384

0.06224

C. C8586

C. 12263

C. 124327

C. 243317

1. 00000

$\begin{array}{rr}100000 & 8702 \\ 91298 & 1526 \\ 89772 & 1233 \\ 88539 & 578 \\ 87961 & 500 \\ 87461 & 1018 \\ 86443 & 1296 \\ 85147 & 1386 \\ 83761 & 1508 \\ 82253 & 1880 \\ 80373 & 2558 \\ 77815 & 3411 \\ 74404 & 4631 \\ 69773 & 5991 \\ 63782 & 7824 \\ 55958 & 9696 \\ 46262 & 11188 \\ 35074 & 11685 \\ 23389 & 23389\end{array}$

100000

89772

87461

86443

85147

83761

8225

77815

74404

69773

55958

46262

23389
$8702 \quad 94135$

90398

267462

441221

438597

435043

429139

422561

415427

406927

395975

381117

361233

334880

300461

256712

2042.72

146484

141238 5963282
5869147 5778749

5511287

5070066

4631469

4196426
3767287

3344726

2929299

2522372

1745280

$13840<7$

1049167
748706

491994

287722
141238
59.63
$64 \cdot 29$

$64 \cdot 37$

$62: 25$

57.64

52.95

$48 \cdot 55$

39.93

35.61

$31 \cdot 38$
$27 \cdot 33$

23.46

19.84

$16 \cdot 45$

$10: 63$

8.20

6.04 


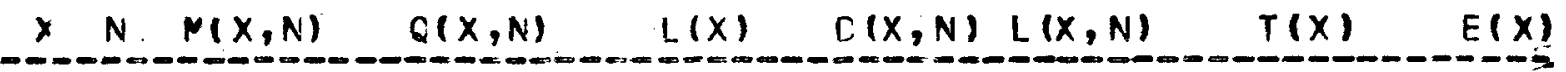

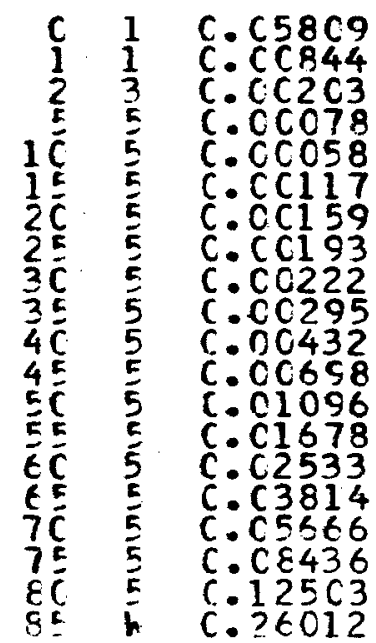

0.05583

0.00840

0.00389

0.00290

C. 00583

0.00792

0.00961

C. 01104

0.01465

0.02139

0.03435

0.05344

C. 0.8074

0.17482

0.24912

0. 34879

0.47312
1.00000
100000

94417

93055

92693

92425

91886

91158

90232

89285

87977

86095

83138

78695

72342

6369.5

52560

39466

25701
5583

793
569

362

268

539
728

876

997

1308

1882

2957

4443

6353
8647

11135

13094

13765

12160

13541

96109
93949
280296
464103
462069
460684
457862
453886
449099
443390
435648
423639
405383
378606
341374
291951
231098
163170
97257
52057

6481630

6385521
6291572

6011276

5547173

5085104

4624420

4166558

3712672

3263573

2820183

2384535

1960896

1555513

1175907

835533

543582

312484

149314

52057
64.82

$57 \cdot 63$
67.20

64.60

59.84

55.02

$50: 33$

$45 \cdot 71$

41.12

$36 \cdot 55$

32.06

27.70

$19: 77$

16.27

$13 \cdot 12$

7.92

5.81

REGION : CUYO

SEXO :-VARONES

EPOCA_:1959-1961

$X N \quad M(X, N) \quad C(X, N)$

$L(x)$

$D(X, N) L(X, N)$

$T(x)$

$E(x)$

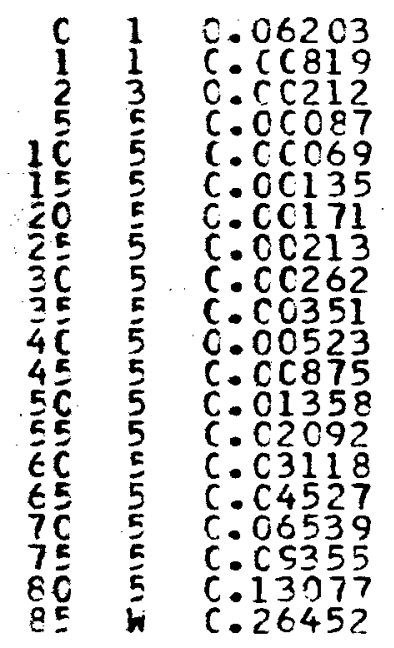

C. 05944

0.00815

C. 00634

0.00434

0.00344

C. 0 C673

C. 00852

C. 01060

C. 01302

c. C1741

0.02584

c. 04288

C. $C \in 582$

C. 05971

C. 14519

0.20413

C. 28196

C. 48878
1.00000
100000

94056

93289

92697

92295

91977

01358

90580

89620

88453

86913

84667

81036

75702

68154

58250

46363

33291

20672
5044

767

592

402

$31 R$

619

778

960

1167

2246

3631

5334

9895

11805

13072

12619

10104

95821
93603
279245
462069
460870
458510
454971
450704
445420
438746
429446
414971
392784
360803
317351
262779
199908
134890
77265
39952

6270117

6174296

6080693

5001443

5339379

4878509

4419990

3965019

3514315

3088895

2630149

$22007 \mathrm{C}$

1785732
1392948

1032145

452015
252107

117217
30952
$62 \cdot 70$
$65: 04$
$65: 13$
$62: 59$
$57: 85$
$53: 04$
$49: 38$
$43: 77$
$39 \cdot 21$
$34: 70$
$30: 26$
$25: 59$
$22: 04$
$18: 40$
$15: 14$
$12: 27$
$9: 75$
$7: 57$
$5: 67$
$3: 79$ 


$x N \quad N(x, N) \quad C(x, N) \quad L(X) \quad D(X, N) L(X, N) \quad T(X) \quad E(X)$

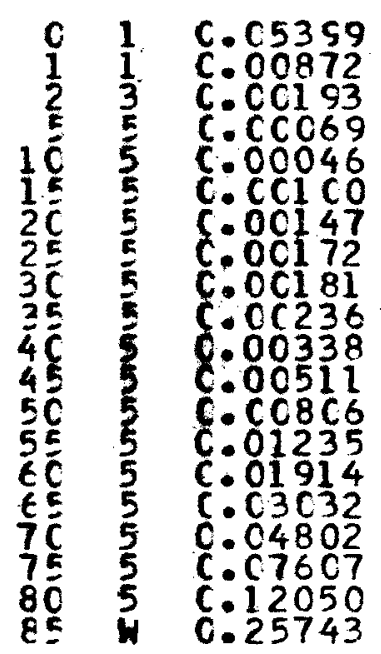

0.05205

0.06867

$0.0 C 577$

0.00344

C. 0.230

C. 00499

C. 00733

0.00901

0.01174

0. 01677

0.02525

0.03956

0.06003

0. 09160

C. 14146

C. 21526

C. 32032

C. 46045

1. 00000

100000
94795
93973
93430
93108
92894
92431
91754
90968
90148
89090
87596
85384
82006
77084
70023
60118
47177
32065
17301

5205

543

214

463

677

786

820

1058

1494

2212

3378

4922

7061

9905

12941

15112

14764
17301

96409
94310
281347
465667
465218
463000
460544
456977
453039
448305
442012
432877
419107
398543
368913
326682
269492
198659
122523
67207

96409 281347

466667

463000

460544

453039

442012

432877

49854

368913

326682

26492

67207
6731831

6635422

6541112
6259765

5793008

5327880

4864880

4404336

3947359

3494320

3046015

2604003

2171126

1752019

1353476

984563

657881

388389

189730
$67 \cdot 32$

70.00

69.61

67.00

$62 \cdot 22$

$52: 43$

48.00

$43 \cdot 39$

34.19

29.73

25.43

$21 \cdot 36$

17.56

14.06

10.94

8.23

5.92

REGION_NOROESTE SEXO : AMBOS SEXOS EPOCA: 1913-1915

$x N \quad M(x, N) \quad Q(x, N) \quad L(x) \quad L(X, N) L(X, N) \quad T(x) \quad E(x)$

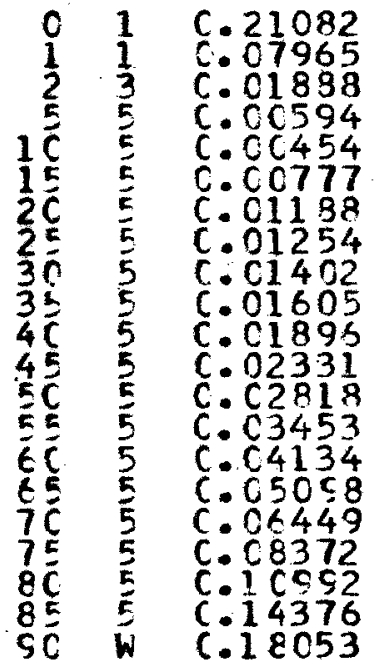

0.18466

0.07608

0.05514

0.02930

0.02246

C. C3816

0.05780

0.06092

0.06788

0.07735

0. 09077

C. 11050

0.13211

0.15957

0.18813

0.22702

0.27863

0.34663

C. 42975

0.52263

1.00000
100000

81534

75331

71177

69092

67540

64962

61207

57478

53576

49432

44945

39979

34697

29160

23674

18300

13201
8625

4918

2348
18466 6203

4154

2085

1552

2578

3755

3729

3902

4144

4487

4966

5282

5537

5486

5374

5099

4576

$370 ?$

2570

2348
87591

77874

220021

351010

341850

331789

316077

297368

278317

258193

236656

213042

187438

150353

132704

105414

79067

54658

33725

13006
3704030

3706439

3628565

3408544

3057534

2715684

2383995

2067818

1770450

1492133

1233940

997284

784242

596804

436451

303747

198333

119266

64608

30883

13006
37.94

45.46

$48 \cdot 17$

47.89

44.25

40.21

$36 \cdot 70$

33.78

30.80

27.85

24.95

22.19

19.62

17.20

14.97

12.83

10.84

9.03

7.49

6.28 


$X N \quad M(X, N) \quad Q(X, N) \quad L(X) \ldots D(X, N) \quad L(X, N) \quad T(X) \quad E(X)$

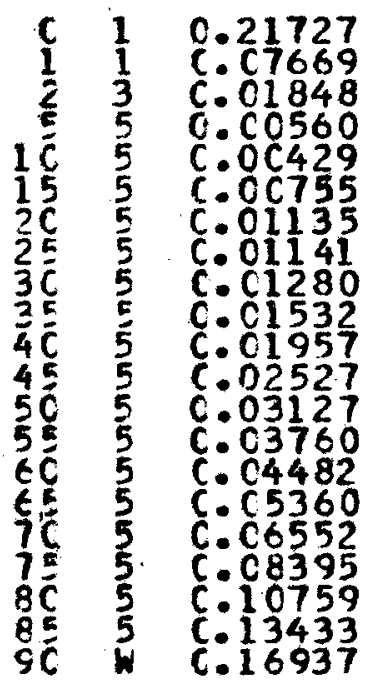

100000

81066

75118

71062

69098

67630

651221

58101

54490

50460

45739

40284

34420

28481

22717

17327

12433

8114

4684

2350
18934

5948 4056

1964

1468

2509

3601

3419

3611

4030

4721

5864

5939

5764

5390

4894

4319

3430

2334

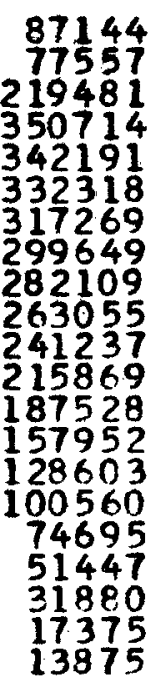

87145

219481

350714

342191

317269

282109

263055

241237

187528

28603

74695

31880

13975
3792508

3705364

3627807

3408326

3057612

2715421

2383103

2065834

1766185

1484076

1221021

763915

576387

418435

289832

189272

63130

31250

13875

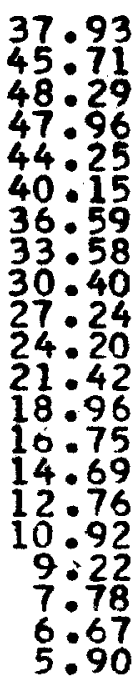

REGION : NOROESTE

SEXO : MUJERES

EPOCA : 1913-1915

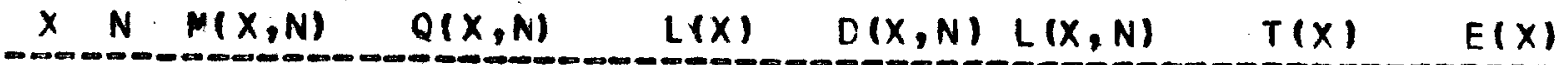

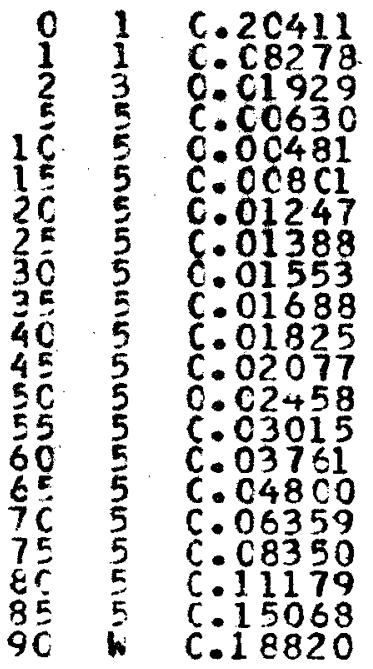

0.17972
0.07893
0.05630
0.03105
0.02379
0.03932
0.06059
0.06723
0.07493
0.08120
0.08751
0.09903
0.11618
0.14072
0.17760
0.121518
0.27530
0.34588
0.43529
0.53980
1.00000

100000

820 ? 8

75554

69086

67443

64791

6086

56773

52519

48255

44032

39672

35063

30129

24929

19565

14179

9275

5238
2411
17972

6474

4254

2214

1643

2652

3926

4092

4254

$\angle 264$

4223

4360

4609

4934

5200

5386

4904

4037

2827

2411

88049
78208
220529
351429
341580
331086
314836
294813
273921
252607
231397
209918
187510
163648
138261
111750
84699
58731
36112
18762
12811

3800657 3634400 3413871

3062442

2720862

2389776

2074940

1780127

1506206

1253599

1022202

812284

624774

481126

322865

211115

126416

67685

31573

12811

33.01

45.25

48.10

47.88

44.33

40.34

36.88

34.09

31.36

28.68

25.98

23.21

20.47

17.82

15.31

$12 \cdot 95$

8.92

$7: 3 n$

$6 \cdot 03$ 
REGION: NOROESTE SEXO: VARONES EPOCA: 1913-1915 _ ORIGEN : ARGENTINA

$\times N M(x, N) \quad Q(x, N) \quad L(x) \quad D(x, N) L(x, N) \quad T(x) \quad E(x)$

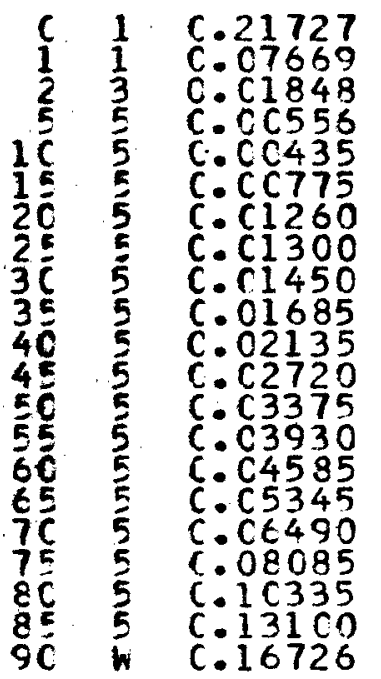

C. 18934

0.07337

0. 05400

C. 02745

0.02153

C. 03807

0.06121

0.06309

0.07013

c. 08106

0.10166

0.12780

C. 15624

0.20654

0.23670

0.28015

C. 33687

C. 40988

c. 48940

1. 00000
10000018934

81066

75118

71062

69112

67624

65050

61069

57216

53203

48890

43920

38307

26515

21039

16059

7666

4524

2310
5948

4056

1950

1488

2574

3981

3853

4013

4313

4970

5613

5985

5807

5476

4980

4499

3894

3142

2314
87144 77557

219481

342069

332129

315952

296385

276759

255964

232787

206360

177333

119433

69322

48163

30402

16901

13811

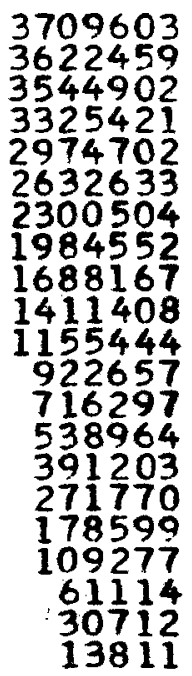

$37 \cdot 10$
$44: 69$
$47: 19$
$46: 80$
$43: 04$
$38: 93$
$35: 37$
$32: 50$
$29: 51$
$26: 53$
$23 \cdot 63$
$21 \cdot 01$
$18: 70$
$16: 67$
$14: 75$
$12: 92$
$11: 12$
$9: 45$
$7: 97$
$6: 79$
$5: 98$

REGION: NOROESTE_ SEXO:_MUJERES_-EPOCA: 1913-1915 - - ORIGEN:_ARGENTINA

$X N M(x, N) \quad Q(x, N) \quad L(X) \quad C(X, N) L(X, N) \quad T(X) \quad E(X)$

C. 20411

c. 08278

C. C1929

C. 00638

C. 00491

C.CC817

C. C. C1 12559

C.C1661

C. 01775

C. 0192175

C. $C 2590$

C. 03145

c. C3965

C. $C 4960$

C. C6450

C. $C 8480$

C. 11280

C. 15000

C.18703
0.17972

0.07893

0.05630

0.03144

0.02427

0.06286

0.07102

0. 07995

0.08521

0.09164

0.10347

0.12205

0.14635

0. 17862

C. 22156

0.27867

C. 43826

0.53814

1. 00000
100000

82028

75554

71300

69059

67383

64682

60616

56311

51809

47394

43051

38597

33886

28927

23760

18496

13342

8669

4870

2249
17972

6474

4254

2241

1676

2701

4066

4305

4502

4415

4343

4454

4711

4959

5167

5264

5154

4673

3799

2621
88049

78208

220529

341344

330600

313977
293057

271042

248732

226789

181892

132318

106129

79907

55106

33679
17473

17473
12025
3744571

44.58

$3578314 \quad 47 \cdot 36$

$3357785 \quad 47.09$

$3006531 \quad 43.54$

$2665187 \quad 39.55$

2334587

2020610

1727553

1456511

1207779

776208

594316

436637

304319

19819

118283

63177

29498
12025
36.09

30.68

$28 \cdot 11$

$25 \cdot 48$

20.11

$17 \cdot 5 \frac{1}{4}$

15.09

12.81

10.72
8.87

7.29

$6 \cdot 06$ 
Untmomomo anintorroptamor or

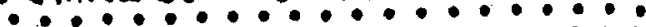

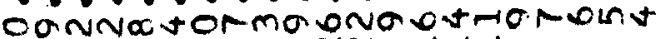
ItenistatmmnNmmand

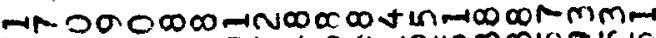

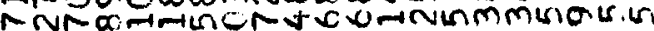

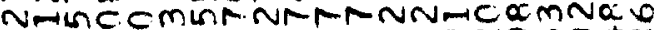

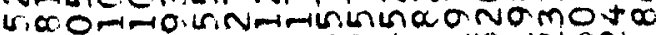

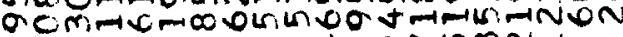

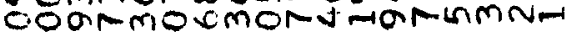

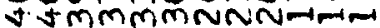

trmanONO toOtatmemtoNh

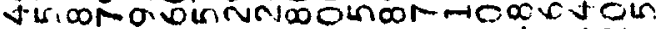

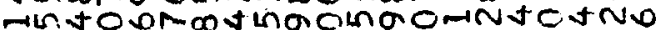

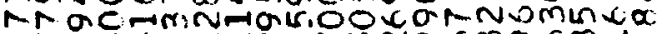

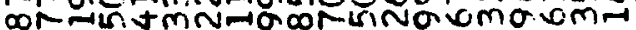

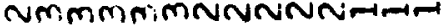

$+\infty 00-1000.0 R O R+N M N \sigma W R M$

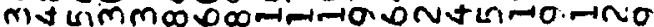

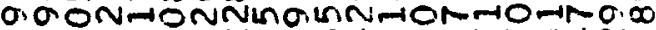
DUN $\rightarrow$

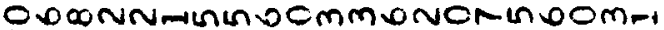
Q oComowh ómeñ

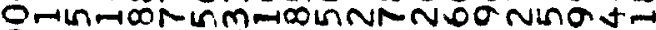

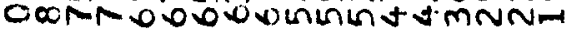
$\rightarrow$

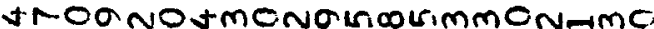
mmom $t \infty+-1 n \infty O+a-10 N 000-10$

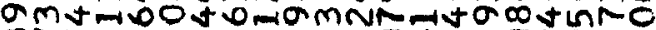

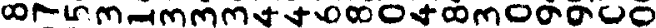
-00000000000-1-1nmmtwo

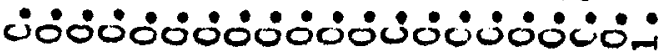

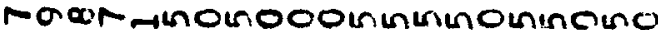

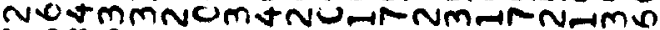

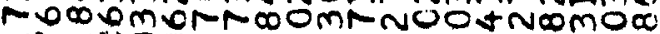

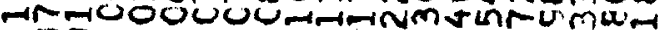

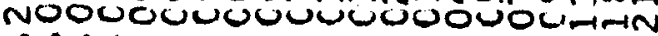

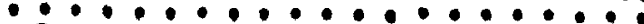

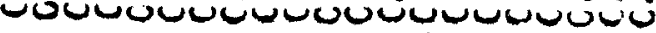

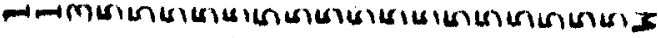

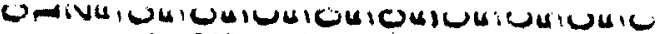

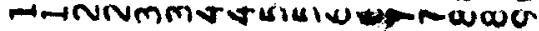




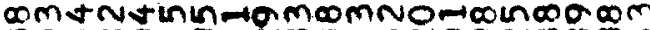

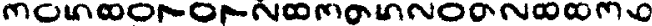

- - - - - - . - . .

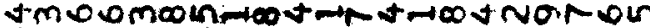

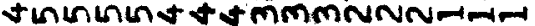

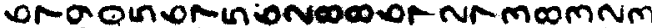

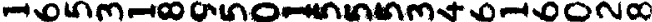

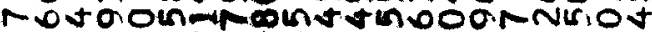

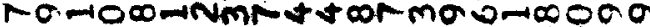

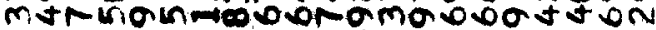
tmivoomolomor traminna $+t+t m m m n N N m-1$

Googingarvatstonghinthinmom

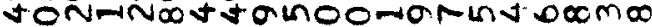
oniriatmutanocalanontmant

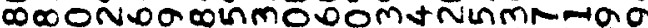

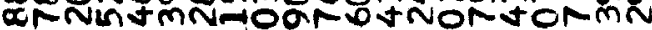
NmmmmnimnNNNNNA-1

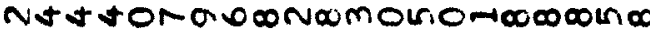

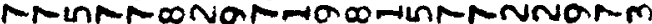

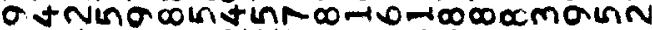

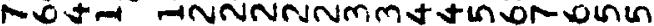
$-$

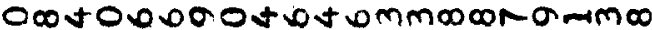
onirioningatolrina oOmommam

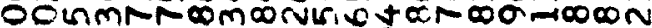
ONin-10000t-00molont mintor

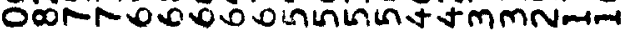
$\rightarrow$

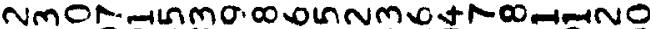

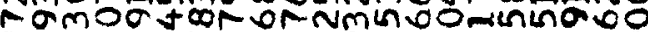

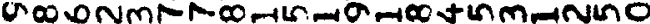

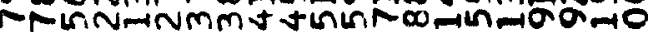
-10000000000000-1nNmine

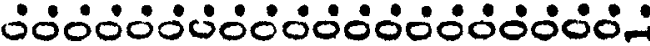

malo 000000 indo000000000

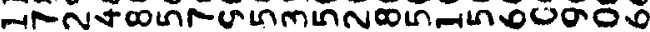

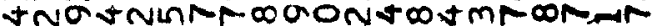

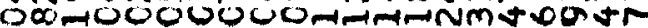

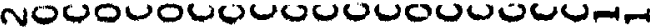

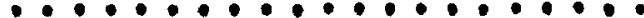

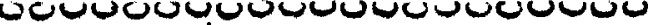

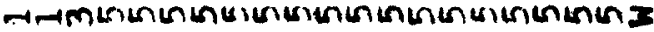

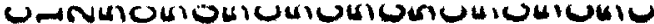

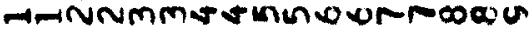


EPOCA : 1946-1948

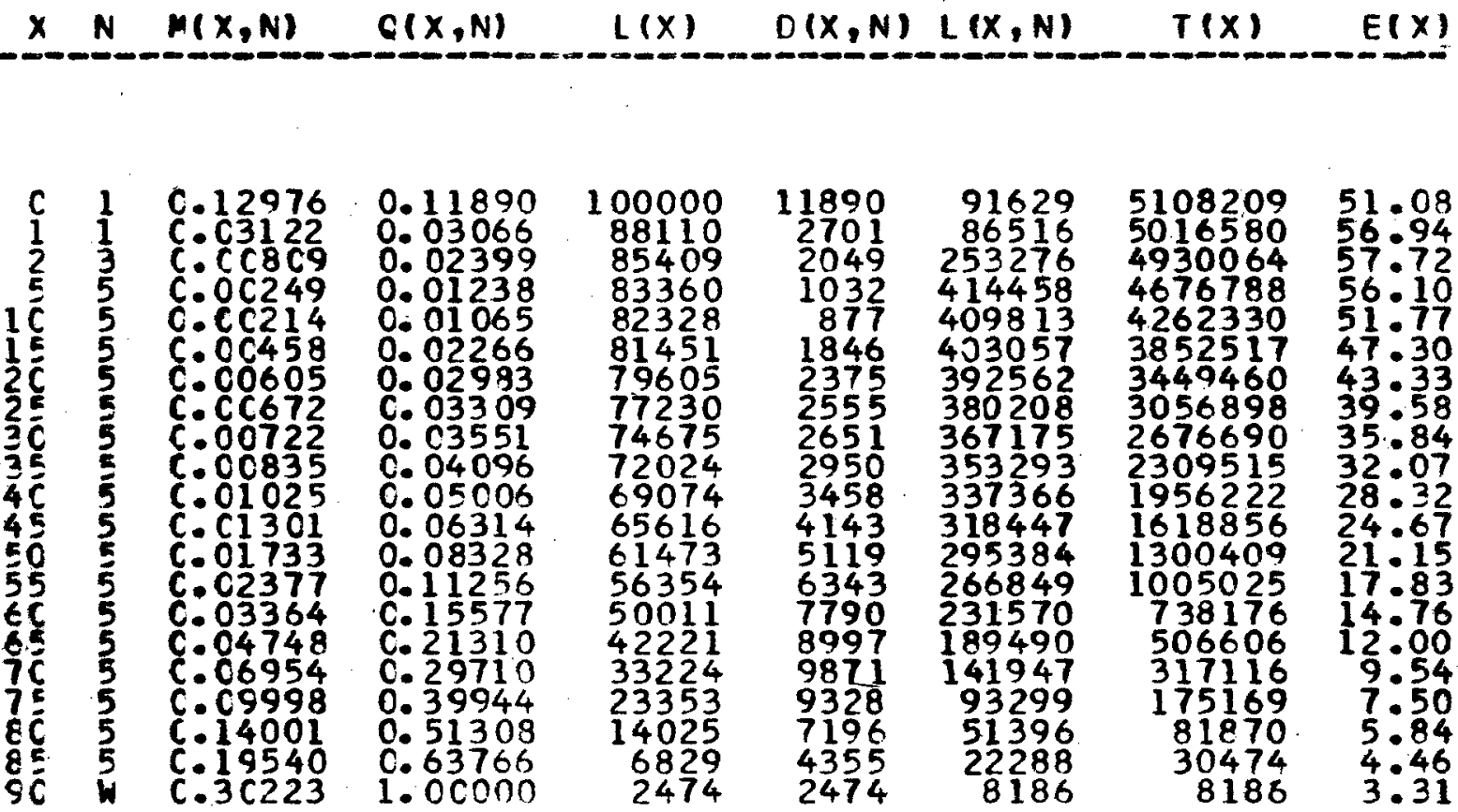

REGION_NONORESTE

SEXO : VARONES

EPOCA : $1946-1948$

$x \quad N \quad M(x, N) \quad Q(x, N) \quad L(x) \quad D(X, N) L(X, N) \quad T(X) \quad E(X)$

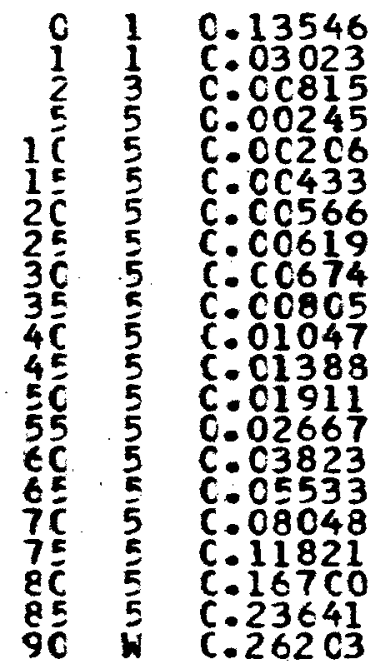

0.12353

0.02970

0. $\mathrm{C2417}$

0.01218

0.01025

0.02144

0.02793

0.03051

C. 03318

0.03951

0.05111

C. 06723

0.05146

0.12546

C. 17520

0.24400

0.33560

0.45394

C. 57806

1. 710002

$\begin{array}{rr}100000 & 12353 \\ 87647 & 2603 \\ 85044 & 2055 \\ 82989 & 1011 \\ 81978 & 840 \\ 81138 & 1739 \\ 79390 & 2218 \\ 77181 & 2355 \\ 74826 & 2483 \\ 72343 & 2858 \\ 69485 & 3551 \\ 65934 & 4432 \\ 61502 & 5625 \\ 55877 & 7011 \\ 48866 & 8561 \\ 40305 & 9834 \\ 30471 & 10226 \\ 20245 & 9190 \\ 11055 & 6390 \\ 4665 & 3312 \\ 1353 & 1353\end{array}$

91192 86111 252147
412653 407767 401617 391973 380452 368398 355031 339160 319308 294349 262880 223934 177734 127063 38263 14010
5026849 4935657 4849546 4184746 3776979 3375362 2983489 2603037

2234639 1879608
1540448 1221140 926791
663911 439977 262243

135180 57437 19174

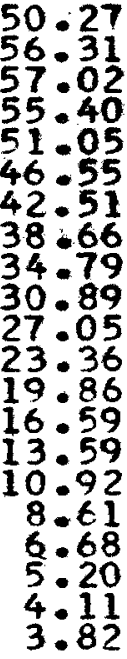


REGIQN - NOROESTE

SEXO_- MUIERES

EPOCA : $1946=1948$

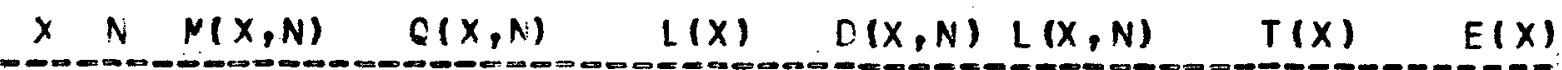

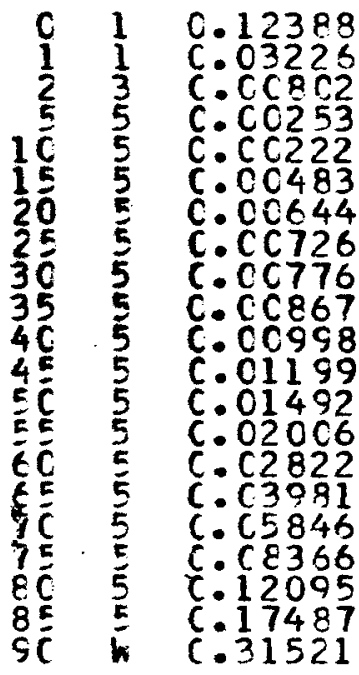

$\begin{array}{rrrr}0.11407 & 100000 & 11407 & 92084 \\ 0.03166 & 88593 & 2805 & 86938 \\ 0.02379 & 85788 & 2041 & 254489 \\ 0.01258 & 83747 & 1053 & 416206 \\ 0.01104 & 82694 & 913 & 411261 \\ 0.02388 & 81781 & 1953 & 404348 \\ 0.03173 & 79828 & 2533 & 393323 \\ 0.03570 & 77295 & 2759 & 380028 \\ 0.03811 & 74536 & 2841 & 366108 \\ 0.04250 & 71695 & 3047 & 351442 \\ 0.04877 & 68648 & 3348 & 33541 \\ 0.05832 & 65300 & 3800 & 317681 \\ 0.07209 & 61491 & 4433 & 297118 \\ 0.09580 & 57058 & 5466 & 272483 \\ 0.13229 & 51592 & 6825 & 241850 \\ 0.18179 & 44767 & 8138 & 204421 \\ 0.25600 & 36629 & 9377 & 160400 \\ 0.34643 & 27252 & 9441 & 112850 \\ 0.46172 & 17811 & 8224 & 67995 \\ 0.59543 & 9587 & 5708 & 32641 \\ 1.00000 & 3879 & 3879 & 12306\end{array}$

5211443

5119359

5032421

4777932

4361726

3950465

3546117

3152794

2772766

2406658

2055216

1719745

1402064

1104946

832463

590613

386192

225792

112042

12306
$52 \cdot 11$

58.66

57.05

52.75

48.31

$44 \cdot 42$

37.20

$33: 57$

29.94

$26 \cdot 34$

$22 \cdot 80$

$19 \cdot 37$

$16 \cdot 14$

13.19

10.54

8.29

6.34

4.69

3.17

REGION_: NQROESTE

SEXO : AMBOS SEXOS

EPOCA : $1959-1961$

$X \quad N \quad P(X, N) \quad Q(X, N) \quad L(X) \quad D(X, N) L(X, N) \quad T(X) \quad E(X)$

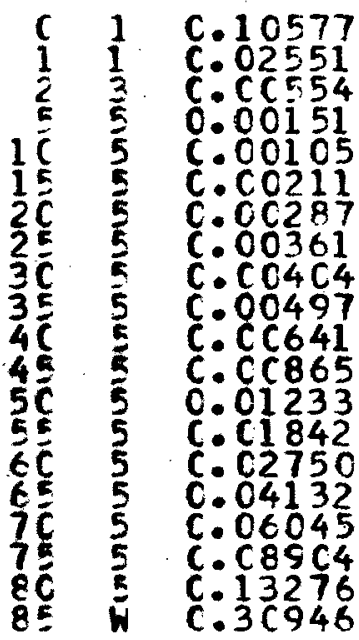

0.09858

C. 02513 . 01649

0.07752

c. 01050

0.01426

0.01790

C. 02001

0.02457

0.03158

0.04240

0.05993

C. 08830

C. 12912

0.18804

c. 26354

C. 36436

0.49410

1. 00000
100000

90142

86428

85778

85329

84433

83229

81739

80103

78135

75667

72459

68116

62102

54083

43913

32340

20556

10399

9858
2265
1449
650
449
896
1204
1490
1636
1968
2468
3208
4343
6014
8019
10170
11573
11784
10157
10399

93198 88806 261552

430464

427619

424645

419512

412742

404951

395976

385023

370867

352230

326493

29160

246128

191447

132345

76506

33604
5765708

5672510
5583704

5322152

4891688

4464069

4039424

3619912

3207170

2802219

2406243

2021220

1298123

971630

480030

433902

242455

110110

33604
57.66

62.93
63.54

61.58

57.03

$52 \cdot 32$

43.49

39.24

34.98
30.80

$26 \cdot 71$

19.06

15.65

12.57
9.88

$7 \cdot 50$
$5 \cdot 36$

$5 \cdot 36$ 


$\times N M(X, N) \quad Q(X, N) \quad L(X) \quad D(X, N) L(X, N) \quad T(X) \quad E(X)$

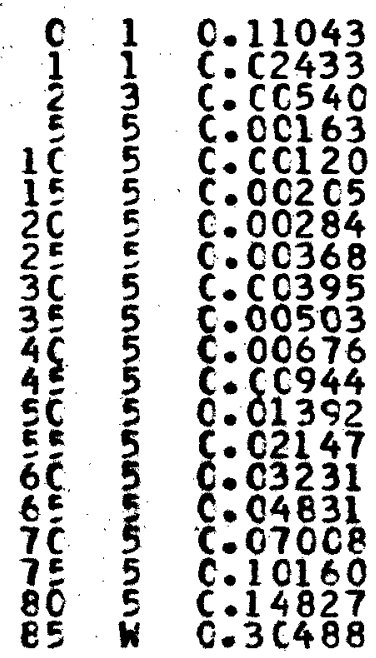

0.10251

0.02399

C. 01608

0.00812

0.00598

C. 01020

0.01411

0.01825

C. 01957

0.02486

0.03328

C. 04619

0.06741

C. 10220

C. 15006

C. 21642

0.29904

C. 40448

C. 53389

1. 0000 ñ
100000

89749

87596

86188

85488

84976

84109

82922

81409

79816

77832

75242

66929

60089

51072

40019

28052

16705
$1025 \frac{1}{2}$

1408

700

512

867

1187

1513

1593

1984

3475

4838

6840

9017

11053

11347

8910

7786

92824
88479
260741
429448
426667
422927
417958
411141
403291
394433
383136
368115
347558
218584
279078
228793
170762
111683
60154
25538

92824

260741

426667

422927

403291

394433

368115

347558

318584

279078
228793

170762

60154
25538
5641310

5548486

5460007

5109266

4769818

4343151

3920224

3502266

3091125

2687834

2293401

1910265

1542150

1194592

596930

368137

197375

85692

25538
$56 \cdot 41$

$61 \cdot 82$

$62 \cdot 33$

$60 \cdot 32$

55.80

$51 \cdot 11$

46.61

$42 \cdot 24$

$33 \cdot 68$

25.39

21.49

17.85

14.58

$11 \cdot 69$

9.20

$7: \mathrm{C4}$

$5 \cdot 13$

REGION : NOROESTE

SEXO : MUJERES

EPOCA : 1959-1961

$X N M(X, N)$

$G(X, N)$

$L(x)$

$D(X, N) L(X, N)$

$T(x)$

$E(X)$

C. 1.00 .56

c. 02672

C. 005.68

C. CC138

C.0CO89

C.00218

C. CC290

c. 0354

C.CC413

c. 04489

C. 00604

C. 01050

C. 01495

C. 2158

C.03295

C. C4988

C.07773

C. 12137

0. 09448

0.02631

0.01690

0.00688

c. 01444

0.01085

0.01440

0.01756

0.02045

0.02418

0.02978

C. 03807

0.05125

D. 07223

C. 10451

0.15281

C. 22267

C. 32611

0.46291
1.00000

$\begin{array}{rr}100000 & 9448 \\ 90552 & 2382 \\ 88170 & 1490 \\ 86680 & 596 \\ 86084 & 382 \\ 85702 & 920 \\ 84773 & 1221 \\ 83552 & 1467 \\ 82085 & 1679 \\ 80406 & 1944 \\ 78462 & 2337 \\ 76125 & 2898 \\ 73227 & 3753 \\ 69474 & 5018 \\ 64456 & 6736 \\ 57720 & 8820 \\ 48900 & 10888 \\ 38012 & 12396 \\ 25616 & 11858 \\ 13758 & 13758\end{array}$

9448

490

382

1221

1679

1944

2337

3753

6736

0888

11858
13758
93585 89147

26232.4
431884

429214

421034

414407

406538

397546

386921

357420

306460

267678

218284

97701

44081
5919443
5825858 5736711

5474387

5042503

4613289

4187142

3766108

3351701

2945163

2547617
2160696

1796760

1429331

1093679

787219

519941

141782

44081
59.19

$64 \cdot 34$

65.06

63.16

$58: 58$

53.83

49.39

45.08

40.83

36.63

32.47

24.40

20.57

16.97

13.64

10.62

$5: 53$ 
PARTE TERCERA 

Capitulo VII

ANALISIS DE LOS RESULTADOS

1. En este capítulo se examinan algunos índices, elaborados a partir de las tablas de vida presentadas en el capítulo anterior, A fin de facilitar y simplificar las comparaciones, se han seleccionado seis índices, referidos a diferentes tramos de edades, que resumen el nivel de la mortalidad representado por cada una de las tablas. Ellos son:

(1) la esperanza de vida al nacer, que simbolizamos E(0)

(2) 1a mortalidad infantil, $Q(0,1)$

(3) la probabilidad de morir entre 1 y 5 años de un niño que cumple la edad $1, Q(1,4)$

(4) la probabilidad de morir entre 15 y 50 años de una persona que alcanza la edad $15, Q(15,35)$

(5) la probabilidad de morir entre 10550 y 65 años de una persona que al canza la edad 50, $Q(50,15)$

(6) la esperanza de vida a la edad $65, \mathrm{E}(65)$

2. Las diferencias de mortalidad se establecen entre (a) épocas, (b) sexos, (c) regiones y (d) origen de la población.

3. Las primeras, diferencias en el tiempo, son quizá las más interesantes: muestran cómo varíó el nivel de la mortalidad en las cinco épocas para las cuales se han construido tablas para el total del país -aceptando que las cuatro regiones que se estudian a partir de 1914 son representativas del ni vel general de toda la Argentina, aunque como se ha señalado anteriormente, pueden subestimarlo ligeramente. Para las cuatro regiones que se analizan se cuenta con tablas de vida para tres épocas. En todos los casos los índi ces se calculan para ambos sexos y también separadamente para varones y mujeres.

4. E1 análisis de las diferencias de mortalidad según el sexo se divide en dos partes: en una se examinan tablas de población total, esto es, nacida en la Argentina y en el exterior; en la otra el examen se limita a la pobla ción nacida en el país.

5. La diferencia de mortalidad según regiones se establece con tablas de tres épocas, 1913-1915, 1946-1948 y 1959-1961, y tomando en cuenta el sexo de la población, aunque también intervienen tablas para ambos sexos.

6. Finalmente la mortalidad según el origen de la población, limitado al período 1913-1915, se hace según regiones y por sexo. 
La variación del nivel de la mortalidad en el tiempo

7. E1 Cuadro VII-1 constituye la base del examen que se éfectúa sobre el punto. Aparecen allí los índices seleccionados mencionados más arriba or denados de modo de facilitar la comparación del nivel de la mortalidad en el tiempo. Para la Argentina se dan índices por sexos -incluyendo los de ambos sexos- y para cinco épocas derivados de 15 tablas; para las regiones los valores se refieren a las cuatro regiones y están dados por sexo y para tres épocas. Equivale esto a 9 tablas por región, 36 en total.

8. Todos los índices -salvo dos excepciones- marcan una tendencia clara: la mortalidad ha descendido francamente a lo largo de los períodos estudiados, ya sea que se considere el país en conjunto o cualquiera de las regiones; ya un sexo o el otro.

9. Las dos excepciones aludidas carecen posiblemente de significación. Se refieren a la región NOROESTE, la de mayor mortalidad del país, y al grupo de más de 65 años. Una corresponde a la población masculina; la otra a la de ambos sexos. Los resultados muestran que la esperanza de vida a esa edad habría descendido de 12.76 a 10.92 años para los varones, entre 19131915 y 1946-1948, 1o que habría determinado una variación de 12.83 a 12.00 en la esperanza de vida de ambos sexos. Decimos que esta tendencia posiblemente no tenga significación porque esos valores pueden estar afectados fuertemente por los errores, tanto censales como de registros de muertes, propios de las edades avanzadas, especialmente en torno a la época de 1914. Tales errores pueden ocultar un descenso de la mortalidad, aunque, como se verá, la baja de la mortalidad en las edades avanzadas no tiene la importancia relativa que se observa en todos los otros grupos de edad.

10. Con el propósito de poner en evidencia la importancia relativa del des censo operado en la mortalidad en diversos grupos de edad, se ha confeccio nado el conjunto de índices que se presentan en el Cuadro VII-2, basado en la información del Cuadro VII-1. Muestra cómo variaron las probabilidades de morir en términos relativos utilizando como base de comparación los valores correspondientes al período 1913-1915.

11. E1 examen de la información de los dos cuadros mencionados permite com probar que el descenso de la mortalidad -expresado en probabilidades de morir en tramos de edades seleccionados-fue mayor en los grupos de edades 15 y 15-50, intermedio en el grupo correspondiente a la mortalidad infantil, 0-1, y menor en el tramo de 50-65 años. Estas tendencias se dan tanto a ni vel nacional como regional, sin excepción -aunque con diferente intensidad. Valen también tanto para la población masculina como para la femenina. No debe extrañar, teniendo en cuenta la tendencia señalada para el tramo 50-65, que en el grupo final considerado, el constituido por personas de más de 65 años, el descenso sea poco pronunciado y acaso pueda quedar desvirtuado por errores que afecten a los índices- como parece haber sucedido en el caso men cionado en el punto anterior. 


\section{Cuadro VII-1}

Indices seleccionados de las tablas de vida ordenados de modo de facilitar la comparación del nivel de la mortalidad en el tiempo, según región y sexo

\begin{tabular}{|c|c|c|c|c|c|c|c|c|}
\hline Región & Epoca & Sexo & $E(0)$ & $Q(0,1)$ & $Q(1,4)$ & $Q(15, \overline{35})$ & $Q(50,15)$ & $E(65)$ \\
\hline $\begin{array}{l}\text { RA } \\
\text { RA } \\
\text { RA } \\
\text { RA } \\
\text { RA }\end{array}$ & $\begin{array}{l}1869-1895 \\
1895-1914 \\
1913-1915 \\
1946-1948 \\
1959-1961\end{array}$ & & $\begin{array}{l}32.86 \\
40.04 \\
48.50 \\
61.08 \\
66.37\end{array}$ & $\begin{array}{l}0.23235 \\
0.17424 \\
0.11612 \\
0.06770 \\
0.05521\end{array}$ & $\begin{array}{l}0.15107 \\
0.10817 \\
0.06528 \\
0.02015 \\
0.01267\end{array}$ & $\begin{array}{l}0.41016 \\
0.34913 \\
0.28948 \\
0.14285 \\
0.09214\end{array}$ & $\begin{array}{l}0.44277 \\
0.39203 \\
0.34483 \\
0.26754 \\
0.20664\end{array}$ & $\begin{array}{r}9.84 \\
10.70 \\
11.82 \\
12.68 \\
14.14\end{array}$ \\
\hline $\begin{array}{l}\text { RA } \\
\text { RA } \\
\text { RA } \\
\text { RA } \\
\text { RA }\end{array}$ & $\begin{array}{l}1869-1895 \\
1895-1914 \\
1913-1915 \\
1946-1948 \\
1959-1961\end{array}$ & $\begin{array}{l}\mathrm{V} \\
\mathrm{V} \\
\mathrm{V} \\
\mathrm{V} \\
\mathrm{V}\end{array}$ & $\begin{array}{l}32.60 \\
39.48 \\
47.59 \\
59.09 \\
63.68\end{array}$ & $\begin{array}{l}0.24342 \\
0.18221 \\
0.12100 \\
0.07216 \\
0.05918\end{array}$ & $\begin{array}{l}0.15024 \\
0.10800 \\
0.06575 \\
0.02031 \\
0.01258\end{array}$ & $\begin{array}{l}0.40243 \\
0.34664 \\
0.29281 \\
0.15869 \\
0.11273\end{array}$ & $\begin{array}{l}0.46936 \\
0.42434 \\
0.38285 \\
0.31587 \\
0.26120\end{array}$ & $\begin{array}{r}9.45 \\
10.14 \\
11.03 \\
11.67 \\
12.90\end{array}$ \\
\hline $\begin{array}{l}\text { RA } \\
\text { RA } \\
\text { RA } \\
\text { RA } \\
\text { RA }\end{array}$ & $\begin{array}{l}1869-1895 \\
1895-1914 \\
1913-1915 \\
1946-1948 \\
1959-1961\end{array}$ & $\begin{array}{l}M \\
M \\
M \\
M \\
M\end{array}$ & $\begin{array}{l}33.32 \\
40.67 \\
49.72 \\
63.59 \\
69.53\end{array}$ & $\begin{array}{l}0.22073 \\
0.16587 \\
0.11100 \\
0.06304 \\
0.05104\end{array}$ & $\begin{array}{l}0.15192 \\
0.10833 \\
0.06475 \\
0.02004 \\
0.01275\end{array}$ & $\begin{array}{l}0.41958 \\
0.35241 \\
0.28417 \\
0.12455 \\
0.07094\end{array}$ & $\begin{array}{l}0.41347 \\
0.35314 \\
0.29206 \\
0.20585 \\
0.14505\end{array}$ & $\begin{array}{l}10.26 \\
11.35 \\
12.77 \\
13.79 \\
15.51\end{array}$ \\
\hline $\begin{array}{l}\text { BA } \\
B A \\
B A\end{array}$ & $\begin{array}{l}1913-1915 \\
1946-1948 \\
1959-1961\end{array}$ & & $\begin{array}{l}51.37 \\
63.77 \\
68.15\end{array}$ & $\begin{array}{l}0.09166 \\
0.04815 \\
0.04555\end{array}$ & $\begin{array}{l}0.05364 \\
0.01033 \\
0.00682\end{array}$ & $\begin{array}{l}0.26258 \\
0.12771 \\
0.08421\end{array}$ & $\begin{array}{l}0.33306 \\
0.26220 \\
0.19911\end{array}$ & $\begin{array}{l}11.54 \\
12.73 \\
14.44\end{array}$ \\
\hline $\begin{array}{l}\mathrm{BA} \\
\mathrm{BA} \\
\mathrm{BA}\end{array}$ & $\begin{array}{l}1913-1915 \\
1946-1948 \\
1959-1961\end{array}$ & $\begin{array}{l}V \\
V \\
V\end{array}$ & $\begin{array}{l}50.07 \\
61.32 \\
65.09\end{array}$ & $\begin{array}{r}0.09631 \\
.0 .05283 \\
0.04957\end{array}$ & $\begin{array}{l}0.05497 \\
0.01083 \\
0.00705\end{array}$ & $\begin{array}{l}0.27165 \\
0.14849 \\
0.10739\end{array}$ & $\begin{array}{l}0.37749 \\
0.31750 \\
0.25919\end{array}$ & $\begin{array}{l}10.61 \\
11.63 \\
13.07\end{array}$ \\
\hline $\begin{array}{l}\mathrm{BA} \\
\mathrm{BA} \\
\mathrm{BA}\end{array}$ & $\begin{array}{l}1913-1915 \\
1946-1948 \\
1959-1961\end{array}$ & $\begin{array}{l}M \\
M \\
M\end{array}$ & $\begin{array}{l}53.23 \\
66.83 \\
71.67\end{array}$ & $\begin{array}{l}0.08679 \\
0.04328 \\
0.04134\end{array}$ & $\begin{array}{l}0.05229 \\
0.00984 \\
0.00661\end{array}$ & $\begin{array}{l}0.24854 \\
0.10403 \\
0.06071\end{array}$ & $\begin{array}{l}0.26947 \\
0.19340 \\
0.13286\end{array}$ & $\begin{array}{l}12.73 \\
13.92 \\
15.89\end{array}$ \\
\hline $\begin{array}{l}\text { CL } \\
\text { CL } \\
\text { CL }\end{array}$ & $\begin{array}{l}1913-1915 \\
1946-1948 \\
1959-1961\end{array}$ & & $\begin{array}{l}48.75 \\
61.42 \\
66.81\end{array}$ & $\begin{array}{l}0.12304 \\
0.06557 \\
0.05056\end{array}$ & $\begin{array}{l}0.05813 \\
0.01816 \\
0.00897\end{array}$ & $\begin{array}{l}0.29332 \\
0.14469 \\
0.09193\end{array}$ & $\begin{array}{l}0.33502 \\
0.26626 \\
0.21035\end{array}$ & $\begin{array}{l}12.26 \\
12.77 \\
13.94\end{array}$ \\
\hline $\begin{array}{l}C L \\
C L \\
C L\end{array}$ & $\begin{array}{l}1913-1915 \\
1946-1948 \\
1959-1961\end{array}$ & $\begin{array}{l}\mathrm{V} \\
\mathrm{V} \\
\mathrm{V}\end{array}$ & $\begin{array}{l}48.01 \\
59.76 \\
64.36\end{array}$ & $\begin{array}{l}0.12829 \\
0.06969 \\
0.05463\end{array}$ & $\begin{array}{l}0.05879 \\
0.01812 \\
0.00907\end{array}$ & $\begin{array}{l}0.29070 \\
0.15635 \\
0.11119\end{array}$ & $\begin{array}{l}0.36699 \\
0.30428 \\
0.25624\end{array}$ & $\begin{array}{l}11.46 \\
11.87 \\
12.86\end{array}$ \\
\hline $\begin{array}{l}\mathrm{CL} \\
\mathrm{CL} \\
\mathrm{CL}\end{array}$ & $\begin{array}{l}1913-1915 \\
1946-1948 \\
1959-1961\end{array}$ & $\begin{array}{l}M \\
M \\
M\end{array}$ & $\begin{array}{l}49.67 \\
63.55 \\
69.75\end{array}$ & $\begin{array}{l}0.11753 \\
0.06127 \\
0.04626\end{array}$ & $\begin{array}{l}0.05750 \\
0.01823 \\
0.00888\end{array}$ & $\begin{array}{l}0.29617 \\
0.13114 \\
0.07213\end{array}$ & $\begin{array}{l}0.29168 \\
0.21496 \\
0.15606\end{array}$ & $\begin{array}{l}13.19 \\
13.83 \\
15.25\end{array}$ \\
\hline $\begin{array}{l}C Y \\
C Y \\
C Y\end{array}$ & $\begin{array}{l}1913-1915 \\
1946-1948 \\
1959-1961\end{array}$ & & $\begin{array}{l}41.45 \\
57.95 \\
64.82\end{array}$ & $\begin{array}{l}0.15733 \\
0.09156 \\
0.05583\end{array}$ & $\begin{array}{l}0.10785 \\
0.03066 \\
0.01443\end{array}$ & $\begin{array}{l}0.34971 \\
0.15787 \\
0.10048\end{array}$ & $\begin{array}{l}0.41838 \\
0.29235 \\
0.23386\end{array}$ & $\begin{array}{l}10.65 \\
12.46 \\
13.12\end{array}$ \\
\hline $\begin{array}{l}\mathrm{CY} \\
\mathrm{CY} \\
\mathrm{CY}\end{array}$ & $\begin{array}{l}1913-1915 \\
1946-1948 \\
1959-1961\end{array}$ & $\begin{array}{l}\mathrm{V} \\
\mathrm{V} \\
\mathrm{V}\end{array}$ & $\begin{array}{l}41.18 \\
56.53 \\
62.70\end{array}$ & $\begin{array}{r}0.16173 \\
0.09589 \\
0.05944\end{array}$ & $\begin{array}{l}0.10617 \\
0.03109 \\
0.01445\end{array}$ & $\begin{array}{l}0.35348 \\
0.16545 \\
0.11895\end{array}$ & $\begin{array}{l}0.44390 \\
0.32836 \\
0.28107\end{array}$ & $\begin{array}{l}10.59 \\
11.58 \\
12.27\end{array}$ \\
\hline $\begin{array}{l}\mathrm{CY} \\
\mathrm{CY} \\
\mathrm{CY}\end{array}$ & $\begin{array}{l}1913-1915 \\
1946-1948 \\
1959-1961\end{array}$ & $\begin{array}{l}M \\
M \\
M\end{array}$ & $\begin{array}{l}41.80 \\
59.63 \\
67.32\end{array}$ & $\begin{array}{l}0.15270 \\
0.08702 \\
0.05205\end{array}$ & $\begin{array}{l}0.10956 \\
0.03022 \\
0.01440\end{array}$ & $\begin{array}{l}0.34463 \\
0.14929 \\
0.08084\end{array}$ & $\begin{array}{l}0.38588 \\
0.24792 \\
0.17990\end{array}$ & $\begin{array}{l}10.74 \\
13.38 \\
14.06\end{array}$ \\
\hline $\begin{array}{l}\text { No } \\
\text { NO } \\
\text { NO }\end{array}$ & $\begin{array}{l}1913-1915 \\
1946-1948 \\
1959-1961\end{array}$ & & $\begin{array}{l}37.94 \\
51.08 \\
57.66\end{array}$ & $\begin{array}{l}0.18466 \\
0.11890 \\
0.09858\end{array}$ & $\begin{array}{l}0.12703 \\
0.05391 \\
0.04120\end{array}$ & $\begin{array}{l}0.40807 \\
0.24528 \\
0.15083\end{array}$ & $\begin{array}{l}0.40784 \\
0.31318 \\
0.25361\end{array}$ & $\begin{array}{l}12.83 \\
12.00 \\
12.57\end{array}$ \\
\hline $\begin{array}{l}\text { No } \\
\text { NO } \\
\text { NO }\end{array}$ & $\begin{array}{l}1913-1915 \\
1946-1948 \\
1959-1961\end{array}$ & $\begin{array}{l}\text { V } \\
\text { V } \\
\text { V }\end{array}$ & $\begin{array}{l}37.93 \\
50.27 \\
56.41\end{array}$ & $\begin{array}{l}0.18934 \\
0.12353 \\
0.10251\end{array}$ & $\begin{array}{l}0.12341 \\
0.05314 \\
0.03968\end{array}$ & $\begin{array}{l}0.40435 \\
0.24201 \\
0.15544\end{array}$ & $\begin{array}{l}0.43608 \\
0.34466 \\
0.28836\end{array}$ & $\begin{array}{l}12.76 \\
10.92 \\
11.69\end{array}$ \\
\hline $\begin{array}{l}\text { No } \\
\text { No } \\
\text { No }\end{array}$ & $\begin{array}{l}1913-1915 \\
1946-1948 \\
1959-1961\end{array}$ & $\begin{array}{l}M \\
M \\
M\end{array}$ & $\begin{array}{l}38.01 \\
52.11 \\
59.19\end{array}$ & $\begin{array}{l}0.17972 \\
0.11407 \\
0.09448\end{array}$ & $\begin{array}{l}0.13078 \\
0.05470 \\
0.04276\end{array}$ & $\begin{array}{l}0.41177 \\
0.24810 \\
0.14556\end{array}$ & $\begin{array}{l}0.37162 \\
0.27197 \\
0.21177\end{array}$ & $\begin{array}{r}12.95 \\
13.19 \\
13.64\end{array}$ \\
\hline
\end{tabular}


Cuadro VII-2

Indices por épocas, regiones y sexos, calculados con las probabilidades de muerte, de tramos seleccionados de edades, utilizando como base los valores de1 período 1913-1915

$I^{E}(X, N)=100 \cdot Q(X, N)^{E} / Q(X, N)^{1913-1915}$

para $E=1869-1895,1895-1914,1913-1915,1946-1948,1959-1961$

\begin{tabular}{|c|c|c|c|c|c|c|}
\hline Región & Sexo & Epoca & $I(0,1)$ & $I(1,4)$ & $I(15,35)$ & $I(50,15)$ \\
\hline RA & Ambos & $1869-1895$ & 200 & 231 & 142 & 128 \\
\hline RA & Ambos & $1895-1914$ & 150 & 166 & 121 & 114 \\
\hline $\mathrm{RA}$ & Ambos & $1913-1915$ & 100 & 100 & 100 & 100 \\
\hline $\mathrm{RA}$ & Ambos & $1946-1948$ & 58 & 31 & 49 & 78 \\
\hline $\mathrm{RA}$ & Ambos & $1959-1961$ & 48 & 19 & 32 & 60 \\
\hline RA & $\mathrm{V}$ & $1869-1895$ & 201 & 229 & 137 & 123 \\
\hline $\mathrm{RA}$ & V & $1895-1914$ & 151 & 164 & 118 & 111 \\
\hline $\mathrm{RA}$ & $\mathrm{V}$ & $1913-1915$ & 100 & 100 & 100 & 100 \\
\hline $\mathrm{RA}$ & $\mathrm{V}$ & $1946-1948$ & 60 & 31 & 54 & 83 \\
\hline $\mathrm{RA}$ & $\mathrm{V}$ & $1959-1961$ & 49 & 19 & 38 & 68 \\
\hline $\mathrm{RA}$ & $\mathrm{M}$ & $1869-1895$ & 199 & 235 & 148 & 142 \\
\hline $\mathrm{RA}$ & $\mathrm{M}$ & $1895-1914$ & 149 & 167 & 124 & 121 \\
\hline $\mathrm{RA}$ & M & $1913-1915$ & 100 & 100 & 100 & 100 \\
\hline $\mathrm{RA}$ & $M$ & $1946-1948$ & 57 & 31 & 44 & 70 \\
\hline RA & $\mathrm{M}$ & $1959-1961$ & 46 & 20 & 25 & 50 \\
\hline $\mathrm{BA}$ & Ambos & $1913-1915$ & 100 & 100 & 100 & 100 \\
\hline $\mathrm{BA}$ & Ambos & $1946-1948$ & 53 & 19 & 49 & 79 \\
\hline $\mathrm{BA}$ & Ambos & $1959-1961$ & 50 & 13 & 32 & 60 \\
\hline CL & Ambos & $1913-1915$ & 100 & 100 & 100 & 100 \\
\hline $\mathrm{CL}$ & Ambos & $1946-1948$ & 53 & 31 & 49 & 79 \\
\hline $\mathrm{CL}$ & Ambos & $1959-1961$ & 41 & 15 & 31 & 63 \\
\hline $\mathrm{CY}$ & Ambos & $1913-1915$ & 100 & 100 & 100 & 100 \\
\hline $\mathrm{CY}$ & Ambos & $1946-1948$ & 58 & 28 & 45 & 70 \\
\hline $\mathrm{CY}$ & Ambos & $1959-1961$ & 35 & 13 & 29 & 56 \\
\hline NO & Ambos & $1913-1915$ & 100 & 100 & 100 & 100 \\
\hline NO & Ambos & $1946-1948$ & 64 & 42 & 60 & 77 \\
\hline NO & Ambos & $1959-1961$ & 53 & 32 & 37 & 62 \\
\hline
\end{tabular}


Comparaciôn con otros países

12. En los Gráficos VII-1 y VII-2 se hace una comparación entre la esperan $\mathrm{za}$ de vida al nacer, de varones $y$ mujeres, respectivamente, estimada para la Argentina y la correspondiente a dos países europeos: Suecia e Italia. Se han seleccionado estos dos países por razones diferentes. Suecia, porque es el que dispone de la serie más completa de información sobre mortalidad y además por ser uno de los países con niveles actuales más bajos; Italia, porque de los países europeos es el que más similitud demográfica puede tener con 1a Argentina (entre la población inmigrante fue siempre pre ponderante la nacida en Italia) y porque se dispone para ese país de tablas de vida desde 1876-1887, época próxima a la primera considerada en el caso de 1a Argentina, lo que facilita la comparación. En los gráficos los valores correspondientes a un período se han representado en el valor de la escala de tiempo correspondiente al año central del mismo. Así, por ejemplo, la esperanza de vida estimada para 1869-1895 se representó en la abscisa correspondiente a 1882, año intermedio a 1869 y 1895 . Los datos que aparecen en los Gráficos están dados, para Suecia e Italia en el Cuadro VII-3; 1os de 1a Ar gentina surgen de1 Cuadro VII-1.

13. La observación de los Gráficos VII-1 y VII-2 permite extraer algunas in teresantes conclusiones:

(a) la esperanza de vida al nacer de Suecia, correspondiente al período más antiguo que se presenta, 1861-1870, de 42.8 y 46.4 años para varones y muje res respectivamente, era superior a la estimada para la Argentina muchos años después. Sôlo hacia 1910 fueron alcanzados aquellos valores por este país;

(b) aunque la diferencia en los valores de la esperanza de vida al nacer de Suecia y la Argentina ha disminuido, especialmente en la población femenina, hay todavía, hacia 1960, una diferencia importante;

(c) la comparación entre los índices italianos y argentinos pone de manifies to tendencias y niveles de mortalidad parecidos: en las épocas más remotas consí deradas, desde 1880 hasta 1910 aproximadamente, la vida media en Italia era claramente superior a la Argentina; entre 1910 y 1940 -también son fechas aproximadas- la situación parece haberse invertido, sin que la diferencia en los valores de la esperanza de vida al nacer entre los dos países haya sido importante $\mathrm{y}$, desde 1940 en adelante Italia muestra nuevamente una mortalidad menor, mayor vida media, ensanchándose la diferencia con el tiempo;

(e) la población nacida en el exterior residente en la Argentina tenía hacia 1914 aparentemente, una mortalidad inferior a la de Italia en 1910-12. En efecto, la esperanza de vida al nacer es de 49.75 y 53.55 para varones y mujeres, respectivamente, en la población de la Argentina nacida en el exterior y de 46.6 y 47.3 para los varones y mujeres de Italia. En buena parte, 1a po blación inmigrante provenía de Italia. Sugieren estos datos que en la época considerada la población emigrante de Europa, en particular la proveniénte de Italia, constituia un grupo seleccionado, con menor mortalidad, que la población no migrante. 


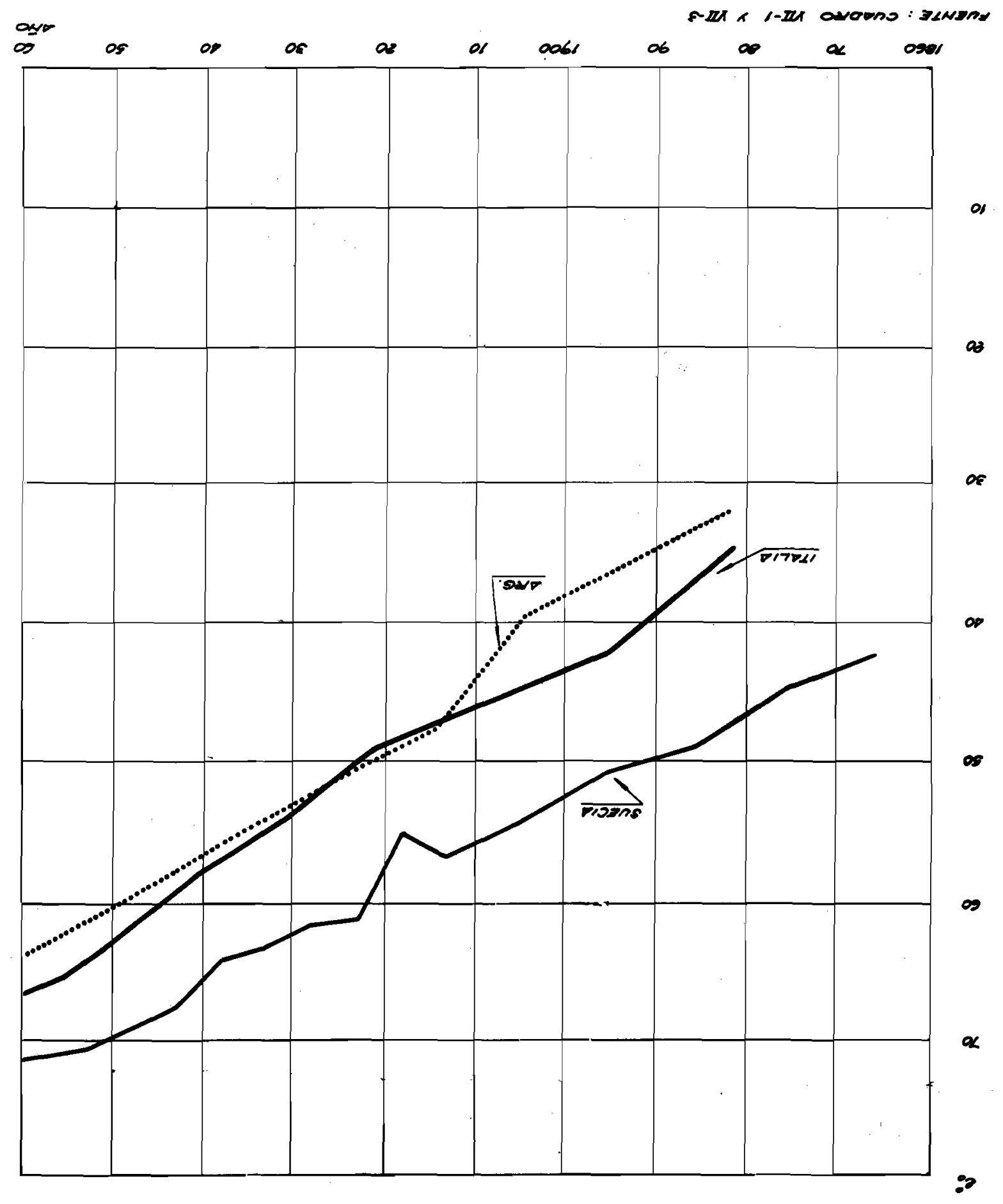

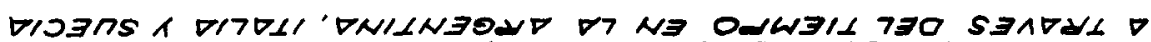



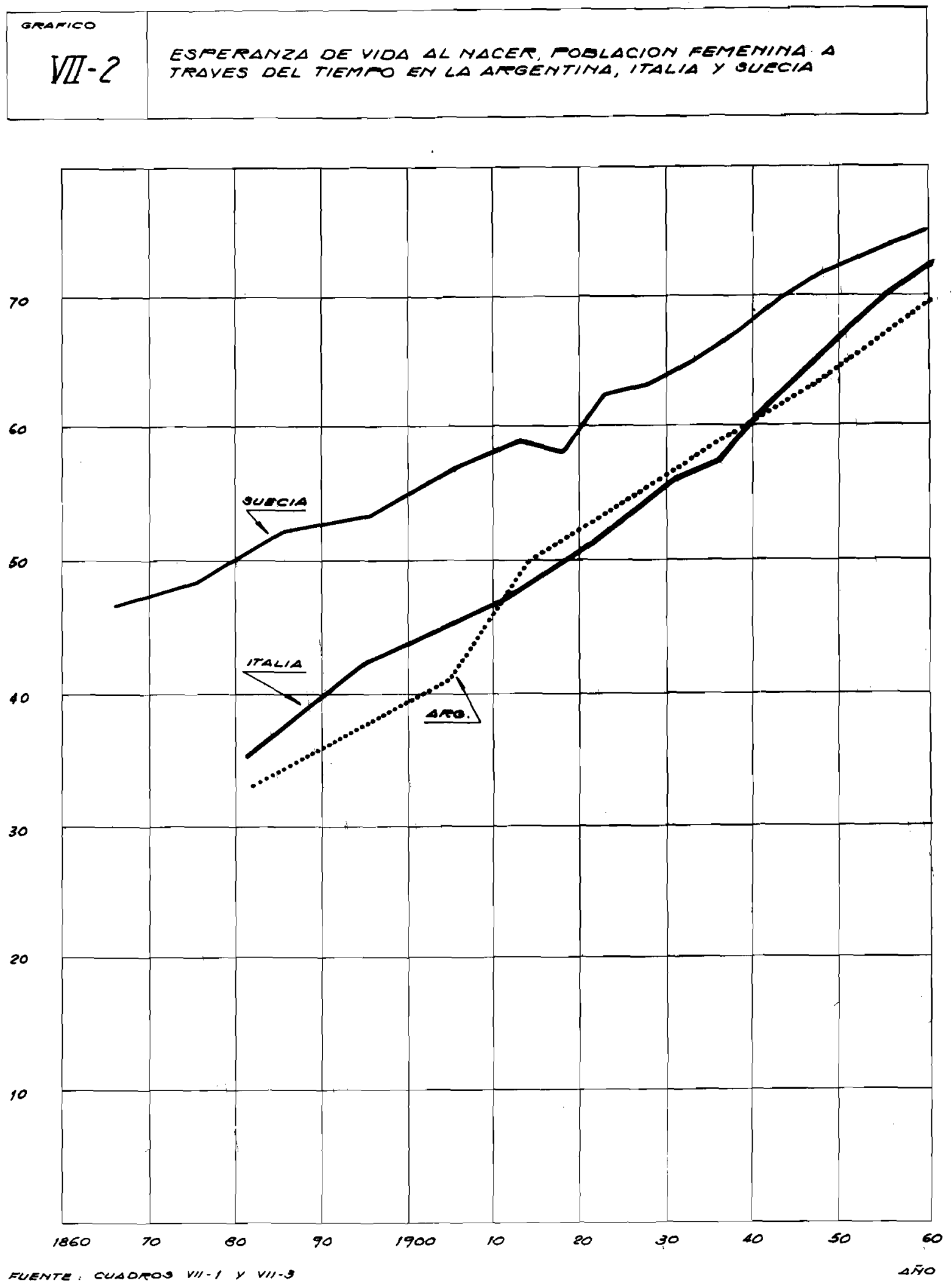
Cuadro VII-3

Esperanza de vida al nacer, por sexo, a través del tiempo en Italia y Suecia

\begin{tabular}{lcc}
\hline & \multicolumn{2}{c}{ Italia } \\
& Hombres & Mujeres \\
$1876-1887$ & 35.1 & 35.5 \\
$1891-1900$ & 42.8 & 43.2 \\
$1910-1912$ & 46.6 & 47.3 \\
$1921-1922$ & 49.3 & 50.8 \\
$1930-1932$ & 53.8 & 56.0 \\
$1935-1937$ & - & 57.5 \\
$1940-1941$ & 57.6 & 60.9 \\
$1950-1953$ & 63.7 & 67.3 \\
$1954-1957$ & 65.8 & 70.0 \\
$1960-1962$ & 67.2 & 72.3
\end{tabular}

Suecia

Hombres

Mujeres

1861-1870

42.8

46.4

1871-1880

45.3

48.6

1881-1890

48.6

51.5

1891-1900

50.9

53.6

1901-1910

54.5

57.0

1911-1915

56.5

59.2

1916-1920

54.8

57.6

1921-1925

60.7

63.0

1926-1930

61.2

63.3

1931-1935

63.2

65.3

1936-1940

64.3

66.9

1941-1945

67.1

69.7

1946-1950

69.0

71.6

1951-1955

70.5

73.4

1960

71.2

74.9

Fuentes:

Boldrini, Marce1lo, Demografia, Dott. Antonino Giuffré, Milano, 1946.

Dublin, Louis I., Lotka, Alfred J. y Spiegelman, Mortimer, Length of Life, The Ronald Press Co., New York, 1949.

United Nations, Demographic Yearbooks, 1951, 1954, 1959 y 1962. 
14. Las conclusiones anteriores, derivadas de la observación de los Gráficos VII-1 y VII-2 deben ser consideradas con cautela, no sólo porque los da tos están sujetos a errores -especialmente los referentes a épocas remotassino también porque en los gráficos se han unido puntos muy distantes entre sí en el tiempo. El variar del índice adquiere así una regularidad, debida a la forma de representación que oculta, con seguridad, oscilaciones que muy posiblemente han debido producirse (que quedan en evidencia en la serie rela tiva a Suecia, constituida por un conjunto de observaciones mucho más numero so que el argentino).

$\underline{\text { La variación del nivel de la mortalidad según el sexo }}$

15. Se divide esta sección en dos partes: una considera la población total, independientemente de su lugar de nacimiento; la otra, la nacida en el país. Para el análisis de la primera parte se dispone de tablas de vida, por sexo, para el país en conjunto, de cinco épocas y para las cuatro regiones de tres períodos, El conjunto de tablas que se utilizan son, por 10 tanto, 5 pares a nivel nacional ( 5 de varones y 5 de mujeres) y 12 pares a nivel regional. Los índices seleccionados, definidos anteriormente, aparecen en el Cuadro VII4. Para el estudio de la segunda parte, relativa a la población nacida en el país, se cuenta con los resultados que se presentan en el Cuadro VII-5. Corresponden a tres pares de tablas ( 3 de varones y 3 de mujeres), a nivel na cional de las primeras épocas analizadas.

16. Antes de entrar a considerar cada uno de esos dos casos, conviene antici par la conclusión general: el nivel de la mortalidad -expresado por la esperanza de vida a1 nacer- es inferior en la población femenina, en todos los pares de tablas considerados, sin excepción.

Diferencia de mortalidad por sexo en la población total (nacida en la Argentina $y$ en el exterior)

17. Un análisis más cuidadoso en relación con la población total debe apoyar se en las tablas elaboradas a partir de 1913-1915, es decir, debe dejar de lä do las relativas a los períodos 1869-1895 y 1895-1914. Estas últimas, como se recordará, muestran una diferencia de mortalidad según el sexo que no resu1 ta de la observación sino de adoptar un patrón elaborado con las tablas modelo de mortalidad de las Naciones Unidas. Este asunto se analiza más adelante al considerarse el caso de la población nacida en el país.

18. La comparación de la mortalidad según el sexo en 1a población total se li mita, por 1o tanto, a tres épocas, en lugar de cinco como se dijo más arriba, a saber: 1913-1915, 1946-1948 y 1959-1961. Se extiende al país y a las cuatro regiones ya conocidas. Se cuenta, por 1o tanto, con 15 pares de tablas con las que se elaboran los seis índices definidos más arriba. De la comparación de esos Índices surge el Cuadro VII-6, donde se indica el número de casos en que la mortalidad de un sexo supera a la del otro. Resultan naturalmente 90 comparaciones, formadas por seis índices de 15 pares de tablas. 


\section{Cuadro VII-4}

Indices seleccionados de las tablas de vida ordenados de modo de facilitar la comparación del nivel de la mortalidad por sexo, según región y época

\begin{tabular}{|c|c|c|c|c|c|c|c|c|}
\hline Región & Epoca & Sexo & $E(0)$ & $Q(0,1)$ & $Q(1,4)$ & $Q(15,35)$ & $Q(50,15)$ & $E(65)$ \\
\hline $\begin{array}{l}\text { RA } \\
\text { RA }\end{array}$ & $\begin{array}{l}1869-1895 \\
1869-1895\end{array}$ & $\begin{array}{l}\mathrm{V} \\
\mathrm{M}\end{array}$ & $\begin{array}{l}32.60 \\
33.32\end{array}$ & $\begin{array}{l}0.24342 \\
0.22073\end{array}$ & $\begin{array}{l}0.15024 \\
0.15192\end{array}$ & $\begin{array}{r}0.40243 \\
0.41958\end{array}$ & $\begin{array}{l}0.46936 \\
0.41347\end{array}$ & $\begin{array}{r}9.45 \\
10.26\end{array}$ \\
\hline $\begin{array}{l}\mathrm{RA} \\
\mathrm{RA}\end{array}$ & $\begin{array}{l}1895-1914 \\
1895-1914\end{array}$ & $\begin{array}{l}\mathrm{V} \\
\mathrm{M}\end{array}$ & $\begin{array}{l}39.48 \\
40.67\end{array}$ & $\begin{array}{l}0.18221 \\
0.16587\end{array}$ & $\begin{array}{l}0.10800 \\
0.10833\end{array}$ & $\begin{array}{l}0.34664 \\
0.35241\end{array}$ & $\begin{array}{l}0.42434 \\
0.35314\end{array}$ & $\begin{array}{l}10.14 \\
11.35\end{array}$ \\
\hline $\begin{array}{l}\text { RA } \\
\text { RA }\end{array}$ & $\begin{array}{l}1913-1915 \\
1913-1915\end{array}$ & $\begin{array}{l}\text { V } \\
\text { M }\end{array}$ & $\begin{array}{l}47.59 \\
49.72\end{array}$ & $\begin{array}{l}0.12100 \\
0.11100\end{array}$ & $\begin{array}{l}0.06575 \\
0.06475\end{array}$ & $\begin{array}{l}0.29281 \\
0.28417\end{array}$ & $\begin{array}{l}0.38285 \\
0.29206\end{array}$ & $\begin{array}{l}11.03 \\
12.77\end{array}$ \\
\hline $\begin{array}{l}\mathrm{RA} \\
\mathrm{RA}\end{array}$ & $\begin{array}{l}1946-1948 \\
1946-1948\end{array}$ & $\begin{array}{l}\mathrm{V} \\
\mathrm{M}\end{array}$ & $\begin{array}{l}59.09 \\
63.59\end{array}$ & $\begin{array}{l}0.07216 \\
0.06304\end{array}$ & $\begin{array}{l}0.02031 \\
0.02004\end{array}$ & $\begin{array}{l}0.15869 \\
0.12455\end{array}$ & $\begin{array}{l}0.31587 \\
0.20585\end{array}$ & $\begin{array}{l}11.67 \\
13.79\end{array}$ \\
\hline $\begin{array}{l}\text { RA } \\
\text { RA }\end{array}$ & $\begin{array}{l}1959-1961 \\
1959-1961\end{array}$ & $\begin{array}{l}\mathrm{V} \\
\mathrm{M}\end{array}$ & $\begin{array}{l}63.68 \\
69.53\end{array}$ & $\begin{array}{l}0.05918 \\
0.05104\end{array}$ & $\begin{array}{l}0.01258 \\
0.01275\end{array}$ & $\begin{array}{l}0.11273 \\
0.07094\end{array}$ & $\begin{array}{l}0.26120 \\
0.14505\end{array}$ & $\begin{array}{l}12.90 \\
15.51\end{array}$ \\
\hline $\begin{array}{l}\text { BA } \\
\text { BA }\end{array}$ & $\begin{array}{l}1913-1915 \\
1913-1915\end{array}$ & $\begin{array}{l}\mathrm{V} \\
\mathrm{M}\end{array}$ & $\begin{array}{l}50.07 \\
53.23\end{array}$ & $\begin{array}{l}0.09631 \\
0.08679\end{array}$ & $\begin{array}{l}0.05497 \\
0.05229\end{array}$ & $\begin{array}{l}0.27165 \\
0.24854\end{array}$ & $\begin{array}{l}0.37749 \\
0.26947\end{array}$ & $\begin{array}{l}10.61 \\
12.73\end{array}$ \\
\hline $\begin{array}{l}\text { BA } \\
\text { BA }\end{array}$ & $\begin{array}{l}1946-1948 \\
1946-1948\end{array}$ & $\begin{array}{l}\mathrm{V} \\
\mathrm{M}\end{array}$ & $\begin{array}{l}61.32 \\
66.83\end{array}$ & $\begin{array}{l}0.05283 \\
0.04328\end{array}$ & $\begin{array}{l}0.01083 \\
0.00984\end{array}$ & $\begin{array}{l}0.14849 \\
0.10403\end{array}$ & $\begin{array}{l}0.31750 \\
0.19340\end{array}$ & $\begin{array}{l}11.63 \\
13.92\end{array}$ \\
\hline $\begin{array}{l}\mathrm{BA} \\
\mathrm{BA}\end{array}$ & $\begin{array}{l}1959-1961 \\
1959-1961\end{array}$ & $\begin{array}{l}\mathrm{V} \\
\mathrm{M}\end{array}$ & $\begin{array}{l}65.09 \\
71.67\end{array}$ & $\begin{array}{l}0.04957 \\
0.04134\end{array}$ & $\begin{array}{l}0.00705 \\
0.00661\end{array}$ & $\begin{array}{l}0.10739 \\
0.06071\end{array}$ & $\begin{array}{l}0.25919 \\
0.13286\end{array}$ & $\begin{array}{l}13.07 \\
15.89\end{array}$ \\
\hline $\begin{array}{l}\text { CL } \\
\text { CL }\end{array}$ & $\begin{array}{l}1913-1915 \\
1913-1915\end{array}$ & $\begin{array}{l}\mathrm{V} \\
\mathrm{M}\end{array}$ & $\begin{array}{l}48.01 \\
49.67\end{array}$ & $\begin{array}{l}0.12829 \\
0.11753\end{array}$ & $\begin{array}{l}0.05879 \\
0.05750\end{array}$ & $\begin{array}{l}0.29070 \\
0.29617\end{array}$ & $\begin{array}{l}0.36699 \\
0.29168\end{array}$ & $\begin{array}{l}11.46 \\
13.19\end{array}$ \\
\hline $\begin{array}{l}\text { CL } \\
\text { CL }\end{array}$ & $\begin{array}{l}1946-1948 \\
1946-1948\end{array}$ & $\begin{array}{l}\mathrm{V} \\
\mathrm{M}\end{array}$ & $\begin{array}{l}59.76 \\
63.55\end{array}$ & $\begin{array}{l}0.06969 \\
0.06127\end{array}$ & $\begin{array}{l}0.01812 \\
0.01823\end{array}$ & $\begin{array}{l}0.15635 \\
0.13114\end{array}$ & $\begin{array}{l}0.30428 \\
0.21496\end{array}$ & $\begin{array}{l}11.87 \\
13.83\end{array}$ \\
\hline $\begin{array}{l}\text { CL } \\
\mathrm{CL}\end{array}$ & $\begin{array}{l}1959-1961 \\
1959-1961\end{array}$ & $\begin{array}{l}\mathrm{V} \\
\mathrm{M}\end{array}$ & $\begin{array}{l}64.36 \\
69.75\end{array}$ & $\begin{array}{l}0.05463 \\
0.04626\end{array}$ & $\begin{array}{l}0.00907 \\
0.00888\end{array}$ & $\begin{array}{l}0.11119 \\
0.07213\end{array}$ & $\begin{array}{l}0.25624 \\
0.15606\end{array}$ & $\begin{array}{l}12.86 \\
15.25\end{array}$ \\
\hline $\begin{array}{l}\mathrm{CY} \\
\mathrm{CY}\end{array}$ & $\begin{array}{l}1913-1915 \\
1913-1915\end{array}$ & $\begin{array}{l}\mathrm{V} \\
\mathrm{M}\end{array}$ & $\begin{array}{l}41.18 \\
41.80\end{array}$ & $\begin{array}{l}0.16173 \\
0.15270\end{array}$ & $\begin{array}{l}0.10617 \\
0.10956\end{array}$ & $\begin{array}{l}0.35348 \\
0.34463\end{array}$ & $\begin{array}{l}0.44390 \\
0.38588\end{array}$ & $\begin{array}{l}10.59 \\
10.74\end{array}$ \\
\hline $\begin{array}{l}\mathrm{CY} \\
\mathrm{CY}\end{array}$ & $\begin{array}{l}1946-1948 \\
1946-1948\end{array}$ & $\begin{array}{l}\mathrm{V} \\
\mathrm{M}\end{array}$ & $\begin{array}{l}56.53 \\
59.63\end{array}$ & $\begin{array}{l}0.09589 \\
0.08702\end{array}$ & $\begin{array}{l}0.03109 \\
0.03022\end{array}$ & $\begin{array}{l}0.16545 \\
0.14929\end{array}$ & $\begin{array}{l}0.32836 \\
0.24792\end{array}$ & $\begin{array}{l}11.58 \\
13.38\end{array}$ \\
\hline $\begin{array}{l}\mathrm{CY} \\
\mathrm{CY}\end{array}$ & $\begin{array}{l}1959-1961 \\
1959-1961\end{array}$ & $\begin{array}{l}\mathrm{V} \\
\mathrm{M}\end{array}$ & $\begin{array}{l}62.70 \\
67.32\end{array}$ & $\begin{array}{l}0.05944 \\
0.05205\end{array}$ & $\begin{array}{l}0.01445 \\
0.01440\end{array}$ & $\begin{array}{l}0.11895 \\
0.08084\end{array}$ & $\begin{array}{l}0.28107 \\
0.17990\end{array}$ & $\begin{array}{l}12.27 \\
14.06\end{array}$ \\
\hline $\begin{array}{l}\text { No } \\
\text { No }\end{array}$ & $\begin{array}{l}1913-1915 \\
1913-1915\end{array}$ & $\begin{array}{l}\mathrm{V} \\
\mathrm{M}\end{array}$ & $\begin{array}{l}37.93 \\
38.01\end{array}$ & $\begin{array}{l}0.18934 \\
0.17972\end{array}$ & $\begin{array}{l}0.12341 \\
0.13078\end{array}$ & $\begin{array}{l}0.40435 \\
0.41177\end{array}$ & $\begin{array}{l}0.43608 \\
0.37162\end{array}$ & $\begin{array}{l}12.76 \\
12.95\end{array}$ \\
\hline $\begin{array}{l}\text { No } \\
\text { No }\end{array}$ & $\begin{array}{l}1946-1948 \\
1946-1948\end{array}$ & $\begin{array}{l}\mathrm{V} \\
\mathrm{M}\end{array}$ & $\begin{array}{l}50.27 \\
52.11\end{array}$ & $\begin{array}{l}0.12353 \\
0.11407\end{array}$ & $\begin{array}{l}0.05314 \\
0.05470\end{array}$ & $\begin{array}{l}0.24201 \\
0.24810\end{array}$ & $\begin{array}{l}0.34466 \\
0.27197\end{array}$ & $\begin{array}{l}10.92 \\
13.19\end{array}$ \\
\hline $\begin{array}{l}\text { No } \\
\text { No }\end{array}$ & $\begin{array}{l}1959-1961 \\
1959-1961\end{array}$ & $\begin{array}{l}\mathrm{V} \\
\mathrm{M}\end{array}$ & $\begin{array}{l}56.41 \\
59.19\end{array}$ & $\begin{array}{l}0.10251 \\
0.09448\end{array}$ & $\begin{array}{l}0.03968 \\
0.04276\end{array}$ & $\begin{array}{l}0.15544 \\
0.14556\end{array}$ & $\begin{array}{l}0.28836 \\
0.21177\end{array}$ & $\begin{array}{l}11.69 \\
13.64\end{array}$ \\
\hline
\end{tabular}




\section{Cuadro VII-5}

Indices seleccionados de las tablas de vida ordenados de modo de facilitar la comparación del nivel de la mortalidad de la población nacida en el país por sexo, según época

\begin{tabular}{|c|c|c|c|c|c|c|c|c|c|}
\hline $\begin{array}{l}\text { Rer } \\
\text { gión }\end{array}$ & Epoca & Ori & Sexo & $E(0)$ & $\mathrm{Q}(0,1)$ & $Q(1,4)$ & $Q(15,35)$ & $Q(50,15)$ & $E(65)$ \\
\hline $\begin{array}{l}\text { RA } \\
\text { RA }\end{array}$ & $\begin{array}{ll}1869 & 1895 \\
1869 & 1895\end{array}$ & $\begin{array}{l}\mathrm{A} \\
\mathrm{A}\end{array}$ & $\begin{array}{l}\text { V } \\
M\end{array}$ & $\begin{array}{l}31.45 \\
32.55\end{array}$ & $\begin{array}{l}0.24342 \\
0.22073\end{array}$ & $\begin{array}{l}0.15024 \\
0.15192\end{array}$ & $\begin{array}{l}0.45222 \\
0.44739\end{array}$ & $\begin{array}{l}0.50119 \\
0.43638\end{array}$ & $\begin{array}{r}9.41 \\
10.12\end{array}$ \\
\hline $\begin{array}{l}\text { RA } \\
\text { RA }\end{array}$ & $\begin{array}{ll}1895 & 1914 \\
1895 & 1914\end{array}$ & $\begin{array}{l}\mathrm{A} \\
\mathrm{A}\end{array}$ & $\begin{array}{l}V \\
M\end{array}$ & $\begin{array}{l}37.61 \\
39.10\end{array}$ & $\begin{array}{l}0.18221 \\
0.16587\end{array}$ & $\begin{array}{l}0.10800 \\
0.10833\end{array}$ & $\begin{array}{l}0.41282 \\
0.39748\end{array}$ & $\begin{array}{l}0.47267 \\
0.39758\end{array}$ & $\begin{array}{l}10.14 \\
11.08\end{array}$ \\
\hline $\begin{array}{l}\text { RA } \\
\text { RA }\end{array}$ & $\begin{array}{ll}1913 & 1915 \\
1913 & 1915\end{array}$ & $\begin{array}{l}\mathrm{A} \\
\mathrm{A}\end{array}$ & $\begin{array}{l}V \\
M\end{array}$ & $\begin{array}{l}44.91 \\
47.05\end{array}$ & $\begin{array}{l}0.12100 \\
0.11100\end{array}$ & $\begin{array}{l}0.06575 \\
0.06475\end{array}$ & $\begin{array}{l}0.37103 \\
0.34382\end{array}$ & $\begin{array}{l}0.44308 \\
0.35705\end{array}$ & $\begin{array}{l}11.01 \\
12.28\end{array}$ \\
\hline
\end{tabular}

Cuadro VII-6

Número de casos en que 1a mortalidad de un sexo excede a 1a del otro resu1tantes de la comparación de 6 indices de mortalidad por edades de 15 pares de tablas de vida, de 1913-1915, 1946-1948 y 1959-1961

\begin{tabular}{|c|c|c|c|c|c|c|c|}
\hline Sexo & $E(0)$ & $\mathrm{Q}(0,1)$ & $Q(1,4)$ & $\begin{array}{l}\mathrm{ndi} c \mathrm{e} \\
\mathrm{Q}(15,35)\end{array}$ & $\mathrm{s}_{\mathrm{Q}}(50,15)$ & $E(65)$ & Total \\
\hline Masculino & 15 & 15 & 9 & 12 & 15 & 15 & 81 \\
\hline Femenino & 0 & 0 & 6 & 3 & 0 & 0 & 9 \\
\hline
\end{tabular}


19. En la comparación de los 90 pares de índices se encuentran 81 que mues tran una mayor mortalidad masculina; en 9 sucede 10 contrario. Estos desvíos a la tendencia general se concentran en edades jóvenes -excluyendo el primer año de vida- ya que 6 de los 9 casos corresponden al tramo de edades (1-5). Los otros 3 casos, que se dan en el tramo 15-50, o son de muy escasa importancia o carecen de significación (surgen dos, por ejemplo, al combinar indices de población nacida en la Argentina y en el exterior. En tanto que separadamente en cada una de esas poblaciones la mortalidad masculina superaba a la femenina en el tramo considerado, al combinar ambos sectores, con muy diferente mortalidad, el peso de la población inmigrante por sexo fue tan desparejo que produjo en el total una diferencia en el Indice considera do, $Q[15,35]$, de sentido inverso). Las tablas de vida en las que se producen esos casos son las de regiones CENTRO LITORAL y NOROESTE de 1913-1915. E1 diferencial de mortalidad por sexo en el tramo de vida considerado, 15-50, es de escasa importancia no sólo para los 3 casos en que la mortalidad feme nina es mayor, sino también para los que muestran un sentido opuesto.

20. En el primer año de vida y en las edades adultas, superiores a los 50 años, la diferencia que muestran los índices analizados, en cambio, es cla ra y no se presentan excepciones.

21. Es interesante señalar que las diferencias de mortalidad por sexo están asociadas al nivel: son menores cuando la mortalidad es más alta. Puede com probarse esta afirmación analizando los índices de la región NOROESTE, la dē mayor mortalidad del país, en donde las diferencias por sexo son relativamen te pequeñas, o estableciendo la diferencia en la mortalidad por sexo en diferentes épocas: a medida que el nivel desciende la diferencia se hace más pró nunciada.

Diferencia de mortalidad por sexo en la población nacida en el país

22. Puede estudiarse sólo para el período 1913-1915 a pesar de que en el Cuadro VII-5, como se indica más arriba, aparecen también valores relativos a 1869-1895 y 1895-1914. Estos últimos, sin embargo, no tienen significación: son el resultado de haber adoptado un patrón de diferencias de morta lidad por sexo elaborado por las Naciones Unidas (véase Referencias, 28). En los puntos que siguen se comparan índices de diferencia de mortalidad por sexo, según la edad; determinados para la población nacida en el país, período 1913-1915, con los elaborados en la publicación aludida. De este cotejo surge la conclusión de que entre las series de valores comparados hay una clara semejanza. Esta comprobación sirve de fundamento a la adop ción del modelo para las tablas de 1869-1895 y 1895-1914. 
23. E1 indice que se elabora es, en símbolos: $100 . Q(X, N) v / Q(X, N){ }^{\text {total }}$ lo que significa, en palabras, valor que toma la probabilidad de morir de la población masculina, entre las edades $x \mathrm{y} x+n$, si se asigna un valor de 100 a la probabilidad correspondiente a la población de ambos sexos. Un valor de ese índice superior a 100 señala sobremortalidad masculina, uno por debajo de 100 expresa lo contrario, esto es, sobremortalidad femenina. Se pre sentan en el Cuadro VII-7 y en el Gráfico VII-3 los valores que toman esos Índices:

(a) en el caso de la población nacida en el país, conforme con la mortalidad de 1913-1915, que corresponde a una esperanza de vida al nacer de 44.91 años para los varones y de 47.05 años para las mujeres, lo que permite estimar que la esperanza de vida al nacer de ambos sexos debió haber sido del orden de 45.95 años;

(b) en un conjunto de 34 tablas de vida con esperanzas de vida al nacer com prendidas entre 45 y 54.9 años, con un valor promedio de 50.3 años. La serie de índices se copia de la publicación mencionada;

(c) en un conjunto de 23 tablas de vida con esperanzas de vida al nacer inferiores a los 45 años, con un valor promedio de 36.77 años. Los valores, también en este caso, son copiados del estudio de las Naciones Unidas.

24. Examinando el cuadro y el gráfico mencionados en el punto anterior pue de concluirse que, en general, los valores observados de la población argen tina caen dentro de la franja definida por las dos series de valores con los que se comparan y muestran, por eso mismo, una variación con la edad de forma aproximadamente similar a la de esas series. Hay algunas excepciones, de muy poca importancia numérica, salvo en los tramos de edades contiguos, 10-15 y 15-20, donde las desviaciones tienen sentidos opuestos: 1os índices argentinos son muy altos en el primer grupo y muy bajos en el segundo, comparados con los provenientes de las tablas que se utilizan como elemento de comparación.

25. La ocurrencia de sólo estas desviaciones y el sentido opuesto que marcan, no altera la conclusión que parece surgir clara: las diferencias de mor talidad por sexo, según la edad de las tablas modelo de las Naciones Unidas parecen ser compatibles con las que se daban en la población nacida en la Ar gentina en el período 1913-1915. Se tomó, consecuentemente, la decisión de 


\section{Cuadro VII-7}

Indice por edad de mortalidad masculina en relación con la de ambos sexos para tres conjuntos de valores; promedios de tablas de vida de diversos países y tablas de vida de la población nacida en la Argentina, 1913-1915

Indice: $100 . Q(X, N)^{V} / Q(X, N)$ ambos sexos

\begin{tabular}{|c|c|c|c|c|}
\hline $\mathrm{x}$ & $\mathrm{n}$ & $\begin{array}{l}\text { Conjunto de } \\
34 \text { tablas } \\
\text { con vida } \\
\text { media entre } \\
45 \text { y } 54,9 \text { años }\end{array}$ & $\begin{array}{l}\text { RA 1913-1915 } \\
\text { Origen: Ar- } \\
\text { gentina } \\
\quad \stackrel{\mathrm{e}}{\mathrm{o}}=45,95\end{array}$ & $\begin{array}{l}\text { Conjunto de } \\
23 \text { tablas } \\
\text { con vida } \\
\text { media menor } \\
\text { de } 45 \text { años }\end{array}$ \\
\hline 0 & 1 & 107.5 & 104.2 & 105.1 \\
\hline 1 & 4 & 101.1 & 100.8 & 99.7 \\
\hline 5 & 5 & 100.0 & 98.0 & 98.7 \\
\hline 10 & 5 & 94.8 & 97.6 & 94.7 \\
\hline 15 & 5 & 99.3 & 91.8 & 95.0 \\
\hline 20 & 5 & 104.4 & 98.6 & 96.4 \\
\hline 25 & 5 & 101.1 & 96.9 & 95.4 \\
\hline 30 & 5 & 102.0 & 99.3 & 96.2 \\
\hline 35 & 5 & 105.3 & 102.9 & 99.4 \\
\hline 40 & 5 & 110.7 & 109.2 & 104.3 \\
\hline 45 & 5 & 114.7 & 114.2 & 108.7 \\
\hline 50 & 5 & 116.3 & 114.6 & 109.6 \\
\hline 55 & 5 & 116.3 & 113.9 & 109.3 \\
\hline 60 & 5 & 114.3 & 111.8 & 106.8 \\
\hline 65 & 5 & 111.5 & 109.9 & 105.3 \\
\hline 70 & 5 & 108.6 & 107.9 & 103.3 \\
\hline 75 & 5 & 106.2 & 106.7 & 102.9 \\
\hline 80 & 5 & 104.0 & 104.4 & 102.0 \\
\hline
\end{tabular}

Fuentes:

Nations Unies, Schémas de variation de la mortalité selon l'âge et le sexe, ST/SOA/Ser.A/22, New York, 1956.

Capítulo VI. 
ORAFICO MOICE PON EOAD DEMONTALIDAD MASCULINA EN NELACION

ITI - 3 CON LA DE $\triangle M E O S$ SEXOS PATA TAES CONJUNTOS DE VALONES:

MPOMEOIOS OE TAOLAS OE VIOA DE OIVEASOS PAISES Y TAELAS

DE VIOA OE LA TOELACION NACIOA EN ATGENTINA $1913-1915$

180
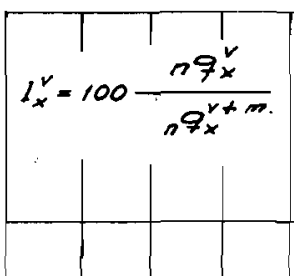

115

110

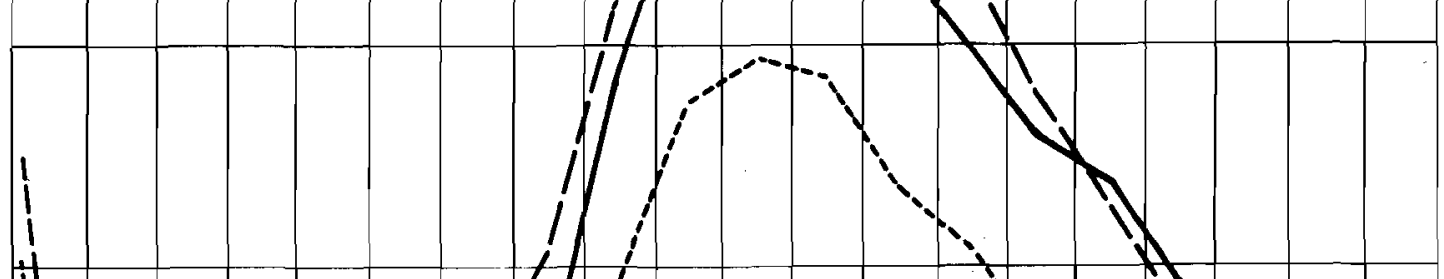

105

100

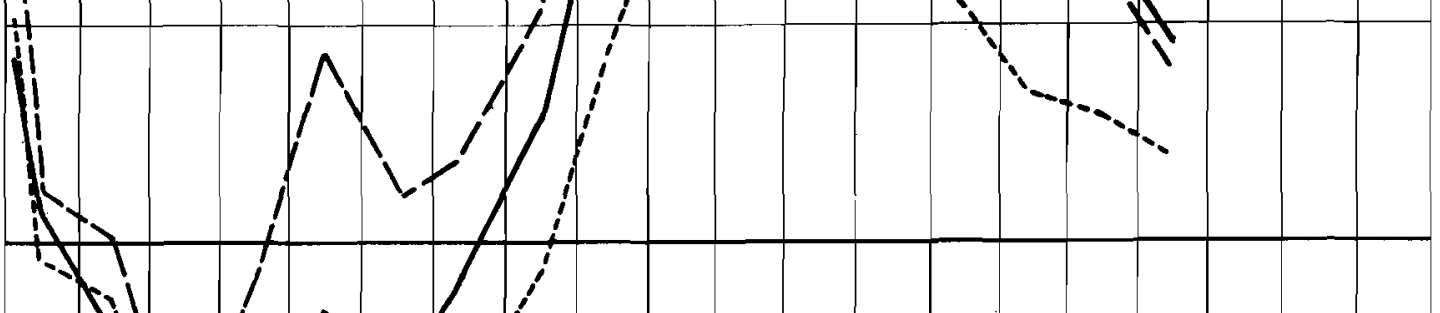

95
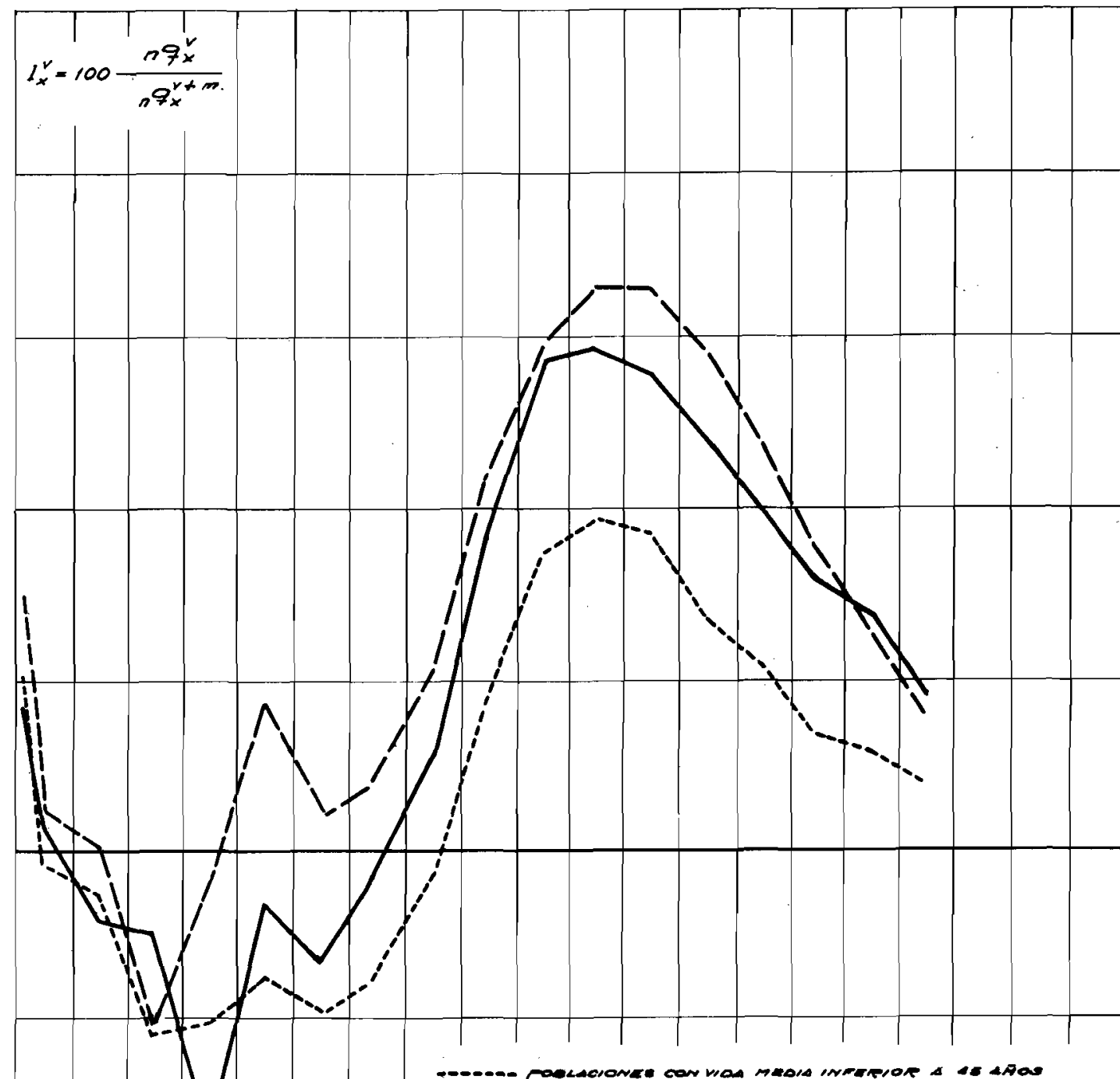
estimar la diferencia de mortalidad entre hombres y mujeres en los períodos 1869-1895 y 1895-1914 suponiendo que, tambiên para esas épocas, era aplicable el patrón. dado por las tablas modelo de las Naciones Unidas, Como se recordará (Capítulo IV), en la elaboración de las tablas intercensales correspondientes a esos períodos, pudo estimarse el nivel de la mortalidad masculina en base a relaciones de supervivencia intercensales. Se tropezó, sin embargo, con el inconveniente de que el procedimiento no era aplicable a la población femenina en razón de que los datos censales estaban afecta dos por gruesos errores y porque, aparentemente, se produjeron emigraciones de mujeres en los períodos intercensales. Al adoptarse esta decisión sobre el diferencial de mortalidad por sexo, las tablas de vida de población feme nina resultan de aplicar a las de varones índices que miden 1a diferencia de mortalidad entre sexos obtenidos de las tablas de Naciones Unidas, Estos índices no son uniformes sino que varían con el nivel de la mortalidad.

26. Resumiendo, las tablas de vida de la población nacida en la Argentina del período 1913-1915 muestran una mayor mortalidad masculina desde el naci miento hasta aproximadamente 1 os 5 años; un exceso de mortalidad femenina desde esta edad hasta el tramo 30-35 y desde la edad 35 en adelante, otra vez hay mayor mortalidad entre los hombres.

$\underline{\text { La variación del nivel de la mortalidad segün regiones }}$

27. Consideramos que una conclusión interesante del trabajo es haber esta blecido, cuantitativamente, la enorme diferencia que hay en el nivel de la mortalidad según regiones. En el capítulo II se consideró este asunto ana lizando la esperanza de vida al nacer. Aquí se hace un estudio más detalla do con los índices ya definidos para diferentes tramos de edades.

28. La base para este análisis está dada por un conjunto de 45 tablas de vida, correspondientes a tres épocas, 1913-1915, 1946-1948 y 1959-1961, a ambos sexos, varones y mujeres y a las cuatro regiones conocidas además, cla ro está, de las correspondientes a la unión de ellas, que denominamos tablas de ARGENTINA, Los indices ordenados de modo de facilitar la comparación del nivel de la mortalidad entre regiones se presentan en el Cuadro VII-8.

29. Con las probabilidades de muerte de tramos seleccionados de ese cuadro se han elaborado números índices, para ambos sexos, relacionando los valores regionales con los correspondientes al país. Expresado en símbolos el indice se define por la relación:

$$
I^{R}(X, N)=100 \cdot Q^{R}(X, N) / Q(X, N)^{R A} \text { para } R=B A, C L, C Y \text {, No }
$$

Estos valores aparecen en el Cuadro VII-9 y sirven para medir, en términos relativos, las diferencias de la mortalidad entre regiones. Así, por ejem plo, el índice correspondiente al primer año de vida $I^{R}(0,1)$ que, para 1959-1961 y las regiones BUENOS AIRES y NOROESTE vale 83 y 179, está señalando que la mortalidad infantil de la primera de estas dos regiones era 


\section{Cuadro VII-8}

Indices seleccionados de las tablas de vida ordenados de modo de facilitar la comparación del nivel de la mortalidad por región, según sexo y época

\begin{tabular}{|c|c|c|c|c|c|c|c|c|}
\hline Región & Epoca & Sexo & $E(0)$ & $Q(0,1)$ & $Q(1,4)$ & $Q(15,35)$ & $Q(50,15)$ & $E(65)$ \\
\hline $\begin{array}{l}\text { RA } \\
\text { BA } \\
\text { CL } \\
\text { CY } \\
\text { NO }\end{array}$ & $\begin{array}{l}1913-1915 \\
1913-1915 \\
1913-1915 \\
1913-1915 \\
1913-1915\end{array}$ & & $\begin{array}{l}48.50 \\
51.37 \\
48.75 \\
41.45 \\
37.94\end{array}$ & $\begin{array}{l}0.11612 \\
0.09166 \\
0.12304 \\
0.15733 \\
0.18466\end{array}$ & $\begin{array}{l}0.06528 \\
0.05364 \\
0.05813 \\
0.10785 \\
0.12703\end{array}$ & $\begin{array}{l}0.28948 \\
0.26258 \\
0.29332 \\
0.34971 \\
0.40807\end{array}$ & $\begin{array}{l}0.34483 \\
0.33306 \\
0.33502 \\
0.41838 \\
0.40784\end{array}$ & $\begin{array}{l}11.82 \\
11.54 \\
12.26 \\
10.65 \\
12.83\end{array}$ \\
\hline $\begin{array}{l}\text { RA } \\
\text { BA } \\
\text { CL } \\
\text { CY } \\
\text { NO }\end{array}$ & $\begin{array}{l}1946-1948 \\
1946-1948 \\
1946-1948 \\
1946-1948 \\
1946-1948\end{array}$ & & $\begin{array}{l}61.08 \\
63.77 \\
61.42 \\
57.95 \\
51.08\end{array}$ & $\begin{array}{l}0.06770 \\
0.04815 \\
0.06557 \\
0.09156 \\
0.11890\end{array}$ & $\begin{array}{l}0.02015 \\
0.01033 \\
0.01816 \\
0.03066 \\
0.05391\end{array}$ & $\begin{array}{l}0.14285 \\
0.12771 \\
0.14469 \\
0.15787 \\
0.24528\end{array}$ & $\begin{array}{l}0.26754 \\
0.26220 \\
0.26626 \\
0.29235 \\
0.31318\end{array}$ & $\begin{array}{l}12.68 \\
12.73 \\
12.77 \\
12.46 \\
12.00\end{array}$ \\
\hline $\begin{array}{l}\text { RA } \\
\text { BA } \\
\text { CL } \\
\text { CY } \\
\text { NO }\end{array}$ & $\begin{array}{l}1959-1961 \\
1959-1961 \\
1959-1961 \\
1959-1961 \\
1959-1961\end{array}$ & & $\begin{array}{l}66.37 \\
68.15 \\
66.81 \\
64.82 \\
57.66\end{array}$ & $\begin{array}{l}0.05521 \\
0.04555 \\
0.05056 \\
0.05583 \\
0.09858\end{array}$ & $\begin{array}{l}0.01267 \\
0.00682 \\
0.00897 \\
0.01443 \\
0.04120\end{array}$ & $\begin{array}{l}0.09214 \\
0.08421 \\
0.09193 \\
0.10048 \\
0.15083\end{array}$ & $\begin{array}{l}0.20664 \\
0.19911 \\
0.21035 \\
0.23386 \\
0.25361\end{array}$ & $\begin{array}{l}14.14 \\
14.44 \\
13.94 \\
13.12 \\
12.57\end{array}$ \\
\hline $\begin{array}{l}\text { RA } \\
\text { BA } \\
\text { CL } \\
\text { CY } \\
\text { NO }\end{array}$ & $\begin{array}{l}1913-1915 \\
1913-1915 \\
1913-1915 \\
1913-1915 \\
1913-1915\end{array}$ & $\begin{array}{l}\text { V } \\
\text { V } \\
\text { V } \\
\text { V } \\
\text { V }\end{array}$ & $\begin{array}{l}47.59 \\
50.07 \\
48.01 \\
41.18 \\
37.93\end{array}$ & $\begin{array}{l}0.12100 \\
0.09631 \\
0.12829 \\
0.16173 \\
0.18934\end{array}$ & $\begin{array}{l}0.06575 \\
0.05497 \\
0.05879 \\
0.10617 \\
0.12341\end{array}$ & $\begin{array}{l}0.29281 \\
0.27165 \\
0.29070 \\
0.35348 \\
0.40435\end{array}$ & $\begin{array}{l}0.38285 \\
0.37749 \\
0.36699 \\
0.44390 \\
0.43608\end{array}$ & $\begin{array}{l}11.03 \\
10.61 \\
11.46 \\
10.59 \\
12.76\end{array}$ \\
\hline $\begin{array}{l}\text { RA } \\
\text { BA } \\
\text { CL } \\
\text { CY } \\
\text { NO }\end{array}$ & $\begin{array}{l}1946-1948 \\
1946-1948 \\
1946-1948 \\
1946-1948 \\
1946-1948\end{array}$ & $\begin{array}{l}\text { V } \\
\text { V } \\
\text { V } \\
\text { V } \\
\text { V }\end{array}$ & $\begin{array}{l}59.09 \\
61.32 \\
59.76 \\
56.53 \\
50.27\end{array}$ & $\begin{array}{l}0.07216 \\
0.05283 \\
0.06969 \\
0.09589 \\
0.12353\end{array}$ & $\begin{array}{l}0.02031 \\
0.01083 \\
0.01812 \\
0.03109 \\
0.05314\end{array}$ & $\begin{array}{l}0.15869 \\
0.14849 \\
0.15635 \\
0.16545 \\
0.24201\end{array}$ & $\begin{array}{l}0.31587 \\
0.31750 \\
0.30428 \\
0.32836 \\
0.34466\end{array}$ & $\begin{array}{l}11.67 \\
11.63 \\
11.87 \\
11.58 \\
10.92\end{array}$ \\
\hline $\begin{array}{l}\text { RA } \\
\text { BA } \\
\text { CL } \\
\text { CY } \\
\text { NO }\end{array}$ & $\begin{array}{l}1959-1961 \\
1959-1961 \\
1959-1961 \\
1959-1961 \\
1959-1961\end{array}$ & $\begin{array}{l}\text { V } \\
\text { V } \\
\text { V } \\
\text { V } \\
\text { V }\end{array}$ & $\begin{array}{l}63.68 \\
65.09 \\
64.36 \\
62.70 \\
56.41\end{array}$ & $\begin{array}{l}0.05918 \\
0.04957 \\
0.05463 \\
0.05944 \\
0.10251\end{array}$ & $\begin{array}{l}0.01258 \\
0.00705 \\
0.00907 \\
0.01445 \\
0.03968\end{array}$ & $\begin{array}{l}0.11273 \\
0.10739 \\
0.11119 \\
0.11895 \\
0.15544\end{array}$ & $\begin{array}{l}0.26120 \\
0.25919 \\
0.25624 \\
0.28107 \\
0.28836\end{array}$ & $\begin{array}{l}12.90 \\
13.07 \\
12.86 \\
12.27 \\
11.69\end{array}$ \\
\hline $\begin{array}{l}\text { RA } \\
\text { BA } \\
\text { CL } \\
\text { CY } \\
\text { NO }\end{array}$ & $\begin{array}{l}1913-1915 \\
1913-1915 \\
1913-1915 \\
1913-1915 \\
1913-1915\end{array}$ & $\begin{array}{l}M \\
M \\
M \\
M \\
M\end{array}$ & $\begin{array}{l}49.72 \\
53.23 \\
49.67 \\
41.80 \\
38.01\end{array}$ & $\begin{array}{l}0.11100 \\
0.08679 \\
0.11753 \\
0.15270 \\
0.17972\end{array}$ & $\begin{array}{l}0.06475 \\
0.05229 \\
0.05750 \\
0.10956 \\
0.13078\end{array}$ & $\begin{array}{l}0.28417 \\
0.24854 \\
0.29617 \\
0.34463 \\
0.41177\end{array}$ & $\begin{array}{l}0.29206 \\
0.26947 \\
0.29168 \\
0.38588 \\
0.37162\end{array}$ & $\begin{array}{l}12.77 \\
12.73 \\
13.19 \\
10.74 \\
12.95\end{array}$ \\
\hline $\begin{array}{l}\text { RA } \\
\text { BA } \\
\text { CL } \\
\text { CY } \\
\text { NO }\end{array}$ & $\begin{array}{l}1946-1948 \\
1946-1948 \\
1946-1948 \\
1946-1948 \\
1946-1948\end{array}$ & $\begin{array}{l}\mathrm{M} \\
\mathrm{M} \\
\mathrm{M} \\
\mathrm{M} \\
\mathrm{M}\end{array}$ & $\begin{array}{l}63.59 \\
66.83 \\
63.55 \\
59.63 \\
52.11\end{array}$ & $\begin{array}{l}0.06304 \\
0.04328 \\
0.06127 \\
0.08702 \\
0.11407\end{array}$ & $\begin{array}{l}0.02004 \\
0.00984 \\
0.01823 \\
0.03022 \\
0.05470\end{array}$ & $\begin{array}{l}0.12455 \\
0.10403 \\
0.13114 \\
0.14929 \\
0.24810\end{array}$ & $\begin{array}{l}0.20585 \\
0.19340 \\
0.21496 \\
0.24792 \\
0.27197\end{array}$ & $\begin{array}{l}13.79 \\
13.92 \\
13.83 \\
13.38 \\
13.19\end{array}$ \\
\hline $\begin{array}{l}\text { RA } \\
\text { BA } \\
\text { CL } \\
\text { CY } \\
\text { NO }\end{array}$ & $\begin{array}{l}1959-1961 \\
1959-1961 \\
1959-1961 \\
1959-1961 \\
1959-1961\end{array}$ & $\begin{array}{l}\mathrm{M} \\
\mathrm{M} \\
\mathrm{M} \\
\mathrm{M} \\
\mathrm{M}\end{array}$ & $\begin{array}{l}69.53 \\
71.67 \\
69.75 \\
67.32 \\
59.19\end{array}$ & $\begin{array}{l}0.05104 \\
0.04134 \\
0.04626 \\
0.05205 \\
0.09448\end{array}$ & $\begin{array}{l}0.01275 \\
0.00661 \\
0.00888 \\
0.01440 \\
0.04276\end{array}$ & $\begin{array}{l}0.07094 \\
0.06071 \\
0.07213 \\
0.08084 \\
0.14556\end{array}$ & $\begin{array}{l}0.14505 \\
0.13286 \\
0.15606 \\
0.17990 \\
0.21177\end{array}$ & $\begin{array}{l}15.51 \\
15.89 \\
15.25 \\
14.06 \\
13.64\end{array}$ \\
\hline
\end{tabular}


equivalente al 83 por ciento de la media del país, en tanto que la del NORO ESTE superaba en un 79 por ciento a esa media.

30. El oxdenamiento de las regiones según su nivel de la mortalidad es generalmente el mismo cualquiera que sea el índice que se considere: BUENOS AIRES es la que tiene el nivel menor, le sigue CENTRO LITORAL, después CUYO y finalmente la región NOROESTE, con la mayor mortalidad, Esto vale para las tres épocas con algunas pocas excepciones que comentamos mảs adelante,

31. La mortalidad infantil, esto es la correspondiente al tramo de vida 0-1 -que, como se sabe, constituye un indicador adecuado del nivel general de vida de una población- a lo largo de las tres épocas estudiadas y tanto en la población masculina como en la femenina, conduce al ordenamiento indicado de las regiones, sin ninguna excepción. La dispersión de los valores, sin embargo, cambia en el tiempo: tiende a hacerse más uniforme la mortalidad infantil de BUENOS AIRES, CENTRO LITORAL y CUYO y a distanciarse de la media la correspondiente a la región NOROESTE. LOs valores relativos del Cuadro VII-9 muestran que los índices de las tres primeras regiones variaban entre 79 y 135 en 1913-1915, y sólo entre 83 y 101 en 1959-1961, Los de1 NOROES$\mathrm{TE}$, en cambio, fueron 159 y 179 para las dos épocas respectivamente, a pesar de que la mortalidad infantil, para ambos sexos, descendió en esa región de 0.18466 a 0.09858. Un análisis de los valores según el sexo conduciría a las mismas conclusiones.

32. La mortalidad en el tramo de edades 1-5 varía entre regiones en forma relativamente mucho más pronunciada que la mortalidad infantil, aunque tam bién en este caso, el ordenamiento de las regiones según el nivel se mantie ne $\sin$ alteraciones en las tres épocas y los dos sexos. En 1913-1915 BUENOS AIRES y CENTRO LITORAL mostraban índices casi equivalentes; CUYO y NOROESTE valores mucho más altos. Con el tiempo todas las probabilidades de morir en tre las edades 1 y 5 decrecen fuertemente pero con diferente intensidad según las regiones. El desceñso relativo es máximo en BUENOS AIRES donde alcanza en 1959-1961 un nivel equivalente a sólo el 54 por ciento del valor medio del país; el índice del CENTRO LITORAL es mucho más alto, 71; el de CUYO 1lega a 114 y e1 de1 NOROESTE a la cifra asombrosa de 325 . En este gru po de edades y en 1959-1961 es donde la dispersión de valores entre regiones es mayor: la mortalidad de BUENOS AIRES está relativamente muy por debajo de la media y el NOROESTE en una situación extremadamente desfavorable.

33. La mortalidad del tramo analizado, 1-5, como la mortalidad infantil, ha sido también recomendada como indicativa del nivel de vida de una población ya que traduce no sólo las condiciones sanitarias, sino también su situación en materia de nutrición, educación, vivienda, etc. Esta consideración es oportuna para otorgar a las diferencias que se comentan toda la enorme sig nificación que tienen: en la Argentina existen, y se han acentuado con el tiempo, a la .1uz del índice analizado, desigualdades enormes en el nive1 de vida de la población según zonas geográficas.

34. En el tramo de vida 15-50, de edades adultas jóvenes, se presentan ten dencias similares a las que se encontraron cuando se analizó la mortalidad 
Cuadro VII-9

Indices por regiones y épocas, de ambos sexos, calculados con las probabilidades de muerte de tramos seleccionados de edades, utilizando como base los valores de la ARGENTINA

$I^{R}(X, N)=100 \cdot Q(X, N)^{R} / Q(X, N)^{R A}$ para $R=B A, C L, C Y, N O$.

\begin{tabular}{|c|c|c|c|c|c|}
\hline Epoca & Región & $I(0,1)$ & $I(1,4)$ & $I(15,35)$ & $I(50,15)$ \\
\hline $1913-1915$ & $\mathrm{RA}$ & 100 & 100 & 100 & 100 \\
\hline $1913-1915$ & BA & 79 & 82 & 91 & 97 \\
\hline $1913-1915$ & $\mathrm{CL}$ & 106 & 89 & 101 & 97 \\
\hline $1913-1915$ & $\mathrm{CY}$ & 135 & 165 & 121 & 121 \\
\hline $1913-1915$ & NO & 159 & 195 & 141 & 118 \\
\hline $1946-1948$ & $\mathrm{RA}$ & 100 & 100 & 100 & 100 \\
\hline $1946-1948$ & $\mathrm{BA}$ & 71 & 51 & 89 & 98 \\
\hline $1946-1948$ & $\mathrm{CL}$ & 97 & 90 & 101 & 100 \\
\hline $1946-1948$ & $\mathrm{CY}$ & 135 & 152 & 111 & 109 \\
\hline $1946-1948$ & NO & 176 & 268 & 172 & 117 \\
\hline $1959-1961$ & $\mathrm{RA}$ & 100 & 100 & 100 & 100 \\
\hline $1959-1961$ & $\mathrm{BA}$ & 83 & 54 & 91 & 96 \\
\hline $1959-1961$ & $\mathrm{CL}$ & 92 & 71 & 100 & 102 \\
\hline $1959-1961$ & $\mathrm{CY}$ & 101 & 114 & 109 & 113 \\
\hline $1959-1961$ & NO & 179 & 325 & 164 & 123 \\
\hline
\end{tabular}


infantil. Cabe señalar, empero, que los índices en este caso muestran menor dispersión que en aquél, Esto es general, vale para las tres épocas, ambos sexos, varones y mujeres.

35. En e1 intervalo de edades 50-65 se presentan, por primera vez, algunas alteraciones en la ordenación establecida de las regiones según su nivel de mortalidad. En 1913-1915 la región de CUYO superaba a la de1 NOROESTE. La mortalidad masculina de BUENOS AIRES era mayor que la del CENTRO LITORAL, en las tres épocas. Las diferencias entre regiones son mucho menores que en los otros tramos de edades considerados sin que surja ninguna tendencia cla ra que muestre una mayor o menor dispersión entre los índices regionales con el tiempo. Entre los varones la dispersión de valores según regiones es menor que entre las mujeres.

36. Finalmente, la variación de la esperanza de vida a la edad 65 no muestra tendencias claras. Debemos recordar que este índice merece menos confianza que los anteriormente analizados porque está afectado -a pesar de los ajustes efectuados a las tasas observadas de mortalidad- por errores provenientes de los censos y los registros. Además, es un hecho comprobado que en los tramos de edades avanzadas las diferencias de mortalidad entre dos poblaciones con alta mortalidad y baja mortalidad son menores $y$, hasta de tendencias con trarias (una población con mayor mortalidad general que otra puede tener menor mortalidad en las edades avanzadas).

37. Las observaciones anteriores pueden ayudar a interpretar los resultados que aparecen en el Cuadro VII-8. Según ellos en 1913-1915 la población de ambos sexos del NOROESTE tenía la menor mortalidad; CUYO 1a mayor. En 19461948 la región CENTRO LITORAL mostraba la menor mortalidad (aunque a un nivel casi igual al de BUENOS AIRES) y el NOROESTE la mayor. En 1959-1961 las regiones se ordenaban en la forma habitual con BUENOS AIRES y el NOROESTE en los extremos. El estudio de los índices por sexo conduce también a comproba ciones inesperadas como las mencionadas en relación con la población de ambos sexos.

38. Puede sacarse la conclusión general de que para lás edades superiores a los 65 años las diferencias de mortalidad según regiones son muy pequeñas aun que es significativo que para el período 1959-1961 las regiones se ordenan en la forma tantas veces mencionada con BUENOS AIRES en la situación más favorable y la región NOROESTE en el otro extremo.

La variación del nivel de la mortalidad según el origen de la población. Perfído 1913-1915

39. El último diferencial de mortalidad que se analiza es el de la población según el origen o lugar de nacimiento: la nacida en la Argentina y la nacida en el exterior, Las tablas de vida de población nacida en el exterior se ini cian a partir de la edad de 5 años. No se calcularon tasas de mortalidad para edades inferiores en razón de que la población inmigrante, de menos de 5 años era muy poco numerosa $y$, consecuentemente, las tasas de mortalidad que pudieron 
haberse calculado hubieran estado afectadas por gruesos errores, sujetas a fuertes oscilaciones. Como se indicó oportunamente (Capítulo IV) las tablas de mortalidad de la población nacida en el exterior, por sexo y región, se extendieron hasta la edad 0, asignando al tramo 0-5 la misma mortalidad de la población nacida en el país, para esas edades y del mismo sexo y región.

40. E1 análisis debe limitarse a la época 1913-1915 puesto que no se dispo ne de estadísticas de muertes clasificadas según origen para los otros períodos considerados 1946-1948 y 1959-1961. Tal información es necesaria para la elaboración de las tablas de vida por lugar de nacimiento.

41, E1 Cuadro VII-10 muestra los Indices de mortalidad, según origen, que se analizan. Se dan para diferentes tramos de vida, por sexo y región. Es tán dispuestos de tal forma que facilitan la comparación entre la población nacida en el país y en el exterior.

42. La conclusión general es que la mortalidad de la población nacida en el exterior era, en 1913-1915, claramente menor que la correspondiente a la nacida en el país. Tal conclusión surge netamente de los datos presentados en el cuadro y vale, sin excepción, para el nivel general de mortalidad -la esperanza de vida al nacer se utiliza como indicador, así como para las probabilidades de morir en los intervalos de edades 15-50 y 50-65. La esperanza de vida a los 65 años es para todo el país, en la población masculina nacida en la Argentina, apenas superior a la de la población extranjera. Esta tendencia es debida a los valores que se registran en la región NOROESTE.

43. Merece destacarse que la diferencia según origen es muy importante en el tramo 15-50, tanto en la población masculina como en la femenina. Aunque tam bién clara, en el intervalo 50-65 no es tan pronunciada como en aquel grupo.

44. En las edades superiores a 10 s 65 años las diferencias de los dos sectores de población comparados son pequeñas. Si se tienen en cuenta las limitaciones de las medidas de la mortalidad en edades avanzadas -especialmente en el caso de la población nacida en el exterior que, en esas edades, era muy po co numerosa- parece razonable no otorgar significación a las diferencias por origen de los valores de la esperanza de vida a los 65 años.

45. Terminamos esta sección con una advertencia: si en los registros de muer tes se hubiera cometido el error de considerar como nacidas en la Argentina a defunciones de origen no declarado, se habría producido un error en el sentido de exagerar la mortalidad de los nativos y subestimar la de la población nacida en el exterior. No hay forma de saber si tales errores se han cometi do y por lo tanto, esta consideración puede parecer innecesaria. Pensamos, sin embargo, que es apropiado llamar la atención del lectorsobre esa posibilidad a fin de que juzgue con mayor cautela el diferencial de mortalidad según origen que se ha presentado. 


\section{Cuadro VII-10}

Indices seleccionados de las tablas de vida ordenados de modo de facilitar la comparación del nivel de la mortalidad por origen, segûn región y sexo. Período 1913-1915

\begin{tabular}{|c|c|c|c|c|c|c|c|}
\hline Regiôn & Epoca & $\begin{array}{l}\text { Ori } \\
\text { gen }\end{array}$ & Sexo & $E(0)$ & $Q(15,35)$ & $Q(50,15)$ & $E(65)$ \\
\hline $\mathrm{RA}$ & 1913-1915 & $\mathrm{A}$ & V & 44.91 & 0.37103 & 0.44308 & 11.01 \\
\hline $\mathrm{RA}$ & $1913-1915$ & $\mathrm{E}$ & $\mathrm{V}$ & 49.75 & 0.23047 & 0.35003 & 10.98 \\
\hline RA & $1913-1915$ & $\mathrm{~A}$ & M & 47.05 & 0.34382 & 0.35705 & 12.28 \\
\hline $\mathrm{RA}$ & 1913-1915 & $\mathrm{E}$ & $\mathbf{M}$ & 53.55 & 0.20065 & 0.23905 & 13.05 \\
\hline BA & $1913-1915$ & $\mathrm{~A}$ & $\mathrm{~V}$ & 47.49 & 0.33947 & 0.43013 & 10.16 \\
\hline $\mathrm{BA}$ & $1913-1915$ & $\mathrm{E}$ & V & 51.41 & 0.23518 & 0.36164 & 10.73 \\
\hline$B A$ & $1913-1915$ & $\mathrm{~A}$ & M & 50.52 & 0.30192 & 0.33405 & 12.17 \\
\hline BA & $1913-1915$ & $E$ & $\mathbf{M}$ & 55.69 & 0.19993 & 0.24222 & 12.91 \\
\hline CL & 1913-1915 & $\mathrm{A}$ & V & 45.03 & 0.37277 & 0.43874 & 11.15 \\
\hline $\mathrm{CL}$ & $1913-1915$ & $\mathrm{E}$ & v & 51.24 & 0.20466 & 0.31462 & 11.59 \\
\hline CL & $1913-1915$ & $\mathrm{~A}$ & $\mathbf{M}$ & 47.36 & 0.34838 & 0.34721 & 12.78 \\
\hline CL & $1913-1915$ & $E$ & M & 54.38 & 0.19053 & 0.22268 & 13.48 \\
\hline $\mathrm{CY}$ & $1913-1915$ & $\mathrm{~A}$ & $\mathrm{~V}$ & 38.92 & 0.42955 & 0.50092 & 10.27 \\
\hline$C Y$ & $1913-1915$ & $E$ & V & 44.25 & 0.25915 & 0.36469 & 11.15 \\
\hline $\mathrm{CY}$ & $1913-1915$ & $\mathrm{~A}$ & M & 40.08 & 0.39162 & $0.431,44$ & 10.20 \\
\hline $\mathrm{CY}$ & $1913-1.915$ & $\mathrm{E}$ & M & 46.75 & 0.23042 & 0.27619 & 12.26 \\
\hline NO & $1913-1915$ & $\mathrm{~A}$ & $\mathrm{~V}$ & 37.10 & 0.43353 & 0.4507 .8 & 12.92 \\
\hline NO & $1913-1915$ & $E$ & $\mathrm{~V}$ & 40.95 & 0.29357 & 0.37488 & 11.78 \\
\hline No & $1913-1915^{\circ}$ & A & M & 37.45 & 0.42720 & 0.38441 & 12.81 \\
\hline NO & $1913-1915$ & $\mathrm{E}$ & $\mathbf{M}$ & 44.38 & 0.26591 . & 0.25033 & 14.98 \\
\hline
\end{tabular}


ANEXOS 

Anexo I (al capitulo II)

CORRECCION DEL SUBREGISTRO DE MUERTES EN 1914, 1947 Y 1960

1. E1 propósito de este Anexo es explicar cómo se estimó 1a omisión en los registros de muertes en los años censales 1914, 1947 y 1960, en qué forma se definió un factor de corrección para esos años que aplicado a las tasas observadas produce presumiblemente tasas de mortalidad ajustadas y finalmen te qué procedimiento se utilizó, a fin de obtener una serie anual de tales factores que se utilizaron en la elaboración de tasas corregidas de mortalidad entre 1914 y 1965.

2. Para cada uno de los años censales se calculó, en primer lugar, el número de muertes esperadas en las cuatro regiones que se analizan en el tra bajo (ver Anexo III). La estimación se hizo aplicando a la población censada en tales regiones -en las primeras edades se utilizó la población estimada en base a nacimientos corregidos y muertes en lugar de la información dada por los censos- las tasas anuales de mortalidad, por grupos de edad, co rrespondientes a las tablas de vida de la época censal y región consideradas. E1 cálculo se hizo tomando la población de ambos sexos y aplicando la tabla de vida, también de ambos sexos. E1 número de muertes estimadas en cada uno de los tres años, en el conjunto de las cuatro regiones, aparece en la Tábla I-1.

3. La estimación de las muertes ocurridas en el resto del país, esto es, los territorios no comprendidos en las cuatro regiones, es más difícil de elaborar porque, como se ha señalado en el texto, no se dispone de informa ción sobre muertes registradas que merezca confianza. Se hace forzoso, porr 1o tanto, hacer alguna hipótesis acerca de cuäl pudo haber sido el nivel de la mortalidad en este sector. En él las condiciones de vida son inferiores a las de la media del país. Puede suponerse, por lo tanto, que el nivel de la mortalidad del sector considerado debe ser superior al estimado para el conjunto de las cuatro regiones. Conforme con este razonamiento se adoptó para él la mortalidad de la región NOROESTE, que es la de más alta mortalí dad de las cuatro regiones consideradas.

4. Es posible, pero no puede probarse, que el nivel de mortalidad del NOROESTE sea superior al del resto del país. Algunas regiones de éste están, indudablemente, más adelantadas que aquella región. Otras, en cambio, tienen características similares. Si un error en exceso pudo cometerse con la hipó tesis adoptada, uno en defecto, de poca importancia, se produjo cuando tasas de mortalidad se aplicaron a la población censada en el resto del país en las primeras edades, sin ajustarla por omisión.

5. Las muertes esperadas en el resto del país, esto es el total menos las cuatro regiones, para cada uno de los tres años, resultado de aplicar a la población dada por el censo, clasificada por edad, las tasas anuales de 
mortalidad de las tablas de vida de la región NOROESTE se presentan también en la Tabla I-1.

6. E1 número de muertes esperadas totales del país se obtuvo por suma de las estimadas para las cuatro regiones y de las calculadas para el resto. Se presentan también en la tabla mencionada las muertes registradas, según las estadisticas oficiales.

7. Puede observarse que en los tres casos el número de muertes estimadas su pera el de muertes registradas. La diferencia, sin embargo, varía con el tiempo. La razón entre las primeras y las segundas, que denominamos "factor de corrección" por omisión, vale 1.1034 en $1914,1.0928$ en 1947 y 1.0352 en 1960, según puede verse también en la Tabla I-1.

8. Si bien los índices mencionados descienden con el tiempo, 1lama la aten ción que entre 1914 y 1947 la baja del valor del factor de corrección es muy pequeña; en otras palabras, a lo largo de ese extenso período los registros de muerte aparentemente casi no progresaron. En contraste con esa situación, entre 1947 y 1960, se advierte un claro descenso en los factores de corrección, indicativo de que los registros mejoraron notablemente.

9. A falta de elementos de juicio que permitieran elaborar sobre bases fir mes una serie anual de factores de corrección para los años intermedios a 1914 y 1960 se recurrió a estimar los valores anuales mediante una interpolación lineal entre 1914 y 1947, primero, y entre 1947 y 1960 después. A partir de 1960 se mantiene constante el valor del factor correspondiente a este año.

10. Los factores anuales de corrección aplicados a la serie oficial de tasas de mortalidad, produjo la serie de tasas corregidas por omisión que se presenta en el Cuadro II-1 del Capítulo II. Ambas series de tasas, las ofi ciales y las ajustadas, son representadas en el Gráfico II-1 de ese mismo capítulo. 
Tabla I-1

Determinación de factores de corrección de las muertes registradas a fin de obtener las muertes ocurridas. Años 1914, 1947 y 1960.

\begin{tabular}{lccccr}
\hline Año & $\begin{array}{c}\text { Cuatro } \\
\text { regiones }\end{array}$ & $\begin{array}{c}\text { Muertes esperadas } \\
\text { Resto del país } \\
\text { (con mortalidad NOROESTE) }\end{array}$ & Total & $\begin{array}{c}\text { Muertes } \\
\text { registra- } \\
\text { das }\end{array}$ & $\begin{array}{c}\text { Factor de } \\
\text { correc- } \\
\text { ción }\end{array}$ \\
\hline 1914 & 103.372 & 28.869 & $(1)$ & $(2)$ & $(1) \div(2)$ \\
1947 & 127.917 & 44.822 & 132.241 & 119.852 & 1.1034 \\
1960 & 147.963 & 37.611 & 172.739 & 158.059 & 1.0928 \\
& & & 185.574 & 179.266 & 1.0352 \\
\hline
\end{tabular}

Fuentes de muertes registradas: 1914 y 1947:

Dirección Nacional de Estadística y Censos, Informe Demográfico de la República Argentina 1944-1954, Gmo.Kraft Ltda., Buenos Aires, 1956.

1960: Dirección Nacional de Estadística y Censos, Hechos demográficos en 1a República Argentina 1954-1960, Gmo.Kraft Ltda., Buenos Aires. 

Anexo II (al capítulo II)

AGRUPAMIENTO DE LAS MUERTES CLASIFICADAS SEGUN CAUSA A FIN DE OBTENER UN CONJUNTO REPRESENTATIVO DE LAS ORIGINADAS EN ENFERMEDADES INFECCIOSAS Y PARASITARIAS

1. Como se explica en el Capítulo II se buscó un índice, basado en la infor mación estadística disponible sobre muertes según causa, que reflejara el descenso de la mortalidad. E1 que finalmente se adoptó, siguiendo la orien tación de una publicación de las Naciones Unidas (véase Referencias, 4), sēe define como la proporción que representan en el conjunto total de muertes aquellas que se originan en un grupo de causas que se identifican con las enfermedades infecciosas y parasitarias.

2. En este Anexo se consideran los problemas que debieron enfrentarse para lograr la serie anual de esos índices. Tales problemas se derivan de (a) 1a falta de información para algunos años, (b) los diferentes criterios utiliza dos en la clasificación de las causas de muerte que variaron de una provincia a otra, como también a través del tiempo, (c) la variación, según los años, del área del país para la que pudo obtenerse información y (d) la diversidad de fuentes de los datos.

3. La serie anual de 1911 a 1960 se interrumpe dos veces por falta de infor mación de 1931 a 1933 y de 1936 a 1944. No fue posible superar este problema a pesar de los esfuerzos realizados en la búsqueda de información.

4. Los criterios de clasificación de las muertes empleados entre 1911 y 1960 cambian con el tiempo aunque el grupo que se utiliza bajo la denominación común "enfermedades infecciosas y parasitarias" está constituido funda mentalmente por las mismas enfermedades en todos los años considerados. En 1a Tabla II-1 se da la nómina de enfermedades que 1o constituyen a 1o 1argo del período 1911-1930. Se indica también allí qué denominación se dio, en cada uno de los otros períodos, al grupo que se tomó como representativo de las enfermedades infecciosas y parasitarias para el cómputo del índice. En estos casos, a diferencia del primer período, no debió elaborarse información a fin de constituir el grupo. Debió, en cambio, compilarse datos dados a ni vel provincial para formar los del conjunto de jurisdicciones que comprendía o no, según los años, la totalidad del país.

5. La información disponible no cubre uniformemente el mismo territorio to dos los años. Durante los primeros veinte, período 1911-1930, se limita a 1a Capital Federal y las 14 provincias existentes en esa época; entre 1934 y 1936 se refiere a todo el país; en el lapso 1945-1953 varía según los años entre un mínimo de 19 jurisdicciones y el total de 24; finalmente, en el último período considerado, 1954-1960, los datos se refieren a todo el país, esto es, a sus 24 jurisdicciones. E1 Cuadro II-2, del Capítulo II, muestra cuántas jurisdicciones aportan información en cada año considerado. 
6. Por último las fuentes de información no son siempre las mismas. Los datos de los dos primeros períodos se extraen, como lo muestra también la Tabla II-1, de anuarios demográficos elaborados por el Departamento Nacional de Higiene. La información de los últimos dos períodos proviene de pu blicaciones de 1a Dirección Nacional de Estadística y Censos. 
Tabla II-1

Definición del grupo de "enfermedades infecciosas y parasitarias" según períodos y fuentes de la información.

Período: 1911-1930

Definición del grupo: se seleccionaron 34 enfermedades dentro del grupo denominado "Enfermedades Generales". Ellas fueron: fiebre tifoidea, tifus exantemático, fiebre recurrente, fiebre y caquexia palúdica, viruela, sarampiôn, escarlatina, coqueluche, difteria y crup, sudor miliar, cólera asiáti co, cólera nostras, disentería, peste, fiebre amarilla, lepra, erisipela, otras afecciones epidêmicas, infección purulenta y septicemia, muermo y lam parones, pústula maligna y carbunclo, rabia, tétanos, micosis, afecciones tū berculosas (que comprenden: de los pulmones, miliar aguda, de las meninges, abdominal, mal de Pott, tumor blanco, tuberculosis de otros órganos, tuberculosis generalizada), sifilis, chancro blanco.

Fuente: Departamento Naciona1 de Higiene, Sección Demografía y Geografía Mé dica, Anuario Demográfico del año 1935. Natalidad, Nupcialidad y Mortalidād. Año IX, Buenos Aires, Talleres Gráficos Argentinos, L.J.Rosso, 1938.

Período: $1934-1936$

Definición del grupo: el designado "enfermedades infecciosas y parasitarias" en la fuente.

Fuentes: Departamento Nacional de Higiene, Sección Demografía y Geografía Mé dica, anuarios demográficos de los años 1934, 1935 y 1936, años VIII, IX y $\mathrm{S}$, respectivamente, publicados, el primero, por Guillermo Kraft S.A. de Impresiones Generales, 1936; los otros por Talleres Gráficos Argentinos, L.J. Rosso en 1938 y 1940.

Período: 1945-1953

Definición: "Enfermedades infecciosas y parasitarias" grupo I de las nomenclaturas internacionales de 1938 y 1948.

Fuente: Dirección Nacional de Estadística y Censos, Informe Demográfico de Ia República Argentina 1944-1954, Talleres Gráficos Kraft, Buenos Aires, 1956.

Período: $1954-1960$

Definición: "Enfermedades infecciosas y parasitarias" grupo I de las nomenclaturas internacionales de 1938, 1948 y 1955, Gmo. Kraft Ltda., Buenos Aires, 1956.

Fuente: Dirección Nacional de Estadística y Censos, Hechos Demográficos en la República Argentina, 1954-1960, Guillermo Kraft Ltda., Buenos Aires, sin año de publicación. 

Anexo III (al capítulo III)

SELECCION DE PROVINCIAS CON REGISTROS DE MUFRTES RAZONABLEMENTE COMPLETOS

1. E1 propósito de este Anexo es informar acerca de los criterios utilizados para seleccionar, del total de jurisdicciones del país, aquellas que pre sumiblemente, a la luz de un conjunto de indicadores analizados conforme con criterios que se adoptan, contaban con registros de defunciones de una cabalidad aceptable, que podía suponerse similar a la de los censos de población. Como resultado queda formado un conjunto de 10 jurisdicciones, 1a Capital Federal y 9 provincias, que por comodidad 11amaremos "10 provincias" que consti tuye la población cuya mortalidad se investiga en cada una de las tres épocas censales: 1913-1915, 1946-1948 y 1959-1961.

2. La presunción de que existen omisiones serias en los registros de muertes de algunas provincias se apoya en la constatación que, según los registros, 1a mortalidad sería en ellas muy baja, en comparación con la del país en conjunto, en tanto que indicadores del nivel de vida las sitúan en una si tuación relativa muy desfavorable frente a los valores medios del país. Además de esos casos relativamente fáciles de detectar, es posible que los registros de defunciones sean deficientes en otras provincias.

3. No es posible, sin una medición directa de las omisiones en los registros, corregir los datos en forma satisfactoria. Por medios indirectos, como los que empleamos en este trabajo, se puede detectar sólo casos sospechosos de omisiones serias y eliminarlos del estudio.

4. Una forma posible de proceder, utilizada alguna vez en el estudio de la mortalidad de la Argentina en 1947 (véase Referencias,11), consiste en calcu lar dos juegos de índices: (a) de mortalidad, segün los datos de registro, y (b) de desarrollo socioeconómico. Cuando un índice relativamente bajo de mortalidad aparece junto a indicadores de condiciones adversas en el nivel de vida, se concluye que en ese caso hay omisión en los registros. No segui mos ese procedimiento por dos razones:

la., porque pueden eliminarse, con ese criterio, sólo muy contadas provincias: las que constituyen seguramente los casos más notorios de omisión en los registros. Creemos que la selección debe ser más estricta.

2a., porque no parece apropiado eliminar una provincia según su nivel aparentemente bajo de la mortalidad en circunstancias en que pensamos estudiar diferencias de mortalidad por regiones. Se corre el riesgo -seguramente exis tente sólo en teoría- de suprimir del estudio provincias de realmente baja mortalidad.

5. E1 procedimiento que se utilizó consistió, en una primera etapa, en dos partes: (a) seleccionar las provincias con mayores dificultades para organi 
zar registros adecuados de muertes o con peores registros de nacimientos, co mo se explica más adelante, y (b) eliminar aquellas que, habiendo sido selec cionadas en (a) tenían un desarrollo sociocultural por debajo de la media de1 país.

6. Los criterios anteriores fueron aplicados en cada una de las tres épocas censales 1914, 1947 y 1960. En una segunda etapa se decidió excluir del con junto de provincias seleccionadas aquellas que habian resultado aceptables en algunos años y eliminadas en otros. En otras palabras 1a investigación de la mortalidad se efectúa con el conjunto de provincias que resultaron aceptables en cada una de las tres épocas que se estudian.

7. Analicemos ahora, con cuidado, cómo deben entenderse los criterios empleados, cómo se justifican y qué normas operativas se aplicaron. Se supu so que "mayores dificultades para organizar registros adecuados de muertes" tenían las provincias con:

(a) mayores Indices de ruralidad (designaremos este indice RURAL y representa la población rural, según definición censal de cada censo, por cada 100 habitantes). Parece razonable suponer que es más difícil la operación eficiente de un sistema de registros de muertes en zonas rurales que en zo nas urbanas. Por 1o tanto, se hace el supuesto que las provincias con mayores indices de población rural tienen mayores dificultades para disponer de un buen registro de muertes;

(b) menores indices de densidad de población (DENSD, habitantes por $\mathrm{Km}^{2}$ ). A mayor dispersión de la población en el territorio puede suponerse que los registros de muertes son más difíciles de organizar que en poblaciones con centradas; el Indice de densidad puede tomarse, en una primera aproximación, como un índice inverso de dispersión de la población.

Se supuso que "peores registros de nacimientos" tenian las provincias con:

(c) mayores porcentajes de omisión [OMISN, porcentaje de nacimientos omitidos por 100 registrados (véase Referencias, 12)]. Cabe esperar que haya asociación entre la omisión de los nacimientos y de las muertes. Ambos registros dependen, en buena parte, de la organización de una misma oficina, la de registro civil. Se contaba con estimaciones sobre la omisión en los registros de nacimiento sólo para los años próximos a 1914 y 1947.

8. No basta con establecer el principio de que los tres índices mencionados están asociados con presumibles omisiones en los registros de muertes. Hace falta, además, adoptar algún criterio operativo que permita seleccionar cuán tas y cuáles provincias son las de mayores indices RURAL, menores DENSD y ma yores OMISN. Para esto se decidió elegir las 8 provincias que representaban las condiciones extremas en relación con las demás y con cada indicador. Es te número fue arbitrariamente seleccionado y corresponde a un tercio del total de jurisdicciones analizadas (25 en 1914, 24 en 1947 y 1960).

9. Haber sido seleccionada entre las 8, conforme con alguno de los tres cri 
terios, constituyó una condición necesaria para que una provincia quedara eliminada. No fue, según se ha dicho anteriormente, una condición suficiente. Una población dispersa, con alto grado de ruralidad y con omisión en los registros de nacimientos puede, en teoría, tener buenos registros de muertes. Razones sanitarias, por ejemplo, pueden hacer imperativo que exis ta una más estricta anotación de las muertes que de los nacimientos; puede haber, pese a la dispersión y carácter rural de la población, un buen siste ma de comunicaciones que facilite el funcionamiento eficiente de los registros civiles. Un buen nivel de desarrollo socioeconómico puede hacer que no obstante las dificultades u omisión en los registros de nacimientos la anotación de las muertes sea completa. Entonces, para que una provincia que dara señalada como sospechosa de tener registros de muertes deficientes se impuso la condición de que, además de haber sido seleccionada entre las que tenían mayores índices presumiblemente asociados con omisión en los registros de muertes, presentara un nivel sociocultural inferior a la media del país, establecido por alguno de los tres indicadores que se mencionan más adelante. Cuando a dificultades para organizar buenos registros y omisión en las anotaciones de los nacimientos, se suma una situación social relativamente adversa, se afirma la presunción de que pueden existir omisiones importantes en los registros de defunciones.

10. Los Îndices socioculturales utilizados en este análisis fueron:

(a) analfabetos por cada 1000 habitantes mayores de 7 años (1914) o 14 años (1947, 1960). Designamos este índice: ANALF.

(b) inasistentes escolares por cada 1000 niños de edad 6-14 (1914), 6-13 (1947) o, población que nunca asistió a establecimientos de enseñanza regular por 1000 habitantes de edad 5-29 (1960). Llamamos a este índice: INAST.

(c) nacimientos ilegítimos por cada 100 registrados. Nombre: ILEGT.

11. Tanto la selección de estos índices, como los considerados anteriormen te, debió efectuarse entre un número muy limitado de posibilidades. Tampoco fue posible, como queda evidenciado en la definición de los indicadores, utilizar definiciones uniformes en los tres períodos estudiados. En otras palabras: no se trataba tanto de imaginar posibles indicadores de omisión o grado de desarrollo con los cuales efectuar el análisis, sino más bien de utilizar los pocos datos disponibles, eligiendo los que parecían más apropia dos de entre unos pocos.

12. En las tablas 1, 2 y 3 de este Anexo III aparecen para los años 1914, 1947 y 1960, respectivamente, los valores que toman los indicadores que se han definido en los párrafos anteriores, tanto los que se presume que están asociados con la omisión en los registros de muertes (RURAL, DENSD, OMISN) como los relacionados, inversamente, con la situación social (ANALF, INAST, ILEGT) .

13. La aplicación de los criterios indicados anteriormente significó selec cionar, como aceptables, a un conjunto de 12 provincias en 1914,11 en 1947 
y 13 en 1960. Había un grupo de 10 que pertenecía a los tres conjuntos, 10 que muestra la asociación estrecha existente entre los indicadores o la estabilidad relativa de algunos de estos Indices a través del tiempo. Por ra zones de orden práctico se decidió uniformar la selección, es decir, considerar un mismo conjunto de provincias en los tres años. El criterio de selección, como se indicó anteriormente, fue riguroso: quedaron seleccionadas las 10 que habían sido aceptables en cada una de las tres pruebas. Las pro vincias que integran este grupo se detallan en el texto del capítulo III y su peso relativo, frente a la población del total del país, puede examinarse en el Cuadro III-1. Quizá sea de interés consignar que las provincias o territorios que resultaron aceptables en algunos años y eliminados en otros $y$, consecuentemente, excluidos en la selección final, fueron las cuatro siguientes: La Pampa, San Luis, Santa Cruz y Tierra del Fuego. Todos territo rios con escasa población.

14. Es pertinente terminar este Anexo con algunas reflexiones acerca de las consecuencias de la decisión de eliminar la información relativa a algunas provincias, en el análisis de la mortalidad de la población argentina a través del tiempo. Ante todo, parece acertado eliminar aquellos casos de notoria deficiencia en los registros, que acusan mortalidad inferior a la media y cuya inclusión tendría el efecto de subestimar el nivel general -bien que en una medida muy reducida en razón de la poca población de las provincias con registros muy deficientes.

Lo que resulta dificil de establecer es el límite de lo aceptable. Exigencias exageradas en cuanto a la coherencia y regularidad de los datos condu cirían al caso extremo de que algunas pocas provincias resultarían aceptables, cerrando la posibilidad de la investigación. Inversamente, 1a acep tación sin reparos de la información existente conduciría a considerar como buenos a resultados de dudosa validez.

E1 problema de dar una solución alejada tanto de un peligro como del otro es difícil de resolver. No hay, ademâs, una solución única, ya que dependerä en cada caso del juicio del investigador. En defensa de la que aquí adopta mos podemos decir que si bien es cierto que se eliminan muchas provincias del estudio -y podríamos ser acusados, por unos de una severidad excesivatambién lo es que el conjunto de provincias investigado representa una por ción muy elevada del total de la población del país -lo que podría ser tomado, por otros, como prueba de falta de rigurosidad. 
Tabla III-1

Repüblica Argentina 1914 - Indicadores: (A) presumiblemente asociados con 1a omisión en los registros de muertes y (B) socioculturales inversamente asociados con el desarrollo

\begin{tabular}{|c|c|c|c|c|c|c|}
\hline \multirow[t]{2}{*}{ Provincias } & \multicolumn{3}{|c|}{$\bar{A}$} & \multicolumn{3}{|c|}{ B } \\
\hline & RURAL & DENSD & OMISN & ANALF & INAST & ILEGT \\
\hline Cap.Federal & 9 & 7922.6 & 1.3 & 178 & 176 & 12.79 \\
\hline Buenos Aires & 447 & 6.9 & 1.3 & 308 & 476 & 14.10 \\
\hline Catamarca & 687 & 0.8 & 77.0 & 488 & 250 & 35.01 \\
\hline Córdoba & 548 & 4.4 & 14.1 & 385 & 411 & 12.99 \\
\hline Corrientes & 628 & 4.0 & 42.7 & 555 & 558 & 58.95 \\
\hline Chaco & 553 & 0.5 & 26.1 & 494 & 560 & 51.89 \\
\hline Chubut & 549 & 0.1 & 44.7 & 365 & 543 & 33.71 \\
\hline Entre Ríos & 614 & 5.8 & 16.0 & 410 & 330 & 33.28 \\
\hline Formosa & 778 & 0.3 & 36.7 & 548 & 606 & 67.07 \\
\hline Jujuy & 675 & 1.3 & 16.5 & 647 & 424 & 42.11 \\
\hline Los Andes & 768 & 0.0 & 39.1 & 667 & 617 & 23.07 \\
\hline La Pampa & 532 & 0.7 & 17.3 & 395 & 597 & 16.52 \\
\hline La Rioja & 741 & 0.9 & 49.8 & 496 & 329 & 33.33 \\
\hline Mendoza & 506 & 1.8 & $5: 6$ & 421 & 434 & 21.81 \\
\hline Misiones & 701 & 1.8 & 8.8 & 533 & 372 & 43.79 \\
\hline Neuquén & 846 & 0.3 & 15.6 & 599 & 698 & 36.37 \\
\hline Río Negro & 690 & 0.2 & 73.8 & 524 & 701 & 40.65 \\
\hline Salta & 685 & 0.9 & 23.9 & 536 & 446 & 39.49 \\
\hline San Juan & 648 & 1.3 & 9.2 & 442 & 314 & 32.08 \\
\hline San Luis & 605 & 1.6 & 12.7 & 372 & 209 & 31.86 \\
\hline Santa Cruz & 516 & 0.0 & 44.7 & 219 & 709 & 8.04 \\
\hline Santa $\mathrm{Fe}$ & 430 & 6.8 & 9.5 & 346 & 555 & 13.39 \\
\hline S.del Estero & 738 & 1.8 & 63.4 & 638 & 467 & 39.94 \\
\hline Tucumán & 569 & $12: 3$ & 20.2 & 507 & 316 & 36.64 \\
\hline T.del Fuego & 415 & 0.1 & 44.7 & 252 & 522 & 10.00 \\
\hline R. Argentina & 426 & 2.8 & 12.2 & 351 & 409 & 21.12 \\
\hline
\end{tabular}

Abreviaturas

Provincia $=$ jurisdicción

RURAL=población rural (por mil habitantes)

DENSD=habitantes (por $\mathrm{Km}^{2}$ )

OMISN=nacimientos omitidos (por cien registrados en 1911)

ANALF=analfabetos (por mil habitantes mayores de 7 años)

INAST=inasistentes escolares (por mil niños de edad 6-14)

ILEGT=nacimientos ilegítimos (por cien nacimientos registrados)

Fuentes:

Censo 1914, Tomo II, pág. 400.

Censo 1947, pág.1.

CIS, No 30, pág.43.

Censo 1914, Tomo I, pág.168.

Censo 1914, Tomo I, pág.178.

Anuario Demográfico del año 1914, Año IV, Dpto. Nacional de Higiene, Bs.Aires, Tal1.Grấficos de 1a Penitenciaría Nacional, 1921, pág.3. 
Tabla III-2

República Argentina 1947 - Indicadores: (A) presumiblemente asociados con la omisión en los registros de muertes y (B) socioculturales inversamente asociados con el desarrollo

\begin{tabular}{|c|c|c|c|c|c|c|}
\hline \multirow[t]{2}{*}{ Provincias } & \multicolumn{3}{|c|}{$\mathbf{A}$} & \multicolumn{3}{|c|}{ B } \\
\hline & RURAL & DENSD & OMISN & ANALF & INAST & ILEGT \\
\hline Cap.Federa1 & 1 & 14987.8 & 0.5 & 57 & 145 & 11.20 \\
\hline Buenos Aires & 286 & 14.2 & 0.5 & 98 & 223 & 16.67 \\
\hline Catamarca & 679 & 1.2 & 6.8 & 182 & 223 & 32.43 \\
\hline Córdoba & 474 & 8.9 & 4.0 & 133 & 259 & 19.25 \\
\hline Corrientes & 658 & 6.0 & 15.7 & 311 & 375 & 53.81 \\
\hline Chaco & 699 & 4.4 & 17.7 & 295 & 446 & 55.31 \\
\hline Chubut & 747 & 0.3 & 1.0 & 251 & 415 & 33.54 \\
\hline Entre Ríos & 465 & 10.7 & 3.5 & 197 & 349 & 36.44 \\
\hline Formosa & 772 & 1.5 & 4.7 & 243 & 332 & 64.05 \\
\hline Jujuy & 632 & 2.8 & 2.3 & 351 & 322 & 46.00 \\
\hline La Pampa & 693 & 1.2 & 0.4 & 146 & 218 & 25.65 \\
\hline La Rioja. & 686 & 1.2 & 22.2 & 180 & 227 & 30.00 \\
\hline Mendoza & 496 & 3.9 & 2.5 & 173 & 302 & 20.44 \\
\hline Misiones & 814 & 8.3 & 2.4 & 226 & 220 & 38.58 \\
\hline Neuquén. & 773 & 0.9 & 0.2 & 253 & 436 & 38.65 \\
\hline Río Negro & 731 & 0.7 & 1.7 & 240 & 362 & 44.82 \\
\hline Salta & 604 & 1.9 & 0.8 & 298 & 332 & 45.11 \\
\hline San Juan & 540 & 2.9 & 3.4 & 193 & 255 & 29.48 \\
\hline San Luis & 609 & 2.2 & 11.5 & 170 & 238 & 29.53 \\
\hline Santa Cruz & 637 & 0.1 & 1.0 & 82 & 315 & 21.76 \\
\hline Santa $\mathrm{Fe}$ & 422 & 12.9 & 9.5 & 134 & 259 & 21.11 \\
\hline S.del Estero & 742 & 3.3 & 14.5 & 311 & 351 & 43.20 \\
\hline Tucumán & 495 & 22.0 & 1.6 & 211 & 248 & 40.36 \\
\hline T.del Fuego & 1000 & 0.2 & 1.0 & 59 & 194 & 6.54 \\
\hline R.Argentina & 375 & 5.7 & 5.0 & 136 & 265 & 27.79 \\
\hline
\end{tabular}

Abreviaturas

Provincia $=$ jurisdicción

RURAL=población rural (por mil habitantes)

DENSD=habitantes (por $\mathrm{Km}^{2}$ )

OMISN=nacimientos omitidos (por cien registrados en 1945)

ANALF=analfabetos (por mil habitantes mayores de 14 años)

INAST=inasistentes escolares (por mil niños de edad 6-13)

ILEGT=nacimientos ilegítimos (por cien nacimientos registrados)

Fuentes:

Censo 1947, päg.LXIX.

Censo 1947, pág.1.

CIS, N: 30 , pág. 43 .

Censo 1947, pág. LXXXI.

Dato inédito censo 1947, Informe 1944-54, p.159 y sgts. 
Tabla III-3

República Argentina 1960 - Indicadores: (A) presumiblemente asociados con 1a omisión en los registros de muertes y (B) socioculturales inversamente asociados con el desarrollo

\begin{tabular}{|c|c|c|c|c|c|}
\hline \multirow[t]{2}{*}{ Provincias } & \multicolumn{2}{|c|}{$\bar{A}$} & \multicolumn{3}{|c|}{$\mathrm{B}$} \\
\hline & RURAL & DENSD & ANALF & INAST & ILEGT \\
\hline Cap.Federal & 0 & 14870.3 & 31 & 32 & 11.83 \\
\hline Buenos Aires & 130 & 22.0 & 56 & 70 & 16.80 \\
\hline Catamarca & 581 & 1.7 & 116 & 102 & 29.97 \\
\hline Córdoba & 318 & 10.4 & 79 & 81 & 12.69 \\
\hline Corrientes & 536 & 6.1 & 215 & 180 & 39.68 \\
\hline Chaco & 622 & 5.5 & 212 & 227 & 48.39 \\
\hline Chubut & 456 & 0.6 & 133 & 171 & 35.96 \\
\hline Entre Ríos & 505 & 10.6 & 128 & 124 & 26.53 \\
\hline Formosa & 664 & 2.5 & 195 & 199 & 59.65 \\
\hline Jujuy & 509 & 4.5 & 242 & 175 & 43.78 \\
\hline La Pampa & 423 & 1.1 & 100 & 102 & 21.65 \\
\hline La Rioja & 574 & 1.4 & 110 & 106 & 25.32 \\
\hline Mendoza & 360 & 5.5 & 113 & 108 & 15.13 \\
\hline Misiones & 682 & 12.1 & 168 & 166 & 35.35 \\
\hline Neuquén & 520 & 1.2 & 190 & 221 & 35.93 \\
\hline Rỉo Negro & 365 & 1.0 & 165 & 195 & 37.75 \\
\hline Salta & 450 & 2.7 & 191 & 176 & 39.43 \\
\hline San Juan & 457 & 4.1 & 121 & 109 & 15.85 \\
\hline San Luis & 482 & 2.3 & 109 & 101 & 25.07 \\
\hline Santa Cruz & 464 & 0.2 & 57 & 91 & 14.02 \\
\hline Santa Fe & 238 & 14.2 & 82 & 90 & 18.03 \\
\hline S.del Estero & 648 & 3.5 & 198 & 146 & 32.10 \\
\hline Tucumán & 456 & 34.4 & 130 & 127 & 34.54 \\
\hline T. de1 Fuego & 112 & 0.4 & 42 & 60 & 11.54 \\
\hline R.Argentina & 262 & 5.0 & 85 & 99 & 23.48 \\
\hline
\end{tabular}

Abreviaturas

Provincia $=$ jurisdicción

RURAL=población rura1 (por mil habitantes)

DENSD=habitantes (por $\mathrm{Km}^{2}$ )

ANALF=analfabetos (por mil habitantes mayores de 14 años)

INAST=población de 5-29 años que nunca asistió a establecimientos de enseñanza regular (por mil habitantes de 5-29 años)

ILEGT=nacimientos ilegítimos (por cien nacimientos registrados)

Fuentes:

Censo 1960, Tomo I, C. 1 .

Censo 1960, Tomo I, C.1.

Censo 1960 , C. 9 .

Censo 1960, C. 10.

Hechos Demográficos en la República Argentina 1954-60, pág.36 y sgts. 
Anexo IV (al capítulo V)

FUENTES DE DATOS Y AJUSTE DEL MATERIAL BASICOO

1. Tablas de mortalidad 1913-1915

$\underline{\text { Población }}$

Fuente:

ARGENTINA, Tercer Censo Nacional, 1914, Talleres Gráficos L.J.Rosso, Buenos Aires, 1916, Tomo III.

Ajuste:

Las personas con edad no declarada en el censo fueron distribuidas en los di ferentes grupos de edades en proporción al númexo de los individuos censados en cada grupo.

\section{Nacimientos}

\section{Fuentes:}

RECCHINI DE LATTES, Zulma, República Argentina. Corrección de la serie anual de nacimientos registrados por sexo y jurisdicción, 1911-1947, Documento de Trabajo N: 30, Centro de Investigaciones Sociales del Instituto Torcuato Di Te11a, Buenos Aires, 1967.

Ajustes:

Se aceptaron los introducidos en la publicación citada a fin de corregir la omisión de los registros.

\section{Muertes}

\section{Fuentes:}

Departamento Nacional de Higiene, Oficina Demográfica, Anuario Demográfico, correspondiente a los años 1911, 1912, 1913, 1914 y $191 \overline{5}$.

Municipalidad de la Ciudad de Buenos Aires, Dirección General de Estadística Municipal, Anuario Estadístico de la Ciudad de Buenos Aires, correspondiente a los años: 1911, 1912, 1913, 1914 y 1915-1923.

KERN, Enrique R., La Mortalidad en la Ciudad de Buenos Aires, Monografía N.7, Universidad Nacional de Buenos Aires, Instituto de Biometría, Buenos Aires, 1948.

Ajustes:

Las muertes se aceptaron sin corrección por omisión. Los conjuntos de muer tes de 0 y 1 años se dividieron en dos subconjuntos según el año de nacimiēn to. Con ese propósito se utilizó información de las muertes de menos de 1 año detallada por edad y el supuesto de que las defunciones se distribuían uniformemente en el año. Para dividir las muertes de 1 año cumplido se empleó un factor de separación invariablemente igual a 0.41 . 
Las muertes de más de dos años de edad que se utilizan en la construcción de las tablas fueron un promedio anual de las registradas en tres años en torno a 1914: 1913, 1914 y 1915.

Hubo necesidad, en ciertos tramos de vida (edades superiores a 10 s 60 años) de distribuir las defunciones registradas, que aparecen clasificadas a inter valos decenales, en dos grupos quinquenales. Para esto se utilizó la población clasificada por grupos quinquenales y tasas de mortalidad, para los mis mos intervalos, derivadas de las tablas, de mortalidad para la República Argentina, para 1914, elaboradas por Kern, por sexo. Se obtuvieron muertes es peradas por quinquenios, dentro de cada decenio, cuya distribución se utilizó en la separación por quinquenios de las observadas.

Se asignaron, dentro de cada región, los casos de defunciones con origen o edad desconocidos en proporción a las muertes de origen y edad declarados. Fueron casos de muy pequeña importancia en términos relativos,

Dentro del tramo de 2 a 9 años cumplidos se utilizó la distribución por edades de muertes registradas en 1913 y 1914, a fin de redistribuir las de 1915.

Como resultado de las elaboraciones anteriores las muertes de más de 2 años de edad quedaron agrupadas en intervalos quinquenales entre 1 os 5 y 90 años. Hubo un grupo inicial de 3 años de amplitud (edades 2-4 años cumplidos) y un grupo final abierto formado por las defunciones de mâs de 90 años.

2. Tablas de mortalidad 1946-1948

\section{$\underline{\text { Población }}$}

Fuente:

Argentina, Ministerio de Asuntos Técnicos, IV Censo General de 1a Nación 1947, Buenos Aires, Tomo I.

Ajuste:

Las personas con edad no declarada en el censo fueron distribuidas en los diferentes grupos de edades en proporción al número de los individuos censados en cada grupo.

\section{Nacimientos}

Fuentes:

RECCHINI DE LATTES, Zulma, Repüblica Argentina. Corrección de la serie anual de nacimientos registrados por sexo y jurisdicción, 1911-1947, Documento de Trabajo N: 30, Centro de Investigaciones Sociales del Instituto Torcuato Di Tella, Buenos Aires, 1967.

Dirección Nacional de Estadística y Censos, Informe demográfico de la República Argentina, 1944-1954, Buenos Aires, 1956. 
Ajustes:

Se aceptaron las correcciones por omisión en los registros elaborados en la publicación citada para los años 1944-1947.

Los datos relativos al año 1948, por sexo y provincia, fueron corregidos por omisión en los registros aplicando un procedimiento similar al utilizado en el trabajo citado.

\section{Muertes}

\section{Fuentes:}

Dirección Nacional de Estadística y Censos, Informe demográfico de la República Argentina, 1944-1954, Buenos Aires $195 \overline{6}$.

Dirección General de Estadística e Investigaciones de la Provincia de Buenos Aires, Instituto de Econometría, Anuario Estadístico 1944-1948, Volumen No 1, Demografía y Territorio.

Dirección General de Estadística e Investigaciones de la Provincia de Buenos Aires, Instituto de Econometría, Boletín Estadístico, N: 1, Primer Trimestre 1948.

Municipalidad de la Ciudad de Buenos Aires, Revista de Estadística de la Ciudad de Buenos Aires, N. 1, Buenos Aires, 1959.

Dirección de Estadística de la Provincia de Tucumán, Boletín Estadístico, N:5 y 7.

Dirección General de Estadística, Censos e Investigaciones de la Provincia de Córdoba, Síntesis Estadística del quinquenio 1944-1948.

Ministerio de Hacienda, Economía e Industria de la Provincia de Santa Fe, Boletín N: 4.

ASTUDILLO, P.L., Tablas abreviadas de mortalidad para 1a región Cuyana, República Argentina, correspondiente a los años 1946-1948, CELADE, 1966 (inédi to).

Ajustes:

Las muertes se aceptaron sin corrección por omisión. Los conjuntos de muer tes de 0 y 1 año se dividieron en dos subconjuntos según el año de nacimien to. Con ese propósito se utilizó información de las muertes de menos de 1 año detallada por edad y el supuesto de que las defunciones se distribuían uniformemente en el año. Para dividir las muertes de 1 año cumplido se em pleó un factor de separación invariablemente igual a 0.41 .

Las muertes de más de dos años consideradas en la elaboración de las tablas de mortalidad resultaron de promediar las registradas en tres años en torno al del censo: 1946,1947 y 1948. 
Las muertes con edad desconocida fueron distribuidas en los diferentes grupos de edades, en proporción al número de defunciones registradas en cada grupo.

Para obtener información clasificada uniformemente en todas las provincias que componen las cuatro regiones que se investigan y en los tres años consi derados, se utilizaron, dentro de cada región, distribuciones detalladas cō nocidas para alguna provincia. E1 caso más importante consistió en dividir en grupos quinquenales las muertes dadas en grupos decenales entre $10 \mathrm{~s} 20 \mathrm{y}$ los 60 años, y en distribuir en grupos también quinquenales las defunciones de más de 60 años que aparecían en un solo grupo. Se utilizó, por ejemplo, información conocida de Córdoba para obtener la correspondiente a Entre Ríos dentro de la región CENTRO LITORAL.

Como resultado de esas elaboraciones las muertes de más de 2 años de edad quedaron agrupadas en intervalos quinquenales entre los 5 y los 90 años, con la excepción de la región de CUYo, donde el tramo fue de 5 a 80 años. Hubo un grupo inicial, de tres años de amplitud (2-4 años cumplidos) y un grupo abierto final, formado por las defunciones de más de 90 años excepto, nuevamente la región de CUYo, donde abarcó las de más de 80 años. En conse cuencia, las tablas de vida que resultan de sumar las 4 regiones, y que se toman como representativas del pais, presentan un agrupamiento similar a1 de la región de CUYO.

3. Tablas de mortalidad 1959-1961

\section{Población}

Fuentes:

Argentina, Dirección Nacional de Estadística y Censos, Censo Nacional de Población, 1960, Tomos: I, II, III, IV, V, VII Partes 1 y 2, y VIII.

Conade, Instituto Nacional de Estadística y Censos, Proyección quinquenal de la población 1965-2000. Incluye la estimación de omisión diferencial por origen, sexo y grupos de edad de la población censada al 30/9/1960.

\section{Ajustes:}

Las personas con edad no declarada en el censo fueron distribuidas en los diferentes grupos de edades en proporción al número de los individuos censa dos en cada grupo.

E1 Instituto Nacional de Estadística y Censos estimó la omisión censal de 1960 para la población total del país según origen, sexo y grupos de edad. Esos resultados fueron utilizados para corregir la población a nivel de cada provincia. 


\section{Nacimientos}

Fuente:

ROTHMAN, Ana María, Repüblica Argentina. Corrección de la serie anual de nacimientos registrados por sexo y jurisdicción 1948-1965, Centro de Investiga ciones del Instituto Torcuato Di Tella, 1968 (inédito).

Ajustes:

Se aceptaron los introducidos en el trabajo citado, a fin de corregir la omi sión de los registros.

\section{Muertes}

Fuentes:

Dirección Nacional de Estadística y Censos, Hechos demográficos en la República Argentina, 1954-1960.

Dirección Nacional de Estadística y Censos, información no publicada (1961).

Municipalidad de la Ciudad de Buenos Aires, Revista de Estadística de la Ciudad de Buenos Aires, N: 5 .

Instituto de Investigaciones Económicas y Tecnológicas de la Provincia de Mendoza, Anuario 1963-1964.

Ajustes:

Las muertes se aceptaron sin corrección por omisión.

Los conjuntos de muertes de 0 y 1 año se dividieron en dos subconjuntos según el año de nacimiento. Con ese propósito se utilizó información de las muertes de menos de 1 año detalladas por edad y el supuesto de que las defunciones se distribuían uniformemente en el año. Para dividir las muertes de 1 año cumplido se empleó un factor de separación invariablemente igual a 0.41 .

Las muertes de más de dos años consideradas en la elaboración de las tablas de mortalidad resultaron de promediar las registradas en tres años en torno al del censo: 1959, 1960 y 1961.

Las muertes con edad desconocida fueron distribuidas en los diferentes grupos de edades en proporción al número de defunciones registradas en cada gru po.

Para obtener información clasificada uniformemente en todas las provincias y años considerados que componen las cuatro regiones que se investigan, se utilizó la información de 1960 y 1961 para cada una de las provincias. Con 1a distribución promedia resultante se obtuvieron las muertes de 1959 de ca da una de las provincias con el detalle requerido. 
Como resultado de esas elaboraciones las muertes de más de 2 años de edad quedaron agrupadas en intervalos quinquenales entre los 5 y 85 años. Se formó un grupo inicial, de tres años de amplitud, con las defunciones mayores de 2 y menores de 5 años, y un grupo abierto final con las muertes de más de 85 años. 
REFERENCIAS

(1) CAMISA, C. Zulma, Argentina, Proyección de la población por sexo y edad, 1960-1980, CELADE, Serie C, N: 62, Santiago de Chile, 1965.

(2) CERISOLA, Elsa M.J., Proyección Quinquenal de la población 1965-2000. Instituto Nacional de Estadística y Censos, Buenos Aires, 1968.

(3) CERISOLA, Elsa, M.J., República Argentina: Análisis de la mortálidad por causas, 1960. Serie C, N: 109, Santiago de Chile, 1968,

(4) Naciones Unidas, Boletín de Población de las Naciones Unidas N. 6, 1962, (ST/SOA/Ser.N/6) Nueva York, 1963.

(5) Dirección Nacional de Estadística y Censos, Hechos demográficos en la República Argentina 1954-1960, Guillermo Kraft Ltda., Buenos Aires (sin año de publicación).

(6) LATZINA, F., La Argentina, Considerada en sus aspectos, físico, social y económico, Segunda Parte, Buenos Aires, 1904.

(7) MULLER, María, Trabajo inédito, CIS 1969.

(8) LATTES, Alfredo E., Evaluación y ajuste de algunos resultados de los tres primeros censos nacionales de población, Documento de Trabajo N: 51 , Centro de Investigaciones Sociales, Instituto Torcuato Di Tella, Buenos Aires, 1968.

(9) TORRADO, Susana, Series estadísticas para el estudio del impacto de 1a inmigración masiva en la Argentina: 1857-1957, trabajo inêdito Universidad Nácional de Buenos Aires, Cátedra de Historia Social e Instituto de Sociologia, 1962.

(10) GREVILLE, Thomas N.E., United States Life Tables and Actuarial Tables 1939-1941, Government Printing Office, Washington, 1946.

(11) MtLlER, María S., Tablas abreviadas de mortalidad para la República Argentina 1946-1948, CELADE, B.58 1/10, Santiago, Chile, 1958.

(12) RECCHINI DE LATTES, Zulma, Repüblica Argentina. Corrección de la serie anual de nacimientos registrados por sexo y jurisdicción, 1911-1947, Documento de Trabajo N: 30 CIS, Instituto Torcuato Di Tella, Buenos Aires, 1967.

(13) DAVIS, Kingsley The Population of India and Pakistan, Princeton University Press, New Jersey,..1951.

(14) MORTARA, Giorgio, A mortalidade da populaçao Natural do Brasil, Revis ta Brasileira de Estafffstica, Ano XIV, Outubro/Dezembro, 1953, N: 56. 
(15) AREVALO, Jorge Colombia, Ajuste del censo de población de 1964, CELADE, A/89, Santiago, Chile, 1968 .

(16) ORTEGA, Antonio y MERLO Pedro, Método para descomponer los grupos abiertos finales de las proyecciones de población, en grupos quinquenales de edad, CELADE, Notas mimeografiadas, 1968.

(17) MERLO, Pedro M., Evaluación y ajuste de los censos de población de1 Ecuador de 1950 y 1962 y proyección de la población al año 2000 y de la población económicamente activa al año 1985, CELADE, inêdito, 1968.

(18) KERN, Enrique R., La Mortalidad en la Ciudad de Buenos Aires, Instituto de Biometría, Facultad de Ciencias Econốmicas, Buenos Aires, 1948.

(19) CAMISA, Zulma C., Tabla abreviada de Mortalidad. República Argentina 1946-1948, CELADE, Serie C/18, Santiago, Chile, 1964 .

(20) ORTEGA, Antonio, Tablas completas de mortalidad para la República Argentina 1959-1961, CELADE, Serie C/103, Santiago, Chile, 1967.

(21) Primer Censo de la República Argentina, Verificado en los días 15, 16 y 17, Septiembre de 1869, Buenos Aires, 1872.

(22) SOMOZA, Jorge L. y LATTES, Alfredo E, Muestras de los dos primeros Censos Nacionales de Población, 1869 y 1895. Documento de Trabajo N: 46, CIS, Instituto Torcuato Di Tella, Buenos Aires, 1967.

(23) Segundo Censo de 1a República Argentina, Mayo 10 de 1895, Tomo II - Po blación, Buenos Aires, 1898.

(24) SOMOZA, Jorge L., Nivel y diferenciales de la fecundidad en 1a Argentina en el Siglo XIX, Documento de Trabajo N: 45, CIS, Instituto Torcuato Di Te1la, Buenos Aires, 1967.

(25) United Nations, Methods for Population Projections by Sex and Age Manual III, ST/SOA/Ser.A/25, Nueva York, 1956.

(26) REED, Lowe11 J. y MERRELL, Margaret, A Short Method for Constructing an Abridged Life Table, The American Journal of Hygiene, Vol.30, No: 2, September 1939 .

(28) Nations Unies, Schémas de variation de la mortalité selon 1'âge et le sexe, ST/SOA/Ser.A/22, New York, 1956. 

